$\therefore$ a (1) rio 23 a axo $\therefore \%$ ond C.9.

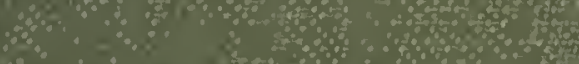
$\therefore$ and

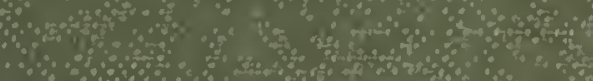

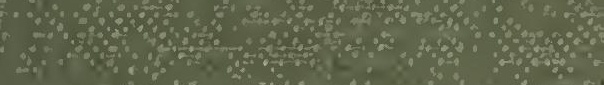

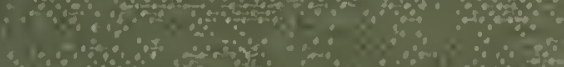
$\therefore$ (1) 10 $\therefore$ 10

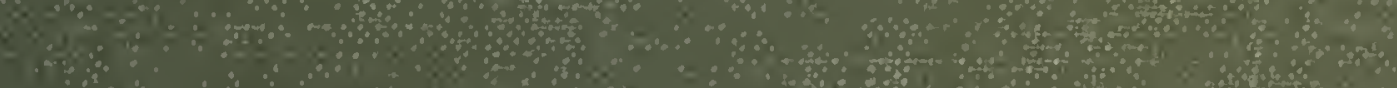

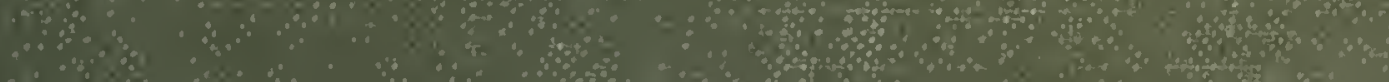
a O and (00\%

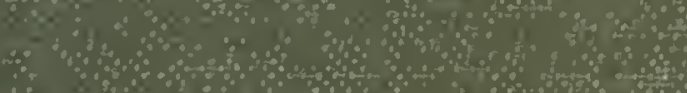

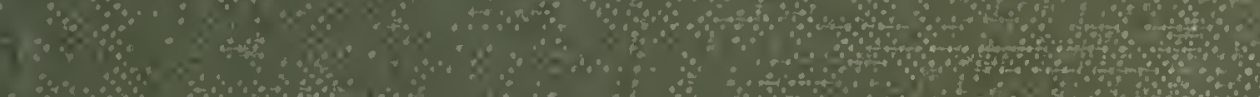
a

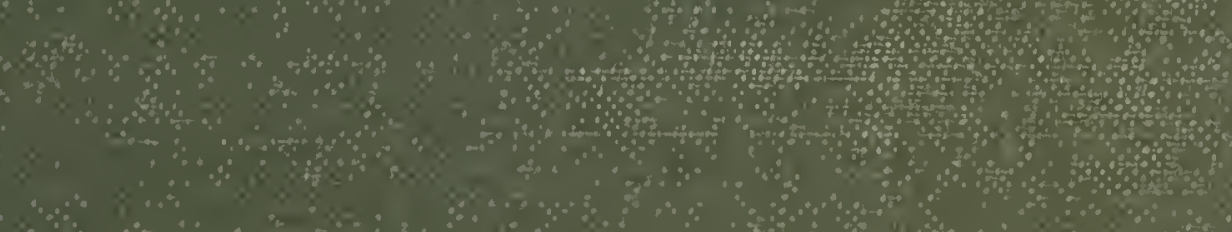

$\therefore$ a

$\therefore$ a

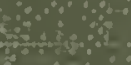

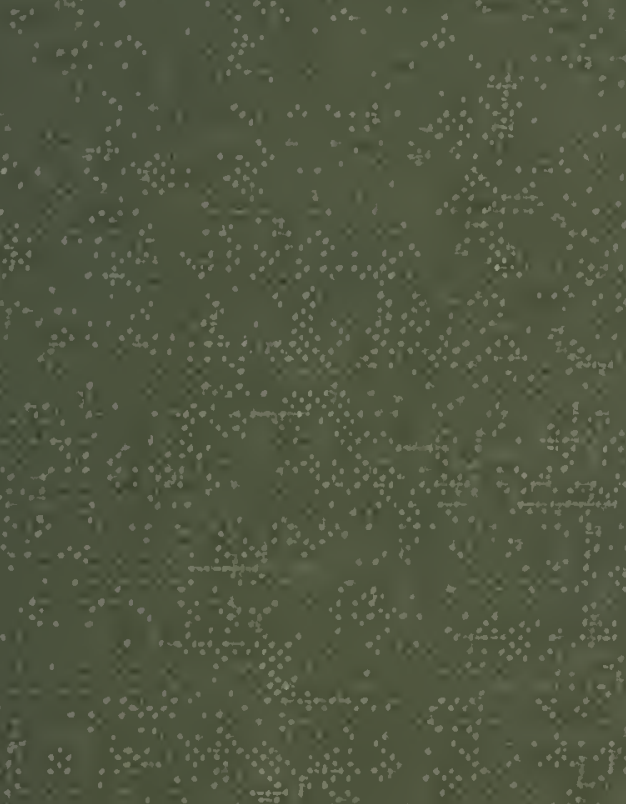




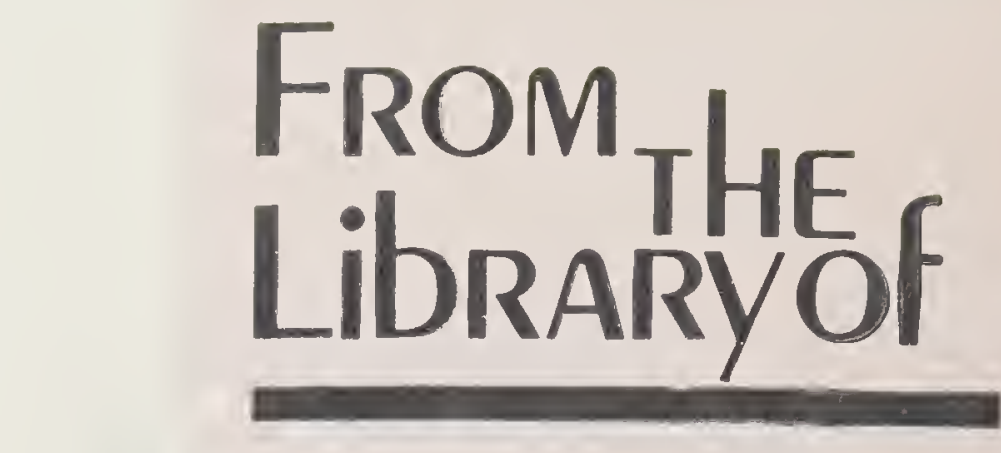

$\rightarrow 4$

Reverend Canon

W. John Zimmerman 
W.9. Gimmeman
Avyclifte College
3/4

LIVING ORGANISMS

An account of

Their Origin $\mathscr{G}$ Evolution 

Digitized by the Internet Archive in 2020 with funding from University of Toronto 


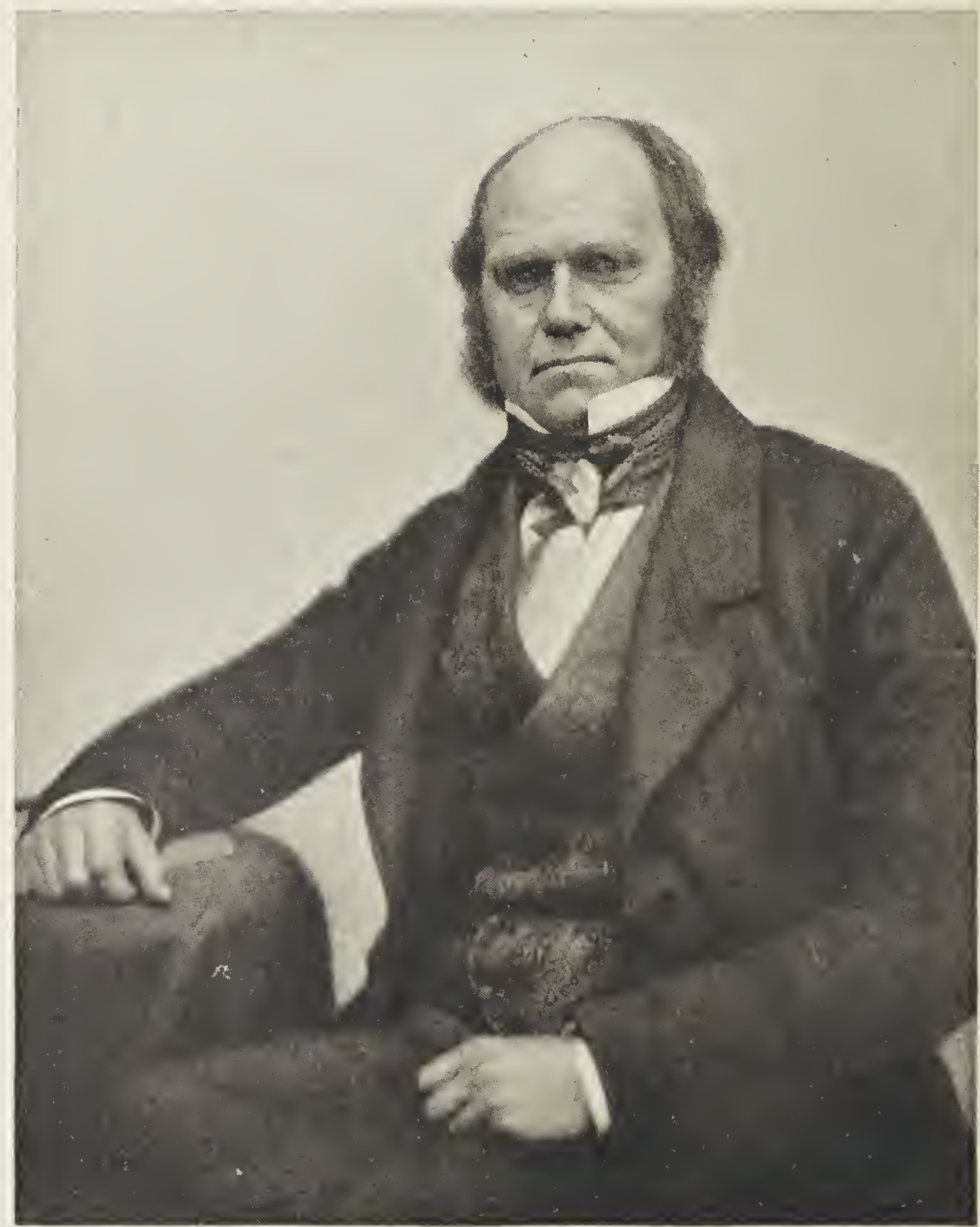

Maull \& Fox, photographers

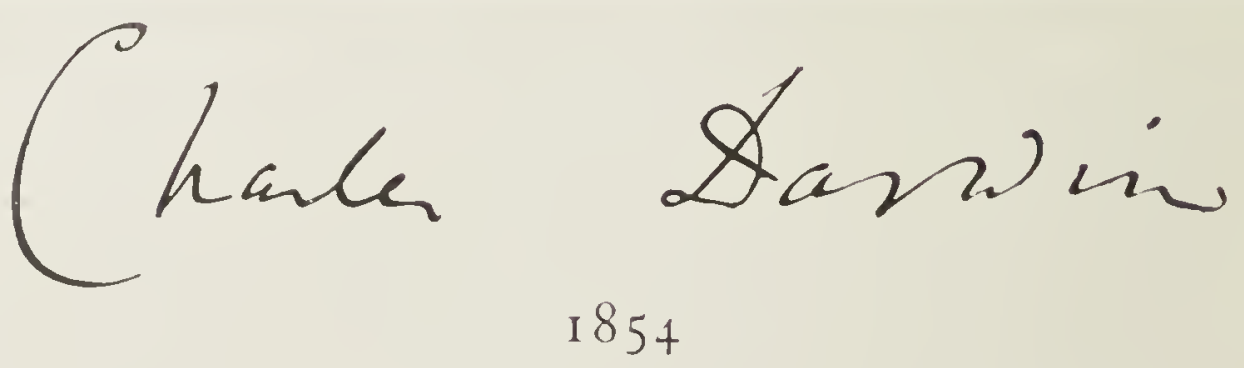




\title{
LIVING ORGANISMS
}

An account of

\section{Their Origin $ฮ$ Evolution}

\author{
by
}

Edwin S. Goodrich, F.R.S.

Fellow of Merton College and

Linacre Professor of Zoology and Comparative Anatomy in the University of Oxford

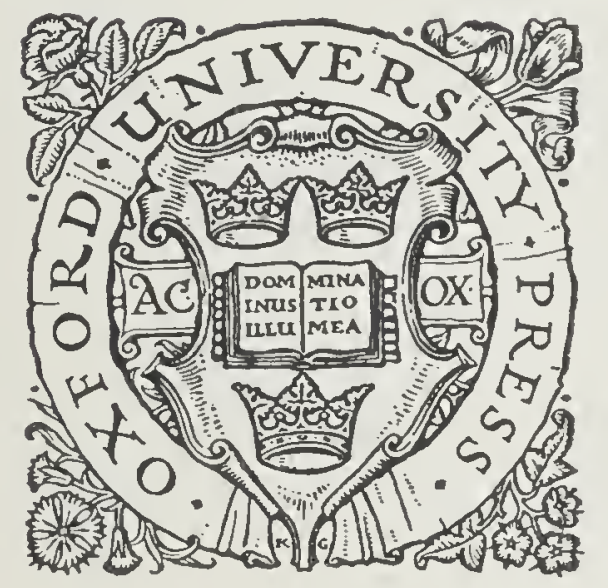

\section{O X F O R D}

AT THE CLARENDON PRESS

I 924 


Oxford University Press
London Edinburgh Glasgow Copenhagen
Ncw Jork Toronto Mclbourne Cape Town
Bombay Calcutla Madras Shanghai

II umphrey Milford Publisher to the Universiny

Printed in England 


\section{PREFACE}

IT is hoped that this book, dealing with modern views on the nature of life and the relation of living organisms to their environment, and with the latest advances in our knowledge of Heredity and kindred problems, will prove a useful introduction to the study of Organic Evolution not only for the scientific student but also for the general reader. Messrs. Nelson \& Sons have very kindly allowed me to embody in it the materials of my little volume, The Evolution of Living Organisms, first published in the 'People's-Books' series in rgr2. To several authors and publishers I am also indebted for the loan of many figures.

$$
\text { E. S. GOODRICH. }
$$

Oct. 20 th, $192 \mathrm{t}$. 


\section{CONTENTS}

\section{THE NATURE AND ORIGIN OF LIFE}

Introduction, p. 9. Characteristics of living organisms, p. 9. Structure and composition of living matter, p. ro. Metabolism the basis of all vital activities, p. $\mathbf{2}$ 2. The principle of the Conservation of Energy and of Matter holds good in living organisms, p. I3. Life a physico-chemical process in Protoplasm, p. I4. No special vital force, and no special vital substance, p. 17. Irritability and response to stimulus, p. I8. Regulation and integration by internal secretions and nervous system, p. 19. Continuity of Life, p. 22. Artificial synthesis of living matter, p. 22. Origin of life, p. 23. Principle of Emergence, p. 25.

\section{THE CELLULAR STRUCTURE OF ORGANISMS, REPRODUCTION, AND DEATH}

Cells and the Cell-theory, p. 26. Protophyta and Protozoa, Metaphyta and Metazoa, p. 28. Growth, p. 29. Regeneration, p. 29. Cell-division, p. 3o. Continuity of cells, nuclei, and chromatin, p. 3o. Chromosomes, p. 32. Reproduction, asexual and sexual, p. 33. Germ-cells or Gametes, p. 34. Fertilization, p. 34. Zygotes, p. 35. Continuity of 'Germ.plasm', p. 39. Soma and Germ-cells, p. 40. Death, p. 40.

\section{DARWINISM AND HEREDITY}

Evolution due to 'Natural Causes', p. 43. Darwin and Wallace; Natural Selection, p. 44. Factors of Evolution, p. 44. Variation, p. 45. Biometrics, p. 46. Heredity, p. 48. Transmission of factors of inheritance in germ-cells, p. 49. Weismann and 'inheritance of acquired characters', p. 5o. r'opular misconceptions, p. 52. Transmission and Inheritance, p. 52. Causes of variation, p. 53. Onekind of character but two kinds of variation, p. 54. Mutations and modifications, p. 55. Effect of external and internal environment, p. 57. Characters are responses, p. 58. Summary of argument, p. 60. 


\section{VARIATION AND THE FACTORS OF INHERITANCE; DETERMINATION OF SEY}

Modifiability, p. 63. Johannsen's experiments, p. 63. Pure lines, p. 66. Darwin's provisional theory of Pangenesis, p. 66. Weismann's theory of inheritance inadequate, p. 68. Menclel's researches, p. 68. Laws of heredity, p. 69. Segregation of factors, p. 71. Homozygotes and heterozygotes, p. 73. Dominance, p. 74. Factors of inheritance, p. 76. Mendelian inheritance, p. So. Reversion, p. $\delta_{2}$. Crossing of races and species, p. $\delta_{3}$. Kinds of mutation, p. 84 . Their origin, p. S4. Factors borne by chromosomes, p. 86. Evidence of Cytology, p. 89. Nature of factors, p. 89. Epigenesis and 'evolution', p. 9o. Development and differentiation, p. 94. Origin of factorial changes, p. 95. Production and control of mutations, p. 96. Determination of sex, p. 97.

\section{THE STRUGGLE FOR EXISTENCE AND NATURAL SELECTION}

Struggle for existence, p. I03. Reproduction of organisms, p. I03. Competition, p. I04. Increase held in check, p. IO5. Natural Selection acts like a sieve, p. ro6. Direction of Evolution determined by environment, p. 107. Objections, p. I07. Adaptation, p. Io9. Selective death-rate, p. IIO. Disease, p. II3. Effect of selection, p. II 5. Ancestral inheritance, p. I 77. Domestic races, p. II7. Regression, p. II $S$. Continuous and discontinuous variation, p. II g. Variation not adaptive, p. I22. Usefulness of characters, p. I23. Correlation, p. I24. Animal coloration, p. I25. Persistence of mutations, p. 127.

\section{ISOLATION AND SEXUAL SELEC'TION}

Divergence a result of Isolation and Selection, p. I28. Geographical Isolation, p. I2S. Parasitic isolation, p. I30. I'hysiological isolation, p. I30. Sterility, p. I3I. Secondary sexual characters, p. I3I. Sexual Selection, p. I 32. 


\section{PHYLOGENY AND CLASSIFICATION}

Phy'ogeny the basis of Classification, p. I 36. Degeneration, p. I39. Vestigial organs, p. I 40. First Origin of complex organs, p. I4I. Convergence, p. I43. Analogy and Homology, p. I45. Recapitulation not of adult, but of developmental stages, p. 145. Affinity and blood-relationship, p. 147. Species and the principles of classification, p. 147 .

\section{THE GEOLOGICAL RECORD OF SUCCESS AND FAILURE}

Failures in the struggle, p. I 52. Geological evidence as to Evolution in the past, p. 153. Adaptive Radiation, p. 153. History of Land Vertebrates, p. 154. Amphibia, p. I54. Reptilia, p. 154. Aves, p. 158. Mammalia, p. 158. Ungulata, p. 161. Extinction of most groups and success of few, p. 163. Rate of erolution, p. 165. Gradual transition, p. 167. Risks of specialization, p. 169. Adaptability, p. 170 .

\section{PSYCHOLOGY AND THE EVOLUTION OF INTELLIGENCE}

Simple adaptability in plants, p. I71. In animals, p. I73. Behaviour, p. I74. Physiological Psychology, p. I74. Mental processes correlated with physico-chemical changes, p. 174. Body and Mind two abstractions, p. I75. Instinctive behaviour, p. 177 . Tropisms, p. 178. Differential sensibility, p. I82. Instincts and Heredity, p. I83. Associative memory, p. I84. Intelligent behaviour p. 184. Consciousness emergent, p. 186. Darwinism and human progress, p. I86. Origin of Man from lower Primates, p. I87. Conclusion, p. 192.

BIBLIOGRAPHY, p. 195.

INDEX, p. 197. 


\section{LIST OF ILLUSTRATIONS}

FIG.

I. Diagram to show the proportionate amounts of the chemical elements in living organisms. W. M. Smallwood: Te.rt Book of Biology (Lea \& Febiger) . . . . . .

2. Enlarged view of stained microscopic preparations to show the structure and multiplication of cells and their nuclei in plant tissue • • • • • • • • .

3 Diagrams illustrating the division of a cell and its nucleus into tivo

4. A nearly ripe Human Ovum in the living condition. E. G. Conklin: Heredity and Environment (O. U. P.) . . .

5. Diagrams of the Fertilization and First Clcavage Division of the $Z_{y}$ gote in a Metazoon . . . . . . . 36

6. Diagram of the life-cycle of the Protozoon Copromonas subtilis. After Dobell, from G. C. Bourne: Comparative Anatomy of Animals (Bell) . . . . . .

7. Diagram illustrating the continuity of the germ plasm and discontinuity of the soma of successive generations . . 40

8. Reproduction by fission of the Infusorian Paramecium. H. S. Jennings: Heredity and Environmest (R. G. Badger, Gorhain Press, Boston) . . . . • • •

9. Curves showing distribution of stature in women and in men. L. Doncaster : Heredily (Camb. Univ. Press)

Io. Diagrams illustrating: $\mathrm{A}$, organisms (plants) of similar germinal constitution grown under uniform conditions; $\mathrm{B}$, of different germinal constitutions grown under uniform conditions; c, of similar grerminal constitution grown under different conditions

I I. Young fish. After Stockard, from E. G. Conklin : Itcredity and Enviroment (Princeton Univ. Press, New Jersey) • •

I2. Dandelion. After Bonnier, from Schimper: Plant Geograpliy (O. U. P.) . . . . . . • • • . 59

I3. Curves illustrating the conception of pure-lines in a population $6_{4}$

I 4. Eight diverse families of Paramecium showing variations. H. S. Jennings: Life and Death (R. G. Badger, Gorham Press, Boston) 
FIG.

15. Diagranis of the descent of generations of organisms reproducing by fission and by sexual reproduction. H.S. Jennings: Life and Death (R. G. Badger, Gorham Press, Boston)

16. Cross between white- and crimson-flowered Snapdragons ( $A n$ tirhinum) illustrating Mendelian inheritance of characters and segregation of factors . . . . . . . 69

17 Diagram illustrating the cross shown in Fig. I6 . • . $7 \mathrm{r}$

18. Cross between splashed-white and black parents. T. H. Morgan : Physical Basis of Iteredity (Lippincott \& Co., London)

I9. Diagram illustrating a cross between a pink heterozygote

parent and a crimson homozygote parent Antirrhinum .

20. Diagram illustrating a cross between a white homozygote parent and a pink heterozygote parent . . . .

2 I. Cross between a tall and a short race of garden peas, illustrating dominance. T. H. Morgan: Physical Basis of Heredity (Lippincott \& Co., London).

22. Cross between two vinegar flies, Drosoplita, illustrating the inheritance of two characters, due to presence of two independently segregating factors. T. H. Morgan: Physical Basis of Heredity (Lippincott \& Co., London)

23. Diagram illustrating the distribution of factors in gametes of parents, $P$, and $F_{1}$, of flies shown in Fig. $22 .$. .

24. Diagrams illustrating the maluration divisions of germ-cells leading to the formation of four gametes, each with half the number of chromosomes found in the body-cells and immature germ mother-cells . • . • . .

25. $A-F$. successive eariy stages in development of fertilized egg of Frog. The diagrams show the appearance and later distribution of differences in the protoplasm indicating ' organ determining' substances. E. G. Conklin : Heredity and Enviromment (Princeton Univ. Press, New Jersey) .

23. Later stages of development of egg of Frog. The diagrams represent longitudinal median sections, and show the fate of the 'organ determining' substances. E. G. Conklin : Heredity and Enviromment (Frinceton Univ. Press, New Jersey) . ( 
FIG.

28. Diagram illustrating the behaviour of the chromosomes in

Protenor. Sex-chromosomes represented unshaded, other six pairs of chromosomes black. R. C. Punnett: Mcudclism (Macmillan).

29. Diagram illustrating behaviour of sex-chromosomes when a $0^{\lambda}$ of formula XY is crossed with a $q$ of formula XX. Males and females are produced in equal numbers

30. Boncllia viridis. Large female, and three males drawn to same scale

3I. Protective rescmblance to surroundings, three cxamples from insects. G. J. Romanes: Darvin, and afler Darwin Macandrew, Wright \& Murray, Edinburgh)

126

33. Two spiders, Marptusa familiaris, in courtship. G. W. and E. G. Peckham : Observations on Scrual Selection (Nat. Hist. Soc. Wisconsin)

33. Three stages in the life-histary of a Sea-squirt or Tunicate .

34. Early and later free-swimming stages in the development of the parasitic Cirripede, Sacculina neglecta. G. W. Smith: Cambridge Nat. Hist. (Macmillan)

35. Sacenlina earcini; adult parasitic stage fixed on to the host, a crab. After Delage, from A. Lang: Comparatize Anatomy (Macmillan).

36. Restoration of Arehaeopteryx marma, from Upper Jurassic of Bavaria

37. Convergent evolution. Salamandra (I), a normal urodele Amphibian; Siphonops (2), a legless Amplnibian; Agama (4), a normal Lacertilian; and Amplisbaena (5), a legless Lacertilian

38. Three plants showing convergence of structure in three different families in adaptation to dry condilions

39. Corresponding embryonic stages in development of a dogfish, lizard, and man . . . . . . . . . . I46

40. Diagram to illustrate the principles of classification . . . I50

4 r. Diagram of a phylogenetic tree . . . . . . I5I

42. Divergent evolution in the Class Reptilia in adaptation to various modes of life . . . . . . . . 156

43. Diagram illustrating the Phylogeny, divergent evolution, survival, and extinction in the Reptilia . . . .

44. Skull of Trivachodon, an extinct Theromorph reptile from South Africa, and sliull of the Arctic Wolf . • . . I59 
FIG.

45. Ventral view of skull of Gomphognathus, an extinct Thromorph reptile from South Africa, and ventral view of sliull of the Arctic Wolf

46. Divergent evolution among Placental Mammals in adaptation to various modes of lice

47. Diagram of the Phylogeny of the Ungulata, showing their adaptive radiation from an archaic unspecialized group (Condylarthra) in the Eocene

48. Diagram illustrating the gradual evolution of the Camels. R. S. Lull : Organic Ezolution (Macmillan, New York) .

49. Diagram illustrating the evolution of the Limbs and Molars in the Equine Ungulata. A. Smith Woodward: Vertcbrate Pulacontology (C. U. P.)

50. Rammoulus flutans. A. F. W. Schimper: Plant Geography (O. U. P.)

51. Uie. curopens; $a$, form of growth in ordinary air ; $b$, in damp saturated air. A.F.W. Schimper: Plant Gcography (O U.P.)

52. Diagram illustrating the mechanism of 'reflex' action or response to stimulus

53. Secdling of Brassica migra in which root and stem have curved as a result of geotropism or response to gravity. Pfeffer : Physiology of Plants (O U. P.)

54. Seedling of Simapis alba growing in water. Pfeffer : Physiology of Plants (O. U. P.)

55. Polyps of the zoophyte Eudcudrimm all growing lowards the source of light. J, Loeb: Forced Movements (Lippincott \& Co, London) . . . . . . . . I 81

56. Fly with ore (right) eye blackened can creep only in a spiral. After Garey, from J. Loeb : Forced Morements (Lippincott \& Co., London )

57. Table of Geological Agrs during which Man has lived in Western Europe. A. Smith Wcodward, Brit. Mns. Ginide (O. U. P.)

58. Left outer side view of lower jaw of Chimpanzee, Piltdown, Heidelberg, and modern man. A Smith Woodward: Brit. Mus. Guide (O. U. P.) .

59. Le.t side view of the skull of Piltdown, Neanderthal, and modern man. A. Smith Woodward: Brit. Mus. Gnide (O. U. P.). I 78 I 80 180 182 187 189 189

6o. Restorations by J. H. McGregor of the head of A, Pithecanthropus erectis; $\mathrm{B}$, Homoneanderthalensis; c, Itomosafiens. Photos lent by J. H. McGregor 


\section{I \\ The Nature and Origin of Life.}

EVEr since the time of the ancient Greek philo. sophers men have speculated as to the origin of life and living organisms; but it was not until the middle of the last century that Darwin placed the doctrine of Organic Evolution on a thoroughly scientific basis. Within the limits of a single small volume it would be scarcely possible to deal with so vast a subject from all points of view. Since, however, it is now universally admitted by students of Biology that erolution has taken place, the following pages will be devoted not so much to an exposition of the evidence for the doctrine of the transformation of 'species' as to a discussion of the results of modern research on the nature and relative importance of the factors which have contributed to the-production of the various forms of life we see around us.

The variety of living things is so great, the manifestations of life so diverse and wonderful, that it may seem at first sight impossible to explain them all as the result of the continuous and uniform action of certain fundamental 'natural causes'. Yet this is the ambition of the scientific student of nature. But, before attempting to describe the process of evolution, let us see what science can teach concerning the physical and chemical properties of living organisms.

All living things have certain characteristics in com- 
mon as regards their structure and composition, their properties and activities. They all feed, grow, and reproduce. But if we say that in the possession of these characteristics living matter differs from non-living matter, we do not mean to imply that the difference is absolute, that a perfectly hard and fast line can be drawn between them, that the gap separating the living from the nonliving can never have been bridged. On the contrary, although far from being able to give a complete scientific explanation of all the phenomena of life, we have made so much progress towards that final goal of the evolutionist that we seem fully justified in believing that the transition from the non-living to the living has indeed occurred, and even in hoping that some day the very origin of life will be explained.

The organisms now living on this earth are known as plants and animals. The study of plants is called Botany, that of animals Zoology; while Biology is the name given in England ${ }^{1}$ to the science of living things in general, including both animals and plants. Now one of the first results of a deeper knowledge of living organisms is to show us how much there is in common between them, and how much they differ from their non-living surroundings. There can be no doubt that even the simplest plant or animal now living is the product of a long series of evolutionary changes the initial steps of which have long since disappeared, or are at all events unknown to us.

In the frrst place, all living matter contains substances of peculiar molecular structure and composition, far more complex than any compounds found in inorganic nature.

3 The word Biology is often used abroad with a somewhat different meaning. 
Such complex compounds occur only in living matter itself, or in its products. But the difference between these organic and the inorganic substances is only one of degree, and many of the most characteristic of them have been artificially made in the chemical laboratory.

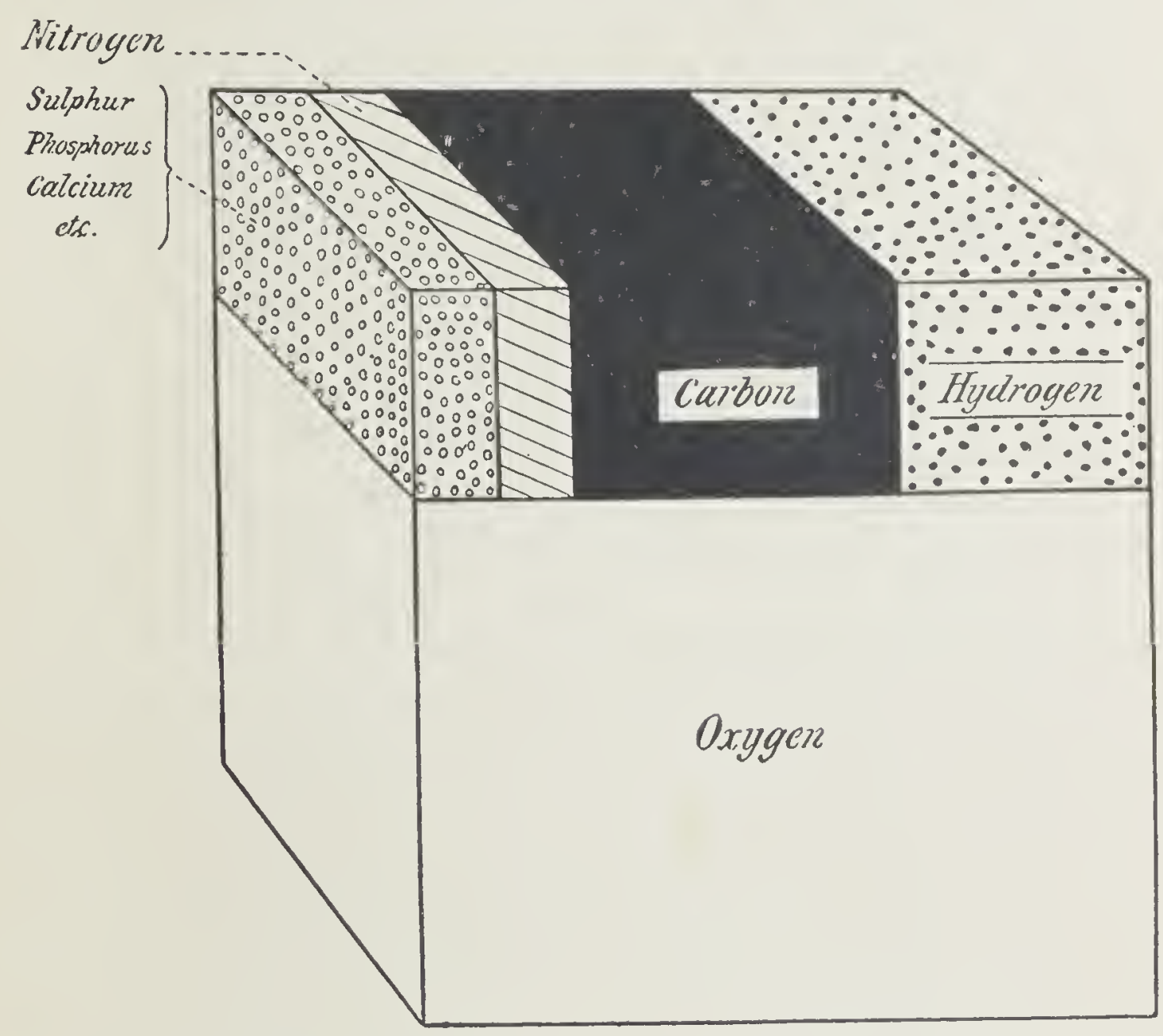

FIG. I. Diagram to show the proportionate amounts of the chemical elements in living organisms. (From W. M. Smallwood: Text Book of Biology.)

Built up of the ordinary elementary chemical substances of nature, chosen indeed as we might expect from among the commonest elements on the surface of the earth, these organic compounds may be grouped in three classes: carbohydrates (such as sugars, starch, and cellulose), fats, and proteins. Of these the proteins are 


\section{2 The Nature and Origin of Life}

by far the most important. For while the molecule of fat or carbohydrate consists entirely of various combinaLy chuts tions of the three elements carbon, hydrogen, and oxygen, the protein molecule always contains in addition nitrogen and sulphur, and hence can attain a far higher degree of complexity endowing it with many new properties (Fig. I). - Small quantities of other elements, such as phosphorus, iron, chlorine, potassium, sodium, calcium, and magnesium are also found combined with the five essential elements mentioned above in the protein molecule. So complex are the proteins that the exact chemical formula of even the simplest varieties has not yet been made out. We know, however, that the molecule is very large, containing some hundreds or even thousands of chemical atoms, with certain characteristic groupings of $\mathrm{C}, \mathrm{H}, \mathrm{O}$, and $\mathrm{N}$. A single molecule of the red colouring matter of the blood, haemoglobin, one of the simplest of the proteins, contains over 600 atoms of $\mathrm{C}$, over 100 atoms of $\mathrm{H}$, and some 200 atoms of both $\mathrm{N}$ and $\mathrm{O}$. Further, the proteins display several physical properties which play an important part in the processes of life (see p. 25).

Correlated with this complexity of chemical composition is the most striking and important of all the physicochemical properties of living matter, namely a capacity for perpetual change. It involves both an exchange of material and a transformation of energy. This fundamental process, the basis of all vital activities, is called metabolism. Briefly to explain the process it will be best perhaps to take first the case of animals. What is said of metabolism in animals applies in principle to living organisms in general. An animal is perpetually taking in food and oxygen, and perpetually giving off carbon dioxide and other waste products. Hence the 


\section{The Nature and Origin of Life}

necessity for respiration (oxygen being derived from the air) and nutrition. Now the food consists chiefly of fats, carbohydrates, and proteins; and since energy has been consumed in the building up of these compounds, it will again be freed if they are broken down or split up into simpler compounds. During their whole life animals perform work, and give off heat; and the energy so spent is derived from the food. The stored-up potential energy of the food is continually being converted into kinetic energy (various forms of motion) and heat. The freeing of the energy is brought about by the burning or oxidation in the tissues of the food materials, which are thus more or less completely broken down from a highly complex state into such comparatively simple compounds as water, carbon dioxide, and urea. Hence the necessity for excretion to remove these waste oxidized substances. In ourselves the urea is passed out by the kidneys and the carbon dioxide by the lungs. An organism may be compared to a heat engine, which derives its energy from the fuel supplied to it. Throughout the process neither matter nor energy is either gained or lost, but merely changed from one form to another.

One of the most important and fundamental generalizations of biology is that the principles of the conservation of energy and of the conservation of matter hold good in living things as they do in inorganic nature. All the matter which enters an organism as food and oxygen eventually leaves it as waste product, except in so far as it is retained for purposes of growth and repair. Similarly all the energy brought in is balanced by work done and heat given off. Neither new matter nor new energy is produced, although both are undergoing unceasing change. This is the metabolic process in terms of 
physics and chemistry ; it is quite characteristic of living things. There is no life without metabolism, and no metabolism without life.

In the living engine not only is the food consumed, but the machinery itself is involved in the process of change, so that the food material brought in does not for the most part merely pass through as fuel; it serves to build up that complex living substance, or machinery, part of which, at all events, is perpetually breaking down again into non-living matter. Chemical instability, a tendency to unite with other substances, or to break up into simpler groups, is manifested by these highly complex protein molecules. It is, indeed, on this instability that metabolism ultimately depends. There is thus a double process continually going on in metabolism: a building up or synthesis of substances to form higher and higher compounds in the making of which energy is absorbed - this is the anabolic process; and a corresponding breaking down of these highest compounds into simpler ones, and eventually into waste products, during which energy is freed-called the catabolic process. In living substance there are, then, two series of compounds: one leading up to the highest complexity, and the other leading down to waste products from which energy is no longer drawn. This mixture of a double stream of substances undergoing these physico-chemical changes is the living matter itself the very physical basis of life, Enown as protoplasm.

In physical structure protoplasm is a viscid or semiliquid colourless substance; seen under the highest powers of the microscope it appears to be composed of the minutest globules of a more liquid substance enclosed in a meshwork of denser fluid. When dead protoplasm 
is analysed it is found to be composed of a variety of anabolic and catabolic proteins, associated with water and certain mineral salts. Protoplasm is the essential living substance present in all living organisms, the seat of all their activities. There is no protoplasm apart from life, and no life without protoplasm.

Most animals, though possibly not all, have lost the power of building up new protoplasm from inorganic matter, indeed from any compounds lower than the simplest nitrogen-containing proteins or their immediate derivatives (albumoses, peptones, amino-acids). Thus protein being their only natural source of nitrogen they inevitably starve sooner or later on a diet without it, however much fat or carbohydrate the food may contain, since they are unable to replace the highest nitrogen compounds which necessarily break down in the metabolism of protoplasm. Speaking generally, animals can build up the most elaborate proteins from the simplest, or from amino-acids, and fats from simpler carbohydrates or proteins; but the carbohydrates themselves they are incapable of forming from inorganic matter. Thus although they run the risk of starvation if no proteins are available, yet by feeding on other organisms they make use of the best fuel, with the greatest amount of potential energy, and may have large quantities of surplus energy to dispose of--for the amount of energy freed by the breaking down of the food material much exceeds that consumed in the anabolic processes in the ordinary course of life.

Animals, then, depend ultimately on plants for their food. Carnivorous live on herbivorous animals, and these in turn on plants, whose powers of synthesis are more complete. 
Even the ordinary green plants can only build up protoplasm from inorganic material in the presence of sunlight. This they accomplish with the help of the green substance, chlorophyll, which decomposes the carbon dioxide of the atmosphere, freeing the oxygen, and combining the carbon with water to form starch, $\mathrm{C}_{6} \mathrm{H}_{10} \mathrm{O}_{5}$, thus storing up energy from the sun. With the help of inorganic nitrogen compounds derived from the soil, protein can then be formed.

Many lower plants have the power of building up protoplasm without chlorophyll and sunlight. Fungi can synthesize protein from carbohydrates and inorganic salts of nitrogen, but depend on organic compounds for their supply of carbon. Among the multitude of bacteria which abound in the soil there are many which can build up proteins, and therefore protoplasm, from inorganic compounds alone; and some indeed which can make use for this purpose of the free nitrogen of the air.

All the phenomena of life are associated with the physico-chemical processes of metabolism taking place in protoplasm alone. The three most characteristic properties of living matter: irritability, or the power of responding to stimuli, growth, and reproduction, all depend on metabolism. An excess of anabolic over catabolic processes leads to increase of protoplasm, to growth, and ultimately to reproduction. An excess of catabolic over anabolic processes leads, on the contrary, to reduction and to death.

Like all physico-chemical processes, metabolism is limited by definite conditions. The essential elements must be present, and a sufficiency of food to balance the waste Water is another essential, since all the 


\section{The Nature and Origin of Life}

chemical reactions really take place in solutions 3 Free oxygen is also necessary for the burning of the food material, except in the rare case of certain parasitic organisms and bacteria, which can obtain it from compound substances. Moreover, metabolism can only take place at all within a somewhat narrow range of temperature, the exact limits of which vary with different organisms. No metabolism is, of course, possible at a temperature so high as to coagulate or destroy the proteins, or so low as to stop chemical action.

Most, perhaps all, of the processes of metabolism take place with the help of special proteins, known as ferments or enzymes, which have the property of facilitating and hastening chemical actions. Just as a small trace of platinum black will cause an indefinitely large amount of hydrogen peroxide $\left(\mathrm{H}_{2} \mathrm{O}_{2 .}\right)$ to decompose into oxygen and water, so a small quantity of ferment will cause an indefinitely large amount of carbohydrate, fat, or protein to break up into simpler substances. Similarly, enzymes may hasten the building up of simple substances into more complex compounds. Such ferments, which are not themselves affected, which are not involved in the end products of the actions they facilitate, are called catalytic; they are produced in protoplasm and play a most important part in the mechanism of life.

In the foregoing pages we have seen that living organisms contain no special vital elements differing from those of non-living matter, and are actuated by no special vital force. From the physico-chemical point of view life is a process involving perpetual change in a complex of elaborate compounds continually being built up and continually being broken down. A stream of non-living matter with stored-up energy is built up into living 
matter, and again passes out as dead matter, having yielded up the energy necessary for the performance of the various activities of the protoplasm. All the phenomena of metabolism on which these activities are based are strictly limited by external conditions and the properties of the material taking part in it.

We cannot, therefore, speak of a special living chemical substance. The full attributes of life are only possessed by a mixture of substances, some very complex, others more simple, which make up protoplasm as a whole. The living process forms a chain of interdependent actions every link of which is essential. No single link by itself can be said to be living, nor can we really draw a hard and fast line marking off where the life process begins and where it ends. The protoplasm itself contains many substances, such as yolk or starch granules, which are merely materials for future use in the building up of new protoplasm, or special products of decomposition stored for future use (digestive ferments, secretions) or again granules of waste products, which may never re-enter the life cycle.

It was mentioned above that irritability, or the power of responding to a stimulus, is one of the most important characteristics possessed by all living matter. A manifestation of metabolism, it depends on the fact that the material of protoplasm is in a state of unstable equilibrium capable of being disturbed by a stimulus or, in other words, has a physico-chemical structure easily altered so as to liberate energy. Stimuli are those things or conditions in the environment which can bring about such a disturbance or response. Naturally the character and amount of the stimulus has no direct relation to the character and amount of the response. Just as the 
pressure of a button may ring a bell, explode a mine, or start an engine, so a stimulus applied to living protoplasm may cause a plant to grow, an animal to move, or a man to embark on a course of action. Although response is not directly proportional to stimulus, yet the latter must be of sufficient strength, must pass the threshold of stimulation, to initiate a change. The extent and nature of the response depend on the structure of the mechanism stimulated, and on the amount of energy stored in it. But the mechanism may be so disposed as to respond only to one particular stimulus, and to vary in its response according to the intensity and duration of the stimulus. As the various steps in the metabolic process are dependent on those which preceded them, so when an organism becomes differentiated into parts, when the main process becomes subdivided into subsidiary processes, these react on each other. Moreover, when an external stimulus fires off, so to speak, an internal metabolic change, this may give rise to other changes, some of which may react on the first. So the motion of a mechanism may regulate its own action; as does, for instance, the governor of a steam-engine. An internal change may become an internal stimulus starting new reactions. But there is no absolute distinction between internal and external stimuli; what is internal to the whole may be external to a part.

Modern study has made it increasingly clear that, in addition to the well-known co-ordination of various parts of the body by an elaborate system of nervous supply seen in the higher animals, there is a more subtle and still more elaborate integration present in all organisms, and brought about by the secretion by one part, tissue, or organ, of special substances which effect the action of 
other parts. For the normal development and carryingon of the proper activities of the organism these internal secretions or 'hormones' are quite essential. Their effect is profound and far-reaching. Thus, it has been shown by Starling and Bayliss that the small intestine secretes a substance which stimulates the pancreas to activity. The thyroid gland regulates the growth of the embryo, the condition of the skin, and the functioning of the brain. In many rertebrate animals the secondary sexual characters and sexual instincts depend on the secretion of certain cells of the ovary or testis for their development.

We must think, then, of living organisms as marvellously complex mechanisms, with their parts so adjusted as to set going; regulate, or restrict each other's action. A chain of such interactions forms the self-repairing, self-regulating mechanism so essential for the continuance of the process of life.

It is by means of the fundamental attribute of irritability that protoplasm comes into relation with its environment. It is the secret of adaptation. Of the stimulating factors of the environment some, like temperature and water, are of a general nature, ever present and necessary; others, like sound or light or some particular chemical compound, are more special, and not always essential.

When first we approach the problems of evolution we are apt to ask for definitions; to seek for distinctions separating the living from the dead, the organic from the inorganic: we try to discover hard and fast lines between species and rarieties, between plants and animals, between the conscious and the unconscious. But as we study the question deeper, and extend our field of vision, 
we come to recognize that the definitions are usually misleading, the distinctions artificial, the sharp lines arbitrary. The breaks in nature, if breaks there seem to be, are gaps in our knowledge, and diminish in size and number as science advances. If we analyse one by one the distinguishing features of living matter, they can all be paralleled in inorganic nature. No one universally present in the first is universally absent in the second. Complex chemical compounds, the properties of which cannot be discovered in those of their component elements, cyclic changes of matter and energy, even selfregulating mechanisms, occur in the non-living world. As the untutored savage explains the movements of a watch by attributing them to a spirit which has entered into it, so many writers hold that the activities of living matter are due to some special and mysterious vital force. They attempt to bridge the gaps in our knowledge by merely giving them a name. This is no scientific method; science advances by explaining, that is describing, the unknown in terms of the known. If vital force is merely a general term for those new properties manifested in new mechanisms of increasing complexity, there is no harm in it; certainly living matter must display properties not found in simpler substances (see p. 25). But it has no intelligible meaning if used to denote some force added, so to speak, from without over and above the ordinary properties, some force acting on the physico-chemical mechanism but not of it. Like a vortex, the metabolic process in living matter draws in inorganic substance and energy at one end, and parts with them at the other; it is inconceivable that these should, as it were, pass outside the boundaries of the physico-chemical world, out of range of the so-called 
physico-chemical laws, at one point to re-enter them at another.

When we maintain that the physico-chemical processes of metabolism, with which are correlated all the phenomena of life, form a continuous series without break, we do not in the least mean to assert that this is a complete and satisfying explanation of 'life' from all points of view. It is only one aspect of the problem, and the psychical is another. Doubtless there are still other aspects within the wider scope of philosophy or religion. But we hold that these various aspects cannot be described in the same terms, that they neither overlap nor break into each other's continuity. The scientific aspect has its limitations; it is a one-sided abstraction based on a reality, with the ultimate nature of which it is not the function of natural science to deal (see p. I 75).

But, it will be asked, if life is thus correlated with a physico-chemical process, why cannot living substance be made in the laboratory? The answer is that the expectation is premature, perhaps never to be realized. ${ }^{1}$ Since we are still ignorant of the intimate structure of the proteins, we can hardly be expected to manufacture them. Moreover, it would not be sufficient to make one or even several such compounds, but the whole chain of growing complexity. If the machine is to work, the mechanism must be complete. There is, also, a long

1 Nevertheless an important advance will have been made if the recent work of Professors Moore and Baly be confirmed. For they have slown that under the influence of light of appropriate short wave-length there is produced in water containing $\mathrm{CO}_{2}$ a comparatively high compound of $\mathrm{C}$ known as formaldehyde, and further that it can be built up into sugar, and also made to combine with nitrites to form nitrogenous 'organic' compounds. Moreover, Moore finds that such reactions take place in ordinary sunlight provided a suitable photocatalytic substance is present. 


\section{The Nature and Origin of Life}

history behind even the simplest organism found at the present day; there must be a vast difference between the very simplest of these and the initial stages in the evolution of protoplasm. It would be as absurd to expect an experimenter to build up an organism in a laboratory as, for instance, to expect a refined civilization to arise in a day among the savages of Central Africa. Great advances have already been made in the synthesis of organic compounds of carbon and nitrogen; many of the substances most characteristic of living matter have already been synthetized, such as the sugar glucose, the alkaloid cocaine, and various amino-acids. But if any stage in the development of living substance were artificially made, it would probably be so different from the protoplasm of modern plants and animals that we should scarcely recognize it as living at all, even if we had it before us.

An attempt to reconstruct in imagination what we believe may have been the history of the origin of living matter may be made not altogether without profit.

Before the principle of the continuity of life, to which we shall refer later, was established, it was thought that living things arose spontaneously from organic compounds. Moulds, the bacteria of putrefaction and fermentation, infusoria, and such-like forms, were supposed to develop de novo in liquids of appropriate composition. But Pasteur and others in the last century definitely proved that such organisms really arise from germs or spores originally present in the liquids; that neither putrefaction nor fermentation will take place, nor organisms of any kind appear, in substances which have been thoroughly sterilized, or from which all living germs have been rigidly excluded. So far as we know, living 
organisms at the present day do not develop spontaneously, but are all derived from pre-existing organisms.

We must, however, suppose that at some period in the earth's history, when conditions were favourable and perhaps very different from those of the present time, living protoplasm made a first appearance. Possibly these conditions will never be repeated, either in nature or in the laboratory, and the first stages in the evolution of life may never be discovered. The temperature, moisture, pressure, and other conditions must have been such as to allow of the formation of high compounds of various kinds. Many of these would be quite unstable, breaking down almost as soon as formed; others would be stable, and merely persist and accumulate. Still others might, possibly with the help of some catalytic substance, tend to reform as fast as they broke down. Once started on this track such a self-repairing compound or mixture would inevitably tend to perpetuate itself, and might combine with, or 'feed' on, other compounds less complex than itself, as was long ago suggested by Lankester. For any chemical action will continue so long as the conditions are favourable; a trail of gunpowder will inevitably explode from end to end provided it be continuous, and will go on burning so long as powder is supplied.

The principle of the survival of the fittest applies with all its force to such initial steps in the evolution of life. The more completely self-regulating mixtures would outlast the others. And so we may imagine did the nicely balanced mixture of anabolic and catabolic proteins finally become elaborated into protoplasm. Innumerable compounds must, of course, have failed to establish themselves in this way owing to too great fixity or too 
great instability. For many reasons it seems probable that life originated in the sea; protoplasm contains the same salts of calcium sodium and potassium as sea-water, and in much the same proportions.

Here we may draw attention to an important consideration to be borne in mind when interpreting evolution-the principle of 'Emergence'. Water displays certain properties not found in either of its constituents, oxygen and hydrogen; add to a molecule of water an atom of carbon and formaldehyde will be produced, having again quite new properties. So, as step by step the complexity increases, new properties emerge not possessed by, and not predictable from our knowledge of, the lower stages. Now, even before molecules reach the complexity of the proteins, they begin to exhibit many important new physico-chemical qualities: for instance those characteristic of colloids. The molecules become too large to pass through certain organic membranes and thus may be confined; they may tend to aggregate together in solutions, and surface tension may produce new effects leading to adsorption and the deposition of material at the surface of the colloid; definite limits may thus become established between the colloid and the 'external world'. These and other emergent properties probably played an all-important part in the early stages of organic evolution, as they certainly do to-day in the processes of assimilation and growth.

Speculating further, we may suppose that it became an advantage for some of the vaguely defined metabolizing substance mentioned above to become separated off into individual masses, which came to acquire the structure of cells. From this point onwards we can appeal to known evidence for our history of the evolution of life. 


\section{The Cellular Structure of Organisms: Growth, Reproduction, and Death.}

Although all living organisms necessarily contain some protoplasm, yet they are far from being entirely made up of it. All the parts of an organism are not truly alive, but only that portion which is protoplasmic. However, the substances of which it is composed are either about to be assimilated into protoplasm, or are the products of protoplasm. Indeed, the great bulk of a plant or animal may be formed of the accumulated products of its past activity. Such, for instance, is the woody supporting tissue of a tree, the skeleton of a coral, the shell of a snail, the bony substance or hair in ourselves. While the living element is continually undergoing change, the dead deposit may continue unaltered during the life of the organism, and even afterwards.

A microscopic examination of living organisms teaches us that the protoplasm is always present in the form of cells. We now come to another of the great generalizations of biology: the so-called 'cell theory', founded by Schleiden and Schwann more than seventy years ago, and much modified and extended since then. Briefly it may be summed up as follows: The cell is a small mass of protoplasm consisting of a nucleus and surrounding cell-body. All plants and animals are made up of such cells, either singly or in aggregates. Growth is due to the increase in size and multiplication of the cells. They do not grow indefinitely but, having reached a certain bulk, divide into two daughter cells, and all the cells of 
the body of an individual are thus derived by repeated binary fission from a single original cell. Differentiation in multicellular organisms is related to the progressive division of labour among the cells, comparable to the division of labour among the individuals of a civilized community. The body of a multicellular organism is thus an aggregation, not of separate units brought
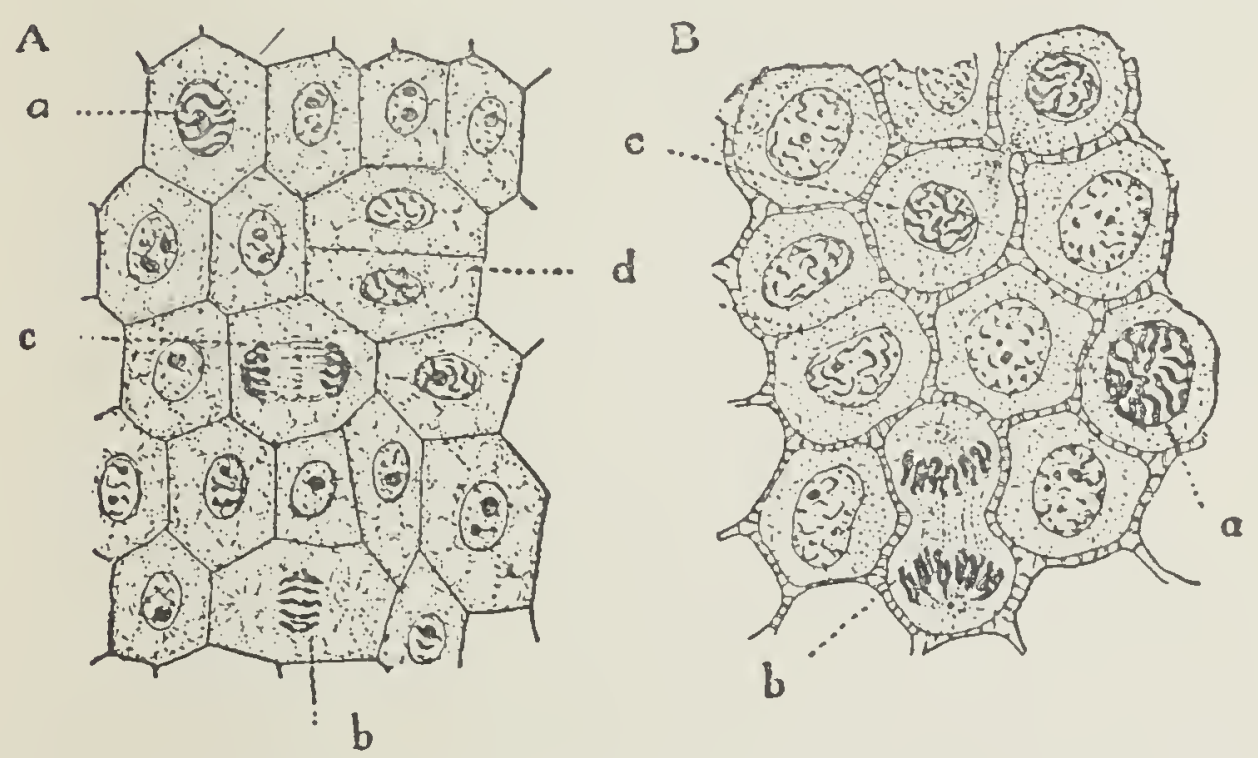

FIG. 2. Enlarged view of stained microscopic preparations to show the structure and multiplication of cells and their nuclei in plant tissue $A$ (section through the tip of a root,) and in animal tissue $B$ (epithelium of the gill of a larval Salamander). $a, b, c, d$ represent successive stages in the divisions of cells.

together, but of a multitude of related cells remaining in association, and building up its tissues. As a rule the tissue-cells remain in actual protoplasmic continuity; but in animals certain cells may become free and lead a quasi-independent life, as for instance the white corpuscles of the blood. The activity of an organism is the sum of the activities of its component cells. All living phenomena are ultimately questions of cell-life; all organic products due to the action of cells (Fig. 2). 
While the cell-body consists of ordinary granular protoplasm (cytoplasm), the nucleus is formed of special protoplasm differing from it both in structure and in chemical composition. In the nucleus may be distinguished by appropriate methods, besides a more fluid nuclear sap, a meshwork of substance known as linin, in which are suspended masses of another substance called chromatin, from the fact that it colours deeply with certain stains after having been killed and coagulated with appropriate reagents.

For the life of a cell both body and nucleus are essential. An interchange of material takes place between them; one cannot live without the other. If a cell is divided into halves, only that which contains the nuc'eus will continue to live, grow, and reproduce. The cell is the smallest known unit of life. But in the Bacteria there is no well-defined nucleus, the chromatin being scattered. They probably represent a primitive condition before the typical cell-structure was completely differentiated.

Among the lowest plants, Protophyta, and the lowest animals, Protozoa, the whole individual consists of a single isolated cell, which consequently has to perform all the functions of life. Such organisms may, nevertheless, become highly differentiated, developing special cellorgans-a mouth for taking in food, motile processes for locomotion, contractile vacuoles for excretion, and so forth, all within the limits of one cell. But in the multicellular plants, Metaphyta, and animals, Metazoa, where the cells form tissues and organs, starting from primitive cells capable of performing all the essential processes of life (irritable, metabolic, growing, and reproductive) the cells become as differentiation advances 
adept at performing certain functions, but correspondingly incapable of carrying out others. The more they become adapted in special directions, the more they are apt to lose their other powers. So the highly specialized cells of the alimentary, nervous, muscular, and other tissues of animals can only continue to live in association with each other, supplying each other's wants. Moreover, the specialized cells of differentiated tissues can usually only produce by division cells like unto themselves, and may lose the power of reproducing at all.

Multicellular organisms all start from a cell in a primitive undifferentiated condition, rich in unspecialized protoplasm, capable of becoming adapted to perform any of the necessary functions of life. Of such are built up the early embryonic stages, and the actively growing tissues of adults. But soon they become burdened with the accumulated products of their own activities, their potentialities are narrowed down, their irritability restricted so as to respond only to special stimuli, their capacity for regeneration more or less exhausted.

Speaking generally, the lower the organism the less specialized are its cells, and the greater are their powers of growth and regeneration. A single cell of the freshwater alga Vaucheria or of the fungus Mucor will grow into a new plant; the propagation of plants by cuttings is familiar. While the regenerating powers in a man are restricted to the simple growth of tissues, the healing of wounds and so forth, a newt or a crab will regenerate a whole limb; a worm deprived of its head or tail will replace the missing parts; a fresh-water polyp, Hydra, may be cut into several pieces, each of which can grow into a complete animal. Speaking generally, also, the younger the organism the greater are its powers of 
regeneration. Thus the embryo of a sea urchin, while still composed of only a few still undifferentiated cells, say two, four, or eight, may be divided into two, four, or even eight separate cells, each of which is capable of growing into a complete larra.

All that is necessary for complete regeneration to take place is protoplasm retaining its unimpaired potentiality of development, and present in sufficient quantity for metabolism to be carried out in full. So soon as the potentiality becomes limited by specialization the power of regeneration becomes restricted.

We must now return to the consideration of the reproduction of cells. A unicellular organism does not increase indefinitely in bulk; when it exceeds that size which is normal for the adult of the species, it tends to divide into two. The nucleus divides first, then the cellbody, forming two daughter cells, each with its own nucleus. The daughter cells then separate, growing into adults similar to the original parent. It is the same with the cells of the higher organisms. Each multicellular animal or plant starts life as a single cell, which grows and divides repeatedly. In every case the nucleus divides, each half passing into one of the two daughter cells. But here, instead of the cells separating to lead an independent life, they remain more or less closely associated as parts of a single complex individual (Fig. 2).

Thus not only is every cell derived from a pre-existing cell, but every nucleus is formed from a pre-existing nucleus, just as all protoplasm is derived from preexisting protoplasm. The continuity of protoplasm, of cells, and of nuclei is one of the most important facts established in modern biology. 
Rarely the nucleus divides 'directly', by simple constriction into two halves; usually the division is 'indirect', by an elaborate process known as caryokinesis, and taking place as follows. The chromatin gathers together into a coiled thread, the linin network becomes disposed as a system of fibres radiating through the
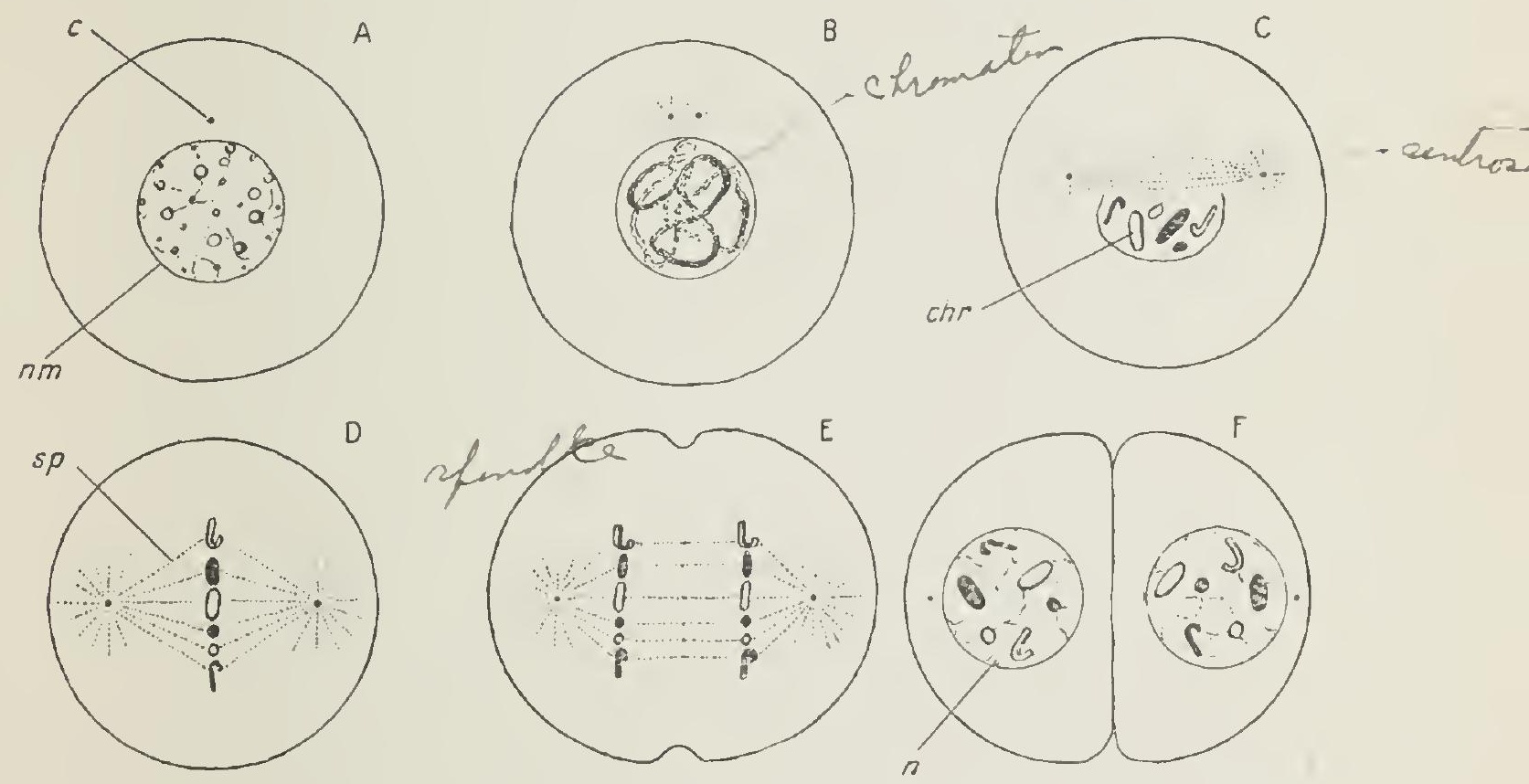

FIG. 3. Diagrams illustrating the division of a cell and its nucleus into two. A, resting stage; $\mathrm{B}$, division of centrosome and appearance of chromatin thread; c, separation of centrosomes, formation of achromatic spindle and of chromosomes, and disappearance of nuclear membrane; $\mathrm{D}$, arrangement of chromosomes in equatorial plane of spindle ; $\mathrm{E}$, division of chromosomes and their migration to opposite poles of spindle; $\mathrm{F}$, reconstitution of daughter nuclei, and division of cell-body into two. $c$, centrosome; chr, chromosome; $n$, nucleus; $n$ m, nuclear membrane; sp, spindle.

cytoplasm from two minute bodies, the centrosomes. Between these centrosomes the fibres join across, forming a spindle. The centrosome can be seen to originate from the nucleus or its neighbourhood, as a single body which divides, the two halves moving to the opposite sides of the nucleus. The chromatic thread now breaks 
up into a definite number of separate pieces, the chromosomes, which arrange themselves in a circle round the equator of the spindle. Each chromosome now divides into two halves which travel to the opposite ends of the spindle. There they join together to form a thread; the thread breaks up into granules, the system of fibres disappears, and thus a new nucleus is reconstituted similar to the resting nucleus of the original cell. A division of the cell-body then yields two nucleated cells (Fig. 3). As a rule the centrosome persists to give rise to that of the next division. Now it is important to notice the continuity of substance during this process of division. Cytoplasm, linin, centrosome, and chromatin are all parcelled out to the two daughter cells; above all, each daughter nucleus receires the same number of chromosomes, and apparently exactly the same amount of chromatin. Although the process of caryokinesis may differ in detail in various forms, yet it is essentially the same in all plants and animals. The number of chromosomes is approximately constant in each species, but differs widely even among allied forms. The great importance of these facts will appear later when we discuss the pliysical basis of heredity (p. 86).

Just as the organism takes material from the external environment, so every part of the cell selects from the internal environment appropriate substances. By a characteristic process of assimilation, whereby it forms more substance like unto itself, every essential element of the cell can grow in a way which may be somewhat loosely compared to the growth of a crystal in a suitable fluid, and reproduce by division. Thus the fundamental principle of continuity mentioned above applies not only to cells and their nuclei but also to chromatin and other 
essential constituents of the mechanism of the uninterrupted main stream of life. Why, it may be asked, has the cell structure been universally adopted? To this question we can give no more definite answer than this: that there seems to be some proportion of mass to surface, and of nucleus to cytoplasm, within which it is necessary for the protoplasm to keep if metabolism is to be satisfactorily carried out. The size of cells varies considerably; much more than the size of nuclei. It bears no direct relation to the size or complexity of the organism to which the cell belongs. A cell may be so small as scarcely to be visible with the high porvers of the microscope, or as large as the yolk of an egg, for instance, the greater portion of which is, however, made up of inert yolk granules.

If living organisms did not reproduce, they would sooner or later be extinguished, if not by natural at all events by accidental death. Therefore only those creatures survive which can multiply, and indeed multiply rapidly by the separation of some portion of their substance capable of growing into a new individual. This may give rise to a vegetative or asexual mode of reproduction by fission, or by the formation of special reproductive cells (spores), or by multicellular bodies (buds). Mention has already been made above of asexual reproduction in connexion with growth and regeneration. Propagation by shoots developed on runners or on tubers is common among the higher plants, and gemmation or bud-formation is a widely distributed mode of reproduction among animals. It is found not only among lowly organized forms like the zoophytes, and polyps (Coelenterata), and sponges (Porifera); but even in such highly differentiated groups as the marine and fresh-water bristle-worms 
(Chaetopoda), sea-mats (Polyzoa), and sea-squirts (Tuni cata). But while in the bacteria asexual reproduction by fission and by spores seems to be the only method of propagation, in all other groups of plants or animals sexual reproduction occurs, though the asexual method may also be retained.

The typical sexual reproduction of multicellular plants and animals takes place by means of special cells of two kinds set apart for the purpose, and called the germ-cells or gametes. Each gamete of one kind by fusion with a gamete of the other kind in the process of fertilization gives rise to a single cell, the zygote, which grows into a new individual. The two kinds of cells have become differentiated along divergent lines, being adapted to the particular functions they have to perform (Fig. 4).' One, the ovum, is quiescent, stored with foodmaterial to provide for the nutrition of the developing embryo, and consequently is generally of large size. The other, the spermatozoon of animals or spermatozoid of plants, is on the contrary small, active, and usually furnished with a vibratile whip-like 'tail', with the help of which it swims towards and bores its way into the ovum. (Fig. 5). The individual bearing ova is of the female sex; that bearing the spermatozoa, of the male sex. ${ }^{2}$ But the names male and female are often conveniently extended to the gametes themselves. Hermaphrodites give rise to both kinds of germ-cells.

In fertilization one male gamete fuses with one female; and not only do the cell-bodies unite, but the nuclei of

1 In some of the lowest animals, Protozoa, the gametes are not differentiated into two kinds, and the zygote is formed by the union of two similar cells (see below).

2 The symbol o $o^{7}$ is conveniently used to denote the male sex, and the symbol $q$ to denote the female sex. 
the cells also combine into one nucleus (Fig. 5). Thus the nucleus of the resulting zygote contains chromatin from two individuals, since the cells usually come from different parents; for it is only exceptionally that herma-

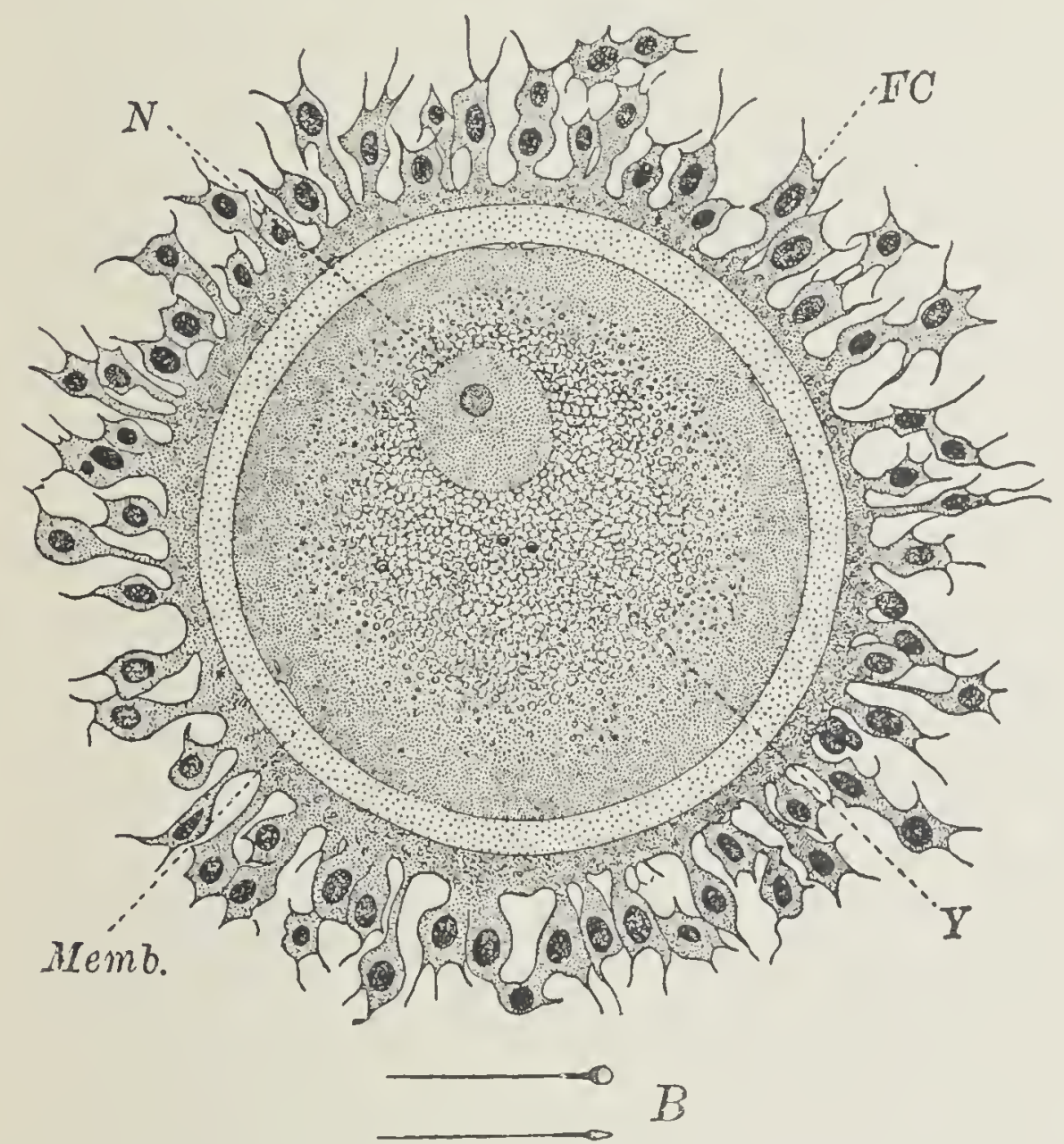

FIg. 4. A nearly ripe Human Ovum in the living condition. The ovum is surrounded by follicle cells $(F C)$ inside which is the clear membrane $(M e m b$.), and within this is the ovum proper containing yolk granules $(Y)$ and a nucleus $(N)$ emhedded in a clear mass of protoplasm. Magnified 500 diameters $(\times 500)$. (After O. Hertwig.) $B$, two human spermatozoa drawn to about the same scale of magnification. (After G. Retzius.) From E. G. Conklin's Heredity and Environment.

phrodites are self-fertilizing. Unsuccessful male gametes, which do not reach an ovum, perish sooner or later ; and likewise, unfertilized ova die, except in those rare cases where parthenogenesis occurs. Instances of partheno- 


\section{$3^{6}$ The Cellular Structure of Organisms}

genetic reproduction are the fresh-water stonewort (Chara crimita), of which only females occur in northern Europe, and the plant lice (Aphidae) and certain other insects, which propagate in this manner in the summer.
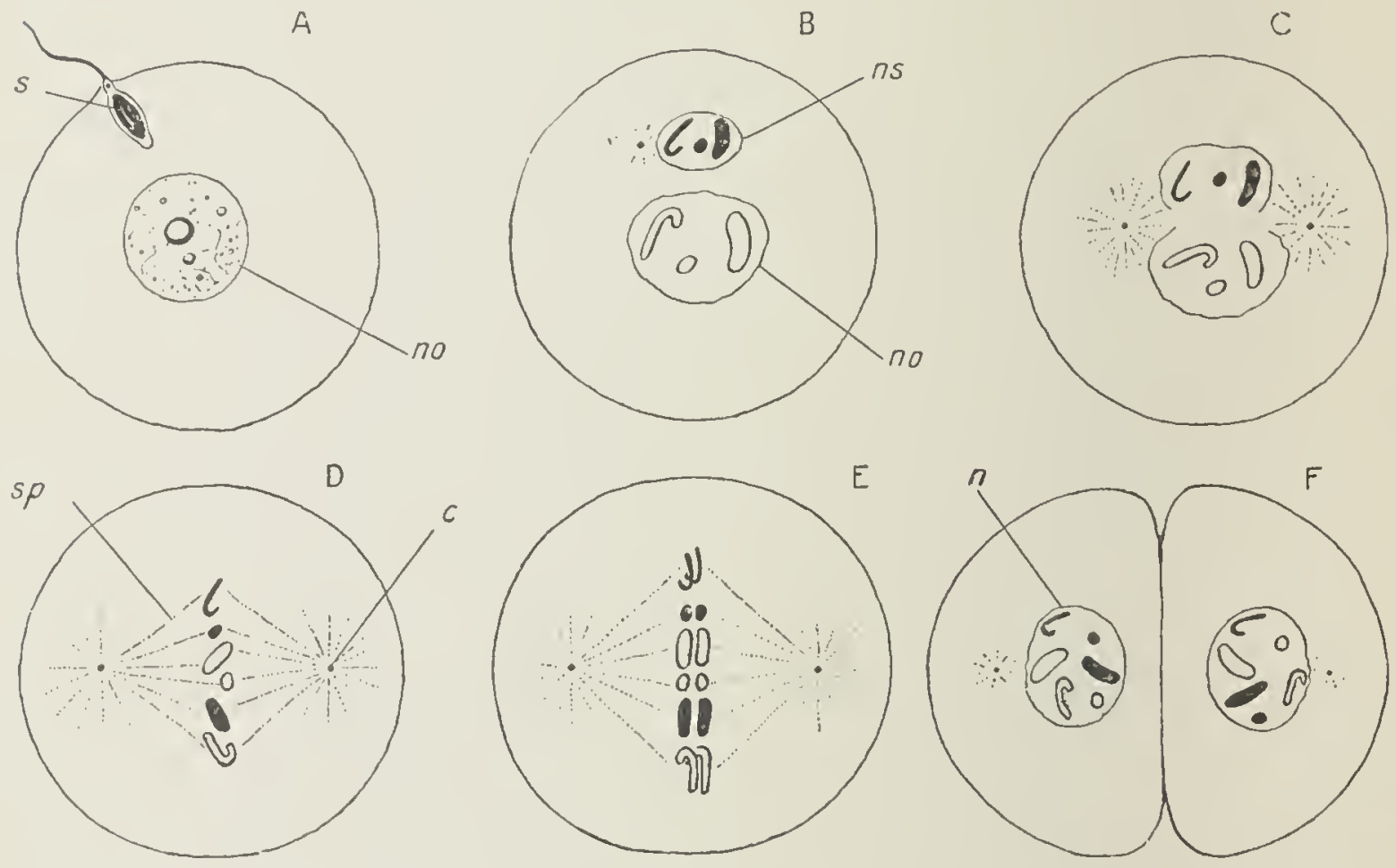

Fig. 5. Diagrams of the Fertilization and First Cleavage Division of the Zygote in a Metazoon. A, entrance of spermatozoon. B, appearance of chromosomes in 'male' and 'female' nuclei ; centrosome brought in by spermatozoon. C, division of centrosome and fusion of nuclei; disappearance of nuclear membrane. D, chromosomes set on equatorial plane of spindle. E; division of chromosomes which pass to opposite ends of spindle. F, reconstitution of two daughter nuclei and division of zygote into two cells. Paternal chromosomes black, maternal chromosomes white. $c$, centrosome; $n$, daughter nucleus; $n o$, nucleus of ovum ; $u s$, nucleus of spermatozoon; s, spermatozoon; sp, achromatic spindle.

It is important to note the great significance of fertilization: on the one hand it provides a stimulus for derelopment, and on the other it combines two streams of hereditary substance (see p. 49).

The differentiation of the germ-cells and of sex has had a profound influence on the evolution of organisms. 
To secure the nourishment, fertilization, distribution, and survival of the reproductive cells is their chief function; to this end have been developed that wonderful diversity and elaboration of structure, both bodily and mental, found in living nature.

At the same time it has had a no less profound influence on the individual development (ontogeny) of multicellular organisms in general, since it compels them to return for reproduction to a unicellular stage at every generation (p. I 46).

Among the unicellular forms sexual reproduction may be of a much simpler kind than that described above. Often one individual may divide up into a number of small 'male' gametes, each capable of fertilizing another individual playing the part of a 'femaie' ovum. Or, as in many of the lower multicellular algae and in Monocystis, a parasitic protozoon found in the earth-worm, two individuals may each form a set of similar gametes without visible sexual differences; but the gametes of one set can only fertilize those of the other. Again, two similar whole individuals may fuse, and subsequently give rise to new cells; a common form of reproduction among fresh-water algae and Protozoa (Fig. 6). The infusorian Paramecium merely exchanges cytoplasmic and nuclear material with another individual during a temporary union or conjugation.

Although these various simpler modes of fertilization do not in all probability represent actual phylogenetic stages in the evolution of sex, yet they give us some notion of how sex may have become developed. For its very first origin one must perhaps go back to that early time in the history of protoplasm before definite forms had become differentiated, and when it might have 


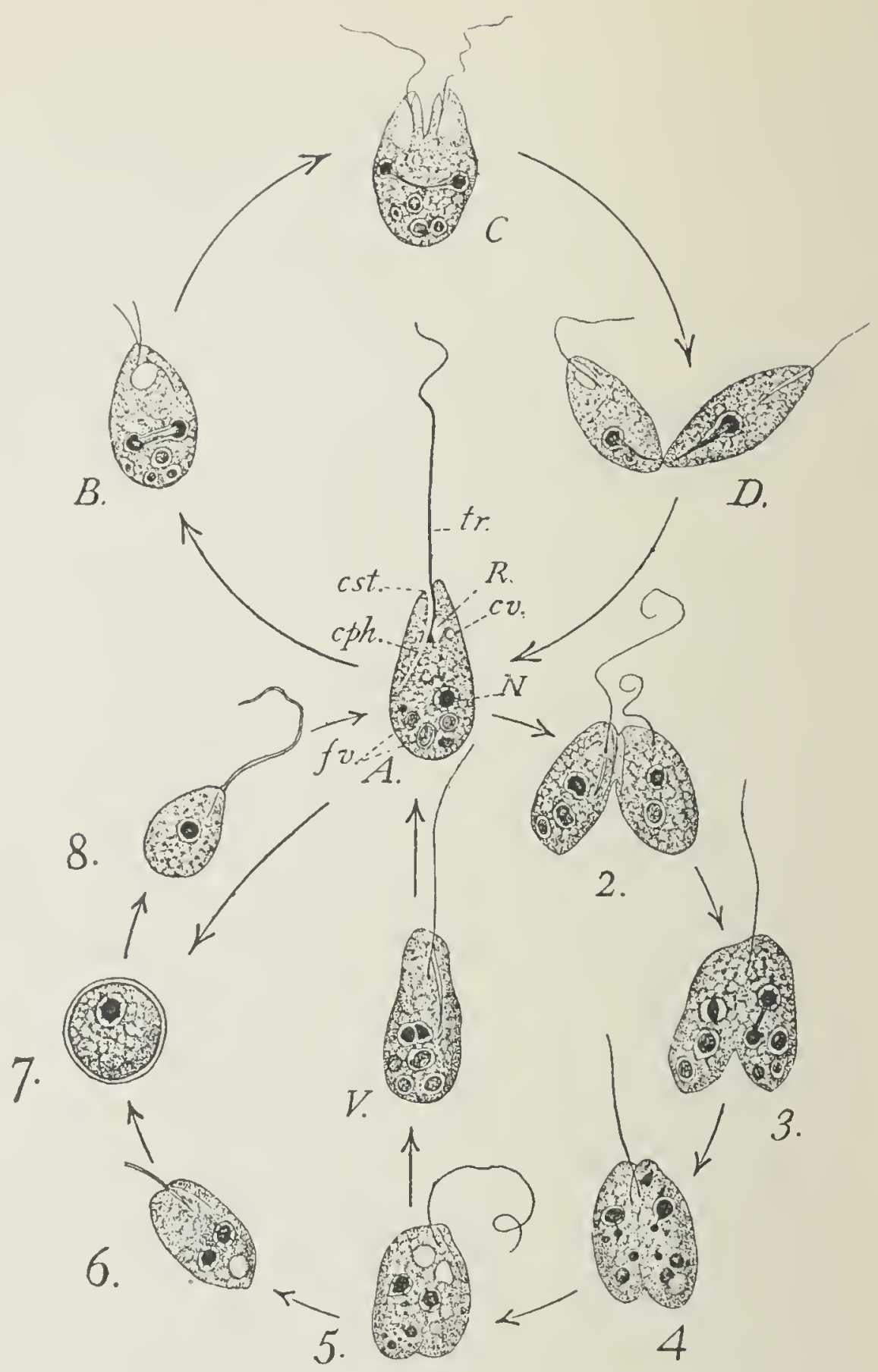

Fig. 6. Diagram of the life-cycle of the Protozoon Copromonas subtilis. $A$, full-grown individual. $B, C, D$ in upper circle shows asexual reproduction by longitudinal division. 2-8 in lower circle shows sexual reproduction by fusion of two individuals (gametes) to form a $z y$ gote, encysted as in 7 or free-moving as in $V$. (After C. C. Dobell, from G. C. Bourrees Comparative Anatomy of Animals.) 
been beneficial for two masses of protoplasmic material, differing slightly in composition, to mix and combine their properties together.

But whatever may have been its origin, under natural conditions fertilization now gives a stimulus necessary to development, and brings about some sort of rejuvenation. Even among those plants and animals which propagate freely asexually recourse is had sooner or later to sexual reproduction. It would seem, as Bütschli and Maupas maintained, that prolonged reproduction by fission in the protozoa in some way exhausts their vitality. Certain it is that under somewhat unfavourable conditions which would lead to their death if unable to conjugate, they can be seen to start with renewed vigour on a fresh career of growth and multiplication after conjugation has taken place.

It has already been mentioned that in multicellular organisms active growth occurs among the less differentiated cells which have retained a primitive richness in protoplasm, an embryonic character. Now the germcells, usually produced in enormous numbers, are derived from such undifferentiated cells set apart for the purpose of reproduction, sometimes from the very earliest stages of embryonic development. Especially in animals, they may be traced back, and occasionally even be distinguished under the microscope through an unbroken lineage of embryonic cells to the fertilized ovum. Weismann's famous theory of the continuity of the germ-plasm is founded on these facts. According to it, the germplasm, that special protoplasm of the gametes which is handed on by them from generation to generation and gives rise to new individuals, becomes in a limited sense independent of the body or soma in which it develops. 
Whereas the rest of the multicellular organism, the soma, undergoes differentiation and dies, the germ-cells continue for ever giving rise to new generations, the germ-plasm passing in them from parent to offspring (Fig. 7). This brings us to the consideration of the origin and biological significance of death.

Is death an essential inevitable attribute of life? If by death we mean mere decay, mere catabolic changes, the answer is yes. In this sense we begin to die as soon as we are born. But this is not what is meant by death in

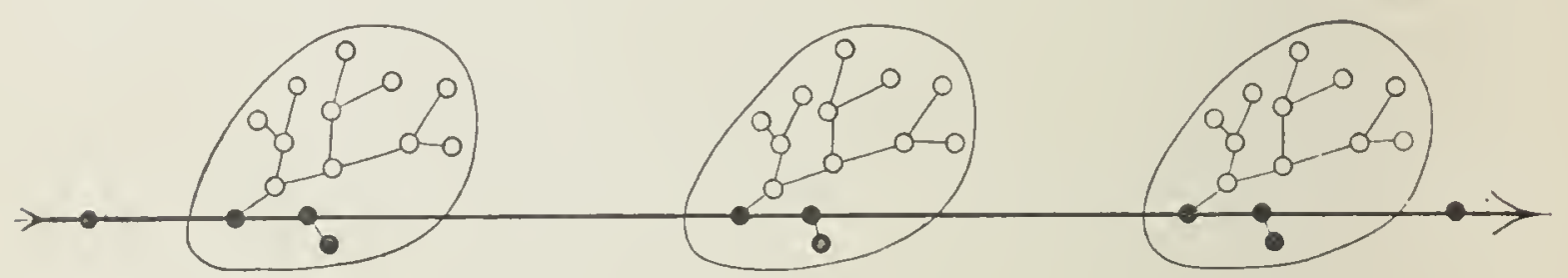

FIG. 7. Diagram illustrating the continuity of the germ-plasm and discontinuity of the soma of successive generations. A black line represents the continuous series of germ-cells. Ovals represent successive individuals made up of somatic cells (white) and containing gcrm-cells (black).

ordinary language. We do not speak of death unless there is a corpse. And the question is, putting aside accidental death through violence or disease : does natural death occur always, or does it even occur at all? Would an organism shielded from all unfavourable conditions continue to live for ever, or is it wound up, so to speak, to live for only a limited time? It has already been mentioned that among the bacteria and unicellular organisms propagation by fission, or a process of spore formation, may go on indefinitely if the conditions are farourable. ${ }^{1}$

1 It is not necessary here to recapitulate in detail the long controversy which has taken place concerning natural death among unicellular organisms. Enriques has bred the infusorian Glancoma through some 3,000 generations without the occurrence of sexual union or degenera- 
True it is that the individual may be said to disappear in the splitting; but death can have no sting for an organism which divides into two living halves_(Fig. S). Among

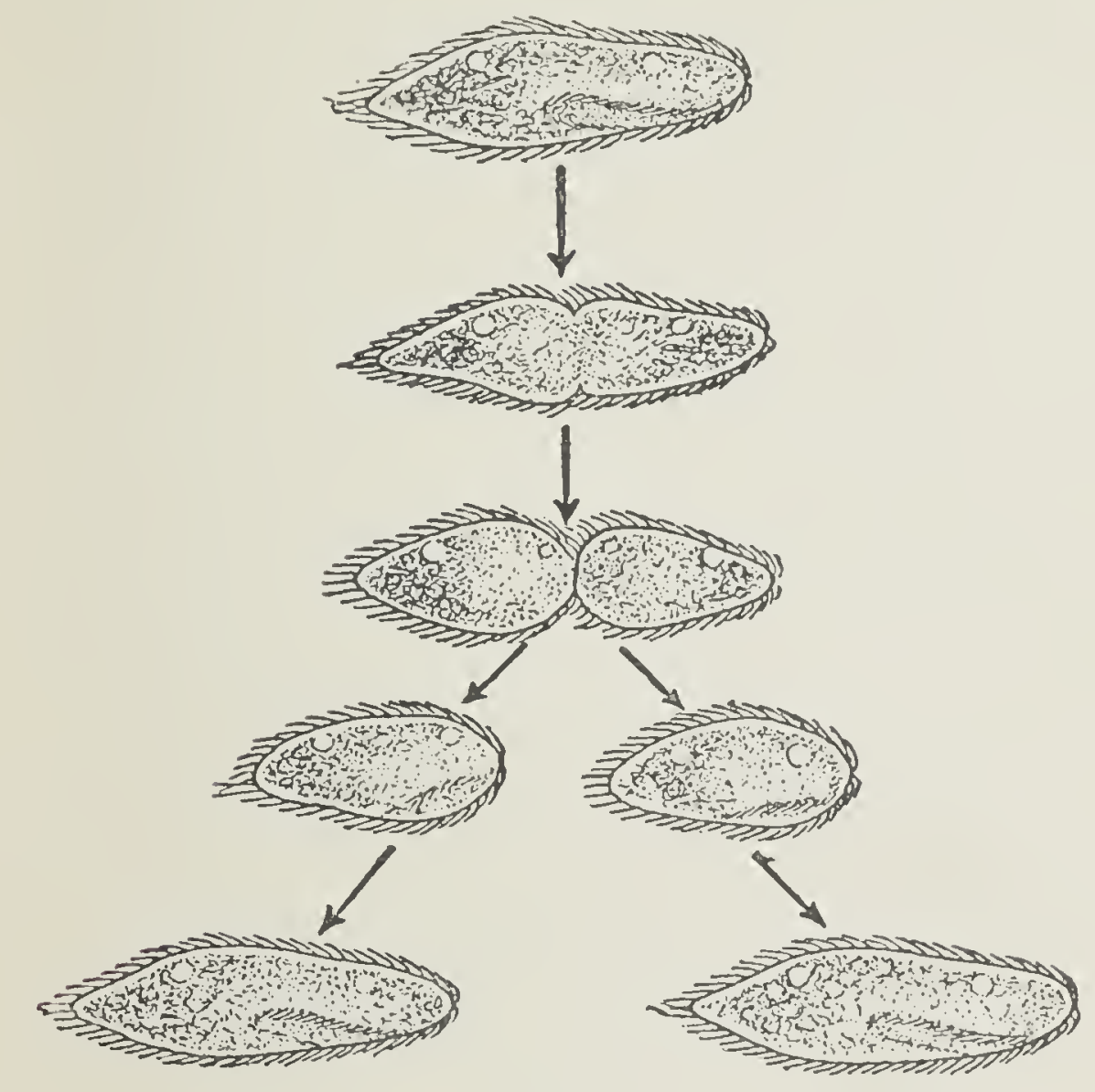

Fig. 8. Reproduction by fission of the Infusorian Paramecium, a ciliated Protozoon. (From H.S. Jennings's Heredity and Environment.)

Infusoria, for instance, even when sexual union is necessary, no corpse need be produced. But, doubtless, a hard and fast line cannot be drawn between death and

tion. On the other hand Wocdruff and others have shown that with such forms as Paramecium, although fission may occur for an apparently unlimited number of generations, yet they are only saved from ageing and death by a natural periodic rejuvenation due to the reconstruction of the worn out nuclear mechanism from reserve nuclear material. It is probable, then, that the repeated fission of cells can only take place if the wear and tear of the nucleus is continuously or periodically repaired, and that natural death does not occur among unicellular organisms if this repair is carried out. 
mere waste. Even a Protozoon may secrete a cuticle or shell, and later when it divides abandon it to secrete a new one; thus leaving behind what was once part of itself.

Death, then, appears among living organisms when_a soma or body becomes differentiated from the germ-cells. The soma dies; but the germ-cells live on, passing from one mortal parent to another. As pointed out by Weismann, germ-cells, like the unicellular organisms just mentioned, are potentially immortal. Since the first appearance of living substance on this earth death has never interrupted the main streams of life. Typical death is, so to speak, a by-product of multicellular organisms.

But even the soma might conceivably go on living for ever, provided only it continue growing, or the wear and tear of life be perpetually repaired. We are familiar with plants which can be propagated by cuttings for an indefinitely long period, and we know of others, such as trees, which, preserving vigorous embryonic cells at their growing surfaces, may prolong their natural life for thousands of years. Even in the best regulated organism, however, thọse essential proportions between surface and volume can hardly be so well preserved; that nice coordination of parts, that power of repairing injuries and waste, can hardly be so accurately adjusted as to continue working smoothly for ever. Especially is this the case in animals, where both size and shape are almost always definite and limited. If one may be allowed to use metaphorical language-rather than go on resisting the wear and tear of life, nature sacrifices the old and battered soma, and trusts the germ-cells to start a new individual afresh. 
So the length of life of an organism may become definitely adapted to its needs; as in the case of annual plants and most animals, where the energies of the individual are exhausted in securing the success in life of the next generation. Thus a large number of animals in the colder regions live only for one season, leaving behind them their eggs to survive the winter and develop next year. Frequently the male sex dies as soon as fertilization has been accomplished. A definite relation can be traced between the length of life of the individuals of a species and the number of young produced, and the care required to bring them up. Thus the average longevity of a species is inevitably bound up in erolution with its method and rate of reproduction.

\section{III}

\section{Darwinism and Heredity.}

SCARCELY more than half a century ago Darwin, in his immortal work on The Origin of Species, first gave a satisfying truly scientific explanation of the evolution of living organisms, though, of course, he left many difficulties unsolved. Before his time many authors had recognized that the various forms of life have been evolved from one another by gradual transformation. From the earliest times, indeed, philosophers had speculated on the possible modification of organisms, laying stress now on external environment, now on internal factors. All such speculations failed to convince, being either obviously inadequate, or calling in mysterious evolutionary forces of which no scientific explanation 
could be given. Darwin first clearly showed how overwhelming is the evidence that evolution has actually taken place; but his great merit is to have shown that it can be accounted for by the action of 'natural causes', which can be seen at work at the present time, can be tested by observation and experiment, and leave no room for any mysterious governing causes in addition; that, in fact, a complete scientific aspect of the process of evolution can be described as an unbroken series of ' natural ' events, a sequence of cause and effect, a series of steps each one strictly determined by that which came before, and determining that which follows after.

Darwin and Wallace simultaneously discovered the great principle of natural selection, the keystone of the Darwinian explanation of evolution. Like many great truths, when stated it appears extraordinarily simple and obvious. It can be described in the single phrase: the survival of the fittest in the struggle for existence. If we ask who are the fittest? the answer is-those which survive. This is no mere argument in a vicious circle; it is the definition of the word fittest from the point of view of the scientific observer. When one organism is said to be more or less fit than another, no aspersion is cast on the moral worth or aesthetic beauty of either from a purely human standpoint; but the fact is expressed that in the environment in which they live, one will succeed and the other fail. So when we speak of higher and lower forms in the evolutionary series, we have no desire to make invidious distinctions, but take into account the fact that some organisms are more complex and elaborate in their structure, bodily and mental, than others.

According to Darwin, the chief factors which contribute 
to the process of evolution are, variation, heredity, and the struggle for existence. He pointed out that man has modified the characters (bodily and mental structure) of domestic animals and plants by continually selecting and breeding from those individuals which varied in directions favourable to his purpose, and gave the name natural selection to the similar process going on in nature. While the doctrine of evolution has been universally accepted, there is still much difference of opinion as to the relative importance of the various factors concerned.

The impetus given by Darwin to the study of biology was enormous, especially with regard to variation and heredity, subjects which before his time had received little serious attention. We must now examine more in detail these factors of evolution.

However closely related organisms may be, they always differ from each other: parents and offspring, brothers and sisters, are never quite alike. The differences between them are called variations. Familiar to us among forms which we know well and observe closely, as for instance individuals of the human species, or our domestic animals and plants, variation is no less universally present among all sorts of living organisms. Variability occurs in various degrees, in all possible directions, and extends to every sort of character, structural or functional. Shape, size, colour, scent, number and relative position of parts, are all subject to variation. The most complex capacities, such as fertility, the power of resistance to disease, and intellectual ability are notoriously variable. Moreover, variation occurs at every stage of life: the seed, seedling, young and adult plant, the egg, embryo, young and adult animal, all show variations.

These variations can often be accurately measured, and 
the statistical study of variation begun by Quetelet and Galton, and carried on by W. F. R. Weldon, K. Pearson, and others, has yielded many important results. If we took a number of sticks picked up at random, and measured their length, we should find that while sticks of medium length are the most numerous, the sticks become rarer and rarer as they approach the extreme of length and shortness. If the number of sticks be large enough, the length occurring most frequently (the modal value or mode) would be found at or near the mean between the two extremes. In fact the length is, as we say, determined by chance, and the results obey the laws of probability, being due to a number of independent causes acting at random on the individual sticks. It is the same with variations, as shown by the examples below.

Frequency of different lengths of beans measured by de Vries.

\begin{tabular}{|lr|r|r|r|r|r|r|r|r|r|}
\hline Length in mm & - & 8 & 9 & I0 & I I & I2 & I3 & I4 & I5 & 16 \\
Number of beans & I & 2 & 23 & I08 & I67 & I06 & 33 & 7 & I \\
\hline
\end{tabular}

Frequency of different types of beech leaves measured by K. Pearson.

\begin{tabular}{|c|c|c|c|c|c|c|c|c|c|c|c|c|c|}
\hline $\begin{array}{l}\text { Number } \\
\text { of veins } \\
\text { in leaf }\end{array}$ & IO & I I & I 2 & I3 & $I_{4}$ & I 5 & 16 & I 7 & I 8 & I9 & 20 & $\approx I$ & \\
\hline $\begin{array}{l}\text { Number of } \\
\text { leaves of } \\
\text { each type }\end{array}$ & I & 7 & 34 & I I O & 3 I 8 & 479 & 595 & 516 & 307 & I 8 I & $3^{6}$ & I 5 & I \\
\hline
\end{tabular}

These results can be graphically represented in the form of a curve, which will be found to agree with a normal 
curve of 'error' or 'deviation' (Fig. 9). The vertical passing through the apex of the curve will represent the mode, and the distance from it along the base will give the range of variation or measure of deviation above or below the mode. The greater the variability the wider and lower will be the curve.

Asymmetrical or skew curves occur when for some reason the variation is more limited on one side than the other.

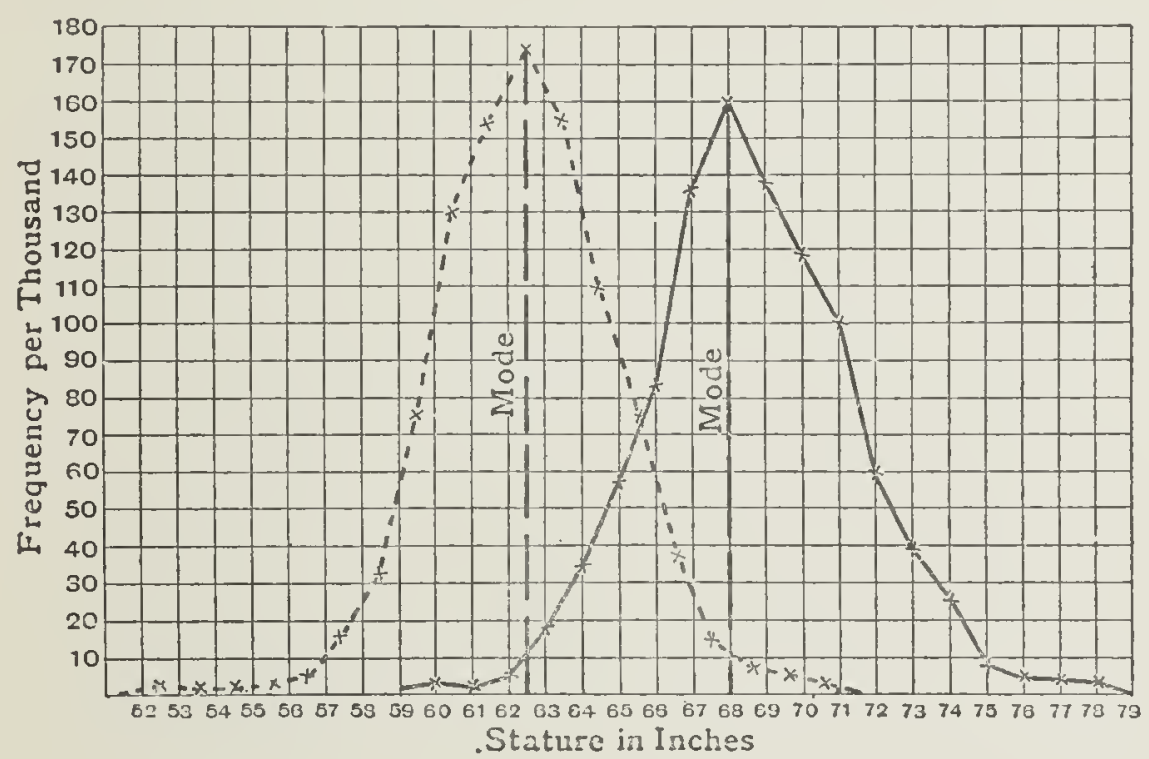

FIG. 9. Curves showing distribution of stature in women (mothers)dotted line; and in men (fathers) - continuous line. The curves approach the normal curve of deviation. (Data from Pearson, from L. Doncaster's Heredity.)

The systematic study of variation and heredity in general was greatly advanced by Galton, who submitted to statistical analysis measurements of single characteristics such as weight, stature, eye-colour, in man and other organisms, and even estimations of intellectual capacity and artistic ability in man. He showed the frequency and range as well as the gradation of variations, and deduced certain general 'laws', which apply to average results when dealing with large numbers of individuals, thus 
founding the science of Biometrics. For instance, the law of regression was established, according to which, if in a population sons and fathers are compared, the mean deviation of the sons will be found to lie between that of their parents and that of the general population, or, in other words, that on the average the offspring vary less from the mode of the population than their parents. Thus very tall parents will on the average have offspring taller than the mean of the population, but not as tall as the parents themselves. Regression is a measure of the intensity of inheritance.

We cannot in this little book enter into a detailed account of the results of biometrical studies. Important and interesting as they undoubtedly are, they take no account of the fact that variation may be due to two different sets of causes, and yield little information as to inheritance in individuals.

These variations, then, afford the materials from which natural selection has to choose; but to understand their nature and importance in evolution we must analyse them further in the light of heredity.

When the characters of the parent reappear in the offspring we say in popular language that they are inherited. There is a mechanistic aspect of heredity just as there is of life. Why, we may ask, do the reproductive egg-cells of a snail, a fly, and a fish, all under the same conditions, and bathed by the same water, reproduce the same bodily structure, the same functional capacities, the same psychological powers, the same complex kind of individuality as each of the parent forms? The answer is that they are formed of the same protoplasm as the parent; they are chips of the old block. Both parent and offspring derelop from the same starting-point : a particular 
mixture of substances, having a peculiar intimate architecture, specific structure, or organization, and undergoing a particular kind of metabolic change. Under approximately similar conditions they are bound to develop into approximately similar organisms. This particular kind of substance and particular association of qualities is transmittech by means of the reproductive cells; hence the importance of the principle of the continuity of living protoplasm established above (p. 30). The direct continuity of living substance, obvious in the case of the unicellular organisms which reproduce by fission, is no less essential in all other modes of propagation. In this way only can the physico-chemical and other properties of one generation pass on to another. The process of metabolic change has continued without interruption from generation to generation since its first appearance.

The full importance of heredity is perhaps, even yet, not always appreciated. This or that striking peculiarity reappearing in parent and child is pointed at as having been inherited, as if the countless resemblances in the whole organization were not also dependent on heredity. Not only the similarities, but all the vast differences which distinguish man from the lowest animal have been built up through heredity. Without it no evolution could take place. For we must think of the continuous stream of protoplasm, the physical basis of evolution, as the means of piling up, so to speak, hereditary differences along diverging lines.

In ordinary sexual reproduction, the specific substance containing the essential factors of inheritance must be passed on from one generation to the next in the germcells. It forms either the cell as a whole or only its nucleus, or some part of its nucleus: it is now generally 
admitted that it is contained in the chromatin (see p. 32). Moreover, it is carried in the germ-cells of both sexes, since inheritance is equal from both parents. The characters due to these factors usually reappear in the same order in the offspring in which they developed in the parent; but some of them may remain for ever latent, though capable of reappearing in later generations.

Now the older writers on evolution generally assumed that the course of heredity and the progress of evolutionary change were greatly influenced by the direct action of the external environment and of the characters of the parents on those of their offspring. It was supposed that the changes directly induced in the body of the parent by such stimuli as temperature, moisture, nutrition, repeated use, and constant disuse, are inherited as such, and would reappear in the progeny. The theories of evolution propounded by Erasmus Darwin and by Lamarck were founded on this supposition; and even in the time of Charles Darwin it was not yet questioned whether characters thus acquired by the parent in the course of its lifetime are directly transmitted. It was not till Weismann critically examined the evidence for "the inheritance of acquired characters' that the theory was definitely overthrown. He showed convincingly that mutilations (such as the repeated cutting off of the tail in dogs), the effects of use and disuse (such as callosities produced by friction, the enlargement of muscles or other organs, the fruits of education, \&c.), or any direct modification due to the action of any particular stimulus, have never in any single instance been proved to be transmitted as such from one generation to another, while the evidence that they are not is overwhelming. These conclusions of Weismann, which had been to some extent foreshadowed 
by Pritchard and Galton, are the most important contribution to the science of evolution since the publication of Darwin's Origin of Species. Let us now examine the question more closely, and further analyse the 'variations' dealt with above.

Owing to that universal property of irritability or the power of response to stimuli already described, all organisms are the result of the interaction of the factors of inheritance, and the conditions of the environment. By the latter we mean all those conditions or stimuli which are capable of influencing the differentiation, growth, behaviour, or in other words the metabolism of the organism. By the factors of inheritance, on the contrary, we mean that complex association (transmitted from the parents) of substances with properties or capacities which make up the specific inheritance characteristic of each organism, and which may be called its assemblage of germinal factors of inheritance, or its germinal constitution. They are contained in the germ-plasm, and constitute the physical basis of inheritance. Not only are organisms as we see them before us necessarily the results of the combined action of these factors and conditions; but so also is every part of them, every structure, every activity, every organ, every habit. Therefore the characters observed and measured, dealt with in statistics and experiments, are likewise their products. The inheritance might be compared to a musical instrument, the stimuli to the player, and the organism and its characters to the music produced. What particular tune is called forth will depend on the player; but the range of possible sound will be limited by the structure of the instrument, by the factors which make up its capacity to respond to the touch of the player. 
Every character of whatever kind is, in a sense, partly acquired, since it is called forth by stimuli, and partly inherited, being a product of the activities of the germplasm; and no character is more acquired or more inherited than any other. Hence the popular distinction between acquired and not acquired characters, between those which have been developed in the course of the individual's lifetime and those which are inborn, is misleading. The very terms involve a fallacy. We cannot point to this or that bodily or mental structure and say this is acquired and that is not. Characters being of the nature of a response must necessarily be produced anew at every generation. The characters of an organism are but the sum of its past responses.

And yet there are characters which reappear regularly in offspring and others which do not; in other words, some characters are inherited and others are not. ${ }^{1}$ The fact is that we must revise the popular conception of inheritance just as we have revised that of 'acquired characters'.

It is, therefore, very important to define if possible what we mean by the word 'inherited', and in the following pages it will be used to signify merely that a character possessed by the ancestor reappears in the offspring-a fact which may be observed and described regardless of any theory as to its cause. What is actually transmitted is the complex of germinal factors. Factors are transmitted, but characters are inherited, and we should carefully distinguish between them.

1 Much of the controversy in writings on evolution is due to the use by various authors of the term 'inherited' with very different meaningssometimes to signify mere reappearance, at other times an actual transmission or transference of a character from one generation to the next, or merely the transmission of the factors which give rise to it. 
It is sometimes asserted that old-established characters are inherited, and that newly-begotten ones are not, or are less constant in their reappearance. But this statement will not bear critical examination. For, on the one hand, it has been conclusively shown by experimental breeding that the newest characters may be inherited as constantly as the most ancient (see Chapter IV); and on the other hand the oldest fail to appear if the necessary conditions are removed (see p. 55). Nor is the suggestion any better that the, so to speak, more deep-seated and fundamental characters are more constantly inherited than the trivial or superficial. A glance at organisms around us, or experimental trial, soon convinces us that the apparently least-important character may reappear as constantly as the most fundamental. But while an organism may live without some trivial character, it can scarcely do so when a fundamental character is absent; hence such incomplete individuals are seldom met in nature.

Returning now to the reason why some characters are inherited and others not, we conclude that for a character to reappear in the offspring it is essential that the germinal factors and the environmental conditions which co-operated in its formation in the ancestor should both be present. Inheritance depends on this condition being fulfilled.

Obviously if either the factors or the conditions be altered the resulting organism will be changed; variation will occur. What is called the normal mental or bodily structure is that developed under the usual complex of environmental stimuli. Any divergence from this normal structure may be due either to some change in the germinal constitution in a constant environment, or to 
an altered environment acting on an unchanged germinal constitution (Fig. Io). The two results differ to some extent; they should not be called respectively inherited and acquired, the real distinction being that in the one case the new character is called forth by a new stimulus, whereas in the other case the stimulus remains unchanged. but brings forth a new result because it acts on altered germinal factors. If some characters are inherited regularly and others are not, the distinction lies not in the

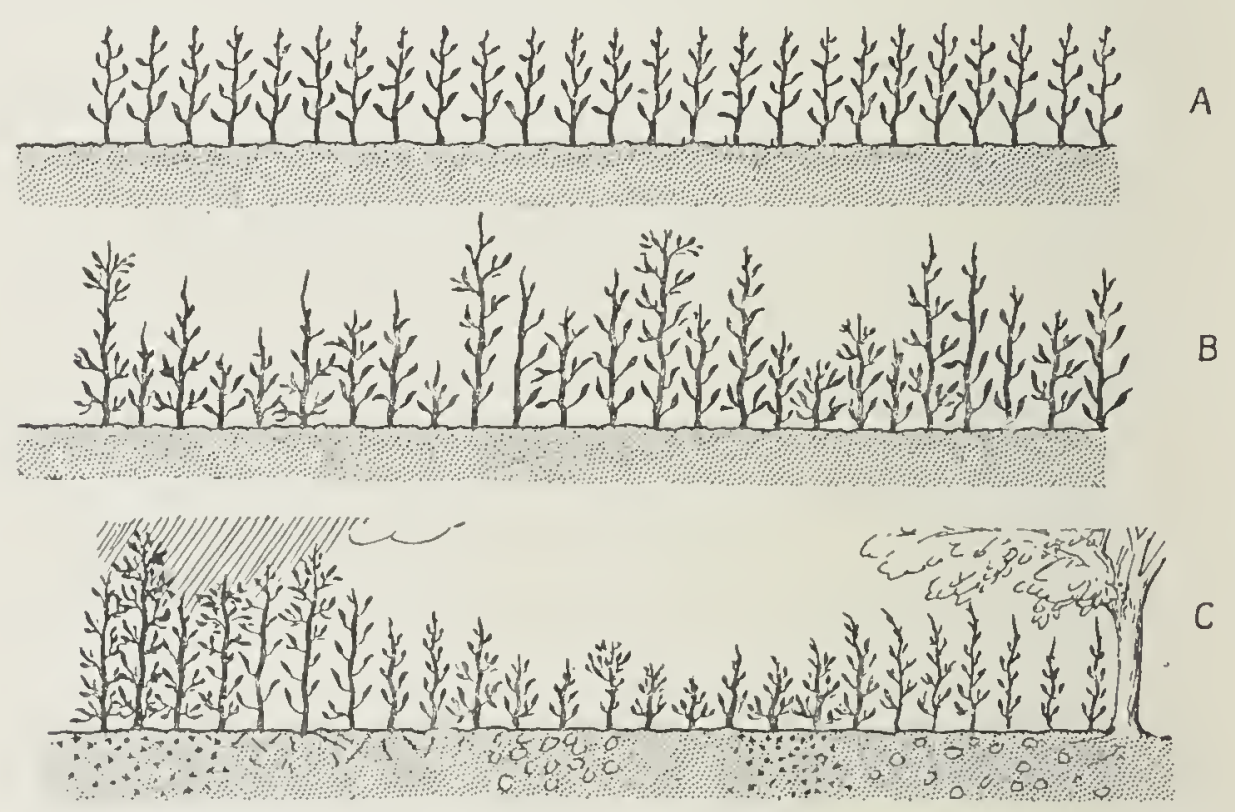

FIG. Io. Diagrams illustrating: A, organisms (plants) of similar germinal constitution grown under uniform conditions; $\mathrm{B}$, of different germinal constitutions grown under uniform conditions; c, of similar germinal constitution grown under different conditions. A shows no variation; $\mathrm{B}$ shows mutation; C shows modification.

nature or mode of production of the characters themselves, but in the constancy of the factors and conditions which give rise to them. Thus, although there is only one kind of character, there are two kinds of variation.

That new character (due to variation) which is caused by germinal (factorial) change will always reappear in a constant environment, provided the germinal constitution continues the same. The other new character (due 


\section{Darwinism and Heredity}

to variation) will never reappear unless the causal stimulus is also present. If the new stimulus be removed the character necessarily goes also. The real difference between characters which always appear and those which do not is that the former depend on stimuli which are always present, while the latter depend on stimuli which may be absent.

It follows that there are two quite distinct kinds of variation for which new names must be found. The name 'mutation' may be adopted for new characters due to the changes in the factors of inheritance, to the alterations in germinal constitution; and we may call 'modifications ' those induced by changes in the environment. ${ }^{1}$ The former changes are transmitted in the germplasm, but not the latter. By mere inspection these two results of variation cannot, of course, be recognized; they can only be distinguished by systematic observation and experiment. The two kinds of variation are independent of each other, but may often be combined. A few instances will help to make the foregoing discussion clear.

At first sight nothing could appear more firmly fixed by heredity than the greenness of plants; for countless

I Here again much confusion has arisen owing to the use of the word 'variation' in different senses : sometimes to mean the degree of divergence between two individuals, sometimes the character itself in which they differ (such as a white spot, or forked spine), at other times a variety or race differing from the normal form of the species. We shall define it here to mean the extent or degree of difference between the characters of two individuals, or between an individual and the average of the species, the divergence of the new form from the old: not a new character, but a difference which can be measured or at least estimated. The name 'mutation' has also been applied to three different things: the factorial change, the variation or difference, and the new product. response, or character. We shall use it as far as possible in the last sense; but it may conveniently be extended to include the variation, as when we compare a large with a small mutation. 
generations green plants have reproduced themselves on earth. Yet take the seed of the greenest plant you like, and grow it in a dark cellar - the new plant will come up not green at all. The stimulus of light has been denied it, so the green 'character' does not appear; it is not transmitted, it is not inherited. But the capacity to become green is nevertheless transmitted, as can be shown at once by bringing the pale seedling into the light, when it will soon turn green. This capacity depends on the factors contained in the germ-plasm. Just in the same way, if the seed be sown in soil devoid of iron the young plant will not be green, however much light there may be; the stimulus of iron has been removed. Add a trace of iron to the soil, and the plant will turn green. A similar instance is furnished by the experiments of Stockard on the fish Fundulus (Fig. I I). Ever since Devonian times vertebrates are known to have inherited paired eyes; few structures would seem to be more completely 'innate'. Yet it is sufficient to add a little magnesium chloride to the sea water in which the eggs develop for the young to appear with one median cyclopean eye! Again, Englishmen in the tropics become sunburnt; this ' character', dark pigmentation, is due to the interaction between the environmental stimulus, sunlight, and the transmitted germinal constitution. Their children will be likewise sumburnt, provided they are exposed to the rays of the tropical sun. But they will not be sunburnt if they are sent home to England. Once the maximum effect of the stimulus has been reached, once the maximum response has taken place, they will not be increasingly burnt, however many generations of their parents may have lived in the tropics; and the children, if removed from the action of the sun, will not 
be sunburnt at all. The negro, on the other hand, will continue to be black and his children will be black, even when he lives in a temperate climate among white fellow men. For the black character of a negro is called forth not by the external stimulus of sunlight, but by some
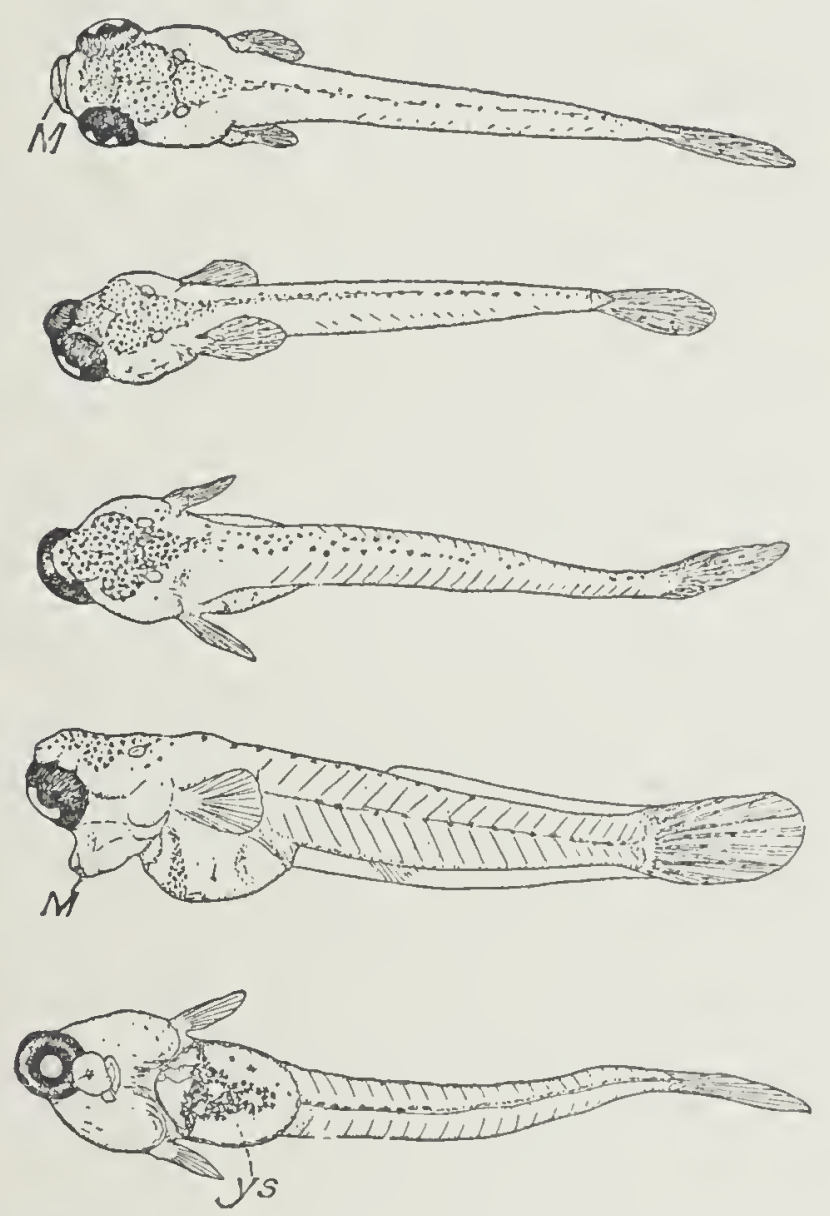

Fig. II. Young fish (Fundulus). Above a normal individual with two eyes; below cyclopean monsters with one eye, produced by treatment with magnesium solution. (After Stockard, from E. G. Conklin's Heredity and Environment.)

other external or internal stimuli which are not removed when he changes his abode.

This example illustrates a most important principle in the evolution of organisms. Obviously those characters will be most constant which depend for their appearance on ever-present stimuli. And, except in so far as an organism can choose its environment by moving from 
one place to another, the so-called internal stimuli are those whose presence is most assured. An organism, therefore, must have such a germinal transmitted constitution that it can develop fully under the ordinary stimuli of its environment, and it will develop fully with the greater certainty the more it does so with the help of internal stimuli. Hence, in the struggle for existence, those may succeed best which are, so to speak, freed from dependence on merely external stimuli. This explains the importance of self-regulating processes so much developed among the higher animals. A familiar instance is that of the warm-blooded mammals. In them has been evolved an automatic mechanism for keeping the temperature of the body at the most favourable point for the carrying on of the process of metabolism, and they have become thus to a great extent independent of the changes in their environment; while the cold-blooded reptiles and insects, for instance, are at the mercy of the surrounding temperature, unable to live an active life except in warm weather.

Two more very instructive examples may be mentioned to illustrate our discussion on the factors of inheritance. Many plants live both in the alpine heights and in the low plains, and acquire a characteristic structure in these two different habitats. So different in appearance may the two forms become that a botanist, not knowing of their common origin, would certainly place them in separate species. Now, the French botanist Bonnier divided a common dandelion (Taraxacum vulgare) and grew one half in the lowlands and the other half in the mountains (Fig. I 2). While the former grew into a tall and slender plant, the half raised in the alpine heights grew into a plant of very different appearance, with longer 


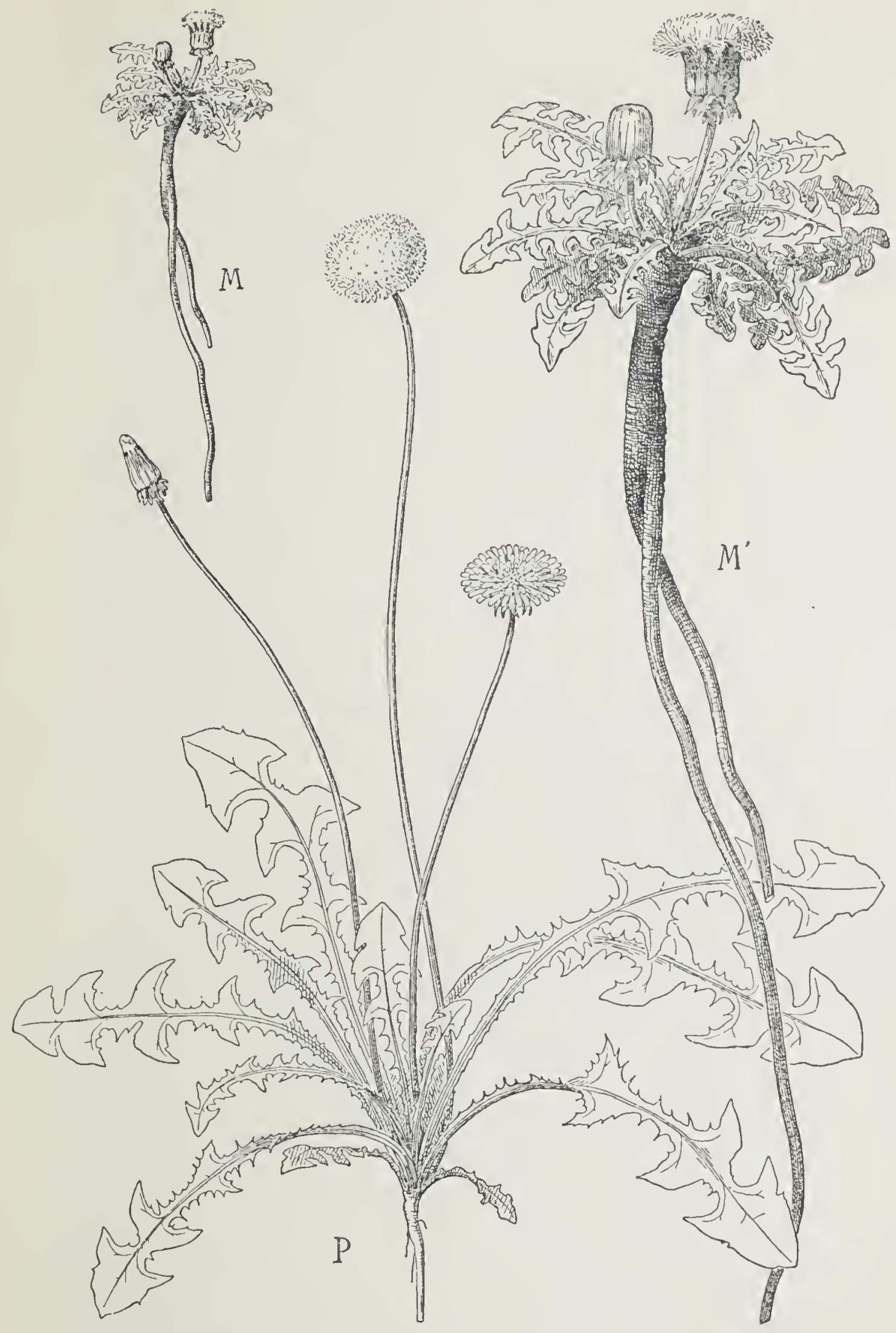

Fig. I2. Leontodon (Taraxacum), Dandelion. p, lowland form; м, alpine form. (After Bonnier, from Schimper's Plant Gcography.) 
roots, much shorter stems, smaller and more hairy leaves, larger and brighter flowers. Each variety will reproduce its like in its own locality; but seeds of the alpine plant will produce only the lowland form if sown there, and, vice versa, the seeds of the lowland form will grow into the alpine form in the mountains. Moreover, if either form be transplanted into the other region, it will soon grow into the variety characteristic of its new habitat. This change is accomplished by the new-growing tissues, for the already formed tissues are no longer capable of altering; once fully differentiated they are 'fixed'. So we see that organisms are moulded by their environment; it is not the developed result which is transmitted, but the capacity for modification in certain directions, the modifrability.

The other example is taken from some experiments on Primula sinensis, a well-known garden plant of which there are several constant races or varieties with different coloured flowers. If the variety with red flowers (P.s. mora) be grown in a hothouse at a temperature of between $15^{\circ}$ and $20^{\circ}$ centigrade, it will yield white flowers. Brought back to a normal temperature it will again bring forthred flowers. Which of these two modifications appears depends on the stimulus. Now, there is another variety $(P . s$. alba) which has white flowers at any temperature from the normal to $20^{\circ}$. At a temperature between $15^{\circ}$ and $20^{\circ}$ these two varieties would both bear white flowers, yet they would not be the same; they differ in their hereditary factors, in their modifiability. In one case the factors are such that they remain unresponsive to change of temperature, in the other case they are responsive.

The argument may be briefly summarized as follows: 
An organism is moulded as the result of the interaction between the conditions or stimuli which make up its environment (the conditions under which it grows up), and the factors of inheritance (the germinal constitution, transmitted through its parent by means of the germ-cells). No single part or character is completely 'acquired ', or due to inheritance alone. Every character is the product both of factors of inheritance and of environment, and can only be reproduced when both are present. Characters are due to responses, and have to be made anew at every generation. ${ }^{1}$ Only those characters reappear regularly in successive generations which depend for their development on stimuli always present in the normal environment. Others, depending on a new or occasional stimulus, do not reappear in the next generation unless the stimulus is present. But both being equally due to factors of inheritance and to conditions of environment the popular distinction between acquired and not acquired characters is illusory. ${ }^{2}$ In every case it is the material basis with the capacity to acquire, to become modified, or to respond which is really transmitted; the direction and extent of the response

1 Sir Ray Lankester (189.4) drew attention to the important fact that characters are responses, and pointed out that Lamarck's first law, that a new stimulus alters the characters of an organism, contradicts his second law, that the effects of previous stimuli are 'fixed' by inheritance. The Lamarckian position is illogical, and to support it its advocates are driven to the performance of 'illogical' experiments. They usually begin by taking an organism and submitting it to a new stimulus. If a change is thus induced, this very fact shows that the previous stimulus (under whose influence the organism has perhaps been living for centuries) has not 'fixed' the character in inheritance. To prove that characters are rendered permanent, evidence is constantly brought forward that they are changeable!

2 Much the same view was advocated by Professor A. Sedgwick in r899, and it lias been developed by Dr. Archdall Reid and others since. 
depends on the stimulus encountered. The presence of a given hereditary factor cannot be determined by mere inspection of the characters of an organism; the factor may be present, but the corresponding character fails to show itself owing to the absence of the necessary stimulus. On the other hand, dissimilar stimuli acting on different factors may give apparently similar results. 'Heredity' must be admitted to include two different processes: the transmission of the factors of inheritance, and the reappearance of characters in successive generations. To avoid confusion we speak of the factors as transmitted, and the characters as inherited. ${ }^{1}$

Modifications, then, are not transmitted as such. In the absence of the stimuli which originally gave rise to them they could only reappear if the new environment produced such a change in the factors of inheritance themselves, that when replaced in the old environment they continued to respond as if the new stimuli were still present. This is what the Lamarckian theory of evolution demands. We will not say that such a thing is impossible; but it is in the highest degree improbable, and it is very difficult to conceive how such a result could be reached. At all events no case of the supposed transmission of modifications has yet been brought forward which could not be better explained in other ways. ${ }^{2}$

1 It would be weli to drop altogether the use of the expression ' acquired character'. Confusion would be avoided if we adopted the clear system of nomenclature proposed by Professor W. Johannsen, and much used in America. He uses the term 'gene' for' a factor, 'genotype' for the whole assemblage of factors transmitted from one generation to the next, and 'phenotype' for the characters developed from them in a particular environment. Thus one genotype may give rise to a number of different phenotypes, according as the environment is changed.

2 The real question Biology has to answer in the future, as $O$. Hertwig has pointed out, is not 'Are modifications inherited?', but 'How are new factors acquired?' 
shade, and so forth, and the particular combinations of favourable and unfavourable stimuli fall haphazard on each particular bean, the variation in weight of the seeds of each plant will be found to follow the normal curve of probability (p. 46). The mean weight will be the most frequent, and round it the modifications will fluctuate in decreasing number towards the two extremes. Now,

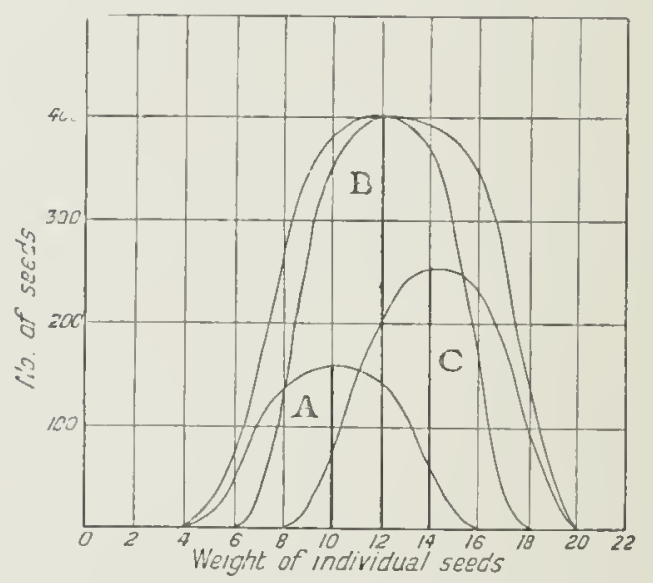

FIG. I3. Curves illustrating the conception of pure-lines in a population. A, curve of bean seeds fluctuating between 4 and 16 centigrams with a mean of IO. B, fluctuating between 6 and 18 with a mean of $I 2$. c, fluctuating between 8 and 20 with a mean of $\mathrm{J} 4$. The outermost curve represents the curve of the whole population.

Johannsen took a number of beans from a large field, and found that the offspring of each differed to some extent from that of the others in the position of the mean weight. While the whole population of beans varied between 20 and 90 centigrams, the offspring of one bean might vary between 20 and $6_{5}$ centigrams with a mean of about 50 , and the offspring of another between 40 and 90 with a mean of about 60 centigrams. So the curve of variation of the whole population is made up of a number of curves, each of which has its own mean, each of which corresponds to a strain derived from one bean (Fig. I3). Each strain, with its own inheritance giving a characteristic mean round which fluctuation may take 


\section{0}
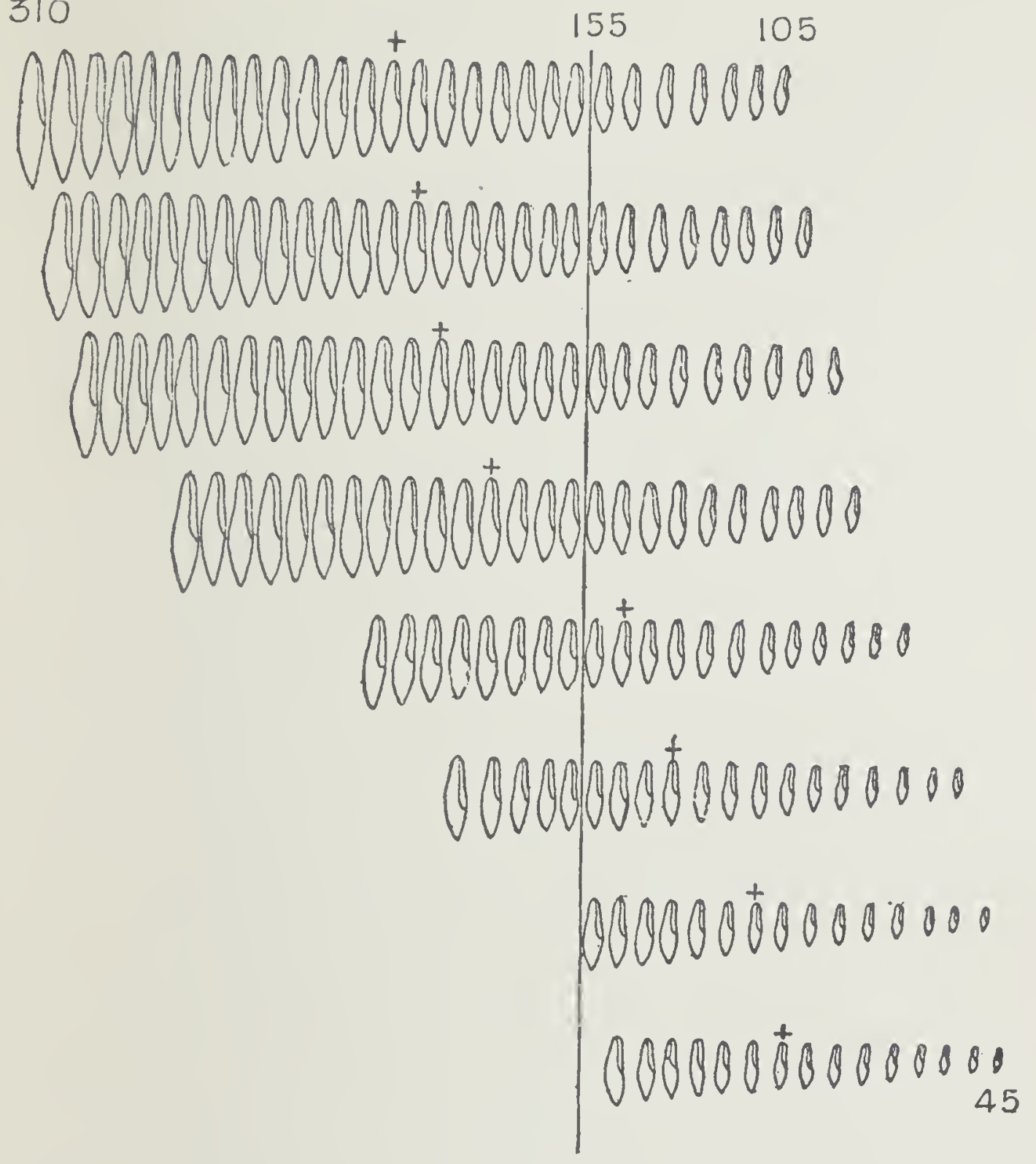

FIG. I4. Eight diverse families of Paramecium showing variations. Each row represents a single family of individuals produced by fission, showing the maximum, mininum, and intermediate sizes. The differences in size within the family are due to differences in growth and environment. Tlie differences in average size between the families are hereditary. The numbers show the lengths in microns. The mean length for the entire set together is given by the perpendicular line at 155 microns. The mean size for each family is that of the individual above which is placed $\mathrm{a}+$ sign. (From H. S. Jennings's Life and Death.) 
place, is called a 'pure line'. Inheritance is uniform within each pure line, so that light or heavy beans taken from the same line will yield offspring varying about the mean characteristic of the line; in other words, there is complete regression. A bean weighing 55 centigrams might belong to either of the pure lines mentioned above; to which of them it belongs would only be revealed by the average weight of the seeds derived from it. Similar results have been reached by other observers with plants and animals (Fig. I4).

If the various strains making up a population were really pure, of uniform factorial inheritance, then under uniform conditions they should yield, when plotted out, not an even curve, but a series of parallelograms each corresponding to one strain-there would be a series of steps marking the sudden jump from one strain to the other. It is, therefore, the modifications which smooth down these steps to a graduated curve corresponding to the variation of all the strains combined.

Pure lines can rarely if ever persist in nature, except perhaps in such forms as bacteria, where sexual reproduction is not known to occur. Even here inheritance must sooner or later split into new strains owing to some alteration in its factors. But practically all organisms reproduce sexually; there is a perpetual crossing and mixing of strains, self-fertilization being quite exceptional. With these few exceptions, factors of inheritance are brought into the zygote by the gametes of two parents (Fig. I 5). What happens in such a case? For an answer we must turn to the facts and theories of heredity.

In his great work, Amimals and Plants under Domestication, Darwin put forth the provisional hypothesis of Pangenesis, the first complete corpuscular 
theory of heredity. ${ }^{1}$ He supposed that each cell of an organism gives off a living gemmule or pangene, that the pangenes are collected together in the germ-cells, and that they give rise in the next generation to cells similar
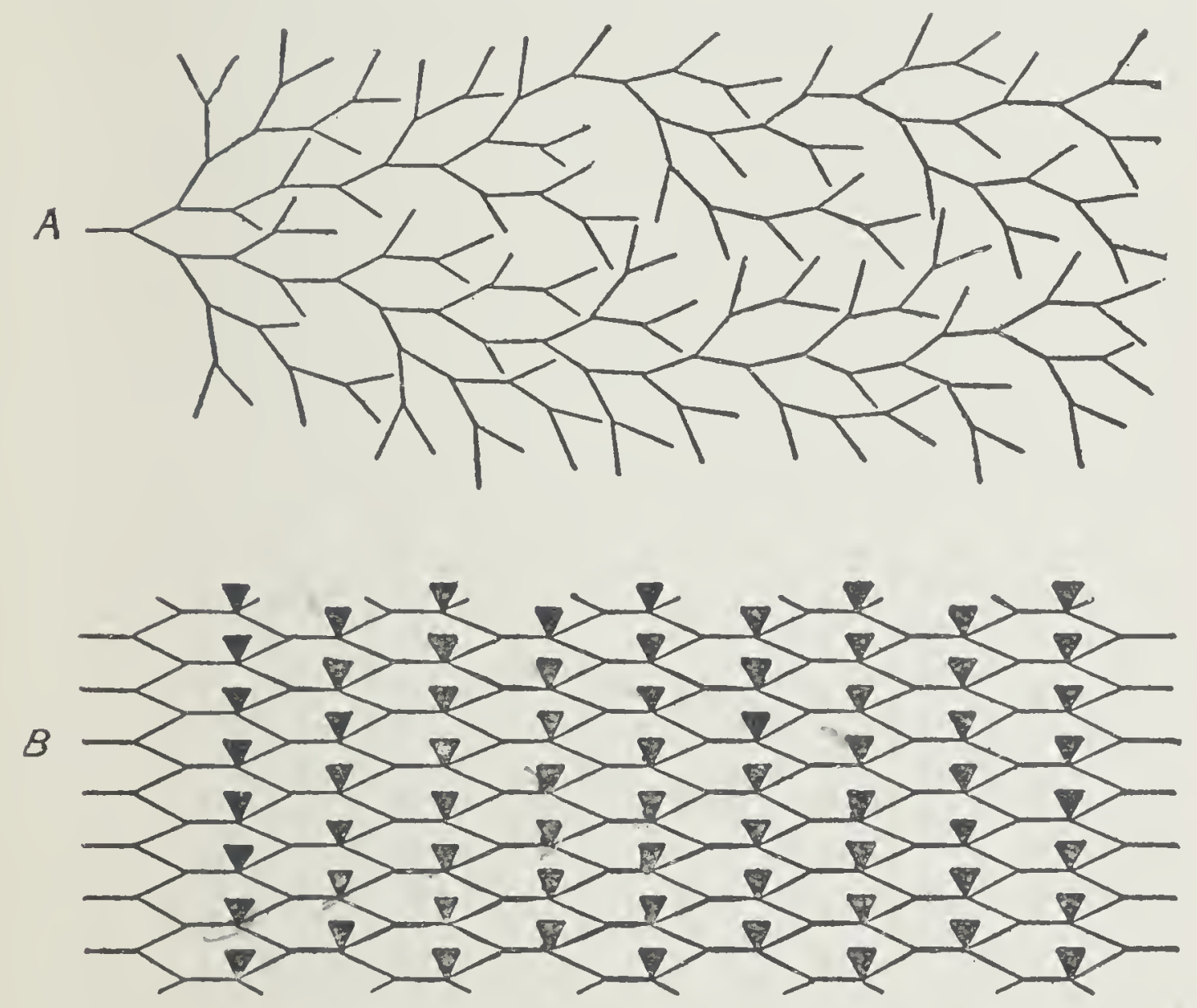

F1G. 15. Diagrams of the descent of generations of organisms reproducing by fission from a single parent, A, or by sexual biparental reproduction, B. The lines represent the lines of individuals or germcells, beginning on the left and passing to the right; the triangles represent the bodies. In A the line of ancestry traced back from any individual on the right is always single, and there is no corpse found at any point. In $\mathrm{B}$ the line of ancestry from any individual traced back forks at each generation, becoming multiplex in a few generations, and the bodies of any generation are not continuous with those of previous generations. New bodies are produced by germ-cells from two diverse lines. (From H. S. Jennings's Life and Dea!h.)

1 Herbert Spencer's 'physiological units', Darwin's 'pangens', Weismann's 'determinants', Johannsen's 'genes', are all terms denoting factors of inheritance, but with somewhat different meaning. 
to those from which they have been derived. Darwin thus suggested a means of transmission both for hereditary factors and for modifications in accordance with the views then prevalent. When Weismann showed that modifications are not transmitted as such, the first part of the hypothesis of Pangenesis became unnecessary, and his elaborate theory of inheritance by means of corpuscles, the determinants, is an extension of Darwin's theory of the distribution of the pangenes from the germ-cells in development. Each independently variable organ or cell is supposed to be represented in the germ-plasm by a separate determinant, itself compounded of several of the hypothetical ultimate units of life, the biophors. These, and the determinants formed of them, are supposed to multiply, and to be transmitted along the continuous stream of germ-cells. Differentiation in development is supposed to follow the sorting out and distribution to the nuclei of the various cells of the appropriate determinants. Ingenious as is the theory, it depends too much on unproved assumptions to carry conviction; moreover, when applied in detail it soon lands us in a maze of difficulties from which there appears to be no escape. As we pointed out in the first chapter, life is not the attribute of any one special substance or corpuscle, and the conception of unit biophors is not really tenable. Moreover, the theory is not consistent with well-known phenomena of regeneration; nor is there any evidence that the nuclei of the different tissue cells are of unequal value.

Modern theories of the mechanism of heredity, while less comprehensive, are more satisfying, because they are based on direct observation and experiment, and depart as little as possible from the conclusions immediately 
deducible from the evidence. They were founded on the work of the Austrian monk Mendel, whose observations and conclusions published in i $\$ 66$ were not appreciated at that time, and lay neglected and forgotten until again brought to light in 1900 by the botanists Correns,

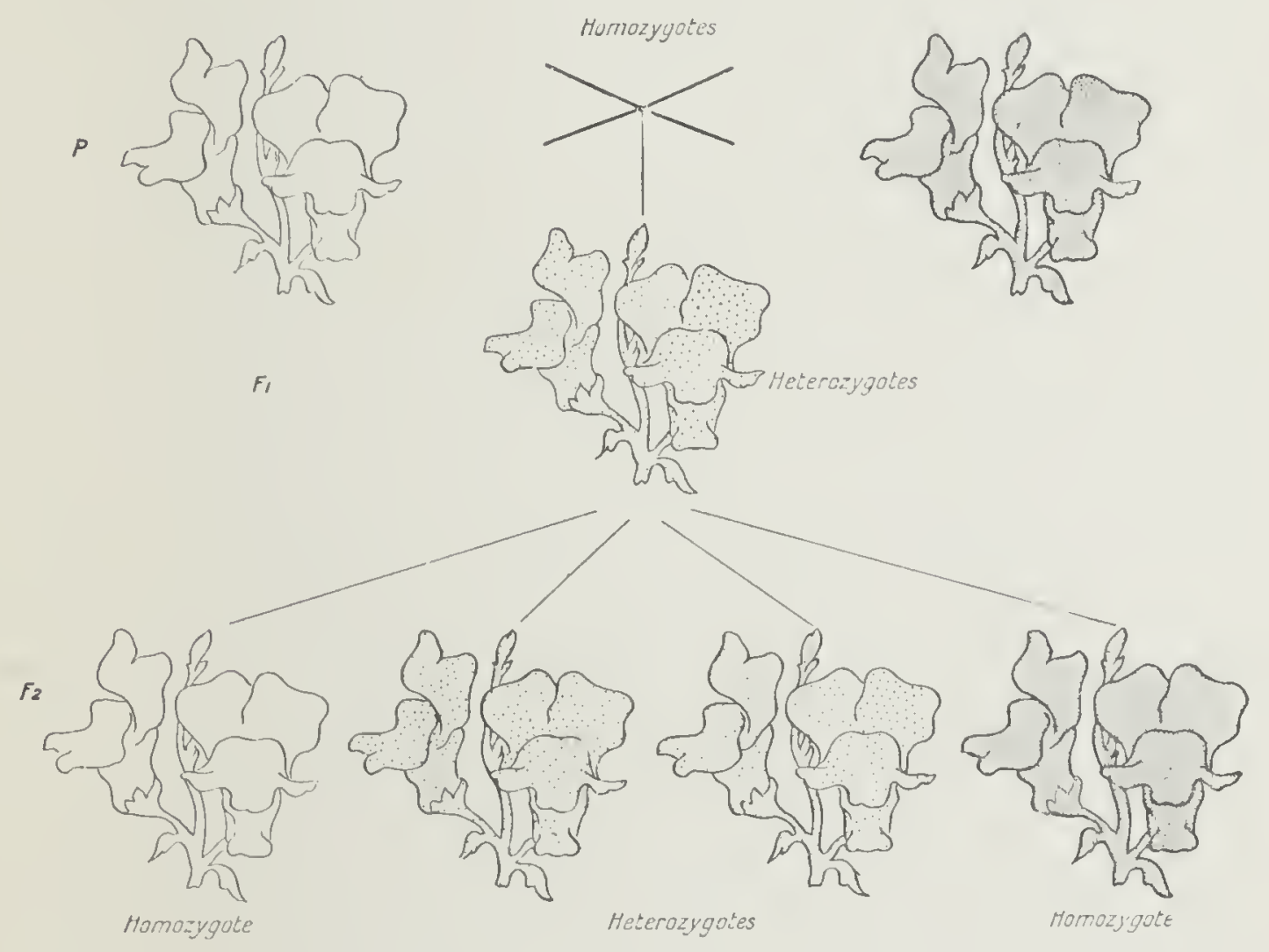

Fig. I6. Cross between white- and crimson-flowered Snapdragons (Antirhimum) illustrating Mendelian inheritance of characters and segregation of factors. $P$, homozygote, white and crimson parents. $F_{1}$, first generation all pink heterozygotes. $F_{2}$, second generation of white lomozygotes, pink heterozygotes, and crimson homozygotes in the proportion I, 2, I.

Tschermak, and de Vries. The illuminating researches of Mendel, to some extent anticipated by the Frenchmen Sageret and Naudin, have since been confirmed and extended by a vast number of observers, among whom one may mention Bateson, Punnett, and Doncaster in this country and Morgan in America.

The laws of inheritance have been worked out by 
crossing individuals belonging to closely allied races of plants and animals differing from each other by certain easily recognizable characters, and observing the results in the subsequent generations. For example, as shown by Baur, if two individuals of the snapdragon (Antirrhimm majus) are crossed, one belonging to a constant race with crimson flowers and the other belonging to a constant race with ivory-white flowers, the hybrid offspring will all bear pink flowers like those of neither of the parents (Fig. I6). But if these hybrids are now inbred (crossed among themselves), a second generation will be obtained of mixed character. One quarter of this second generation will bear crimson flowers like those of the first parent, two quarters (half of the whole number) will bear pink flowers like those of the first hybrid generation, while the remaining quarter will produce white flowers like those of the second parent. The crimson-flowered plants will breed true if crossed among themselves, like the original parental stocks, and also the white-flowered plants will breed true; but the pink-flowered plants will never breed true. On the contrary, they will always split, like the original hybrid,into three kinds and in the same proportions (In-2n-In). This example well illustrates the fundamental principle of the segregation of the hereditary factors in the gametes of the hybrid individual, which is the foundation-stone of Mendel's theory of heredity. The facts are accounted for as follows: Individuals belonging to each of the constant parent stocks give rise to germ-cells or gametes of similar inheritance; all the gametes of the first parent will contain the factor producing the crimson character, all the gametes of the second parent the factor producing the white character. On crossing, the two factors will 
meet in the zygotes, giving rise to the hybrid offspring. If both factors were now transmitted to each of the gametes of the hybrid, it would of course breed true. The splitting of the offspring of the hybrids is accounted for on the simple supposition that the factors segregate;

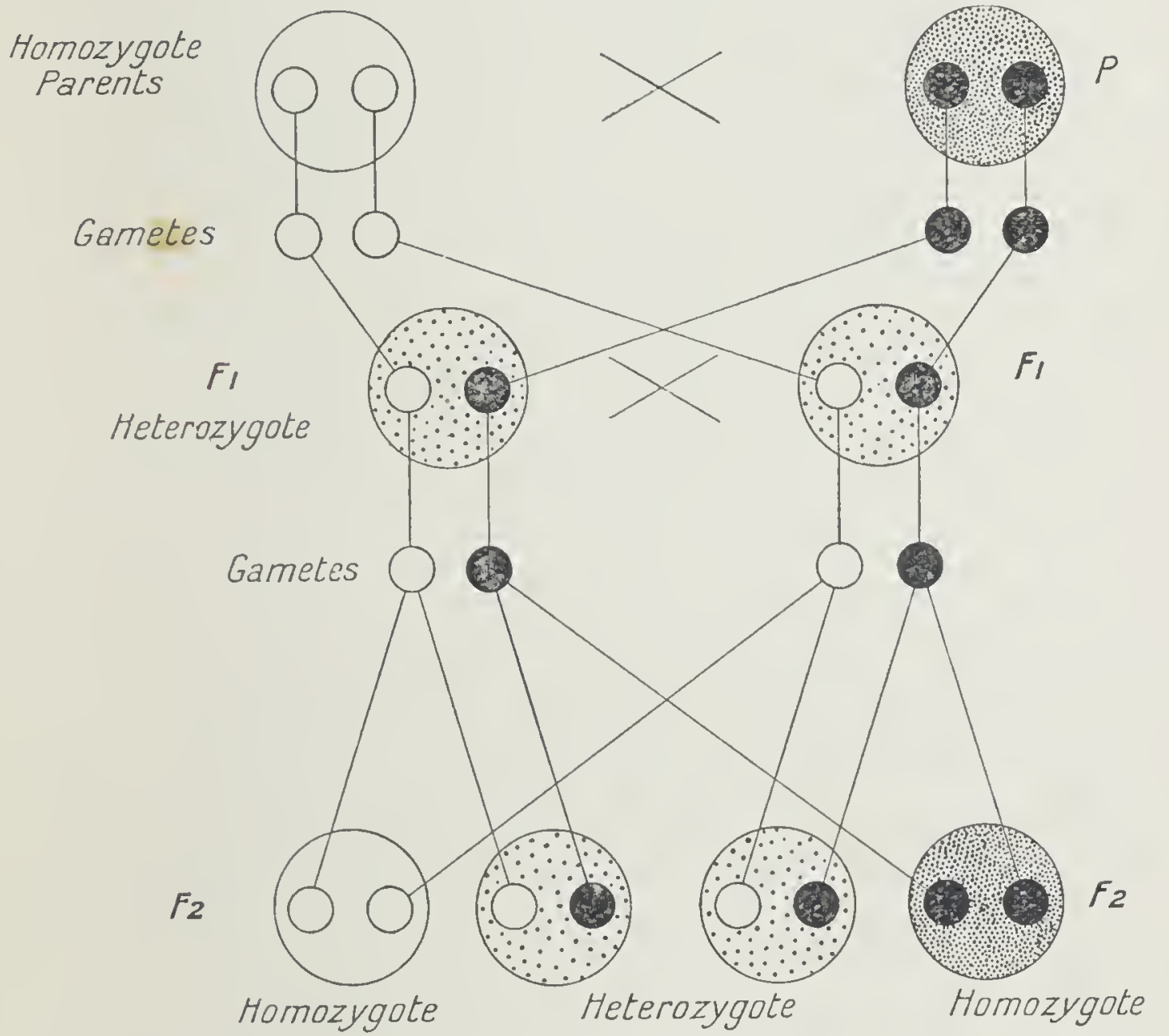

FIG. I7. Diagram illustrating the cross shown in Fig. I6. Large circles represent individuals, white, crimson (shaded dark), and pink (shaded light). Small circles represent gametes; white containing factor for white, black containing factor for crimson.

that the crimson-producing factor passes into half the total number of gametes, and the white-producing factor into the other half in each hybrid parent. No gamete contains both factors. The gametes are then 'pure' in respect to the particular factor (Fig. I 7 ). It follows that when the gametes of the hybrids fertilize each other three kinds of zygotes will necessarily result; one-half of the 
total number containing both factors will give rise to new hybrids; while one-quarter with white-producing, and one-quarter with crimson-producing factors only will give rise to pure individuals like the parents. Another
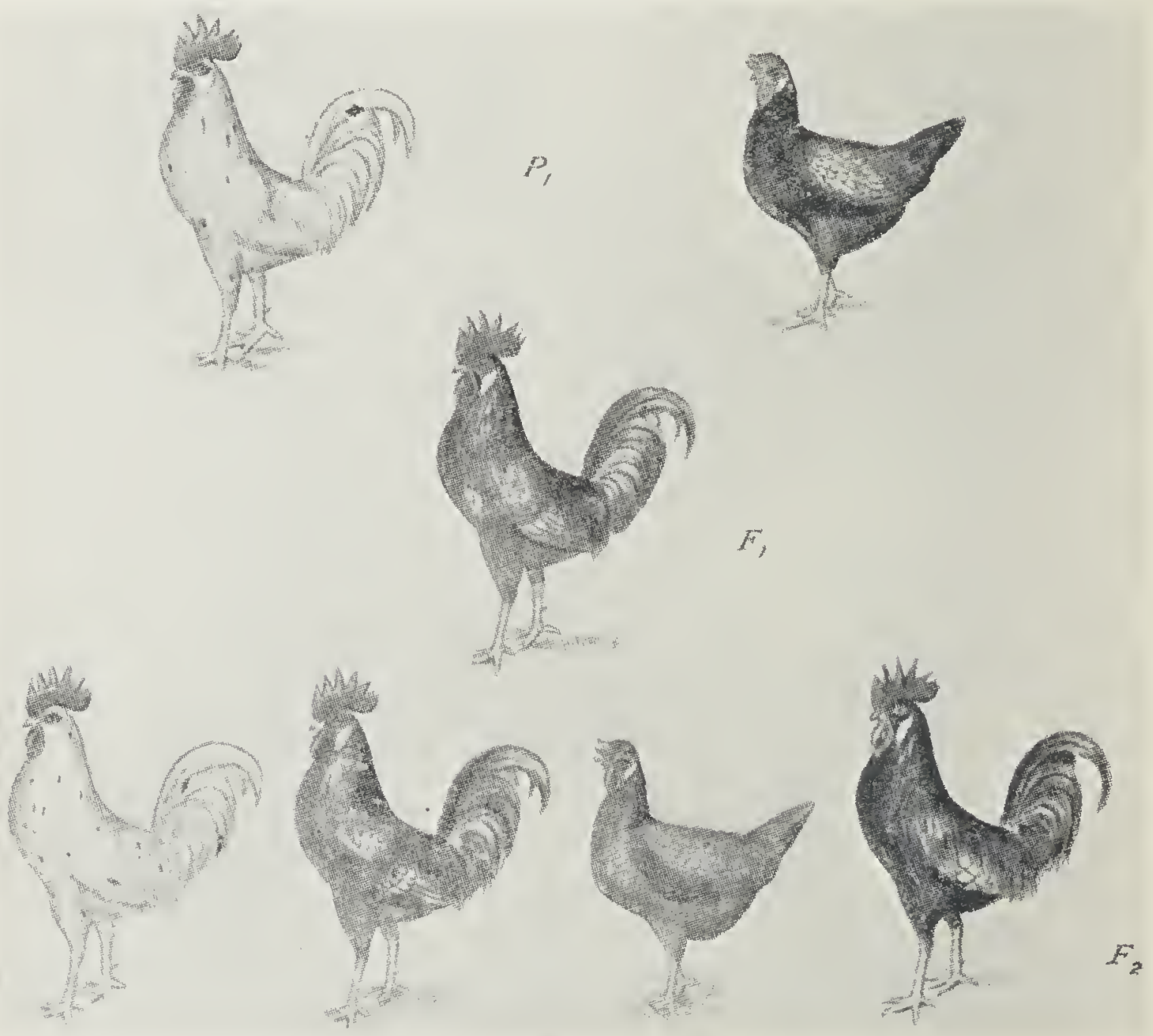

Fig. I8. Cross between splashed-white and black parents, $P_{1}$, giving in first generation, $F_{1}$, blue Andalusians, and in $F_{2}$ one splashedwhite, two Andalusians, and one black. (From T. H. Morgan's Physical Basis of Heredily.)

case in point is the 'Blue' Andalusian fowl, which never breeds true, being a hybrid between the Black Andalusian and the splashed White, both constant races. A cross between these two will always yield 'Blues' only; while the Blues if interbred always split into r $n$ Black, $2 n$ Blue, and $m$ splashed White (Fig. I 8 ). 
True-breeding individuals, containing only one kind of gamete, are called homozygotes; they have grown from zygotes formed by the union of gametes containing the same factors, and gire rise to gametes of uniform value. Hybrids derived from mixed zygotes are called heterozygotes, and give rise to gametes of different factorial value, each factor or set of factors passing into half the total output of gametes. This conclusion is confirmed on

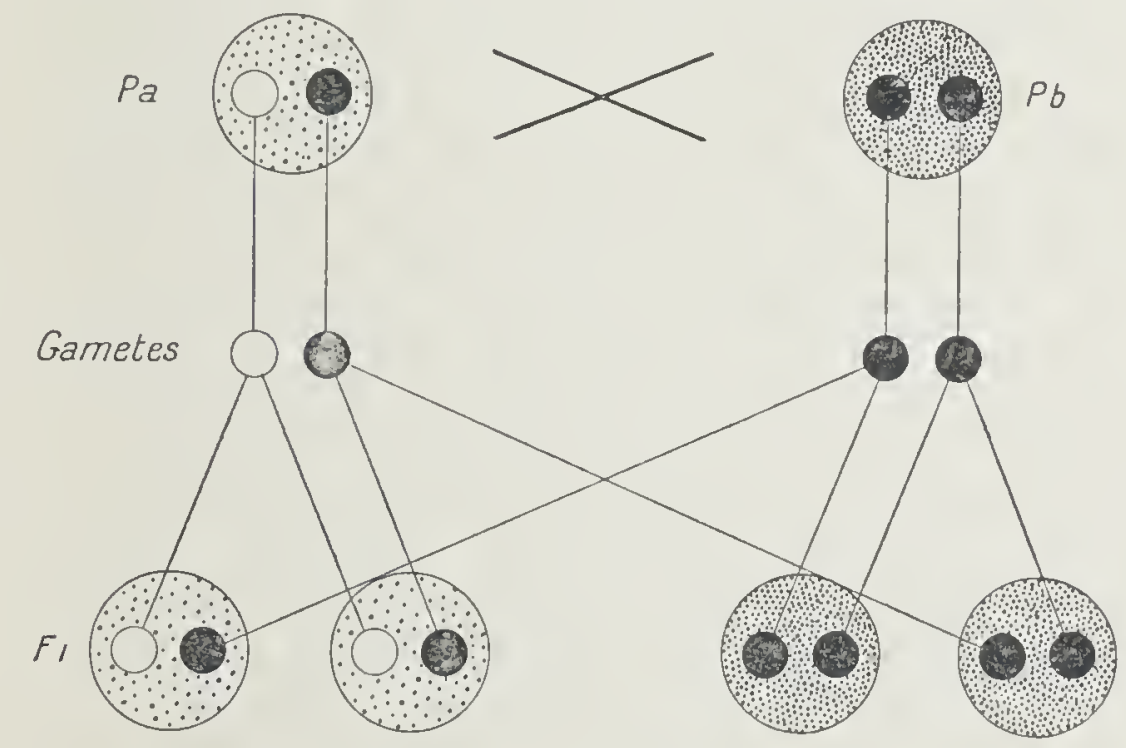

FiG. 19. Diagram, similar to Fig. I7, illustrating a cross between a pink heterozygote parent, $P a$, and a crimson homozygote parent Antirrhinum, $P b . F_{1}$ composed of pink and crimson only.

crossing the offspring of the hybrid with the homozy gote, when half the resulting generation will resemble the homozygote, the original pure parent, and the others will resemble the heterozygote (Figs. I9 and 20).

Now the hybrids or heterozygotes may be more or less intermediate in appearance between the two parent forms, or like neither of them (as in the case of the Blue Andalusian); or again they may closely resemble one of the parents. Indeed the resemblance of the heterozygotes to one of the homozygote parents may be so 
complete as to deceive a keen observer. For instance, as shown by Mendel himself, if two races of the common pea (Pisum sativum) be crossed, one being tall and the other dwarf, the first heterozygote generation will all be tall. These interbred yield one-quarter dwarf plants, and three-quarters tall plants. Of these tall plants one in every three breeds true to tallness, is a tall homozy-

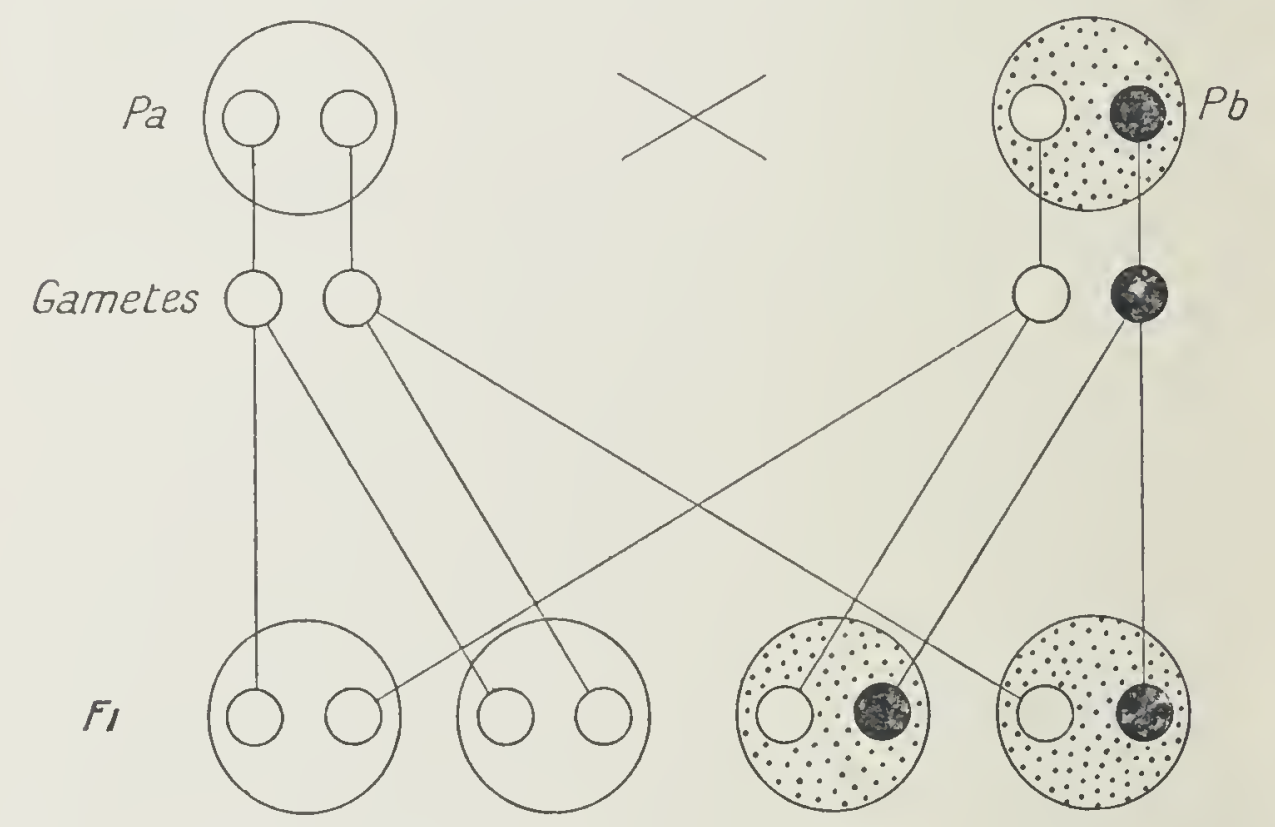

FIG. 2o. Diagram, similar to Fig. I9, illustrating a cross between a white homozygote parent, $P a$, and a pink heterozygote parent, $P b . \quad F_{1}$ composed of white and pink only.

gote, while the other two prove to be heterozygotes, splitting again into the three kinds. The character tallness, then, always shows itself in those individuals to whom its factor has been transmitted, whether they be homo- or heterozygotes (Fig. 2I). It dominates over the dwarf character which is suppressed; and therefore the one is called the dominant character and the other the recessive. From this, and indeed from the whole study of heredity, it follows that we can never judge of the true inheritance or gametic constitution of an individual by mere inspection of its 'characters'. 


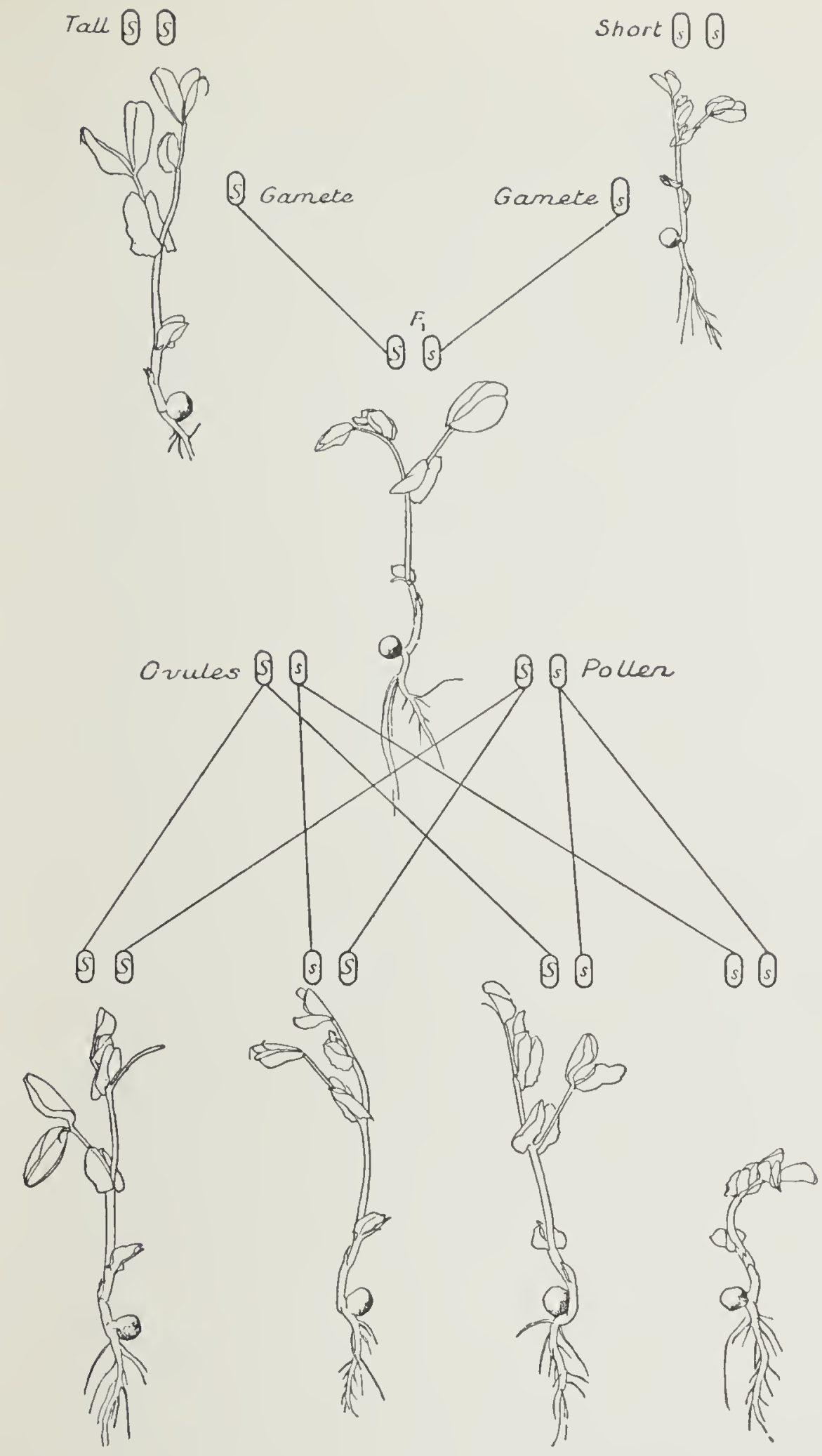

FIG. 2r. Cross between a tall and a short race of garden peas, illustrating dominance. The $F_{1}$ generation is tall. In the $F_{2}$ generation there are three talls to one short. (Reared from peas supplied by Dr. O. E. White. From T. H. Morgan's Phy'sical Basis of Heredily.) $S$, factor for tallness; $s$, factor for shortness, represented in the chromosomes. (Compare Fig. I7.) 
The completeness of dominance varies greatly and may be affected by other factors or by environmental conditions. Hence gradations of dominance may occur even among brothers and sisters. When dominance iscomplete it is evident that a single 'dose' of the dominant factor in the heterozygote has produced approximately the same effect as the double 'dose' in the homozygote.

Since it would be out of place to attempt to give a complete account of the Mendelian interpretations of the phenomena of inheritance, we will only summarize some of the main conclusions in so far as they affect the doctrine of evolution in general. It is held that in an organism a number of characters may be distinguished capable of varying independently, and of being isolated or followed separately in breeding experiments, and each depending on a special transmissible germinal factor or factors. These characters are known as ' unit characters', and the factors which govern them as 'unit factors' (see, however, p. $8_{3}$ ). The whole inheritance would be made up of the sum of its unit factors. No character appears in an individual unless the corresponding factor has been transmitted to it; yet it may inherit factors which remain undeveloped, and the presence of which may be revealed by their transmission to and effects on later generations. ${ }^{1}$ Now when two races are crossed, such as the tall and dwart peas mentioned above, the two opposed, contrasted, or allelomorphic characters, as Bateson calls them, may be

1 It is customary to represent factors by letters. When dealing with a pair of factors governing the appearance of allelomorphic characters one is designated by a capital and the other by a small letter; the capital letter being given to the dominant factor when dominance occurs. Thus the factorial constitution of a homozygote tall pea is T T, of a heterozygote tall pea $\mathrm{Tt}$, and of a homozygote dwarf pea $\mathrm{t}$. On the other hand the factors in their gametes would be respectively $\mathrm{T}, \mathrm{T}$ or $\mathrm{t}$, and $t$. The first generation from two parents is called $F_{1}$, and the second $\mathrm{F}_{2}$. 
due not to the result of two different factors, in the one case representing tallness and in the other shortness, but merely to the presence in the first of a factor for tallness which is absent in the second. Thus a pure recessive would be without a factor present in the pure dominant and in the hybrid. ${ }^{1}$ Moreover an apparently simple character may be due not to a single factor, but to the co-operation of several, which must all be present at the same time and in the same zygote for the character to appear. Yet the factors are sufficiently independent to be capable of segregation, and to give rise when so separated each to some different character. Thus the colour of an animal or plant may be a complex character due to a group of factors transmitted as a whole, and so far constant in the species, but which can be analysed out into a number of separate strains, each breeding true to its own new colour. The grey colour of the wild mouse, for example, has been shown to depend on the cooperation of at least six different factors. Change any one of them and the resulting colour will be changed also. A colour factor may be unable to show itself in the resulting character, unless accompanied in the zygote by an independent colour-developing factor. Thus a white individual may hold colour factors, but appear as an albino because it lacks the essential colour-developing factor; and there may be as many different varieties of partial albinos as there are colour factors in the species capable of segregation. If interbred they will always breed true to albinism, since they are devoid of the necessary factor for the production of their colour. In certain cases

1 It will appear in the sequel that this simple theory is not now generally accepted. It is held that a pair of unlike factors correspond to a pair of alternative allelomorphic characters. 
whiteness seems to be due not to the absence of a factor, but to the presence of an inhibiting factor hindering the derelopment of pigment. Such a white race can behave as a dominant. A cross between a dominant white and a recessive white fowl will yield some coloured offspring in the second generation. So the factors may influence each other's results when meeting in a zygote, may interact in such a way as to produce characters differing more or less completely from those produced by any of them separately.

We have seen that when two varieties are crossed differing possibly in the presence or absence of one hereditary factor, as with the tall and short peas, a dominant and a recessive form result in the second generation, in the proportion of three to one. If, now, the varieties differed by two factors, as for instance tall purple-flowered and dwarf white-flowered peas, the hybrid would show both the dominant characters, would be tall and purple, and would give rise to four kinds of gametes in equal proportions. One might contain both factors, one the factor for tallness, one the factor for purple, and one neither factor; the gametes would appear in equal proportions, since the factors segregate independently by 'chance'. The product of random fertilization among these gametes will yield zygotes in the proportion of nine with both factors, three with the factor for tallness only, three with that for purple only, and one with neither, the pure 'extracted recessive'. So the second, $F_{2}$, generation will grow into tall purple, tall white, dwarf purple, and dwarf white peas in the proportion 9, 3, 3, I ; but the proportion of purple to white, and of tall to dwarf, will still be as 3 to I (Figs. 22, 23, a similar case in Drosophita). Each factor, then, not only segregates, 

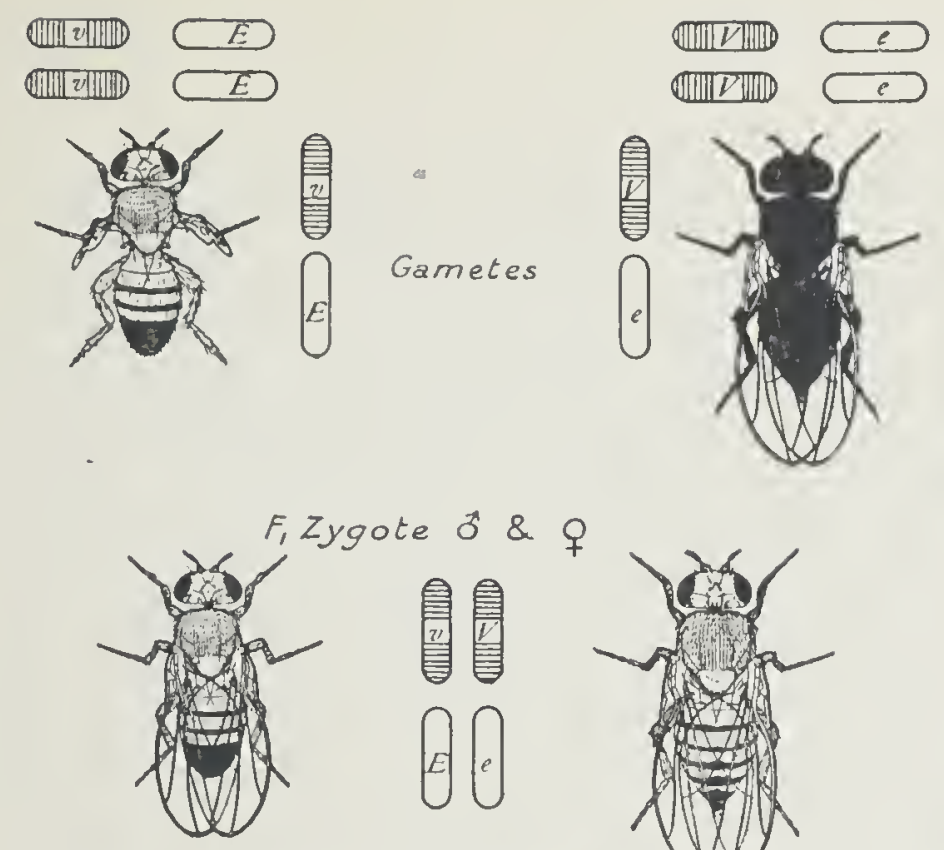

$F_{2}$
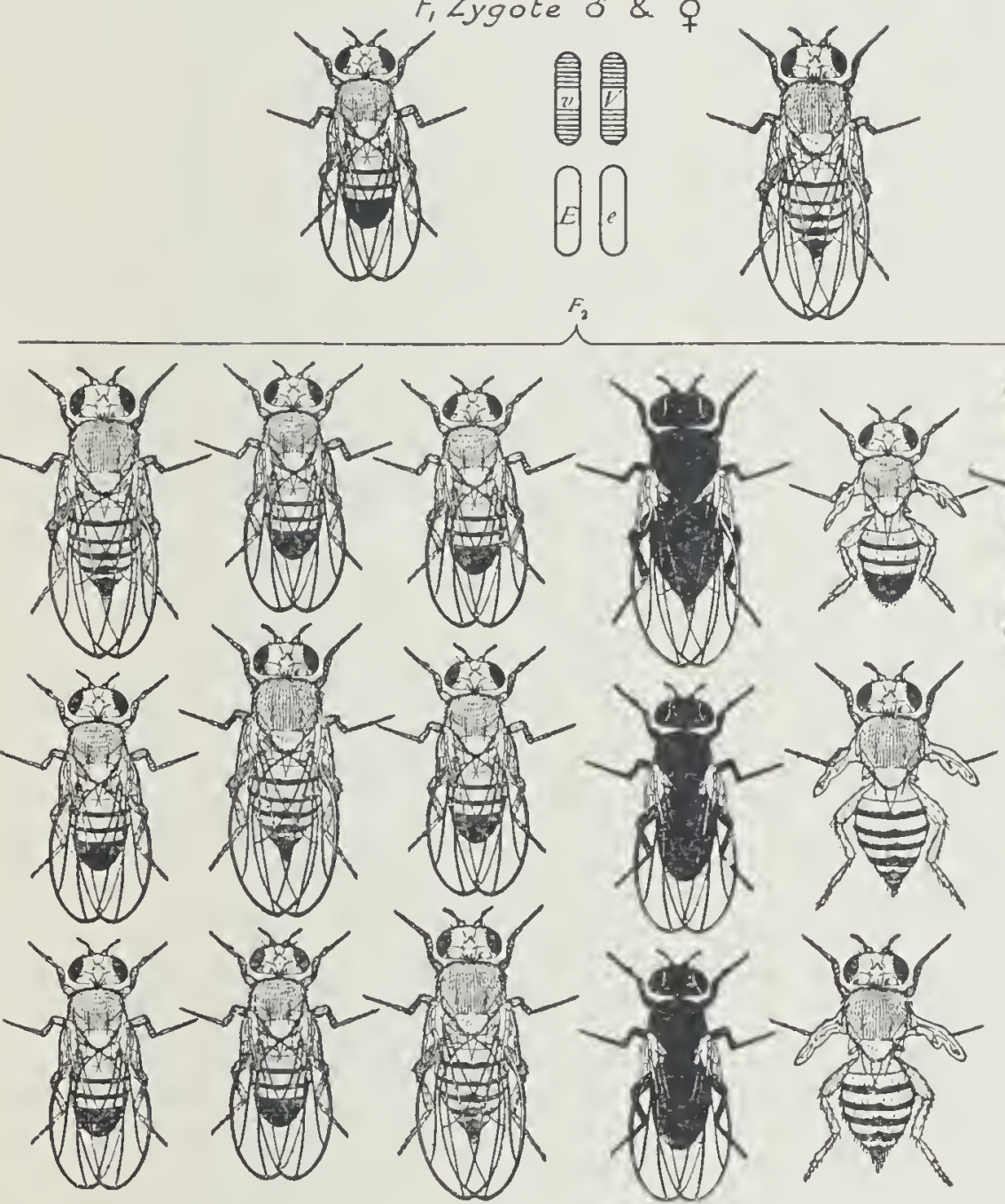

Fig. 22. Cross between two vinegar flies, Drosophila, illustrating the inheritance of two characters, due to presence of two independently segregating factors. Factor for vestigial wing, w, and its allelomorph for long wing, $V$, and factor for ebony colour, $e$, and its allelomorph for wild type colour, $E$, represented in chromosomes (see Fig. 23).

Above are two parents; on left $\sigma^{\top}$ of wild type colour (dominant) and with vestigial wings (recessive); on right $q$ with long wings (dominant) and of ebony colour (recessive). All $F_{1}$ generation show dominant characters. In $F_{2}$ generation there are long-winged wild type coloured, long-winged ebony, vestigial-winged wild type coloured, and vestigialwinged ebony coloured flies, in proportion 9, 3, 3, I. Each separate character is in proportion 3, I. (From T. H. Morgan's Physical Basis of Heredity.) 
but segregates independently of other factors. The number of possible combinations increases rapidly with the number of factorial differences. ${ }^{1}$

The most complete analysis of the factors of inheritance yet made is that of the fruit fly (Drosophila ampelophila), recently worked out by Prof. Morgan and his pupils.

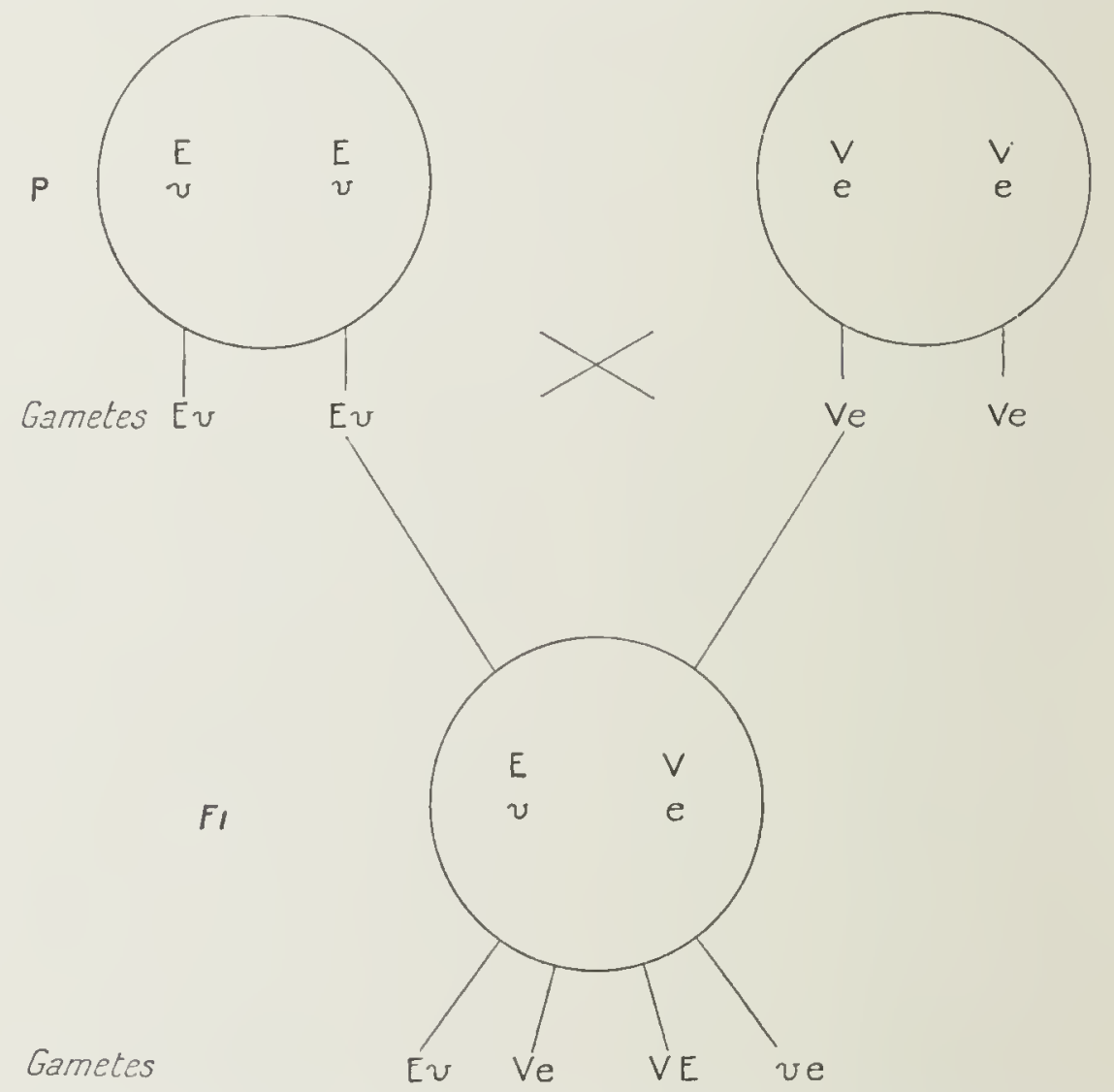

FIG. 23. Diagram illustrating the distribution of factors in gametes of parents, $P$, and $F_{1}$, of flies shown in Fig. 22.

By breeding experiments about 125 different factors have been distinguished, the eye-colour alone being influenced by some 30. Some of the more important results of this work will be referred to later (p. $\delta_{9}$, foot note).

1 As shown in Fig. 23 there will be produced in generation $F_{1}$ four kinds of gametes giving I6 possible combinations in $F_{2}$. Of these $V E V E$ and veve will be true-breeding homozygotes with a combination of characters not found in either of the original parents. It is important to notice that the discovery of the laws of Mendelian heredity thus enables the breeder in a few generations by appropriate mating to obtain a pure race with any desired combination of chararters. 
The conclusion is that the total inheritance transmitted in a gamete may be interpreted as made up of definite independent unit factors contributing to the production of corresponding characters. The factors are separable, relatively constant, and can be transmitted independently ; they preserve their individuality and properties unchanged when entering into combination with other factors; they may reinforce or hinder each other's action. Occurring in pairs in the zygote they are distributed singly to the gametes, and when one of the pair comes to differ from the other, unlike gametes are produced and alternative allelomorphic characters result. These characters may be more or less developed according to interaction with other factors of inheritance and conditions of the internal or external environment.

The origin of domestic races of animals and plants is often obscure, as many of them seem to have had a mixed origin due to the crossing of two or more wild species. So the great diversity of such races may be due largely to the mere sorting out of the different strains from a mixed stock. Nevertheless in many cases domestic races may be accounted for on the theory that the complex of factors of inheritance possessed by the primitive wild form has been split up among a number of races, each distinguished by the loss or alteration of some factor or set of factors belonging to the original stock. If no new factorial mutations have occurred since their domestication, the various domestic races of pigeons, fowls, sweet-peas, and so forth, would differ from each other merely in holding a different selection out of the whole number of available unaltered original factors. If this were true we might expect to be able to bring together again the separated fragments of inheritance 
and reconstitute the complete set by crossing various races with the necessary elements. And this can indeed be done, giving rise to 'reversion', the reappearance of an ancestral combination of characters. Thus the original wild form of sweet-pea found in Sicily can be reconstructed by crossing the 'Bush' and the 'Cupid' domestic varieties. The 'Agouti' colour of the wild rabbit reappears on crossing a yellow with a Himalayan variety ; and the plumage of the wild 'blue rock pigeon' (Columba livia) can be reproduced on crossing certain very unlike domestic races. A simpler and demonstrative case is afforded by Drosoplizila: from the normal long-ivinged wild fly the forms with miniature wings and with vestigial wings each arose by a single mutation, and if these two are crosscd the normal long-winged type is reproduced.

But do all factors of inheritance 'mendelize'? In answer to this question it may be said that the law of segregration, the law of Mendel, appears to hold good with all sorts of characters and in all sorts of plants and animals. No thoroughly established case has yet been brought to light in which the factors have been proved not to segregate. Many of the supposed instances of blended inheritance, with the formation of series of intermediates, have been shown to be due not to failure of segregation, but to incomplete dominance, multiplicity of factors, direct effect of environment, and other complications which blur the result. Yet there are still some cases known, such as the colour of human races, the factorial basis of which has so far defied analysis; and it is possible, though improbable, that the rule is not universal, and that segregration may sometimes be incomplete or even not occur at all.

Now most of these experiments have been made on domestic varieties, differing from one another by only 
a few well-marked characters: differences due probably to the alteration or 'dropping out' of certain factors of heredity. We may now inquire what happens if two natural 'species' are crossed. This is a most interesting question, and one directly affecting the general problem of evolution, since the experiment might possibly reveal some hidden but genuine distinction between a 'species' and a 'variety' or 'race'. The variety might mendelize but not the species; as, indeed, was suggested by de Vries. Such, however, does not appear to be really the case; but the problem is much complicated owing to the large number of factors of varying importance which may distinguish two even closely allied natural 'species' In so far as some of the characters are conspicuous and dominant, it may be possible or even easy to trace out the segregration in later generations; but the task may become too difficult if the distinguishing characters are small and very numerous. In such a case thousands of 'intermediate' heterozygotes may be produced, each with its particular inheritance, and a bewildering number of intermediate forms result. This is after all perhaps not a matter of great general importance, since hybridization of different 'species' can play but a small part in evolution, and reed hardly be considered at all as a factor in the general process.

The term 'unit' character, sometimes used to denote a character which behaves as a unit in Mendelian inheritance, is apt to be misleading. For practical purposes it is convenient to fix the attention on some conspicuous result, such as the colour of a flower or the height of a plant, but it must always be remembered that the influence of the factor may-possibly always does--extend over the whole organism. When a strik- 


\section{4 \\ Variation and the Factors of Inheritance}

ing character is developed it is seized upon by the observer, while other less obvious changes due to the presence of the same factor may attract little notice or be altogether ignored.

In Chapter III it was shown that two kinds of variation can be distinguished: modifications and mutations. The latter alone are due to changes in the inheritance, and may be further classified into 'combination mutations' due to the mere rearrangement of the factors of heredity already present, and 'alteration mutations' due to some change in the factors themselves. In the former case new characters may come out, but the factors are merely segregated and recombined though they remain unaltered. In the latter case, on the other hand, the differences between the hereditary material of parent and offspring are due to factors having undergone some definite change. If such a change leads to the appearance of a recessive character, owing apparently to the partial or complete suppression or loss of a factor, it is called a retrogressive mutation. On the contrary, if a dominant character appears seemingly due to the increased efficacy of a factor or even perhaps to the inclusion of a new factor, the mutation may be called progressive.

So far as experiment has shown, the multitudes of domestic varieties of our plants and animals are almost all of a retrogressive or combinational kind; that is to say, are due to the separation and rearrangement or suppression of the factors of inheritance already present.

Similar mutations are known to occur in nature. Common instances are albino animals and white-flowered plants. The botanist de Vries, who has made a special study of these variations, has collected and studied a large number of cases. But it cannot be that all mutations are 
of this negative nature. Indeed, though the observed occurrences of mutations giving rise to dominant new characters are strangely few, yet there is an increasing number of well-authenticated instances in Drosophiza (bar-eye, notched wing, \&c.) as well as in other animals and plants. All the differences that distinguish man from the primitive stock whence arose the whole animal kingdom can hardly be due, as suggested by Bateson, to man having lost certain factors which this early ancestor possessed, or to the factors having been mixed, shuffled, and redistributed. To say that evolution is due only to such mixing and reshuffling of pre-existing factors is merely to to push the problem a step farther back, for we would still have to account for their origin and diversity. The same objection applies to the suggestion that the original complex of factors present at the beginning has simply become altered by the successive loss of some of them. To account for the progressive change in the course of evolution of the factors of inheritance and for the building up of the complex, it must be supposed that from time to time new factors have been added; it must further be supposed that new substances have thus entered into the cycle of metabolism, and have been permanently incorporated as selfpropagating ingredients entering into harmonious and lasting relations of co-operation with previously formed factors. In the course of evolution new material has been swept from the banks into the stream of germ-plasm. It must be admitted that such a building-up process has occurred, and we have no right to assume that it ceased at a certain time. Presumably it is still going on.

Mutations, then, are produced by the addition to, subtraction from, or alteration in, the factors of inheritance already present. 
This whole system of factors may appear to the reader somewhat artificial; yet it is the legitimate deduction from facts for which no other explanation can at present be given. Moreover it has received most striking confirmation from studies on the structure and development of cells carried out quite independently and by quite other methods.

We have already seen (p. $5^{\circ}$ ) that the factors of inheritance are contained in the chromatin of the nucleus. The full evidence for this conclusion cannot here be given; but it may be pointed out that the inheritance is transmitted equally from both parents, although the male gamete which penetrates into the ovum often consists of little else but chromatin, that an abnormal distribution of chromosomes leads to a corresponding abnormal development of characters, and that the chromosomes have been shown to be of unequal value in heredity, the different factors being parcelled out among them.'

It has also been stated (p. $3^{2}$ ) that the number of chromosomes is constant in individuals and in species. Usually, between successive divisions the nuclei pass through a resting stage during which the chromosomes are no longer recognizable as such, but there is good evidence that as a matter of fact they always persist throughout in some form sufficient to preserve their individuality. Now, it is clear that when the two gametes combine in fertilization the zygote so formed would contain double the parental number of chromosomes were not some device adopted for reducing them. This necessary process is brought about by a special 'reduction

1 That the chromosomes themselves are not the factors of inheritance is proved by breeding experiments which show that the number of factors capable of segregation is far greater than the number of chromosomes. 
division' of the nucleus in the course of which instead of the chromosomes dividing into two halves which move to opposite poles of the spindle (p. $3 \mathrm{I}$ ), they combine in pairs and then simply separate again to form the daughter nuclei. Thus each of the resulting nuclei has half the usual number of chromosomes found in the ordinary somatic cells (Fig. 24). A reduction division takes place in all organisms reproducing sexually: in the Metazoa only in the first of the two 'maturation divisions ' undergone regularly by the germ-cells in the formation of gametes, the second being of the normal type. Four spermatozoa in the case of 'male' cells, or one true ovum and three polar bodies (functionless small cells) in the 'female' cells, are thus produced with the 'haploid' number of chromosomes (half the number found in the cells previous to maturation). On fertilization the normal 'diploid ' number is of course restored (Fig. 5).

In plants a large number of cell-divisions may intervene between gamete formation and reduction, which takes place when the spore-mother cell divides into spores. The haploid and diploid phases then give rise to a regular alternation of generations reproducing sexually and asexually respectively. In the Bryophyta the haploid sexual generation derived from a spore is the familiar moss plant; while in the Pteridophyta it is the diploid asexual generation derived from a zygote which grows into the large fern plant and bears spores. The haploid gametophyte is still further reduced in the Phanerogams and is no longer independent.

The theory of the individuality of the chromosomes is further supported by the fact that in many organisms they have persistent characteristic individual shapes, and in such cases are found to occur in pairs, one being of 


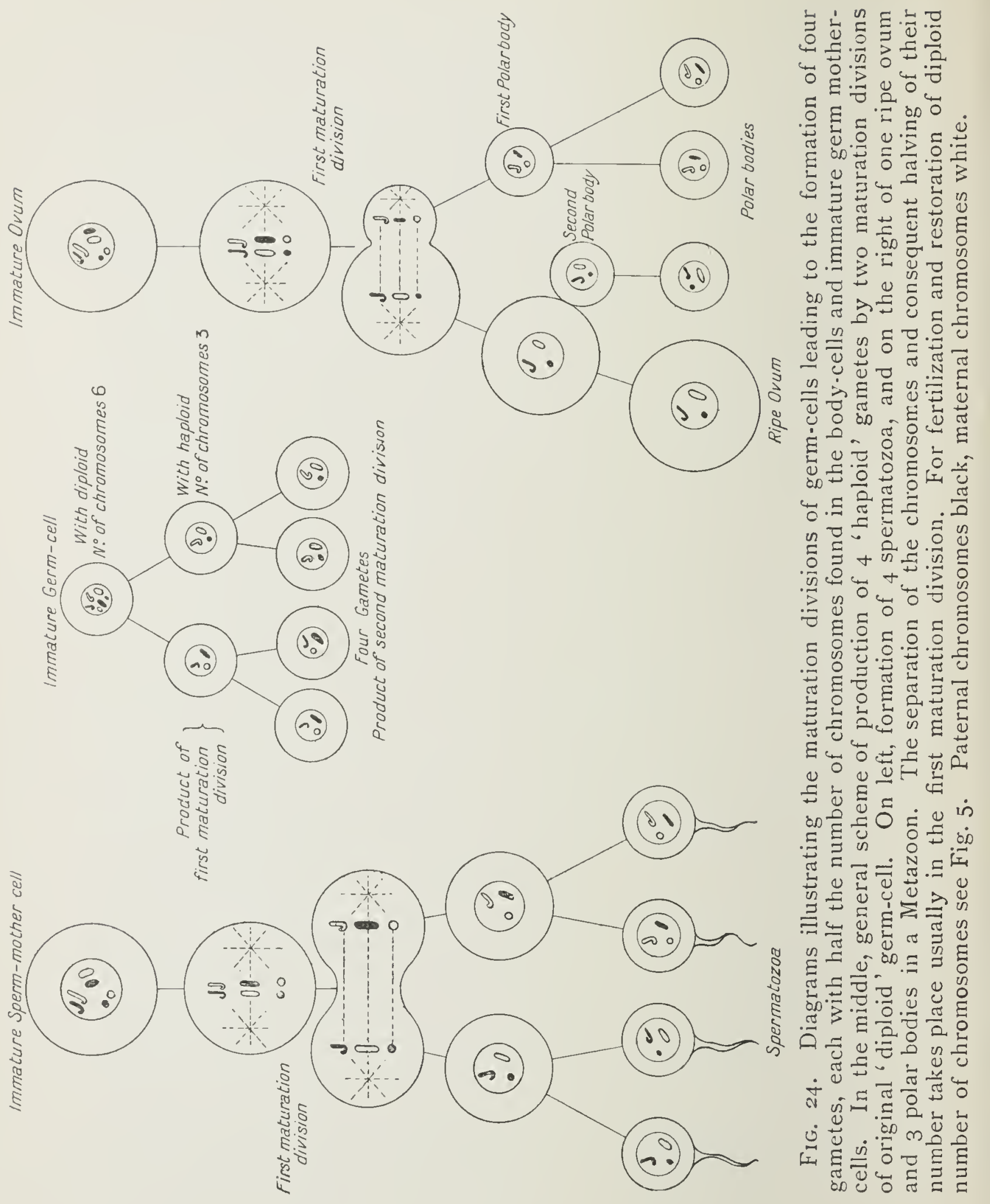


maternal and the other of paternal origin. It is these pairs which unite in the reduction process, and when they separate again they are distributed haphazard to the daughter nuclei. So the gamete receives one chromosome of each kind, but it may be either paternal or materna!. It is clear that the behaviour of the chromosomes affords just the mechanism necessary to account for the phenomena of Mendelian segregation and inheritance, if we assume that the substances determining the development of characters are situated in the chromatin, a permanent constituent of the nucleus. Every cell of the body derives half its complement of chromosomes from one parent and half from the other. When reduction occurs only one of each pair of chromosomes can pass into a gamete, carrying with it one of a pair of allelomorphic factors. Hence the 'purity of the gametes' and the forced segration postulated above, p. $7 \mathrm{r}{ }^{1}{ }^{1}$

What the factors are we can only surmise. They are not distinct corpuscles of living matter like the hypothetical gemmules of Darwin or biophors of Weismann, representing separate cells or parts of the organism.

1 The modern study of heredity, especially the brilliant work of Professor Morgan and his collaborators on Drosophila, has yiclded many important results, of which it is not necessary for our present purpose to give a detailed account. It may, however, be mentioned that there is evidence that the mendelizing factors or genes are placed in a row and occupy constant positions along each chromosome, that consequently they can only be independently transmitted if they occur in different chromosomes, that all those present in one chromosome will be transmitted together as groups of 'linked' factors, and that there should be no more such groups than there are chromosomes to hold them. Further, when a pair of chromosomes unite at 'reduction' an exchange of material may occasionally take place involving the exchange or 'crossing over' $^{\prime}$ of one or more factors from corresponding regions and consequent disturbance of the normal Mendelian proportions in the resulting characters. 
Rather should they be conceived as definite chemical substances forming part of, or entering into, the chain of metabolizing compounds and thereby influencing the course of metabolism in such a way as to bring about a certain definite result (the ' character'). Probably these substances are proteins of complex composition, but the suggestion often made that they are enzymes will not hold, since enzymes are really end-products incapable of selfpropagation. Yet it is possible that the factors act by giving rise to ferment-like bodies which influence the course of metabolism.

If such a substance is destroyed, or fails to pass into the gamete, a retrogressive mutation arises. If the physico-chemical structure of a factor is altered by the shifting and rearrangement of the chemical atoms, for instance, a mutation may result. A truly progressive mutation would be produced when new atoms or compounds become permanently involved in the metabolic cycle of the germ-plasm.

One must be careful not to assume that every character and every part of an organism is necessarily represented by a separate corpuscle or even by a separate substance, present from the beginning in the germ. Such a supposition would soon lead us into that tangle of difficulties which have proved fatal to the corpuscular theories of heredity. It is the old controversy between the supporters of 'epigenesis ' and ' evolution ' in development (evolution being used here in the restricted sense of an unfolding during ontogeny of parts already present on a small scale in the germ). While the latter held that the parts of the adult are developed by the mere unfolding of corresponding elements preformed in the germ, the 'epigenetists' held that they are formed de novo in 
every embryo from an undifferentiated substance. In modern language we should say that the structure of the adult is gradually developed by a series of epigenetic changes, each one of which is strictly determined by the stage preceding it, and strictly determines that which follows it. So every feature of a landscape, every detail of a melting view, is doubtless strictly predetermined by the nature of the geological strata and the surrounding conditions, but cannot be said to have been preformed in previous geological epochs. If every separately variable character had to be represented by a separate unit the number of units in every gamete would become fantastically large. Moreover, characters are variable independently at different stages of growth-not the butterfly only, but the chrysalis, the caterpillar, and the egg may vary; must there be a unit for every stage of every character? Again, it is difficult to account for the marshalling and development of all these units in proper order without calling in the aid of some mysterious governing force. These are some of the difficulties which have led to the downfall of the older theories of heredity by means of independent corpuscles.

Only in so far as characters can be proved to behave as independent units in heredity need it be supposed that they are represented in the germ by some special substance or factor.

Great as has been the advance in our knowledge of the inheritance of characters through breeding experiments conducted on Mendelian lines, there is some danger of the factorial theory becoming a mere formal explanation of results. So far we are presented with a picture of independent particles without any clue as to how they co-operate or succeed in producing the finished result. 
Students of genetics are apt to overrate the importance of an explanation of the mere mechanism of transmission.
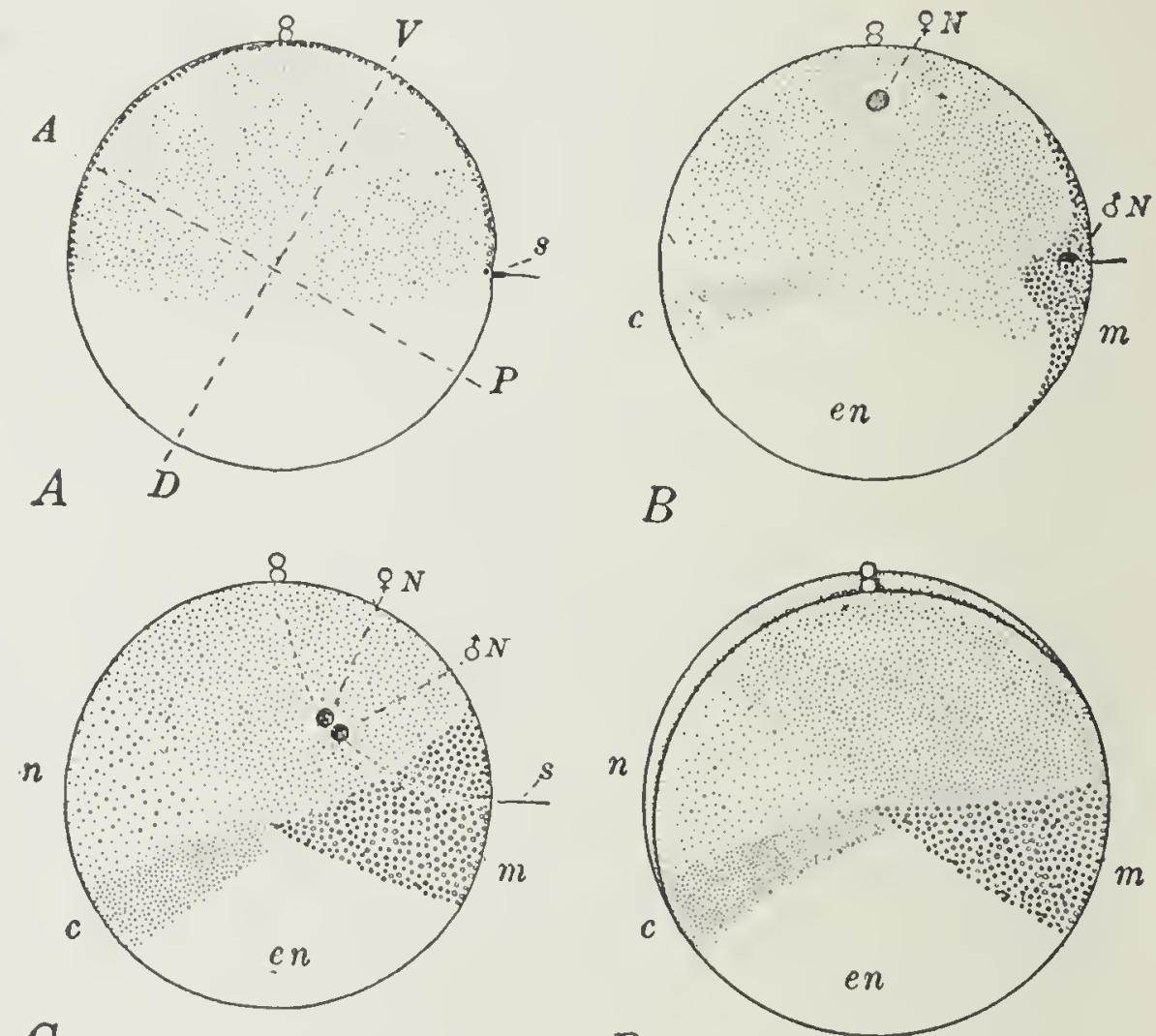

C
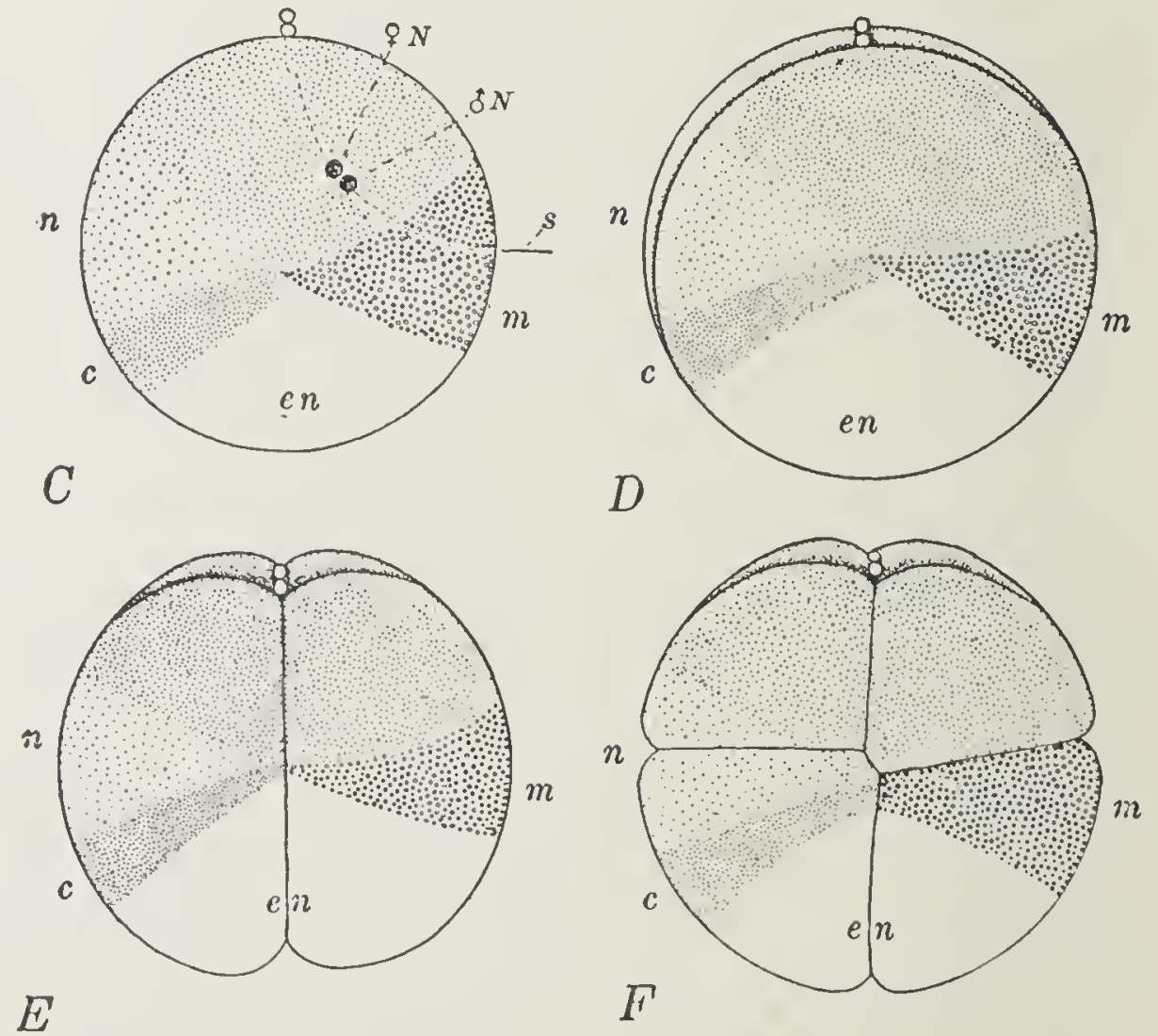

FIG. 25. $A-F$, successive early stages in development of fertilized egg of Frog. The diagrams show the appearance and later distribution of differences in the protoplasm indicating 'organ determining' substances. Lines $A P$ and $D V$ indicate antero-posterior and dorso-ventral axes. $s$, spermatozoon; $\sigma^{T} N$, sperm-nucleus; $q N$, egg nucleus; $m$, mesodermal substance; $c$, notochordal substance; $n$, nervous substance; $c n$, area of endoderm; area round polar bodies will form ectcderm of skin. (From E. G. Conklin's Heredity and Environment.) 
Not until the factors have been brought into relation with the general metabolism, with growth and reproduction, will the theory of heredity approach completion.
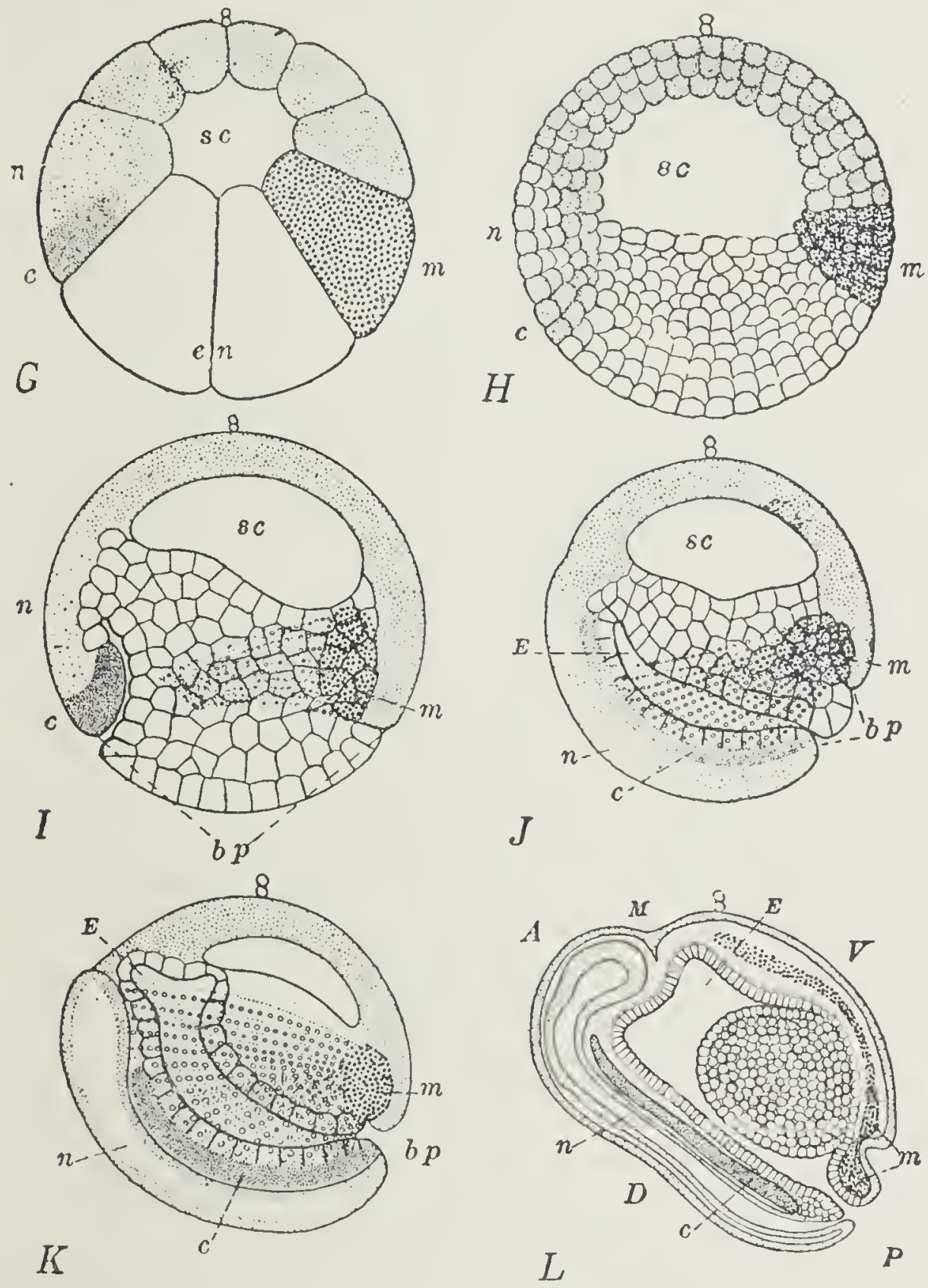

Fig. 26. Later stages of development of egg of Frog. The diagrams represent longitudinal median sections, and show the fate of the 'organ determining' substances (cp. previous figure). $E$, gut; $M$, region of mouth. (From E. G. Conklin's Heredity and Environment.)

It is not possible as yet to describe in full the process of embryonic development, but some sort of epigenesis 
there must be. ${ }^{1}$ All we need assume is that there are factors enough in the inheritance to produce a certain definite result in co-operation with the environment. When, under the same conditions, the results come to differ, when a mutation arises, no doubt some corresponding change must have taken place in the inheritance, some alteration in the composition and properties of what we vaguely call the factors (p. 8r). A consideration of the changes undergone by complex chemical compounds may give us some notion of what the factorial changes may be. The student of Organic Chemistry is familiar with long series of closely allied compounds, formed of molecules often containing vast numbers of atoms. The properties of these compounds all differ from one another, owing to the elements not being quite the same, or to their not being present in exactly the same proportions, or again to their being differently grouped within the molecule. The properties may be

1 It may be asked, if the factors of inheritance are equally distributed to all the nuclei, if therefore all the nuclei throughout the body are of equal value, how does the epigenetic differentiation of parts, the differentiation of tissues and organs, come to occur? The answer seems to be that it is due to differences arising in the cytoplasm leading to the formation of unlike substances which become unequally distributed at division to the daughter-cells (Figs. 25 and 26). These substances, formed of course under the influence of the factors of whose metabolism they are the direct or indirect products, sooner or later accumulate more densely in some region of the cell owing to the action of environmental conditions such as gravity or light. Experiments show that the localized distribution of such 'organ determining' substances may begin to take effect in some cases from the earliest stages of cleavage of the zygote, as for instance in Vertebrates, Insects, Annelids, and Molluscs. In the Echinoderms, however, the eight-cell stage may still be made up of equipotential cells each capable of growing into a complete larva. As Conklin has well shown, a progressive and irreversible differentiation of the cytoplasm thus takes place, forming a system of internal stimuli which react on the factors of inheritance and lead step by step to the differentiation of tissues and finally to the development of the adult form. 
altered at will by removing this or that atom, by introducing a new element, by substituting one group for another, or by merely shifting the grouping within the molecule. The resulting changes will be definite, will appear large or small, important or not, according as they strike our senses. In some such fashion do we imagine the changes occur in the factors of inheritance.

Mutations are generally said to arise spontaneously; this, of course, is only another way of saying that we do not yet know what causes them to appear. The fundamental problem of Biology is how are the factors changed, or how does an organism acquire new factors? In spite of its vast importance it must be confessed that little advance has been made towards its solution since the time of Darwin, who considered that variation must ultimately be due to the action of the environment. This general conclusion is inevitable (that any transmissible differences arising between two originally identical germinal constitutions formed of the same factors of inheritance must in the long run come from the environment), since any closed system must reach a state of equilibrium, and continue unchanged unless influenced from without. We know that mutations occur in natural as well as in domesticated races, that they occur rarely but apparently are more frequent in some species than in others, that they may appear as either dominant or recessive characters, that the same mutation may appear again and again in the same species (for example, white eyes in Drosophila melanogaster). There is also evidence that the same mutational change may occur independently in allied forms (for instance, albinism and melanism), though the same appearance may sometimes be brought about by different factorial com- 
binations. Further, while it is agreed that all mutations are ultimately due to changes in one or more factors or in the make up of the complex of factors, it is known that some are associated with irregularities in the distribution of the chromosomes. For example, the evening primrose (Oenothera lamarckiana) with $\mathrm{I} 4$ chromosomes almost certainly has given rise to the species O. lata with I 5 , and O.gigas with 28. Darwin believed that great and sudden changes in the environment increased variability, a conclusion which is probably well founded; but is difficult to prove, since we know so little about the range of variability in nature under usual and unusual conditions. Many attempts have been made to establish the fact that mutations can be brought about by altering certain stimuli in the environment. The American investigator Tower, experimenting on the Colorado beetle (Leptmotarsa), claims to have found that on exposing some individuals at a certain stage and for a certain time to extremes of heat and dryness there appeared in their offspring beetles differing remarkably from the parents in colour and pattern. That these new forms were real mutants, and not modifications, was proved by their breeding true under normal conditions, and when crossed with the parent form giving the proper Mendelian proportion of parent and new types in the second generation. Similar results have been obtained by others with various animals and plants. For factorial changes of this kind to produce lasting results, constant inheritable mutations, they must of course be persistent. It is a mistake to confuse, as is often done, such changes brought about by the direct effect of external or internal stimuli on the germ-plasm with alleged cases of the so-called inheritance of acquired characters. 
It must not be forgotten that the experimental conditions may only have favoured the survival of preexisting mutations or the emergence of rare recessives and not actually caused their first appearance. Or the mutations may have occurred by chance among the individuals used in the experiment. So far no convincing proof has been given of the artificial production of true mutation. But we may not unreasonably look forward to the possibility of being able some day to produce progressive mutations in any desired direction; a discovery of such immense practical value that it would eclipse even such triumphs as the practical application of electricity, or the use of steam power.

A word may here be said about the determination of sex, although space will not allow us adequately to discuss this most interesting and important problem in evolution. ${ }^{1}$ What determines that a given individual shall be male, female, or hermaphrodite? Since, in the vast majority of cases, when the sexes are separate, they appear in equal numbers, it might seem that here is an excellent instance of Mendelian segregation. We may suppose, as Geoffrey Smith and Wilson suggested, that one sex is a homozygote

1 The determination of the development of sccondary sexual characters which may differentiate the sexes (p. I3I) must be clearly distinguished from the determination of sex itself. There is evidence that the secondary sexual characters are developed owing to the interaction of certain factors of inheritance common to both sexes with a special male and female internal environment or type of metabolism. In some animals, such as Insects, this environment is determined at the start by sex factors transmitted to the ovum; in others, such as birds and mammals, the sex-determining factors act indirectly by inducing certain cells in the orary or testis to secrete hormones at a comparatively late stage which stimulate the development of the secondary sexual characters. Hence the appearance of these characters is prevented or retarded by the removal or reduction of the gonad in the bird or mammal but not in the insect. 
and the other a heterozygote for sex-determining factors (Fig. 27). The heterozygote parent would then yield male-producing and female-producing gametes in equal numbers, and the sex of the offspring would be determined at fertilization (Figs. 27 and 19). Breeding experiments

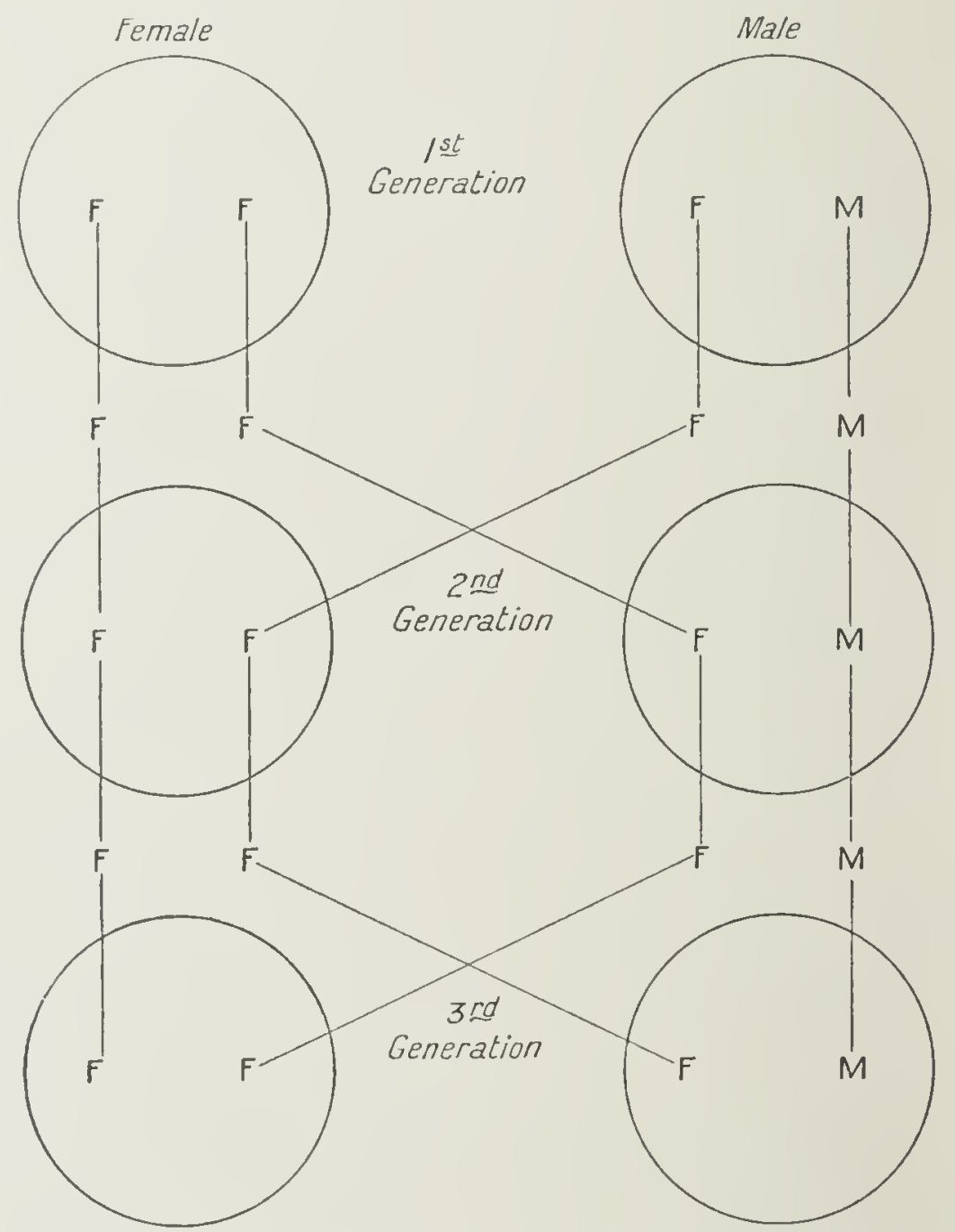

FIG. 27. Diagram illustrating the perpetual splitting of every generation into cqual numbers of males and females, if one sex is homozygotic and the other sex heterozygotic for the sex-determining factors $\mathrm{F}$ and $\mathrm{m}$.

support this view (Correns in plants, and Doncaster in animals, and many others since); but welcome corroboration has come from the observations on chromosomes made by cytologists, more especially by the Americans McClung, E. B. Wilson, Morgan, and Bridges. In the 
first place it was shown that in many insects two types of spermatozoa are produced in equal numbers, one with the normal complement of chromosomes and the other with one of these reduced in size or absent. For example, in the bug Protenor, whereas all the ripe ova have 7 , the full haploid number of chromosomes, some spermatozoa have 7 and others only 6 . Fertilization of the ovum by the first type gives a zygote which develops into a female having I 4 chromosomes in all its nuclei, while fertilization with the second type gives a zygote with $\mathrm{I} 3$ chromosomes,
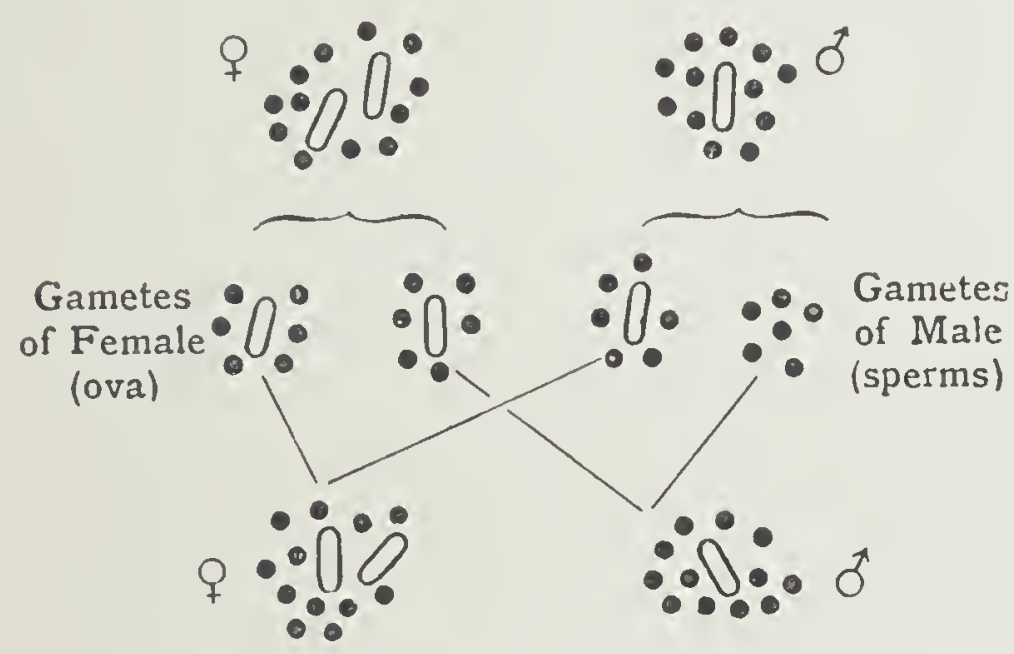

F1G. 28. Diagram illustrating the behaviour of the chromosomes in Protenor. Sex chromosomes represented unshaded, other six pairs of chromosomes black. (From R. C. Punnett's Mendelism.)

which develops into a male retaining this number of chromosomes in all the cells of its body (Fig. 28). Further, when the germ-cells of the male undergo reduction at maturation, the single $\mathrm{X}$ chromosome has no mate and passes into one of the daughter-cells thus destined to produce by division two female-determining gametes; while the sister-cell without sex-chromosome produces two male-determining gametes. There is, therefore, a 'sex-chromosome', called the $\mathrm{X}$ chromosome since it contains a sex-determining factor $(\mathrm{X})$ whose presence in single 
or in double dose determines whether the zygote shall develop into a male or a female. These observations have been extended to other forms, and it is now established that in, at all events, a large number of organisms the egg develops into a male or a female according as it is fertilized by a male-producing or female-producing gamete. Usually, however, the sexchromosomes occur in pairs like the other chromosomes,

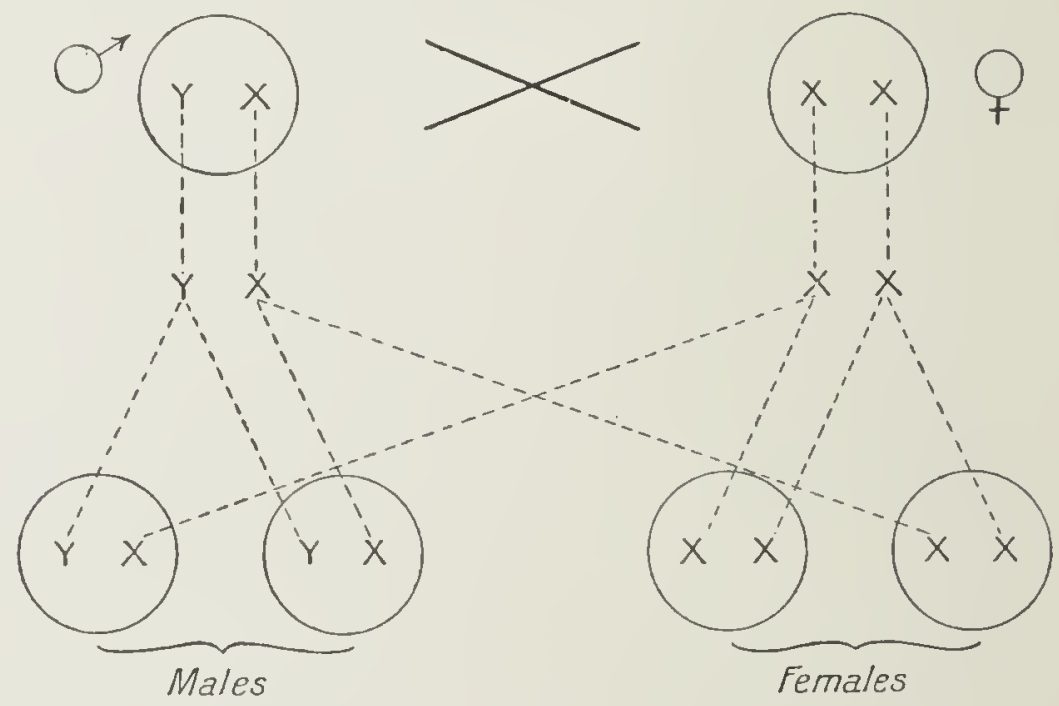

Fig. 29. Diagram illustrating behaviour of sex-chromosomes when a $\sigma^{7}$ of formula XY is crossed with a $q$ of formula XX. Males and females are produced in equal numbers (compare Figs. I9 and 20).

and the one that does not contain the female-determining factor is known as the $\mathrm{Y}$ chromosome. In the vast majority of animals and in man the female is, then, a homozygote of the composition $\mathrm{XX}$, and the male a heterozygote of the composition XY (but in birds and Lepidoptera, strangely enough, the female appears to be the heterozygote) (Fig. 29). Sex, then, would in these cases be determined from the first by the presence of the necessary germinal factors. Yet there are undoubted instances where the sex of an animal is influenced by the 


\section{Determination of Sex}

environment. It should be noted that the 'queen' bee can produce males or females 'at will', for the egg loses an $\mathrm{X}$ chromosome at maturation and, when not fertilized, derelops parthenogenetically into a drone, but if the queen allows it to be fertilized it receives another $X$ chromosome from the spermatozoon and so develops into a female. For in these and many other Hymenoptera, owing to specialization in the formation of the germ-cell of the male, only female-producing spermatozoa are developed. From this, and other evidence which there is not space to deal with in detail but some of which is mentioned below, it is clear that the sex-chromosomes play an essential part in the determination of sex, but that their distribution or behaviour may be controlled from without. In the case of the spider crab, Inachus, attacked by the parasitic crustacean Sacculina, not only does the male undergo 'parasitic castration', and acquire the external characters of the female, as shown by Giard, but, as

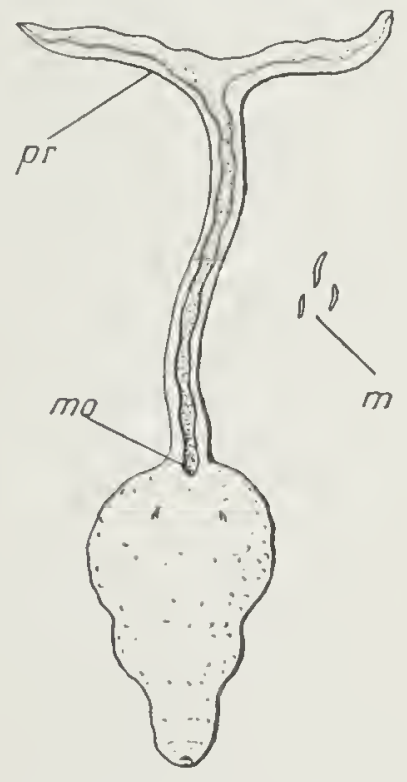

FIG. 3о. Boncllia viridis. Large female, ventral view; mo, mouth ; pr, proboscis ; $m$, three males drawn to same scale. Geoffrey Smith proved, on recovery from the attack the male crab develops ova as well as spermatozoa. Further, Balzer has recently given evidence that the larvae of the strange worm-like animal Bonellia become either female or male according as they live an independent life or become parasitically attached to their mother (Fig. 30). The slipper limpet, Crepidula, has a free-swimming larva which tends to settle down and become fixed on older individuals. Such larvae grow into young male limpets, 


\section{Variation and the Factors of Inheritance}

and later on become females, passing through an intermediate hermaphrodite stage. Gould, however, has shown that if the larva of C. plana should not settle on or quite near an adult female it grows directly into a female without passing through a male stage. Here again the sexual history is determined by the environment. The difficult problem of the determination of sex cannot yet be considered as entirely solved. The evidence seems to show that the sex of an individual may be fixed in different ways and at different times, as mentioned above. Among the Hymenopterous insects, such as the bee, the egg produces a female or a male according as it is or is not fertilized; while in other cases sex is determined by the kind of gamete which fertilizes the ovum. Moreover, although in plants and animals in general the sex of an individual appears to be irrevocably fixed at or before fertilization, according to the chromosomes (carrying sex factors) it receives, yet there is evidence that in certain species it is influenced by environmental conditions. ${ }^{1}$

1 New light has been thrown on the subject by the recent experiments of C. B. Bridges and R. Goldschmidt. The former has shown that in Drosopilila the sex depends on a quantitative relation between the $q$ determining factors carried by the $\mathrm{X}$ chromosomes and the many $\sigma^{7}$ deter. mining factors in the other chromosomes. Thus, when, owing to irregularities in the distribution of the chromosomes, the normal proportion is upset, zygotes will develop into males, intersexes (hermaphrodites), and females according as the proportion of $q$ determining factors increases.

Starting from the fact that crosses between races and species of Lepidoptera frequently produce sex abnormalities, Goldschmidt finds with the gipsy moth, Lymantria dispar, that, by crossing certain selected European and Japanese races, intersexes are regularly obtained. Such individuals start of one sex, and, as the production of sex-determining substances of the opposite sex increases, become at a given point converted into the opposite sex. These results he explains on the supposition that while all the zygotes possess the factors necessary for the development of both sexes, the $\sigma^{7}$ determining factors are in the $\mathrm{X}$ 


\section{V \\ The Struggle for Existence and Natural Selection.}

Of all the primary factors of evolution the struggle for existence is that which lends itself least to controversy. When once stated and understood it must be recognized. Unfortunately, it is not always understood. The phrase is a metaphor to express the undeniable fact that more organisms are born into the world than can survive in it (see p. 4t). As Darwin says, unless 'the truth of the universal struggle for life be constantly borne in mind the whole economy of nature, with every fact on distribution, rarity, abundance, extinction, and variation, will be dimly seen or quite misunderstood'. The enormous rate at which even the most slowly reproducing creatures are capable of increasing is not always fully realized. Organisms have a tendency to increase in geometrical ratio; consequently their powers of multiplication are prodigious. To take an instance quoted by Wallace, a single pair of flies (Musca camaria) produce 20,000 carrioneating ląrvae, which will hatch out into flies ready to reproduce in about a fortnight, giving rise in turn to some 200 milliẹn hungry larvae. Linnaeus did not exaggerate when he; said that a dead horse would be devoured by

chromosome and $q$ determining factors in the $\mathrm{Y}$ chromosome (the $q$ is heterozygous in moths), and that the sex is determined by the relative 'strength' of these two opposing sets of factors and rate at which they act. If a race with 'strong' $\sigma^{7}$ factors is crossed with one with 'weak' $q$ factors a resulting zygote, though starting as a $q$, may sooner or later be converted into a $\sigma^{7}$. 
flies as quickly as by a lion. The fertility of parasites is proverbial: the eggs of tapeworms and other such internal parasitic worms may be counted by the million. Among the vertebrates the fish are the most prolific-a single cod can lay over nine million eggs, though of course they may not all be fertilized. Equally remarkable is the power of reproduction in plants. It has been calculated that a single cholera bacillus would give rise to sixteen hundred trillions of bacilli in a day if propagating freely, forming a solid mass weighing Ioo tons. Doubtless, such unrestrained reproduction rarely, if ever, occurs; but every organism is, so to speak, ready to seize the opportunity of spreading to an indefinite extent and is trying, as it were, to extend its range, to colonize fresh regions. Every available spot, from the top of the highest mountain to the lowest depth of the sea, is invaded, every possible mode of life is adopted, as far as adaptability will allow. The various organisms are packed as tight as possible, exerting mutual pressure. If any one increases, it is at the expense of some other. So the fauna and flora of an old established district are made up of a multitude of interdigitating species, availing themselves of all the resources of the region, fitting close together like the stones of a mosaic, and each occupying that place for which it is best suited. Under ordinary conditions a balance is soon struck, a state of unstable equilibrium established, in which the surviving forms have reached an average number of individuals about which they fluctuate within comparatively narrow limits. The severity of the struggle may vary according to age and the surrounding conditions, but it is never quite absent. Besides the competition for food, for light, for water, for space generally, and the unceasing struggle 
against unfavourable conditions of climate, there is the never-ending war against enemies, parasites, and diseases. All these factors contribute towards the death-rate of the species.

How great are the possibilities of increase and how much they are kept in check under ordinary conditions, is seen when the balance of factors restraining it is in any way disturbed, as for instance owing to some change in the climate or the intervention of man. The occasional immense swarms of locusts, of butterflies or other insects, of lemmings, which sweep over large districts, the great epidemics of diseases, are examples of the temporary removal of barriers to reproduction. Similar expansion of some one species at the expense of others is continually taking place on a small scale even in the most stable fauna and flora. The extraordinarily rapid increase of horses and cattle introduced by the Spaniards in South America, of rabbits in Australia, of terrible insect pests like the Phylloxera which attacked the vines in Europe, or the European gipsy moth (Lymantria dispar), which destroys the forest trees in North America; the spread of the watercress (Nasturtium officinale) blocking the rivers of New Zealand, or the American water-weed (Elodea canadensis) filling the rivers of western Europe; or, lastly, the conquest of vast areas in Australia by the introduced prickly pear;-these are only a few of hundreds of similar cases of the possible result of introducing a species into a new country where it does not meet with the ordinary checks occurring in its native habitat.

Individuals of similar habits stand most in each other's way; therefore, competition is often more severe between closely allied than distantly related forms. It may be most severe within the limits of the species 
itself, between individuals, families, tribes, and social aggregations.

The intensity of the struggle may be judged by the death-rate. In a region where the population has reached a stationary state, the number of each species remains approximately the same. On the average, then, only one out of the whole progeny can survive to represent each parent individual of the previous generation. All except these fortunate individuals are destroyed sooner or later before they have succeeded in leaving offspring to perpetuate their kind. The greatest amount of destruction takes place when the organisms are still quite young.

The struggle for existence, natural selection, and adaptation are so intimately connected, that it is scarcely possible to treat of one of these without at the same time dealing with the other two. While the struggle may be considered as the primary factor, to the action of which the selection is due, it is also the very means whereby adaptation is brought about. The transmission of hereditary factors is, of course, necessary for the selection to be effective. Obviously natural selection acts merely as a sieve, separating individuals so formed as to survive in the struggle for existence, from others which are not. It may be represented equally well as a survival of the fit, or as an elimination of the unfit. This point is worth insisting on, because, strangely enough, it has been often brought forward as a serious criticism that natural selection is, after all, merely a process of elimination.

In the long run those organisms less well adapted to survive will have less chance of le:aving successful offspring behind them, will be crushed out in the struggle, 
will be eliminated. The only difference between the well adapted and the badly adapted in a given environment is that in the first case the total inheritance, the hereditary mechanism or factors, react to stimuli in such a way as to lead to success, while in the second case they do not. Selection, therefore, is between that kind of organization which responds in the right way, and that which does not. If one may be allowed to speak metaphorically, the problem before the organism is to acquire such an organization that under given conditions it will react in the right way. Therefore, those individuals which vary in their hereditary organization in the right direction necessarily have a better chance of succeeding. Success in the struggle is the only criterion of 'right' and 'wrong' in variation. The action of selection, it must be remembered, on the hereditary factors is indirect, since it only acts on the combined product of these and the environment (see P. 5I) - on the characters of the organism as presented to it. It is these characters and their variations which pass through the sieve. The scope of selection is limited to the variations presented; its direction is determined by the environment. This direction will always necessarily be towards better adaptation; adaptation is the key-note to evolution. If the right kind of variation does not occur the organism runs the risk of death, and will inevitably be exterminated if the struggle is severe enough.

When the history of Biological Science in the last fifty years comes to be written, we fancy that the impartial historian will not dwell with much pride on the account of the criticisms of Darwinian doctrines. The violent attacks of theologians, based for the most part on ignorance and prejudice, may be forgiven and forgotten; but 
many of the criticisms from the pens of the biologists themselves are scarcely better founded. It is often said that of late years Darwinism has lost ground, and that natural selection can no longer be regarded as a satisfying explanation of, or even as an important factor in, the process of evolution. Doubtless there is some truth in the saying, at all events in so far as it appears that the doctrine is not what some misguided enthusiasts may have represented it to be, that it does not explain everything, that many problems remain unsolved. Yet the Darwinian theory still stands unassailable as the one and only rational scientific explanation of evolution by 'natural' forces, whose action can be observed, tested, and measured. Nevertheless, the critics are quite right in demanding convincing evidence for cvery step in the argument.

The modern developments of the study of heredity and variation on Mendelian lines, far from weakening the case for natural selection, seem to have definitely disposed of the only rival theory, the doctrine of Lamarck founded on the supposed 'inheritance of acquired characters' (p. 50). Fortuitous changes in the inherited organization, in the complex of factors transmitted, are left as the only elements of primary importance, the only stones of which the edifice is built.

Misunderstanding lies at the root of many of the objections urged against Darwinism. For instance, almost every detractor of natural selection has brought forward with wearisome reiteration the criticism that the theory does not account for the origin of variations. Of course it does not; it was never meant to do so. No one has tried to drive this point home more persistently than Darwin himself: "Some have even imagined that natural 
selection induces variability, whereas it implies only the preservation of such variations as arise ;'... ' unless such occur natural selection can do nothing' (Origin of Species). What selection alone can do is to preserve these variations, and to pile one individual difference on the top of another in the direction of adaptation, leading to ever increasing changes along divergent lines.

Another 'criticism' is that natural selection is not the means whereby adaptation is brought about because organisms must have the desired structure before they are chosen, must be preadapted. But if by adaptation we merely mean the appearance of a favourable variation, the statement amounts to an obvious truism. Further, if by adaptation we merely mean that an organism has such a structure that it will live, all living things are necessarily adapted--viability is the first test they have to pass. Any that fail to satisfy it are eliminated at once. But organisms in competition are further tested in particular directions, and when we can see both the advantage gained and the means whereby it is obtained, the special structure evolved, we speak of it in teleological language as adapted for this purpose. Thus a sense organ becomes specially adapted to receive only certain stimuli; a flower is adapted to be fertilized by insects. Now each step in the formation of such a structure, each fortuitous favourable variation selected to build it up, may, in a sense, be said to have been preadapted. But the word adaptation also implies just that process of gradual building, that continued selection of variations in a particular direction from among variations in all other possible directions, the result of which is represented in the elaborated organ, yet cannot in any intelligible sense be said to be present in each individual step. 
To prove that natural selection is a real working principle, it must be shown that the death-rate is selective. $V$ Unfavourable conditions, diseases, enemies of all kinds, dog the path of every individual from birth to death; the death-rate is consequently enormous, as was shown above. But is it really selective? Are, for instance, the two flies which alone survive out of every 20,000 (p. 103) different on the average from those 19,998 which perish? That is the important point now to be considered.

Doubtless in many cases the death of organisms is due to pure 'accident', causes which exterminate without selective action, as for instance in the wholesale destruction brought about by some natural cataclysm; but such cases must be comparatively rare, and may be neglected. Death of this kind simply fails to select; it does not prevent, it merely delays the work of selection. The survival of the fittest, the elimination of the unfit, is easy enough to prove in the case of well-defined races, species and larger groups, and has been eloquently described by Darwin, Wallace, and others. Every observant naturalist now realizes how intense is the struggle, how rapidly one species can be replaced by another, how completely the geographical distribution, the abundance or rarity, or the extermination of an organism is dependent on the success of its competitors. It is the selective action of this competition, combined with the selective action of the inorganic factors of the environment, which regulates the distribution of living things and the diversity in the fauna and flora found in different regions. If this selective action could be stopped, the whole fauna and flora would soon become almost uni.orm throughout the world and evolution would cease.

The well-known instance of cats and clover, quoted by 
Darwin, well illustrates the extraordinarily complex inter-relationship between different organisms of most diverse structure and most distant affinity. Red clover (Trifolizm pratense) is almost exclusively fertilized by humble-bees, and the abundance of bees in a district is much influenced by the number of mice, which destroy their nests and eggs. Now since the number of mice depends to a great extent on the abundance of cats, these animals will affect the distribution of the red clover in the neighbourhood. So the goats introduced into St. Helena, by eating up the seedling trees, not only destroyed the forests, and greatly altered the general flora and fauna of the island, but have actually changed the climate itself. The notorious tse-tse fly (Glossina morsitans), carrier of the deadly disease germ Trypanosoma Brucei, renders certain districts of South Africa uninhabitable for imported dogs, horses, and cattle; while the distribution of man himself and indeed the history of mankind have been greatly influenced by the mosquito Anopheles, and the malaria parasite which it transmits. But the continuous steady struggle which goes on between more closely allied forms is perhaps best seen in the case of plants. It can be watched not only in the forest and on the mountain slope, in the desert and in the tropical swamp, but also in the garden at our very door. The survival of some forms, the extinction of others less well adapted, the alternate spread of one species and retreat of another as the climatic conditions oscillate from dryness to dampness, from heat to cold, these are familiar to every botanist.

We need not dwell longer on this aspect of the question. These and similar facts are not ignored by the most sceptical of the opponents of Darwinism; nor is their 
significance denied. But they will say-'Granted that the great gaps between the widely divergent forms have been produced by the extinction of the intermediate ones, granted that the struggle between differing species leads to the selection of the best adapted, these well-marked "species" were already present. Show us,' they will ask, 'selection between varieties differing but little from each other, and between the individual variations themselves.' Instances of the success of mere 'varieties' are not unknown. Of late years it has been observed that dark varieties of various moths have tended to increase in northern England, and may even have superseded the original pale forms, as in the case of the peppered moth (Amphidasys betularia). Familiar to us all, though perhaps rarely understood, are the constant struggles between the various races of mankind, which have played and still play so large a part in the history of the world; here there is ample material for the study of the selective value of all sorts of racial characters. More difficult is it to demonstrate the action of selection among individuals, and to express the result in statistical form. Only on rare occasions can we directly compare the eliminated individuals with the survivors. One good example we owe to the American zoologist Bumpus. After a severe storm he collected i 36 injured specimens of the common sparrow (Passer domesticus); and out of this number 72 revived, while 64 did not recover. On measuring all the birds, and comparing the dead with the survivors, it was found that the former on the average were heavier and larger than the latter; but significant also was the discovery that the range of variability was distinctly smaller among the survivors than the eliminated, thus proving that those individuals which departed least from 
the 'ideal type' had on the whole the best chance of surviving. Weldon has also shown, in the case of a terrestrial mollusc, Clausilia laminata, that extreme variations tend to be eliminated. Selection of this kind preserves the mean character of the race. Tower obtained the same results on comparing Chrysomelid beetles (Leptinotarsa decemlineata) before and after hibernation; the extreme variants died off, and the survivors approached nearer to the mean.

The fact that many commonly occurring mutations, such as albinism or variegated leaves among plants, fail to establish themselves is also clear evidence that constant elimination of these variations in individuals must take place.

Of all the agents of elimination among human beings disease is the most potent in modern times, as Reid and others have well shown. Some notion of the death-rate and its causes in the human species may be gathered from the official government reports. In the year 1909 there died in England and Wales $5^{18,000}$ individuals (in round numbers), of whom 100,000 were infants under one year of age. Some i 8,000 persons were killed by violence or accident, while the remaining 500,000 died of disease. Of these tuberculosis carried off 55,000 , pneumonia 36,000 , cancer 32,000 , measles I 2,000 , diarrhœa 10,000, influenza 9,000, whooping-cough 7,000 , diphtheria 5,000, scarlet fever 3,000 , enteric fever 2,000, and other diseases smaller numbers. This death-rate is selective in so far as it affects the fertility and prevents the reproduction of susceptible individuals.

The germs of most of these diseases are so widespread that infection cannot be avoided; therefore a constant elimination takes place of individuals unable to resist 
their attacks. If the resistance to a particular dangerous disease is 'natural', that is to say depends on characters developed in the ordinary environment, then natural (socalled innate) immunity is soon established by selection, and the disease is eventually stamped out, only immune individuals surviving. But if resistance depends partly or entirely on ' acquired immunity,' developed only under the stimulus of the disease itself, then the disease will persist, but become less dangerous as the capacity to resist it is increased by selection of the individuals who recover most easily. How effectually selection acts is realized on observing the rapid and fatal spread of infectious diseases imported by one race into a region inhabited by another race where they were not previously prevalent. Unless the invaded race happens by chance to be preadapted to resist the new disease, it falls an easy victim. Naturally each race is only adapted by selection to resist the diseases of its own habitat; town life is as fatal to the prairie Indian as winter frost to the tropical plant.

Disease has played a most important part in the evolution of the human races. It is not so much by acts of violence that the Spanish and other invaders of America or the European colonists of Australasia have conquered and almost exterminated the native inhabitants of those countries as by the introduction of diseases the natives were unable to withstand. Small-pox, measles, and tuberculosis have almost cleared the fine indigenous races from off the North American continent, severely handi$x$ fcapping them in the struggle against their European rivals. This is merely another instance of the constant struggle between species or varieties which we have discussed above.

There can be no doubt, then, that the death-rate is 
selective. The next point we have to deal with is the part played by selection in the process of evolution. What will be the effect of selection on succeeding generations; or, in other words, what will be the combined effect of elimination and inheritance? It has been far too easily assumed by Wallace, and other writers, that the result of the continued selection of any character must necessarily lead to its gradual increase. For instance, it was supposed that if, out of a number of birds varying in wing-length from 5 to 7 inches, with a mean of 6 inches, individuals with a wing-length of 7 inches were chosen for breeding, the mean length of the wing of the offspring would be raised. And that if for a number of generations the parents were always selected from among the birds with greatest wing-length, the average wing-length of the progeny would be gradually raised from 6 to 7 inches, from 7 to 8 inches, and so on indefinitely, so long as the selection continued. But this is not necessarily the case. ${ }^{\text {? }}$

In the first place, if the variations selected are modifications induced by the environment in individuals endowed with the same hereditary factors, no cumulation at all will take place, however much the selection may be prolonged. Thus the selection of individuals which have become immune to a disease in the course of their lifetime will not increase that immunity, nor free the progeny from the necessity of becoming immune, unless the capacity to acquire immunity itself varies and is selected.

1 Whether the direction of variation is influenced by selection, whether the continued selection of a character and indirectly of its germinal factors encourages their further development, is indeed a most fundamental question. At present, howerer, it cannot fully be answered, since the evidence is quite uncertain. On the whole, current opinion is against the view. 
To take a simpler case---that of the beans mentioned on p. 63. Selection of the heaviest bean-seeds from any one strain or pure line of uniform hereditary capacity will not alter the mean weight of seeds within that strain; the offspring of such a selected bean is no more likely to be heavier than is that of any other bean from the same strain (since its greater weight is due to the incidence of certain environmental conditions not dealt with by the selection). But if heavier beans are selected from the whole group of strains, differing in their hereditary capacities, then the mean weight of the offspring will be raised, and raised rapidly to the highest possible levelthat of the strain with the highest mean weight. For since there are more heavy bean-seeds among those belonging to the strains with the higher mean, they will have a better chance of being selected. The offspring of lines with lower mean weight will be gradually eliminated, and at last only those of the strain with the greatest mean weight will remain. Obviously the same result would be reached at once if this strain could be distinguished at the beginning of the experiment, and alone chosen for propagation. Moreover, the effect of selection will come to a stop as soon as this highest point is reached; unless in the meantime new changes have arisen in the hereditary factors, leading to further possible increase in weight. This limitation is a necessary consequence of the sievelike action of selection-it can only select what is already there. It follows that, unless mutations occur, selection within pure lines can be of no effect: a conclusion borne out by the experiments of Morgan on Drosophila, of Jennings on Protozoa, and of many observers on plants. As already explained, the modifications due to the environment do not materially alter the results of selec- 
tion, which acts only by the indirect choice of particular hereditary constitutions. Cumulation of results can only take place in so far as new mutations occur in the required direction.

The same conclusions have been reached on statistical grounds, and may be expressed as follows. Comparing the characters of offspring with those of parents, grandparents, and great-grandparents, it is found that the resemblance decreases rapidly; so that the 'correlation' with parents is about $\frac{1}{2}$ or 0.5 , with grandparents 0.3 , with great-grandparents $0 \cdot 2$, and so on. The 'correlation' is the ratio expressing the deviation of each generation from the mean of the species. This is the "law of ancestral inheritance' worked out by Galton and modified by Pearson. Pearson has defined it as a rule for predicting the average value of a character in the offspring from the value of that character in the ancestors. From this point of view, therefore, the contributions to inheritance from distant ancestors are negligible, and selection through very few generations is sufficient to yield a practically pure and constant race.

As was long ago pointed out by Darwin, the method and results of natural selection are quite comparable to the methods used and the results obtained by man in artificial selection. Darwin's view has been brilliantly confirmed by the modern work on Mendelian lines. The wonderful diversity of domestic races of plants and animals, showing all sorts of new developments in size, shape, and colour, in function, habits, and mental qualities, is due, often with the help of hybridization, to the selection of individual variations in this or that direction. One mutation after another is isolated and bred from, and so almost any desired form is obtained. Hence the 
great importance of discovering what causes factorial changes (p. 95); for the present we can only wait for a mutation to appear. In the meantime, the breeder can accomplish a great deal by crossing different races and so building up a clesirable complex of factors.

Now it is often maintained that these domestic varieties are not of the same value as natural races; that it allowed to roam wild, or if selection be relaxed, they return to their original condition, degenerate, or regress. This conclusion is, however, mostly based on misconceptions. There is no good reason to believe that domestic races are fundamentally different from or inferior to natural races, either in mode of formation or in constancy when formed. If they are generally unable to compete with wild races when let loose, it is because they have not been selected with this end in view. If they appear to degenerate when removed from the care of man, it is because they no longer enjoy the exceptionally favourable conditions of abundant nutrition, protection from enemies, and so forth. Those domestic races which fail in the struggle for existence among wild competitors are like natural species which, when introduced into a new country, fail to establish themselves because the conditions are unsuitable.

But what, it may be asked, is the effect on domestic races of mere relaxation or cessation of selection? The race will probably tend to regress-that is to say, to return to the original form from which it was selected. There is true regression and false regression. The latter is brought about by the crossing of the new variety with the original species with which it may now come into contact. This kind of regression by hybridization, as de Vries has shown, is very difficult to prevent with plants 
fertilized by wind or by insects. It leads to the formation of intermediate forms; but the new hereditary constitution can never be quite suppressed by mere crossing. True regression is due to the tendency of the offspring of parents which deviate from the mean to return to that mean of the race; it is the inevitable consequence of the interbreeding of individuals endowed with unequal inheritance. If the race is quite uniform, composed of homozygotes with the same hereditary factors, there can naturally be no regression, it will breed true; this has been well established by numerous and prolonged experiments. But if there is inequality of inheritance ever so slight, regression will take place on the cessation of selection. It is a universal phenomenon common to all impure races, whether artificial or natural. In the foregoing chapter it has been shown that natural selection acts by eliminating the unfit and so leaving the fit to continue the race; that this selection is effective not only between widely divergent forms, but also between individuals differing from one another by ordinary variations; and lastly, that the process of natural selection is strictly analogous to that of artificial selection practised by man. But some important points still remain to be discussed.

Are variations continuous or discontinuous? is a question which has given rise to much controversy. Continuity here means gradation of variation from one extreme to another, so that, with regard to the measurement of a particular character, the individuals of a race could be arranged in a series leading gradually from those having the character developed to its greatest extcnt to those in which it is least developed. The more gradual the transition, the more perfect the continuity, the more 
even would be the curve formed by the ascending series. We have already seen (p. 46) that when dealing with large numbers of individuals most characters conform to this rule and vary continuously. On the other hand, discontinuous variation would give rise not to a graduated curve but to a series of steps or jumps, from one stage to the next above. A tendency towards discontinuity is shown in 'meristic' variation. Thus, a cell will either remain single or divide into two, the antenna of an insect may have four, five, or six joints, the number of dorsal vertebrae in a mammal may vary from twelve to thirteen, or from thirteen to fourteen, and so on. But even meristic variations need not be discontinuous, and seldom is gradation more perfectly shown than in the variation of segmental nerves in the plexus supplying the limb of a vertebrate.

The whole subject has been greatly confused by the failure to distinguish between continuity in the variation of characters and continuity in the changes of hereditary factors. Modifications may vary continuously, because the incidence and quality of the factors of the environment are due to chance. Mutations may appear discontinuous if the causal changes in the factors are of such a nature as to produce a striking effect, while in other cases they may be of moderate or even of the minutest size. No hard and fast line can be drawn between 'sports' and small variations. But the variation of characters due to mutation may also be more or less continuous, owing, for instance, to their reactions being modified by other factors, as in incomplete dominance (p. 82). Again, an apparently simple character may become more and more pronounced when it is really a complex character, depending on the co-operation of a number of separate 
factors reinforcing each other-as with the red colour of wheat studied by Nilsson-Ehle, which develops only to its full extent when three factors are all present. The colour of the eye of Drosophila varies by delicate gradations from red to white; this is a case of multiple allelomorphism where one factor has changed in six different ways giving intermediate stages, and the steps between them are still further reduced to almost imperceptible dimensions by the action of other factors which modify the result. Also large numbers of intermediate forms are necessarily produced when two races are crossed differing from each other in several factors, and the differences between the characters of two widely divergent forms may thus be bridged over by a series of gradations; but in these and the other cases just mentioned there is, of course, no proof that in phylogeny one extreme form has been derived from the other through a series of such small transitional steps. Whether the factors themselves may show grades of strength and development is also still a disputed point.

Here may be mentioned the recent researches of Jennings on the Protozoon Diffugia, of Castle on rats, and of Morgan on Drosophila, all of which yield incontrovertible evidence of the occurrence of 'continuity' in mutation-that is to say, of the possibility of isolating strains differing from each other by quite small characters or in the degree of development of some one character, and of gradually increasing the character by selective mating. These results may be interpreted as due to the cumulative effect of numerous modifying factors brought to bear successively on the unit factor of the character.

Like modifications, then, mutational variations may be continuous or discontinuous, and there is no hard and 
fast distinction in size between the two kinds. An interesting question we have now to consider is whether large or small variations are the more important in evolution. Darwin was uncertain on this point, but finally came to the conclusion that natural selection dealt chiefly with the smaller. Certainly they are the more numerous, and, considering how severe may be the struggle for existence, it can hardly be doubted that they greatly influence the death-rate. The attempts which are sometimes made to fix an arbitrary limit to the 'selection value' of a character are futile; it all depends on the intensity of the struggle at any particular time. A character, useless during the greater part of the life of an organism, may prove of vital importance on a particular occasion. The slightest difference in weight between two seeds carried by the wind may decide that the one will reach a favourable spot and not the other; the smallest inferiority in powers of resistance may cause one man to perish of a disease while another recovers. Nevertheless, selection is of course ready to avail itself of large variations or sports, if they are in the right direction. However, it has been shown above (p. I I 2 ) that extreme variations seldom succeed, doubtless because they tend to upset that nice adjustment of parts, that harmony of function so essential in competition. Indeed, we can hardly imagine that the complex adaptations so commonly found, the marvellous cases of protective resemblance between organisms and their surroundings, and similar developments, could have arisen otherwise than by the accumulation of small differences step by step.

For it must never be forgotten that variation is not itself adaptive. Obviously if it were adaptive, a species would never become extinct, since the right 
kind of variation would then always be present to meet the demand. Variation, on the contrary, is blind, fortuitous, but takes place in many directions. Great as may be the number of possible directions, it is not infinite. In a sense, variation is limited, limited by the structure and composition of the substance which varies; and all changes in the hereditary constitution are, in the end, due to additions to, subtractions from, or rearrangements in factors already present. It should not be forgotten that in allied races the bulk of the large number of factors is the same, and that mutational changes only affect a few of them. Therefore, new developments are greatly influenced by the general hereditary constitution of the race, and, we may add, some sorts of mutation are liable to occur more often than others, and repeatedly in the same or even in different groups (albinism, \&c., see p. 77 and 84).

The next point to consider concerns the usefulness of characters. It is often urged against the theory of natural selection that many characters are useless. Now, we have just maintained that variations of whatever kind are not adaptive - they may be useful, harmless, or harmful. But this does not invalidate the Darwinian doctrine; on the contrary, if variations were always useful selection could not take place. But if it could be shown that a cumulation of harmful or even useless variations had occurred, we should have a serious difficulty to deal with. Darwin used to say that a single instance of such useless evolution would be fatal to his whole theory: it need hardly be added that none has ever been found.

Natural selection can n€ver be prophetic; organs cannot be developed before they are needed. Certainly organisms may on rare occasions by chance, so to speak, 
find themselves ready adapted to meet new conditions; so protoplasm may possess properties which have never yet been made use of in the struggle for existence-as, for instance, the power of responding to galvanic stimuli. But every step in the process of evolution by selection must of necessity be useful, must lead to survival.

Apparent exceptions to this rule may be due to correlation. Factors of inheritance are able to affect not one but several characters, or even the whole organism, so that alteration of a character by selection may lead to correlated alterations in other parts. Thus changes may be brought about not for their own sake, and characters useless or even harmful may be developed, so long as the advantage gained is not counterbalanced. Correlation plays an important part in evolution. Its importance is fully recognized by geneticists. It has been elaborately studied mathematically by Pearson and others, and has been proved to occur extensively, and often in most unexpected directions.

At the same time, the tendency shown by the detractors of Darwinism to assert that this or that character is useless because they cannot find a use for it, is strongly to be deprecated. Every day naturalists are discovering the functions of the most insignificant-looking organs. Little importance can be attached to the statement often made that the characters which distinguish nearly allied species are of no value to them; in fact no character should be accepted as useless until it has been definitely proved that it exerts no influence on the death-rate. Some few years ago it might have been held-indeed it was held-that such organs in man as the thyroid gland, the pituitary gland, the suprarenal glands, and others, are useless structures, functionless vestigial remnants. 
They are now known to be of the greatest importance, altering the composition of the blood or secreting substances essential for the regulation of the processes of metabolism. He would be a rash man indeed who would now assert that any part of the human body is useless (p. I $+\mathrm{r}$ ).

The same may be said of the coloration of organisms, and the rash statements so frequently made as to the ueslessness of the differences in colour which so often distinguish species from each other. Doubtless colour variations are not adaptive, and the colour differences between species are not necessarily adaptive either. Their development may be due to correlation with other useful characters. Yet many possible uses of coloration have been brought to light by the labours of Bates, Fritz Müller, Wallace, Poulton, and others, showing that it may often be of the greatest importance in the struggle for existence: as in the case of the protective resemblance to surroundings enabling an organism to escape from its enemies or to approach its prey unnoticed (Fig. 3I); of warning colours exhibited by animals well able to defend themselves with poisonous weapons; of mimicry where a species gains advantage by acquiring a resemblance to some distasteful or dangerous form ; of recognition marks or sexual ornaments which serve to bring the sexes together. An interesting experiment on the selection value of colour differences was performed by Di Cesnola on the praying mantis (Mantis religiosa). This insect occurs in Italy in two varieties, a green and a brown, adapted for concealment on green or brown surfaces; and it was found that green specimens placed in brown surroundings and brown specimens placed in green were invariably eaten by their enemies, while 


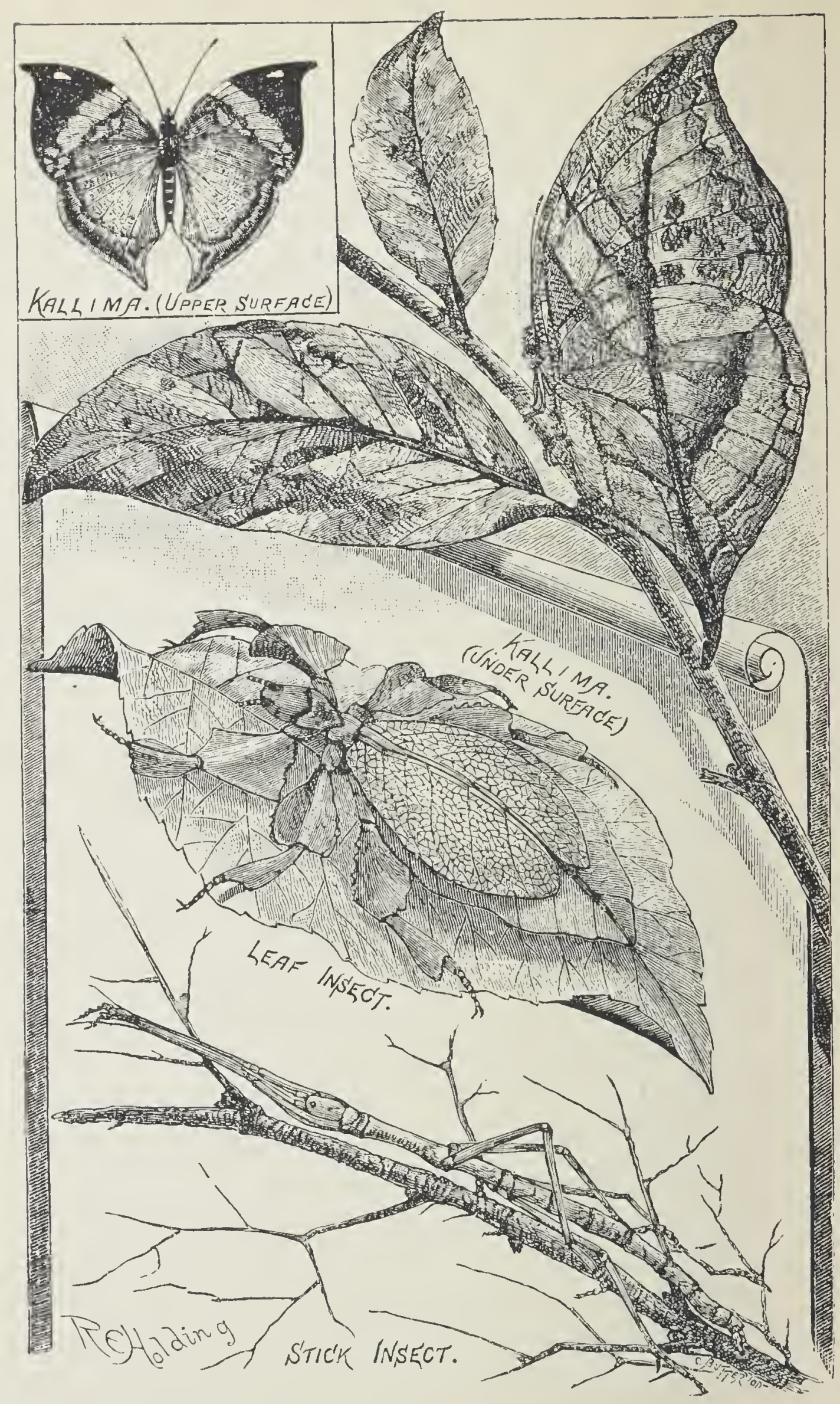

FıG. 31. Protcctive resemblance to surroundings, three examples from insects. (From G. J. Romanes, Darwin, and after Darwin.) 
individuals on a background which they matched frequently escaped destruction.

There was a difficulty much felt by the early advocates of natural selection which has been removed now that the process of inheritance is better understood. It was thought that a variation which appeared in one or even in several individuals of a species would have little chance of establishing itself, since it might be reduced and finally swamped by constant interbreeding with the more numerous individuals of the species not possessing it. Such a swamping by intercrossing, however, does not occur. We have already seen (p. So) that factors of inheritance are as a rule transmitted complete; even when the appearance of the character to which it gives rise is subject to various inhibiting influences, it is liable at any time to reappear in full force, as is seen in reversion. Characters due to factors of inheritance will persist unless eliminated by variation and selection, as can be shown by experiments and by mathematical reasoning. The relative scarcity of the mutation at the start does not prevent that a number of individuals interbreeding at random, some with and others without a certain factor, will give rise to a population of impure heterozygotes and pure homozygotes in which the proportion of the three classes will be in equilibrium so soon as the square of the number of heterozygotes equals the number of pure 'dominants' multiplied by the number of pure 'recessires' (G. H. Hardy). If this proportion is not already present at the beginning it will soon become established, and will continue, provided there is no selection to disturb the equilibrium. In fact a species of interbreeding individuals of unequal hereditary constitution soon reaches a state of stability. Only selection can eliminate a mutation. 


\section{VI}

\section{Isolation and Sexual Selection.}

FREE intercrossing can only mix hereditary strains, hence the necessity for isolation if divergence along various lines of adaptation is to take place. The importance of isolation has been variously estimated by different authors; but it must not be forgotten that it plays a subsidiary part in evolution, and can do nothing without selection and variation. Selection without isolation may give rise to evolution in a straight line; combined with isolation it may lead to divergence into as many lines as there are groups of individuals isolated. There are several kinds of isolation: geographical, anatomical, 'physiological', and isolation due to the adoption of different habits and modes of life.

Means of dispersal are various. Some organisms are borne passively by the wind, as seeds and microscopic plants and animals, others by water currents, and still others by their own activity move from place to place. In one way or another species are always trying, so to speak, to spread over a wider area. Land organisms become geographically isolated by the formation of barriers such as deserts or mountain ranges, or by the separation of parts of a continent as islands. Marine organisms may be divided by the uprising of dry land, and the inhabitants of fresh water by the separation of river basins. But whatever may be the barrier which cuts off more or less completely a number of individuals from the main stock, the result is the same-they tend to diverge from the parent species; so we find that uniform species invariably have a continuous distribution. This 
"(1) divergence is due to differences in the environment directly or indirectly modifying the individualso to the new fauna and flora with which the isolated specimens come into contact altering the course of selection, and lastly to the appearance of new mutations. Thus many local races or species become differentiated; and when a number of closely allied forms occupy neighbouring regions, they are more unlike, generally speaking, the farther they have strayed from the original centre of distribution. The more complete and the older the barrier the greater will be the divergence. Thus the marine and littoral fauna on the opposite coasts of the isthmus of Panama differ considerably, but differ far less than does the fauna of the Mediterranean from that of the Red Sea, these seas having been separated for a much longer time. In the Sandwich Islands there are some 300 species of the genus Achatinella, almost every valley having its own peculiar form of this mollusc. A similar variety of structure has been described by Sarasin among the land molluscs of the island of Celebes, where species become subdivided into an astonishing number of local races still united by transitional forms. Islands afford excellent illustrations of divergence through isolation. While their fauna and flora bear a general resemblance to those of the nearest mainland, each island or archipelago usually acquires a remarkable number of peculiar forms. For instance almost every one of the West Indian islands has its representative species of the golden oriole. The Galapagos archipelago has its own reptiles, insects, and land molluscs; out of some thirty species of land birds about twenty-eight are peculiar, while each one of these islands has developed its own race of the gigantic land tortoise. 
Another kind of isolation is that brought about by parasitism. Since every parasite tends to restrict itself to one particular kind of host to which it is closely adapted, being often actually transmitted from one individual to another, a parasitic species tends to split up into as many divergent races as there are kinds of host, until finally each host species may acquire its own peculiar species of parasite. A somewhat similar subdivision and specialization takes place in plants fertilized by insects. The flowers tend to become specialized in structure and colour to attract particular kinds of insects, while the insects undergo a corresponding specialization in order to derive nourishment from the flowers.

Physiological (including psychological) isolation may result from incompatibility of habits or temperament or from sterility (see also p. I49). ${ }^{1}$ Closely allied rival forms often meet or overlap in some region, yet interbreed little, or not at all, although quite capable of forming a fertile union and of producing fertile offspring. A familiar instance is that of the negroes and whites in America. Sterility in one form or another is the most

${ }^{1}$ One may distinguish between fecundity, or the capacity to produce ripe germ-cells, and fertility, or the capacity to produce living offspring. Capłivity or domestication very commonly reduces fertility and doubtless fecundity as well. Mere inbreeding, however, which has often been considered to lead inevitably to sterility, has been shown in many cases to produce no such unfarourable result, provided fertile individuals are selected. For instance, Castle inbred a poly dactylous race of guineapigs (originating from a mutation in a single parent) for more than ten years; and, with Drosophila, brother and sister have been inbred for some sixty generations without evil effect. In nature, also, cases are known of prolonged self-fertilization. It has recently been shown that sterility may have a definite factorial basis, and may be due to the combination of certain Mendelizing recessive factors (so-called 'lethal' factors), which adversely influence the fecundity of the parents or the viability of the offspring. 
important physiological barrier, and may be due to many different causes. For instance, interspecific sterility, may result from divergences in the structure of the cepulatory organs, as in numberless kinds of insects; or merely in their size or shape. Intercrossing may also be prevented if sexual maturity is reached at different times of the year; and self-fertilization is made impossible for most hermaphrodites by the

(3) spermatozoa developing either before or after the ova in the same individual. Lastly, isolation may result from some variation in the germ-cells themselyes, causing fertilization to be imperfect or sterile even if it take place; this may be called true sterility, and is doubtless often related to differences arising between the protoplasm of diverging groups, rendering them incompatible (see p. I,36). Further, the zygotes when formed-may fail-to-develop normally, or even if viable the hybrid offspring may themselves be sterile inter se, or even with the parent species. This form of sterility is common among plants and animals; the mule produced from a cross between the horse and the donkey is the most familiar instance. In these various ways, then, a barrier is set up and divergences inevitably arise among groups of organisms originally alike, and evolution in its course moves along ever-branching paths.

If a higher organism is to succeed in the struggle for existence it must reproduce itself sexually; hence the importance in evolution of the various adaptations for securing the fertile union of the sexes. The differences between the two sexes, other than those of the reproductive organs themselves, are known as secondary sexual characters. Many are of such a kind as to enable them to find and recognize each other, and to accomplish the 
act of copulation. To this class belong the diverse organs developed in all sorts of animals for grasping the female, the call notes of many insects, birds, and mammals, and the strong scents given off by female hawk-moths, male musk-deer, and stags, and other animals at the time of maturity. Conspicuous sexual differences are often produced by the development in one sex of special organs to receive stimuli from the other, as for instance in the Crustacea, or in the Insecta, where the olfactory organs, the antennae, may be greatly enlarged and modified in the males.

But there are many other secondary sexual characters the use of which is by no means so obvious-such as the beautiful patterns and colours developed in male butterflies and other insects, the marvellous wealth of ornamental colours and plumage in birds, and offensive weapons like the antlers of deer-and it is one of Darwin's greatest triumphs to have given us in the theory of sexual selection a rational explanation of the evolution of these apparently useless characters. No hard and fast line can be drawn between natural and sexual selection. Sexual selection may be considered as subordinate to natural selection, as a special kind of natural selection taking place within the limits of an interbreeding set or 'species' of animals. It is due to the competition between individuals of one sex for the possession of the other. Almost always it is the males which compete for the females, either because they are more numerous or because they are polygamous. This kind of selection takes place only among highly organized animals, and is almost entirely restricted to the vertebrates and arthropods (insects and spiders). It has been aptly called the struggle for wife as opposed to the struggle for life; but 
failure means, in the end, extinction in the one case as in the other.

Darwin has convincingly shown how severe is the competition between the rival males, how universal is the law of battle, leaving the most agile, the strongest, and the best armed in possession of the field. The general superiority of the male sex in strength, pugnacity, and fighting weapons, such as the large canine teeth of male mammals and the antlers of stags, is accounted for by the survival of variations leading to victory in the fierce struggles which take place between the males at the breeding season. The correctness of this view can hardly be doubted; but there is great divergence of opinion when the principle of sexual selection is applied to the more purely ornamental secondary sexual characters. ${ }^{1}$ These characters are very commonly developed among: the higher animals, and one may mention as examples the mane of the lion and bison, the ornamental patches of colour and hair in monkeys, the beard in man; the brilliant wattles and plumage in numberless birds, such as the gorgeous feathers of pheasants, peacocks, birds of paradise, and humming-birds; the ornamental colours in many fish, butterflies, and spiders, the horn-like processes of beetles, the attractive scents of butterflies, the vocal sounds emitted by insects, frogs, and mammals, and the beautiful song of birds. Darwin pointed out that these brilliant and striking characters appeal to the senses of

1 The question is more complicated than was originally supposed, and there is no doubt that Darwin's theory must be modified and supplemented. It has been pointed out that in many cases courtship is concerned rather with the stimulation of the sexual instinct than with the choice of a mate, and may take place after the mate has been chosen. According to Howard, the song of many birds is to a great extent concerned with the occupation of special 'feeding territories' and the warning off of rivals. 
the female, and are deliberately displayed to her at the breeding season. Courtship with these animals is often a lengthy and elaborate business, during which the male may perform a regular dance and strike attitudes to display himself to the best advantage. The more attractive male will thus secure his mate more rapidly and certainly than the less happily endowed, or, in the case of polygamous species, will be followed by a greater number of females. Even if the less successful males eventually manage to pair, they will not have such good or so many chances of leaving offspring. A small percentage of advantage in this respect is sufficient to bring about a selective result. Now it is characteristic of such structures and colours that they develop only in one sex and generally only at maturity; frequently, as in birds, they are periodically renewed at each breeding season. Moreover, they appear only on those parts which are displayed in courtship.

Much scepticism has been shown concerning the efficacy of sexual selection as a factor in evolution, chiefly on the ground that the theory seems to presume an aesthetic taste and power of choice in the female. But this criticism is due, at all events to a great extent, to a misunderstanding of the metaphorical language in which it is convenient, if not necessary, to describe such facts. Strictly speaking, 'choice' and 'taste ' are here but words to express the fact that the female is more stimulated by one kind of form, colour, scent, or sound than by another. In physiological language it is all a matter of stimulus and response; those males will succeed best which most effectually stimulate the females. Doubtless in many cases, here as elsewhere, the facts are but incompletely lnown; but in others the evidence is convincing enough. 
We will here mention only one instance, that of the spiders of the family Attidae, so thoroughly studied by Mr. and Mrs. Pecliham (Fig. 32). These very competent observers show clearly, that when the sexes are differentiated the males are the more brilliantly coloured; that the

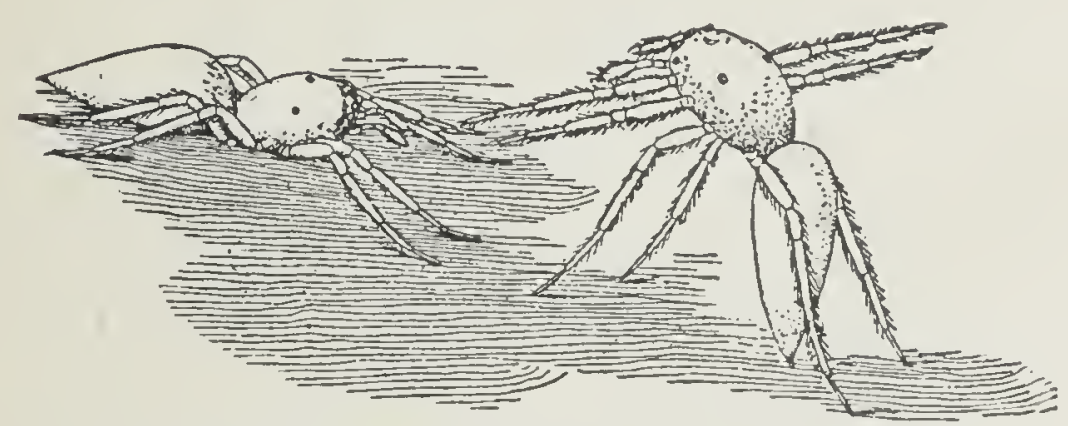

Fig. 32. Two spiders, Marfusa familiaris, in courtship. Female on left, male on right. (From G. W. and E. G. Peckham, Observations on Sevual Selection.)

young male resembles the adult female, and that it is the adult male that has departed from the ordinary ancestral colouring; that the male colours are visible and displayed during courtship; that the females pay attention to them and exercise a 'choice'; and lastly, that the more brilliant males may be selected again and again. Moreover, it must be remembered that sexual selection is known to occur in the pairing of the human species, and that its selective value has been statistically estimated.

Wallace has pointed out that natural selection must oiten compel the female to keep to a more modest and protective type of coloration than the male; for, until she has laid her eggs or reared her young, a female may be more essential for the propagation of the race than a particular male; and there can be no doubt that protective coloration or structure, mimicry, polymorphism, and other such factors, greatly complicate the problem of the evolution of secondary sexual characters. 


\section{VII}

\section{Pliylogeny and Classification.}

IT is the task of the anatomist and systematist to study and compare the structure of adult organisms (Comparative Anatomy or Morphology), and also their development (Embryology), in order to make out their affinities, to discover the lines of descent which connect the various diverging branches of the genealogical tree. These branches are called Phyla, and Phylogeny is the name given to the study of the pedigrees of organisms, the tracing out of their blood-relationships. ${ }^{1} \quad$ A true natural classification is based on phylogeny. Much valuable evidence for this science can be derived from Palaeontology, the study of fossil extinct animals and plants, which may reveal the aciual ancestral forms or their near relatives; but a great deal can be gathered also from a knowledge of the structure and development of the living.

1 We all know the difference between beef and mutton, and as we find out more about the chemical composition and properties of the substances forming the tissues of organisms it becomes increasingly clear that they differ, be it ever so slightly, in different forms. This specificity is shown, for instance, in the haemoglobin red colouring matter of the blood of vertebrates which has been shown to vary slightly in different species, and usually the difference is greater between distantly than between nearly related species. The same can be said of other proteins, as is proved by experiments on immunity which is specific for the protein used; or grafting where the graft will grow well only on an individual of the same species, \&c. In other words, the differences there may be between the factorial inheritance of individuals, however slight, are reflected in all the products of their activity. There has been a phylogenetic divergence of chenical composition as well as of grosser structure. 
Since forms which differ widely in the adult condition often resemble each other much more closely in the young or embryonic stages, by observing their development affinities can sometimes be discovered which would not otherwise be suspected, or at all events would be very doubtful. Familiar instances are those of the Tunicates

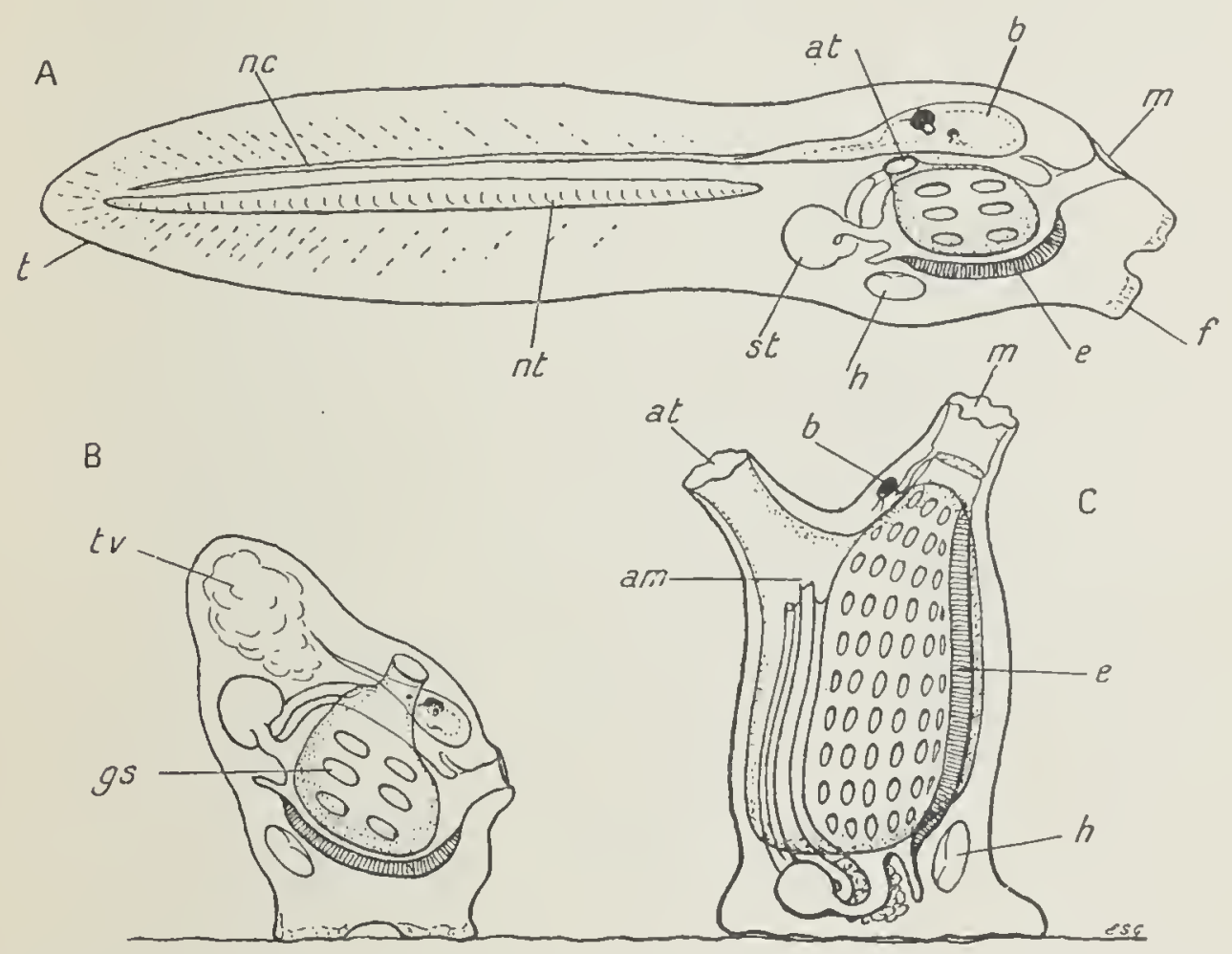

FIG. 33. Three stages in the life-history of a Sea-squirt or Tunicate. A, free-swimming larva with hollow brain, nerve-cord, notochord, and pharynx with gill-slits characteristic of a Vertebrate. B, fixation of larva with loss of notochord. c, adult fixed animal with solid brain, and no notochord; $a m$, anus; $a t$, opening of atrium; $e$, endostyle; $f$, fixing organ; gs, gill-slit; $h$, heart ; $m$, mouth; $n c$, nerve-cord; $n t$, notochord; $s t$, stomach ; $t$, tail ; $t v$, vestigial degenerating tail.

and Cirripedes (Figs. 33 and 34). The former are the Sea-squirts, sedentary animals for the most part, which have undergone degeneration owing to their peculiar mode of life. The adult lives fixed to the sea bottom, and is of very simple structure, showing little resemblance to an ordinary vertebrate, yet the young free- 
swimming larva has all the characteristics of the Vertebrate phylum, with its dorsal central nervous system, gillslits, axial skeletal rod or notochord, and tail (Fig. 33). The Cirripedes or barnacles likewise have taken to a fixed habit in adult life, and have lost almost all resemblance to the Crustacea from which they have been

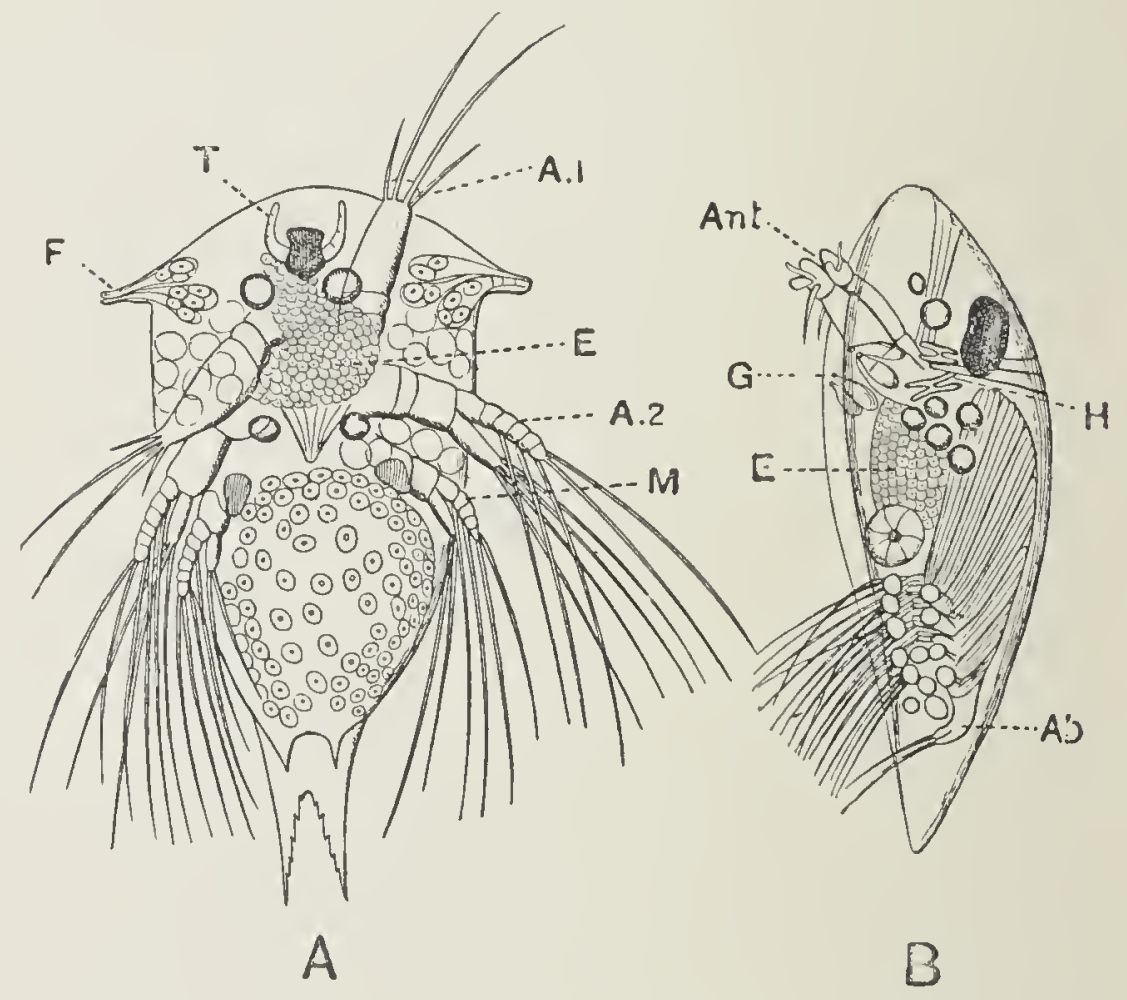

FIG. 34. A, early and, B, later free-swimming stages in the development of the parasitic Cirripede, Sacculina neglecta. A, nauplius larva with three pairs of swimming limbs. B, with antennae (Ant.) modified for fixation on host. The adult stage is shown in Fig. 35. (From G. W. Smith, Cambridge Nat. History.)

derived, as is shown by the larval stages typically crustacean. Other common instances of degeneration are afforded by parasites (Figs. 34 and 35 ). Often they become simplified beyond recognition, but betray their true affinities in their development. Many parasitic crustacea of the order Copepoda lose practically all trace in the adult condition of the characteristic appendages used in 
the normal free-living forms for locomotion or for seizing and cutting up their food. Indeed, parasitic animals, able as they are to absorb the nourishment directly from their host, generally tend to lose not only organs of locomotion and of special sense, but even the alimentary canal, and spend all their energies in producing enormous

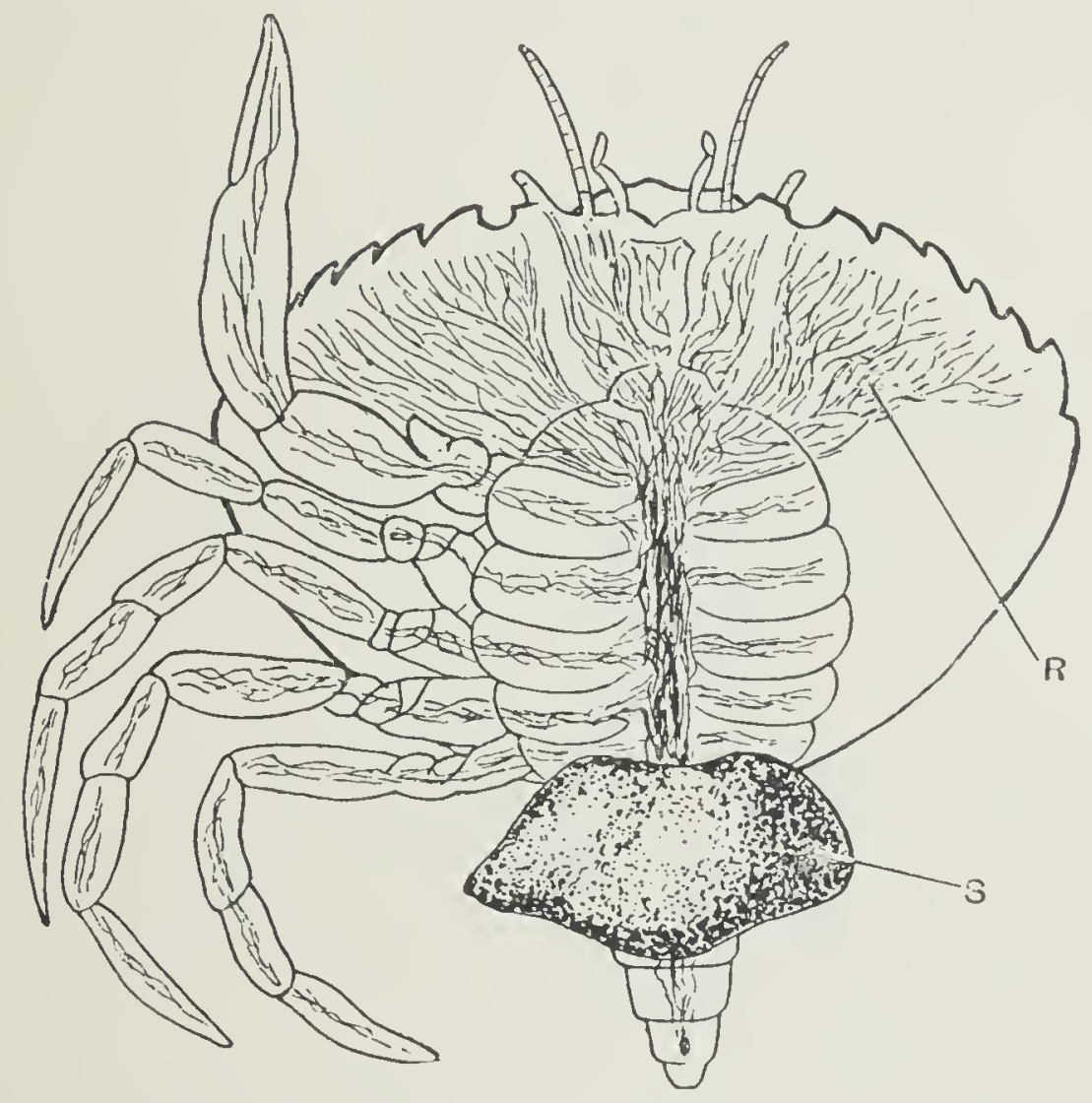

Fig. 35. Sacculina carcini, adult parasitic stage, fixed on to the host, a crab. $S$, sac-like body of parasite. $R$, its root-like nutritive processes ramifying in the crab. (After Delage, from A. Lang's Comp. Anatomy.)

numbers of young to infest new hosts. The loss of the organs of flight in flightless birds and insects, and of the eyes in animals living in caves or the dark depths of the ocean, is also due to degeneration.

Degeneration, in fact, is a widespread phenomenon among animals and plants, and leads to the loss of any special structures, mental or bodily, which the organism 
no longer needs in the particular environment for which it has become adapted. It is a return frcm a complex to a simpler organization; but not to a truly primitive or ancestral condition, for the path of retrogression is generally very different from that followed by the original progressive evolution. Now it is one of the great merits of the doctrine of evolution by natural selection, that it accounts for this simplification as easily as for the development of complexity. For both progressive and retrogressive mutations occur. Variation takes place both in the + and in the-direction, and selection of the one may be as advantageous as selection of the other. Which will be chosen depends on the needs of the organism at the time. On the other hand, it is very difficult to see how any theory of evolution based on some supposed internal perfecting force could possibly be reconciled with these facts.

Strewn along the path of evolutionary change are thus left derelict organs once of vital importance, but now no longer of use, or at all events of less consequence in the struggle for existence, owing to some change in habit and environment. Such organs are known as vestigial; and unless they are turned to some new purpose-that is to say, unless they vary in such a way as to become adapted to fulfil some new function-they are apt to disappear. The exact process of disappearance is difficult to describe, is in fact not thoroughly understood. If an organ thrown out of work is an actual burden on the organism, it will tend to become eliminated by selection of retrogressive variations, and will also be apt to develop incompletely in the individual owing to disuse. But if merely useless, it may remain indefinitely as a vestigial structure. Such, for instance, are the vestigial hind 
limbs in the dugong and in whales, and the teeth in embryo baleen whales, the much reduced wing in flightless birds like the emu, the apteryx, and the extinct moas of New Zealand. It would be rash, however, to take it for granted that even in these cases the vestiges are altogether without function (p. I24).

But it is far more common for the apparent disappearance of an organ to be due to its alteration and adaptation to some new function. And this brings us to another objection often urged against Darwinian doctrines. If natural selection cannot be prophetic (p. I23), if organs cannot develop before they are called into use, how can one account for the initial stages in their development? Of what use can a complex organ be before it is completed? But this objection loses its force when it is remembered that organs rarely if ever can be said to 'begin'. Entirely new functions and entirely new organs are not suddenly developed. All are evolved by the gradual transformation of, addition to, or subtraction from something already there. The wing of a bird, unique as it is, has had no sudden beginning-it has been gradually transformed from the fore-limb of the reptile. The extinct Archaeopteryx from the Jurassic strata has a modified limb in a beautifully intermediate state (Fig. 36). The one-toed hoof of the horse is not a new organ; it is derived from an ordinary five-toed foot by the gradual loss of the lateral digits. Almost every stage of its history can be traced in the fossils. What more complex or useful organ than the human eye? Yet it is merely an instance of the extreme specialization of the property of response to light generally distributed over the surface of the body in the lowest forms. In the evolution of an organ by selection every stage must be useful, and it is often 
difficult to picture the intermediate conditions; but we must not jump to the conclusion that they could not have existed. The heart of the amphibian has one ventricle, in which the venous and arterial blood become more or less mixed; that of the bird has the ventricle completely subdivided into two chambers, so that the venous is kept

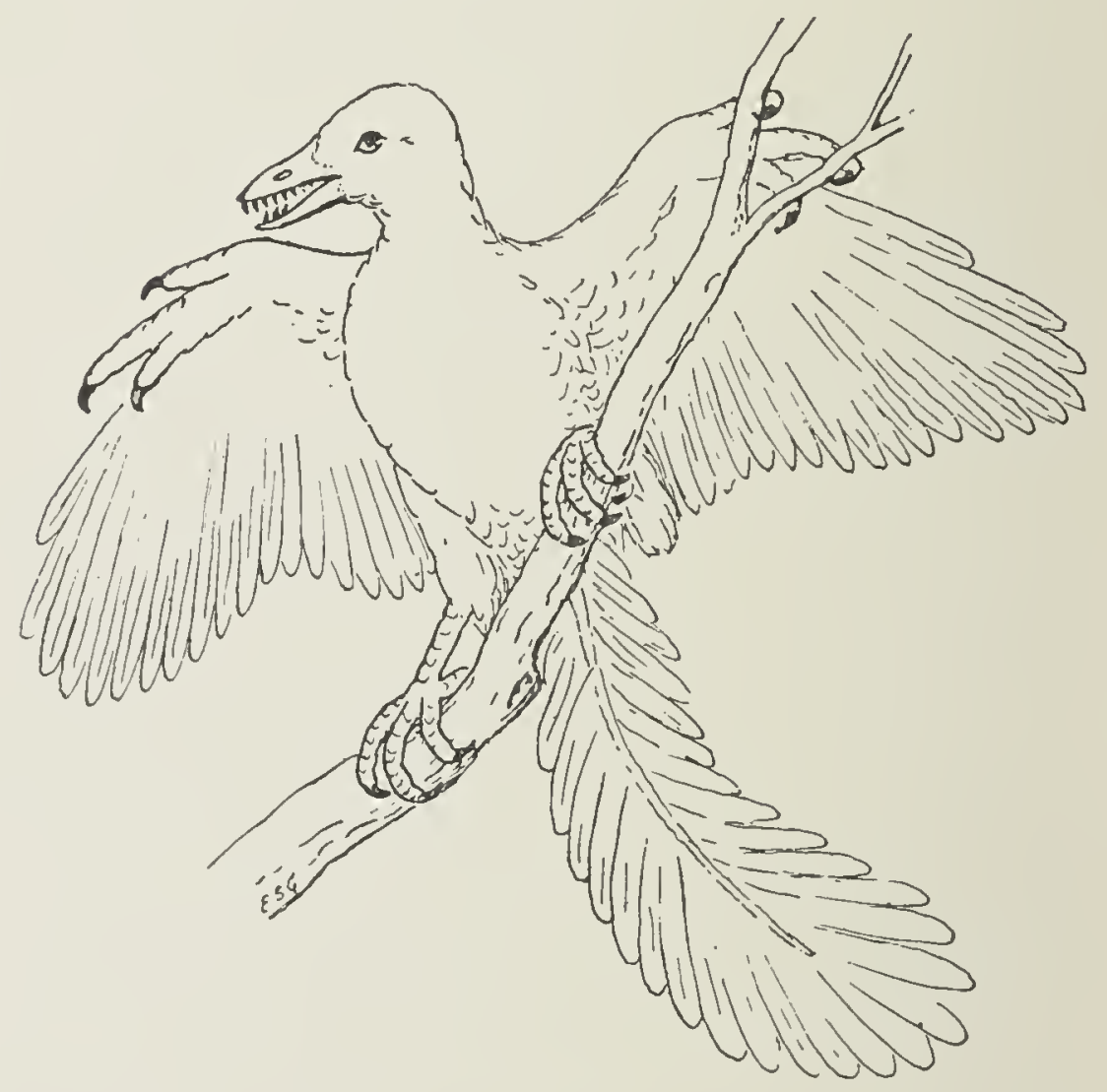

Fig. 36. Restoration of Archacopteryx macmua, from Upper Jurassic of Bavaria, with true teeth, claws on three digits of the wing, and a long true tail.

quite separate from the pure arterial blood. Now if reptiles were unknown, we could well imagine an opponent of the theory of natural selection stating dogmatically that the intermediate steps in the formation of the dividing septum could not have been useful, and therefore could not have been selected. To be effective at all, he would say, the septum must be complete from 


\section{Phylogeny and Classification}

the beginning; if the venous is to be separated from the arterial blood an intermediate stage would be of no use. Such arguments are constantly heard. Fortunately, in this case, we can point to the Reptilia, where these very intermediate steps occur, and the incomplete septum can be shown actually at work.

3

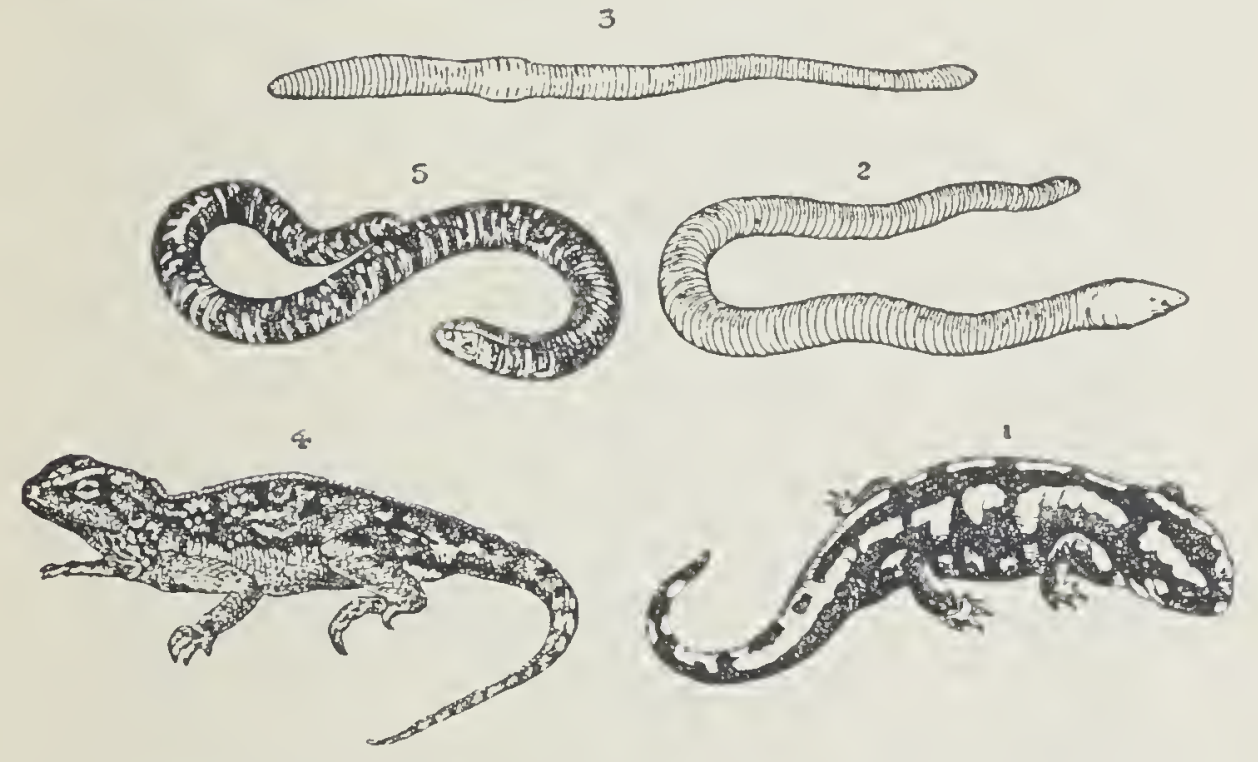

FIG. 37. Convergent evolution. Salamaidra (I), a normal urodelc Amphibian; Siphonops (2), a legless Amphibian; Agama (4), a normal Lacertilian ; and Amphisbacna (5), a legless Lacertilian. (2) and (5), being adapted to a burrowing life, have come to resemble the Earthworm (3) and each other.

As a rule, evolution leads to specialization and differentiation along the ever diverging and forking branches of the phylogenetic tree. Usually the more diverse organisms become the more successful they are in the struggle for existence, since they interfere less with each other owing to their adoption of different modes of life and different feeding habits. On a given plot of ground more individual plants can live if they belong to several species adapted in different ways, than if they belong to one species only. But occasionally evolution leads to convergence in function and structure owing to com- 
peting forms derived from different groups adopting similar modes of life, endeavouring to occupy the same place in nature. Organisms and their parts may then come to resemble each other-analogies are developed. Thus a burrowing snake like Typhlops, a burrowing lizard like Amplisbaena, or amphibian like Siphonops,

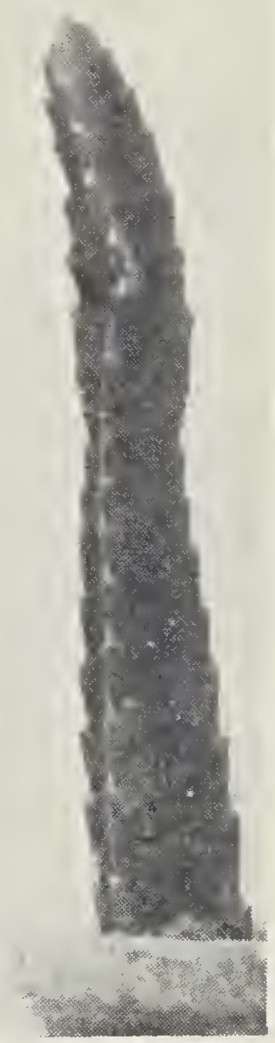

A

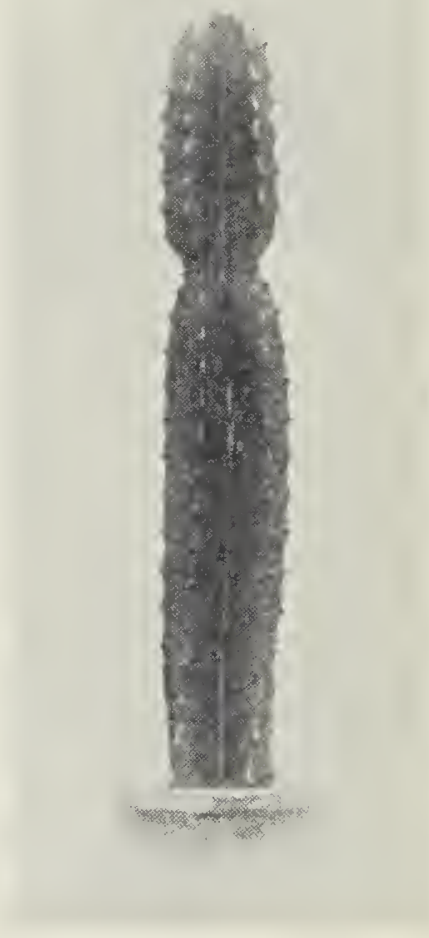

B

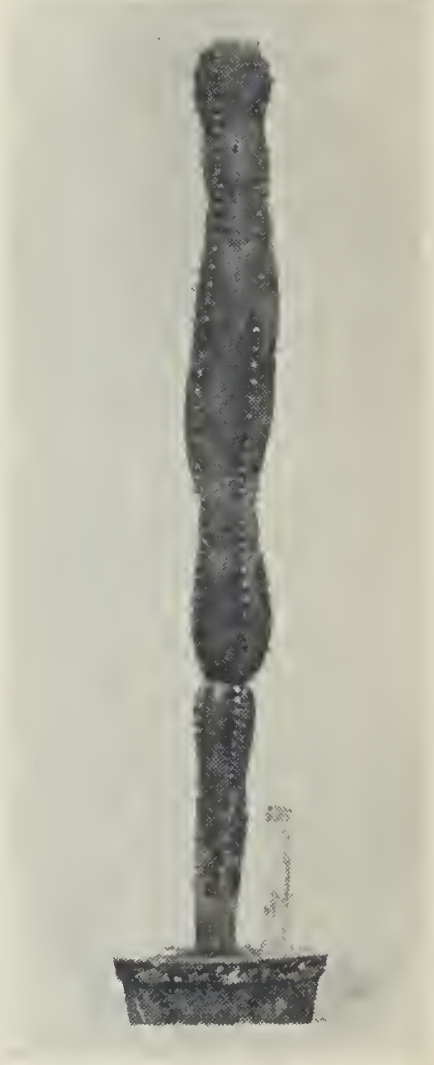

C

FiG. 38. Three plants slowing convergence of structure in three different families in adaptation to dry conditions. A, Pilocercus sublanatus, Central and South America, family Cactaceae. B, Euphorbia arborea, Old World tropical and sub-tropical, family Euphorbiaceae. c, Stapedia sigantca, South and Tropical Africa, family Asclepiadaceae.

acquire a resemblance to an earthworm (Fig. 37); or again, among the Mammalia, the 'flying' squirrel, Pteromys, and the 'flying' phalanger, Petaurus, have become remarkably alike although one is a Placental and the other a Marsupial. Similar instances occur among plants (Fig. 38). Very striking also may be the analogous 


\section{Phylogeny and Classification}

resemblance between two organs of different origin, but fulfilling the same definite function, as the eyes of Polychaete worms, of Molluscs, and of Vertebrates. Mimicry and protective resemblance offer special examples of convergence. Yet, however close the resemblance may be, it is generally essentially superficial, and the separate origin of two structures is usually betrayed not only by fundamental differences, but also by innumerable details. Just as the expert can often detect a forged antiquity by careful inspection, so the comparative anatomist distinguishes analogies from true homologies (comparing one organism with another, those parts are said to be homologous which can be traced back to a common ancestral source). It is worth insisting upon this subject, because the French philosopher Bergson has recently, we think, greatly exaggerated the extent and somewhat misrepresented the significance of convergence.

The doctrine of evolution has generally been admitted to gain strong support from the study of Embryology. One of the pioneers of this science, $\mathrm{K}$. von Baer, long ago pointed out that the embryos of different groups of Vertebrates are much more alike than are the adults; but he was careful to add that the embryo of a higher form is never quite like the adult of a lower form. It is a remarkable fact, for instance, that the embryos of reptiles, birds, and mammals possess gill-arches very like those of a fish at a corresponding stage of development (Fig. 39). Less cautious later writers, and more especially Haeckel, concluded that in the course of its development an organism passes through stages representing approximately the series of ancestors which preceded it-that in fact individual ontogeny, recapitulates phylogeny. This is Haeckel's famous 'Biogenetic Law', which not 
only captured the popular imagination, but has for half a century greatly influenced embryological research, and has perhaps done more to delay the progress of sound views on phylogeny than any other modern speculation. It has been subjected to severe criticism from many sides, and it is now realized that organisms in a phyletic series

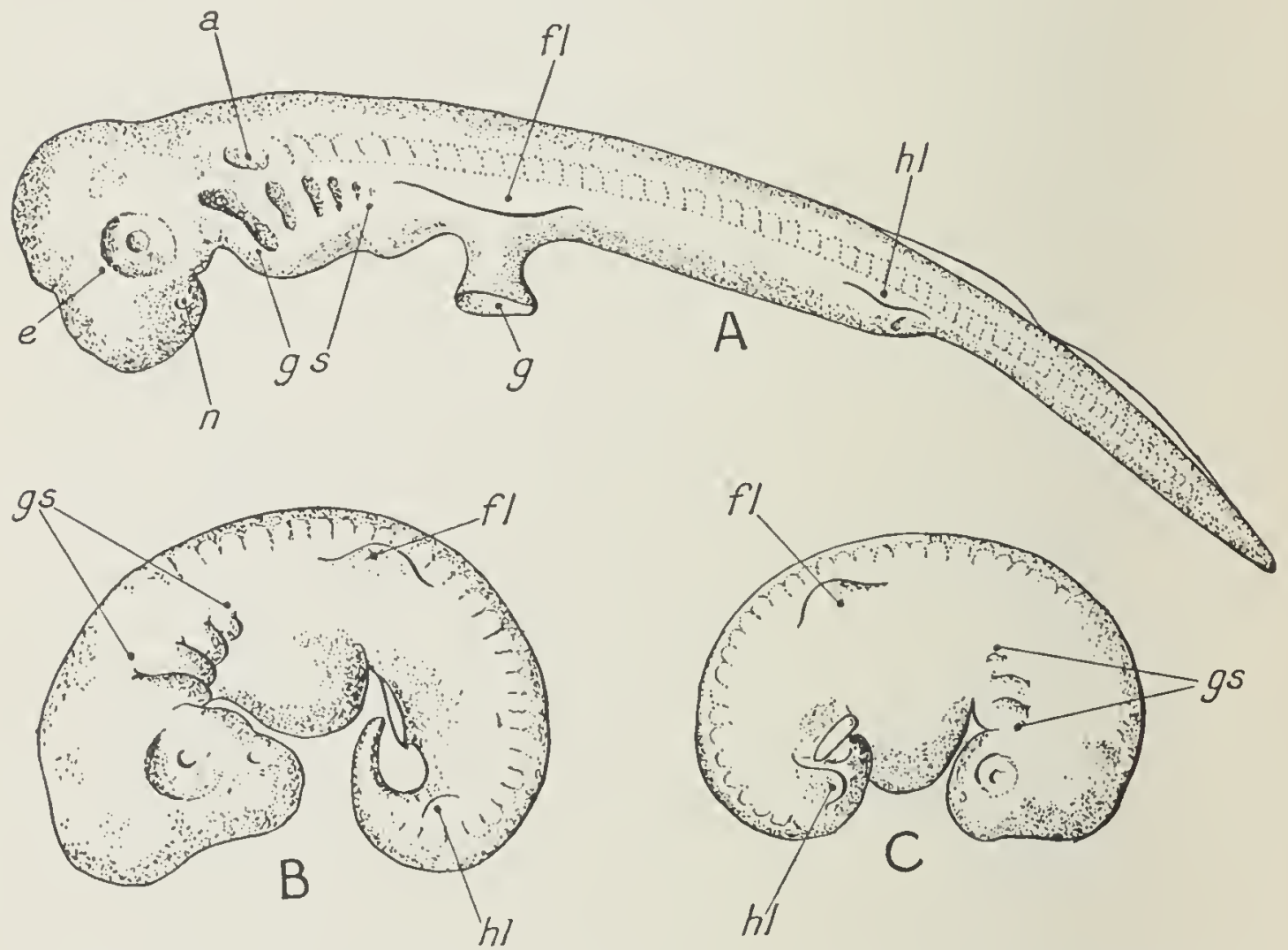

FIG. 39. Corresponding embrronic stages in development of a dogfish. A, a lizard. B, a man. c, a rudiment of auditory sac. $e$, cye; $f$, fore-limb; $g$, cut stalk of yolk-sac; $g s$, gill-slits; $h l$, hind limb; $u$, nasal sac.

do not start from the same point. There has been a phylogenetic evolution of the germ-plasm and of the zygote just as there has been of the adult. It is true that Vertebrates, for instance, begin development as unicellular zygotes (p. 37); but these differ from each other no less than the adults. A fish, a reptile, a mammal, each develops from an egg composed of a special specific 
substance, each is fish, reptile, and mammal respectively from the beginning; hence no stage in the ontogeny of one is really the same as any stage in the ontogeny of the others, nor can it recapitulate the adult stage of an ancestor. However, in so far as the eggs are similar and develop under similar conditions, they necessarily pass through similar stages in development, especially if they are to reach approximately the same adult structure.

Owing to divergences in adaptation the ontogeny may deviate from that of the ancestor at any stage, and often to a remarkable extent. Thus special larval stages may be intercalated or embryonic structures developed having no resemblance to adult ancestors. For example, the presence of a larval nauplius stage in the development of so many Crustacea is evidence, not that the nauplius was the ancestor, but that the ancestor of these Crustacea itself passed through this larval stage. On the other hand, early ontogenies may diverge but little, while the later stages lead to very different adult forms: as in the case of the Tunicata (p. I 37), where the larva still preserves many vertebrate features which must have been possessed by the corresponding stage in the ontogeny of the remote as well as of the near ancestor. So it would appear that, in so far as recapitulation occurs, it is a repetition not of the phylogeny but of the ontogeny of the immediate ancestor. These resemblances are sure signs of affinity, but often very misleading material for the reconstruction of phylogeny.

Coming now to classification, it is the sorting out of organisms into groups according to their natural affinities, their blood-relationship. ${ }^{1}$ Individuals are grouped

1 Unexpected and welcome help in tracing relationships has recently come from a study of the blood itself. Ehrlich proved that the blood 
into species, species into genera, these again into families, orders, classes, and phyla, divisions of increasing size and importance. Before the doctrine of evolution was accepted, it was thought that these groups had definite limits based on some separately created and fixed unit. At one time it was supposed that the comparatively large genus was the unit of creation, the species and varieties within it being merely fluctuations caused by external influences. Linnaeus maintained that the smaller group, the species, is the originally created unit, and succeeded in establishing his views so firmly that they grew into a dogma from which the systematist even of the present day has not entirely freed himself. But the consistent evolutionist recognizes that so-called 'species' are merely serum of an animal treated with certain poisons in increasing doses develops a substance, antitoxin, which neutralizes the effect of the particular poison used. Toxin and antitoxin combine to form an innocuous compound. It has also been shown that specific antibodies may be formed to combine with foreign proteins and cause a precipitate. For instance, if a rabbit be injected with human blood, it will develop a 'precipitin' which will produce a precipitate when added to the diluted blood of man, but not when added to the blood of some distantly related animal. The important and interesting fact is that the amount of the reaction is roughly proportional to the nearness of the relationship of the animals whose blood is tested. For instance, anti-human serum gives the maximum reaction with the blood of men and anthropoid apes, less with that of Old-World monkeys, still less with that of American monkeys, and none at all with that of Lemurs; while anti-dog serum gives a far heavier precipitate with the blood of a Carnivore than of a Primate or any other Order of the Mammalia. The whole subject has been studied in detail by Nuttall, who has supplied valuable evidence as to the blood-relationship of animals whose affinities remained doubtful. Friedenthal has obtained evidence of a similar kind by showing that the serum of one animal tends to destroy the red blood-corpuscles of another; and that this cytolytic action is the more rapid and complete the more distantly related are the animals so tested. For instance, while human serum has little or no effect on the corpuscles of an anthropoid ape it will dissolve those of the cat or horse, and other vertebrates still less closely related. 
closely allied individuals descended from a common ancestor, which normally interbreed, and are sufficiently alike to be conveniently called by the same name. All sorts of vain attempts have been made to draw up stricter definitions of a true species. Mere likeness counts for little: males and females may often differ very considerably from each other, and in polymorphic forms the offspring of the same parents may be of several different types. Sterility has often been held to form a definite barrier distinguishing true species from mere varieties (p. I 3 I); but there are all degrees of fertility, and crosses between forms which no systematist would hesitate to call species often yield fertile offspring. As instances one may mention crosses between the common and the Chinese goose, the common and the pintail duck, also various species of pheasants; and, among mammals, the wolf and the dog, and the American bison and the European wild ox. Sterility is a character variable like any other; it occurs even between members of undoubtedly the same species, as we know in the case of our own.

It is true that cle Vries has recently tried to define 'elementary species' as forms produced with a new progressive mutation, due to the acquisition of some new factor. Such forms, if they really occur suddenly, could certainly be considered as definite discontinuous steps in evolution. Especially among plants there are many widely distributed 'species' containing a large number of local races or subspecies, each breeding true and apparently differing from the others by one or perhaps a few 'unit characters'. Of the whitlow-grass (Lraba verna) some two hundred constant races have been distinguished by Jordan; and similar subdivisions of the 
species of Viola, Helianthemmm, \&c., are known. But the evidence as to the sudden origin of the mutations is weak; and, at all events, it is by no means yet established that new factors may not appear gradually in increasing intensity, so that discontinuity becomes negligible, and the new characters develop in steps small enough to

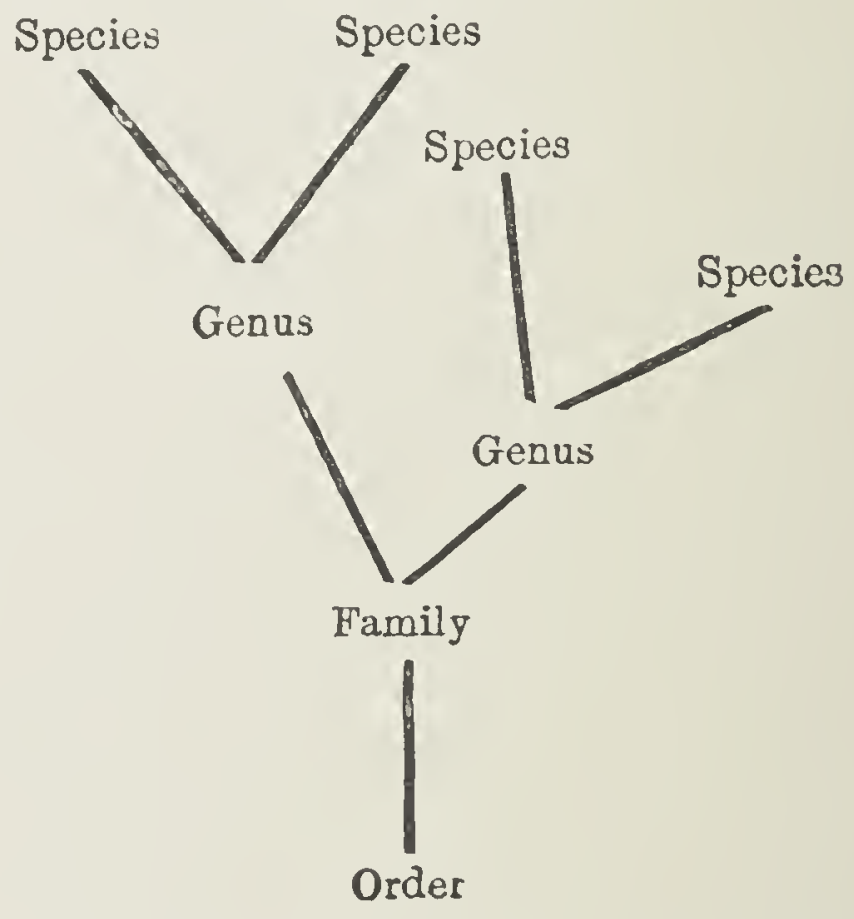

F1G. 40. Diagram to illustrate the principles of classification.

satisfy the most exacting selectionist (p. I i 9). The diversity of rariation and the smallness of the steps in mutation are well illustrated in the case of the hawkweed (Hieracium) and the dandelion (Taraxacum), which reproduce parthenogenetically; as in the Bacteria, there may be differentiated as many 'pure lines' as there are parents, and a bewildering number of races results, each distinguished by some small constant difference of character. Indeed, it is the universal experience of naturalists engaged in the classification of quite modern closely allied 'species', that the great difficulty of the work is due to the fact that it is usually scarcely possible 


\section{Phylogeny and Classification}

to find any character at all sufficiently conspicuous and constant to distinguish them from each other. Sudden mutations and sharp distinctions would be welcomed by all systematists. What we commonly call a species is,

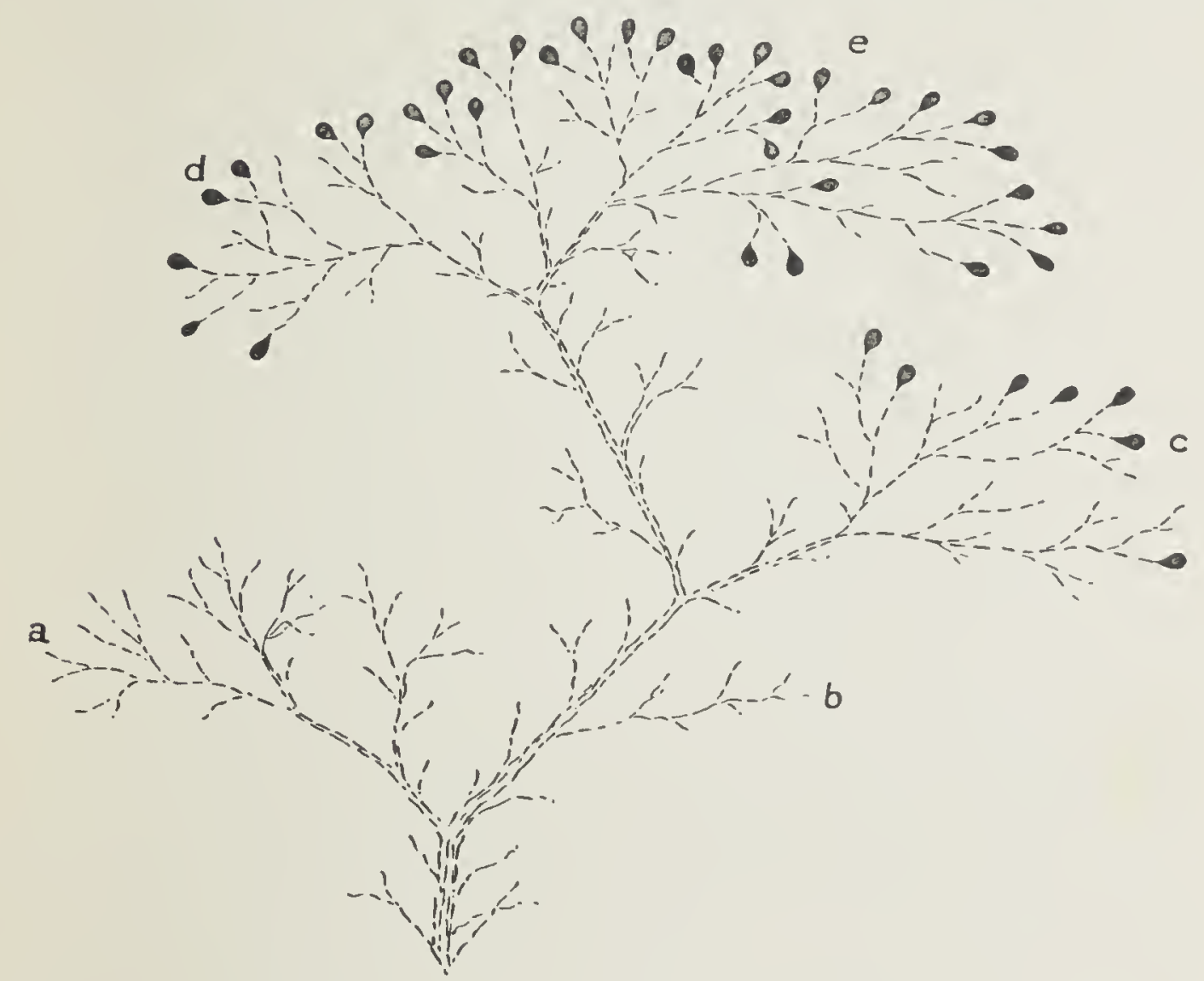

FIG. 4I. Diagram of a phylogentic tree. Extinct stem and uusuccessful branches in dotted lines. Surviving successful species represented by black knobs. Branches $a$ and $b$ totally extinct; $c$ moderately successful; $d$ and $e$ most successful and represented by many closely allied living species.

then, an assemblage of closely allied and interbreeding races differing from each other by small factorial differences, and representing as a whole its present phase of evolution (see 'pure lines', p. 64 and Fig. I3).

The only 'fixed points' in a phylogenetic system of classification are the points of bifurcation, where one branch diverges from another (Fig. 40). It is here that our divisions should be made; and our generic, family, 
and ordinal distinctions naturally come at each fork farther and farther down the stem of the phylogenetic tree. The phylogeny of organisms, however, is but incompletely known ; and often the actual point of divergence or origin of a group may be but vaguely inferred, so we have to compromise and adopt arbitrary divisions which only indicate progressive grades of structure.

There is one more consideration to be borne in mind when dealing with species. The living species around us represent the extreme tips of the branches of the phylogenetic tree, which have succeeded in the struggle for existence. If their ancestors are extinct these living twigs become isolated from each other, and so real limits become established, which of course would disappear if the complete series of extinct forms were discovered. It is the inevitable result of evolution by the elimination of the less well adapted that ever widening gaps come to separate the diverging living representatives of the various branches derived from a common stem (Fig. 4I).

\section{VIII}

\section{The Geological Record of Success and Failure.}

EVOLUTION is too often represented as a history of success and progress; it is also one of failure and extinction. Authors, seeming to forget that for one line of development that succeeds there are a hundred that fail. are fond of invoking some mysterious guiding principle, some internal perfecting agency-an élan vital, or what not-to account for evolution; but there would appear 
to be little scope for such mysterious forces in a world where the majority of individuals are crushed out, where most lines of development fail hopelessly to establish themselves. What guiding principle there may be behind the whole of creation is a subject outside the scope of Natural Science, and on which it can express no opinion. It cannot even prophesy whether man or the bacillus will eventually triumph in the struggle for existence ; indeed, both would seem to be doomed to destruction in the end by an unfavourable environment when this earth becomes too hot or too cold to support life. In the meantime, it is the great merit of the Darwinian principles of evolution that they account for the failures as well as for the successes. The elimination of the unfit, leaving the better adapted in possession, is a necessary part of the process.

The living organisms of to-day show us the types which have succeeded; for the failures we must appeal to the record of the past as revealed by a study of fossil remains. This record, in spite of its incompleteness, has much to teach. Every theory of evolution must be tested by the results of palaeontology; no conclusion can be accepted which is inconsistent with them.

In the first place, the conviction derived from a study of living forms is confirmed : that evolution does not proceed along continuous straight lines, but, on the contrary, along a multitude of diverging branches. Just as individuals are found to vary in all directions compatible with their structure and composition, so groups become differentiated in various directions, each adapted to a particular mode of life. Having reached a certain favourable combination of characters, they start on this new plane of structure to diverge, according to the 
principle of adaptive radiation, as it has been called by Osborn, many instances of which are found in the history of the land vertebrates.

Derived from some fish-like aquatic ancestor in Devonian or pre-Devonian times, the land vertebrates appear in Carboniferous strata as clumsily built Amphibia with four walking limbs. Like their modern representatives, they spent their early life in water, breathing by means of gills, and made use of lungs for respiration in adult life on land. These primitive Amphibia soon diverged in various directions. Some acquired a large size and formidable dentition, like the Labyrinthodonts; others remained small, and were probably harmless herbivores; some became elongated, lost their limbs, and were adapted to an eel- or snake-like mode of progression (Aistopoda); while others (Branchiosauria), losing the original scaly covering of the fishlike ancestor, gave rise to the modern groups (the frogs and toads, or Anura, and the salamanders and newts, or Urodela). These latter are all specialized forms, the existing Urodela being only the degenerate remnants of a once flourishing class which have become more or less completely readapted to an aquatic life. In fact, the Anura are the only order which has succeeded and expanded in recent times.

The Amphibian was the dominant type in Carboniferous times; it now occupies a very subordinate place. But from some unspecialized branch of it arose the more thoroughly terrestrial Reptilia towards the end of the Carboniferous or beginning of the Permian epoch. The class Reptilia reached a higher grade of structure, and soon almost completely superseded the Amphibia on dry land. So successful were the reptiles that already in 
Permian and Triassic times they had spread over the whole earth, becoming adapted in various directions to all sorts of life (Fig. 42). The earliest reptiles known so closely resemble the primitive Amphibia that it is difficult to say where one class begins and the other ends; but these undifferentiated reptiles soon gave way to more specialized successors. The Theromorpha gave rise to remarkable forms: some with large flat grinding teeth (Placodontia); others active, vigorous creatures with a formidable carnivorous dentition (Therocephalia and Therodontia, Figs. 44 and 45); while the highly specialized Dicynodontia retained only two huge tusks. None of these specialized reptiles survived beyond the Trias. Other lines of differentiation lead toward a return to aquatic life. Plesiosaurs and Ichthyosaurs quite independently took to marine life, and their limbs became transformed into swimming-paddles. Neither group persisted beyond the Cretaceous epoch. Among the most interesting extinct reptiles are the Dinosauria. First appearing in the Triassic, they flourished in the Jurassic and Cretaceous, but became extinct before the beginning of the Eocene epoch. Often of gigantic size-as for instance Cetiosaurus and Diplodocus - these remarkable animals were the lords of the earth in later Mesozoic times. Some were adapted to a vegetable diet, like the huge Iguanodon; while others were aggressive carnivores, like Ceratosaurus and Megalosaurus. But in spite of every effort, so to speak, to succeed in all possible directions, in spite of elaborate adaptations, terrible weapons, formidable defensive bony plates, horns, and spines, these splendid Dinosaurs all failed in the struggle for existence by the end of the Cretaceous epoch (Figs. 42 and 43 ). 


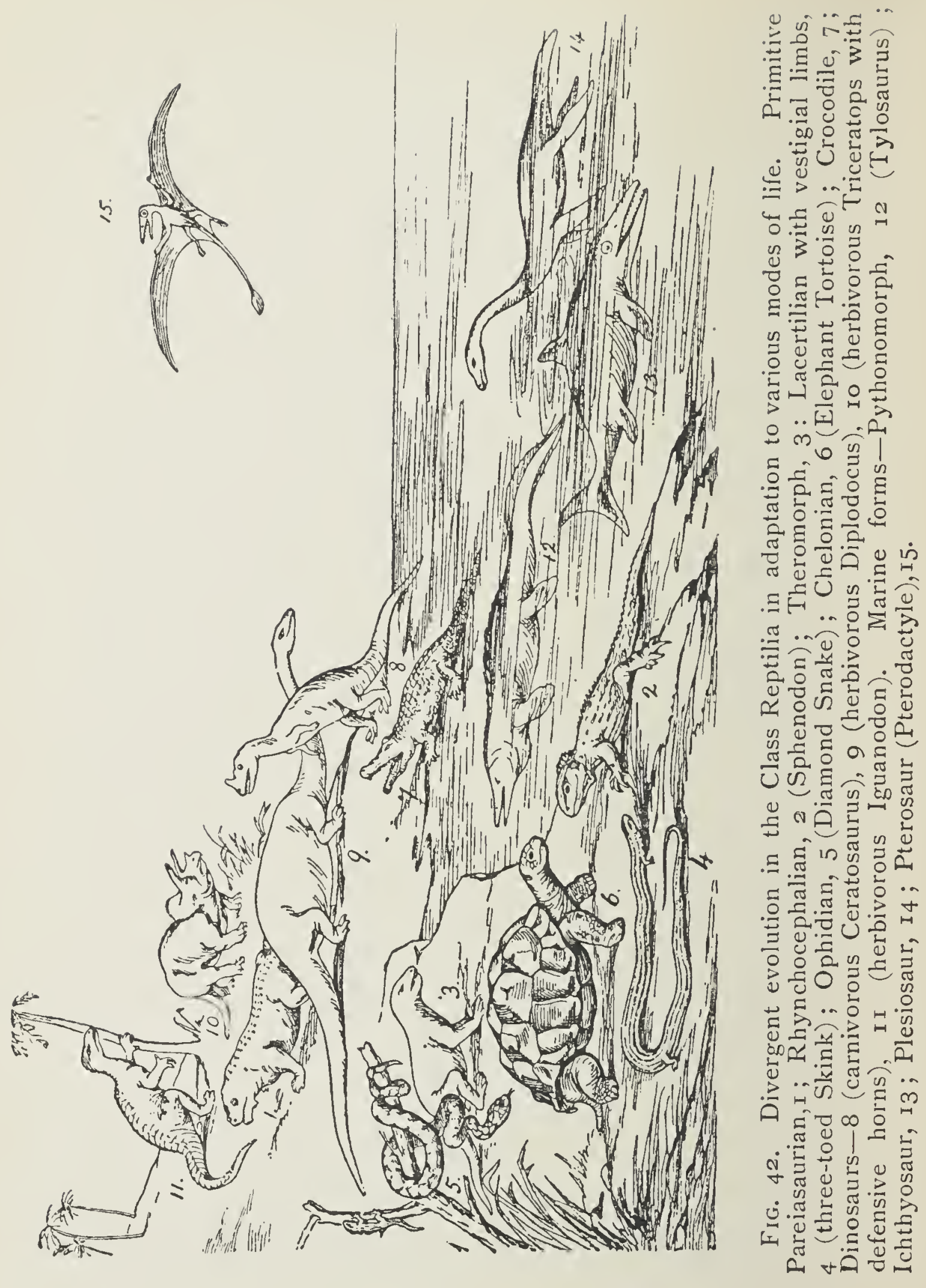


Some representatives of the large order Crocodilia still persist in the tropics; but the Rhynchocephalia sur-

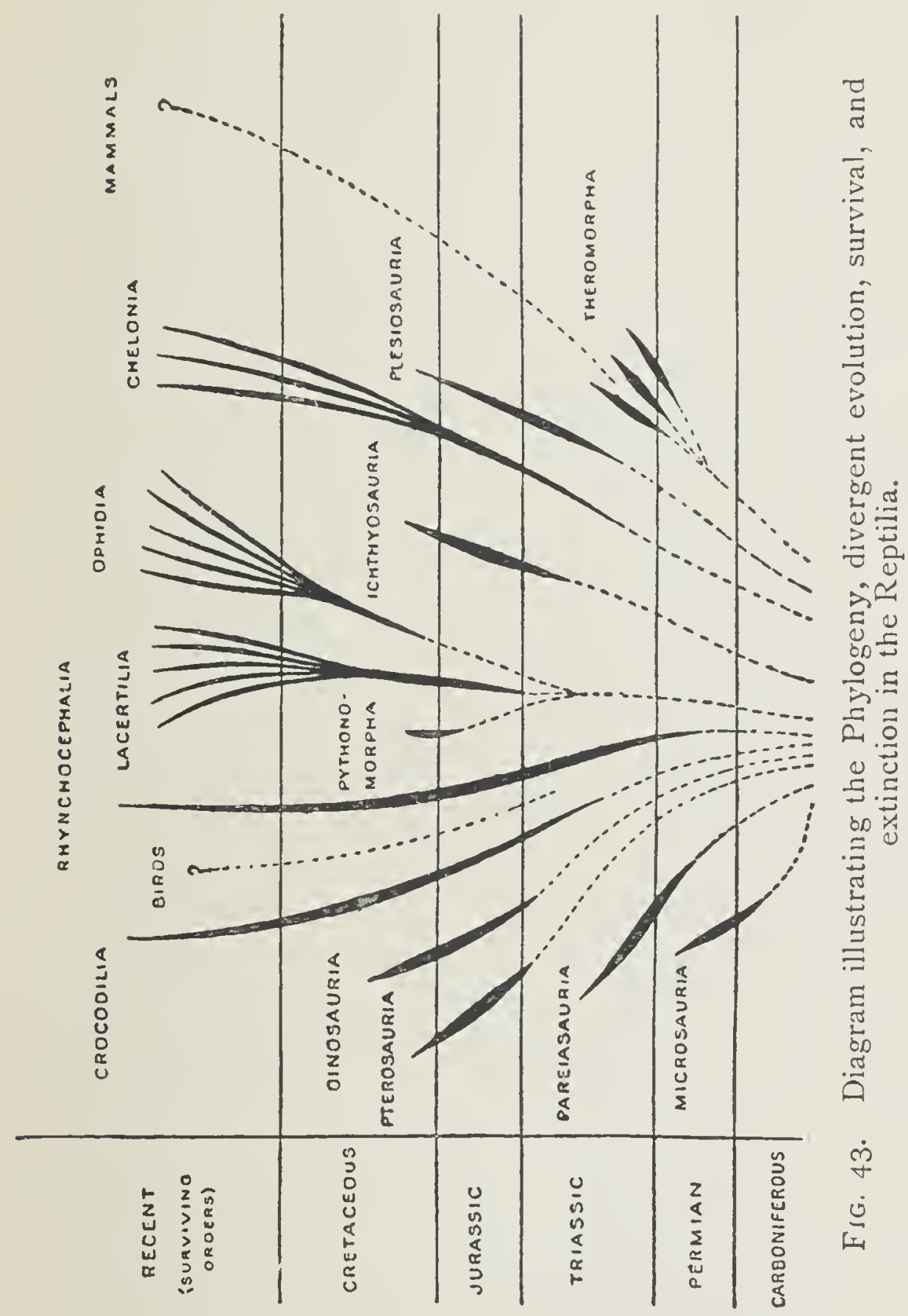

vive at the present day only in a single species, Sphenodon punctatum, preserved byspecial legislation on certain small islands off the coast of New Zealand. The Pterosauria, admirably specialized for flight as they appear 
to have been, had but a short success in later Mesozoic times. On the other hand, the Chelonia (tortoises and turtles), modestly taking refuge in their bony shell, are fairly flourishing in warm countries even at the present day. But of the vast array of reptilian forms the Lacertilia (lizards) and Ophidia (snakes) are the only two orders which have really increased and spread in recent times. A few other orders linger on in reduced numbers; the majority have failed altogether (Figs. $4^{2}$ and 43 ).

But although the reptilian type, once so successful and widespread, has failed so signally in the struggle for existence, it has given rise to other types which have replaced it. The birds are doubtless descended, through some intermediate form like Archacopteryx (Fig. 36), from some primitive reptile allied to the Crocodilia and Dinosauria. The avian branch has undergone comparatively little pruning. Quicklysupplanting the Pterosauria after the Iurassic epoch, birds radiated along all sorts of adaptive lines, most of which survive to the present day. The beautifully adapted organization of birds, with warm blood, efficient lungs, sharp senses, quick movements, and light feathers, has secured them a supremacy in the air which has hardly been challenged even by the mammals.

The Mammalia, that class of vertebrates to which we ourselves belong, arose earlier than the birds, probably from some primitive reptilian stock in Permian times. Indeed, the Theromorph reptiles of the Trias so nearly approach the mammalian type of structure in the character of the skull, palate, lower jaw, and other important points, that they are now generally held to have been, if not the ancestors themselves, at all events closely 
allied to them (Figs. 44 and 45). Quite independently of birds, and on different lines of specialization, the Mammalia have acquired a four-chambered heart, completely separating the arterial blood from the venous, and a self-regulating mechanism, keeping the blood at

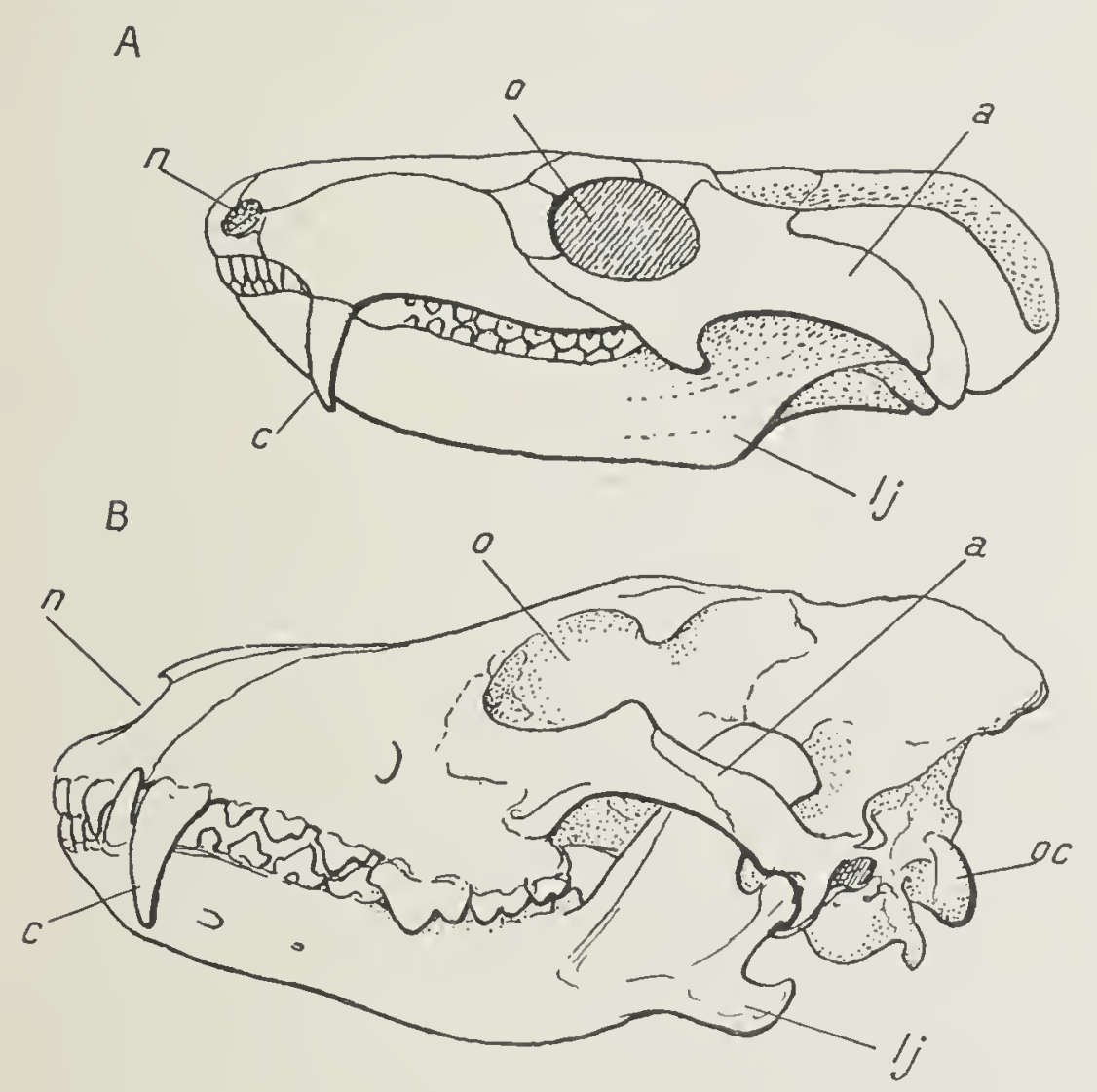

Fig. 44. A, skull of Trirachodon, an extinct Theromorph reptile from South Africa (after R. Broom). B, skull of the Arctic Wolf, Canis occidentalis; $a$, zygomatic arch; $c$, canine tooth; $l j$, lower jaw formed chiefly by dentary bone in $\mathrm{A}$ and entirely in $\mathrm{B} ; n$, external nostril; $o$, orbit.

a constant high temperature, independent of that of the surrounding environment (p. 58). Of very adaptive build, the mammals soon diverged from the primitive ancestral egg-laying type now almost extinct, but still preserved in the archaic Monotremes living in Australia, the famous Ornithorhynchus, and Echidna. Adopting the advantageous method of nourishing tbeir young during early 
life in the mother's womb, the placental mammals spread rapidly over the earth, ousting the lower reptilian type of organization, and diverging in various adaptive directions, they became the dominant group in Eocene times (Fig. 46). The mammals have, however, suffered severely in the struggle. Large groups have vanished altogether,
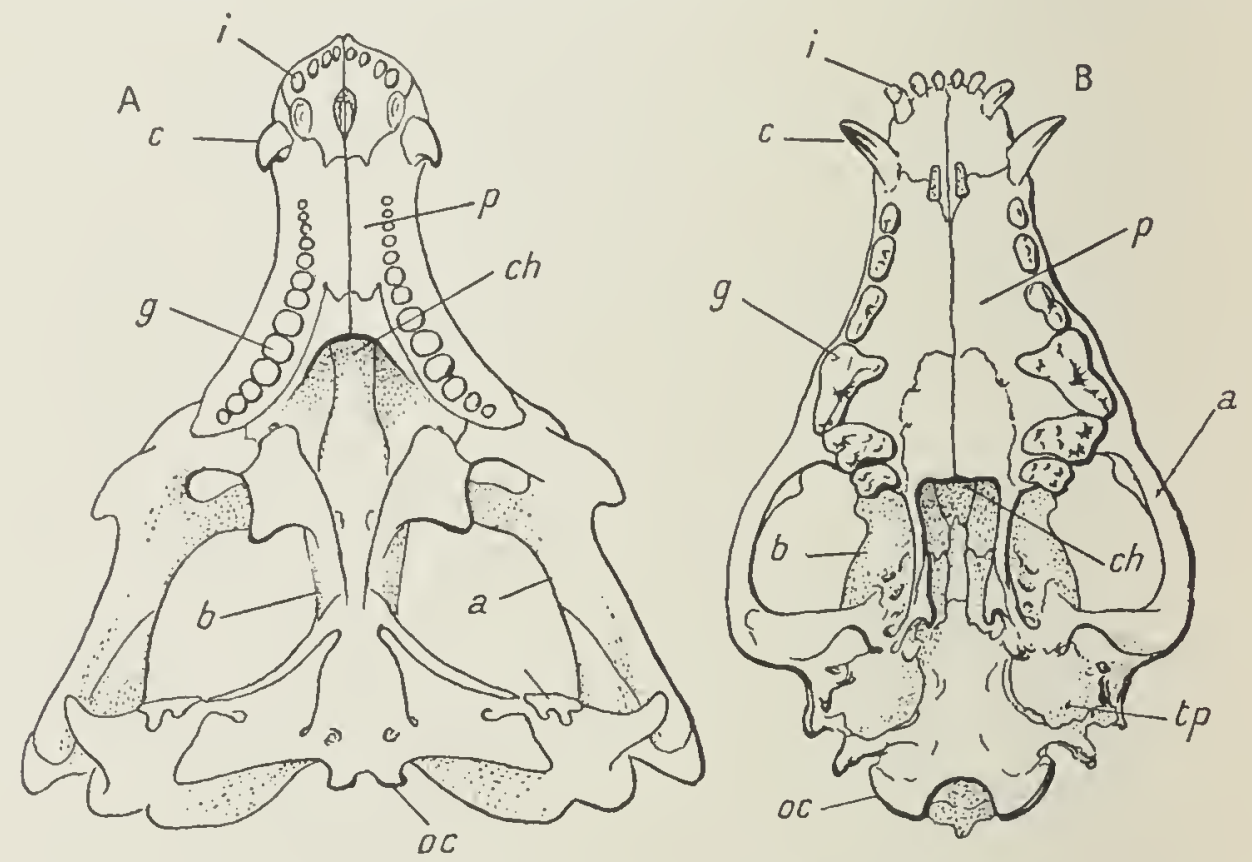

FiG. 45. A, ventral view of skull of Gomphognathus, an extinct Theromorph reptile, from South Africa (after R. Broom), showing mammalian characters such as: Teeth differentiated into incisors, $i$; canines, $c$; grinders, $g$; bony false palate, $p$; and double occipital condyles, $o c$, in both skulls. $\mathrm{B}$, ventral view of skull of the Arctic Wolf, Canis occidentalis, for comparison; $a$, zygomatic arch ; $b$, brain-case ; $c h$, internal nostrils.

while others are on the verge of extinction. The Marsupials, once widely distributed, remain only in Australia, where they have escaped from competition with the more advanced Placentalia, and as scattered genera in America. 'The Dugong and Manatee are now the only representatives of the order Sirenia; while the Edentata, including the gigantic ground Sloths (Megatherium) and Glyptodonts, once all-powerful in South America, are 
reduced nowadays to a few highly specialized tree-sloths and armadillos (Fig. 46).

Most instructive is the history of the large order Ungulata, which includes all the hoofed herbivorous mammals. Starting in Eocene times from primitive forms about the size of a fox, with complete unspecialized dentition and five-toed feet, known as the Condylarthra, and long ago extinct, the Ungulates branched out into a number of sub-orders (Fig. 47). The Amblypoda developed into huge creatures, like Dinoceras, with large tusks and four horns on the skull, but did not survive beyond the Eocene age. A somewhat similar but quite distinct group of massively-built herbivores, the Titanotheria, lasted only into the Miocene, while the highly specialized and aberrant sub-order Ancylopoda occurs up to the Pliocene epoch. Two South American groups, the formidable rhinoceros-like Toxodontia and the more horse-like Litopterna, have left no descendants. The Hyracoidea survive at the present day only in the little coney, Hyrax, and a closely-allied genus; and of the Proboscidea, including mastodons, mammoths, and elephants, a large group once widely distributed over both the Old and the New World, there persists but one species in Asia and one in Africa. Even the large sub. order Perissodactyla (the odd-toed Ungulates), although still represented by a few rhinoceroses, tapirs, horses, and asses, is by no means so widespread or successful as it once was. The even-toed Artiodactyla are at present the most flourishing group, with a large number of genera and species of deer, antelopes, sheep, and oxen. But the pig-like forms, or Suina, have not been very successful; the hippopotamus is nearing extinction, the Tylopoda (camels and llamas) are but the isolated relics 


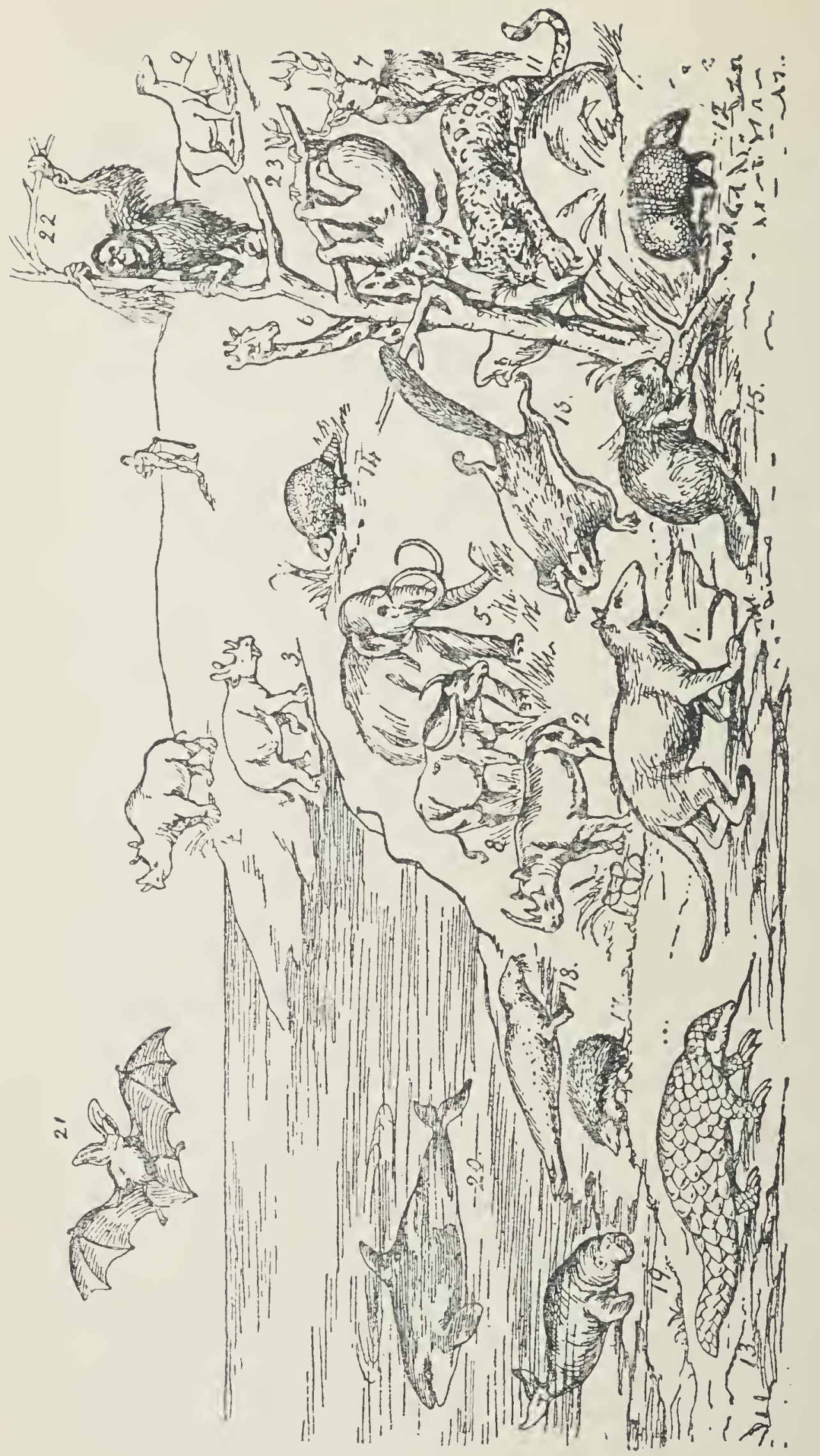

m ن U

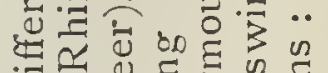

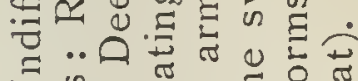
5 证 0.5 के ن

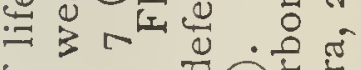

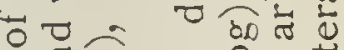

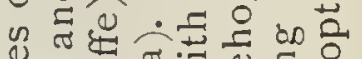

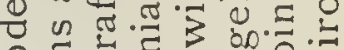

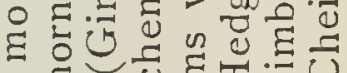
驺00

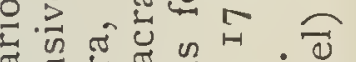

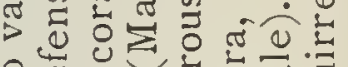

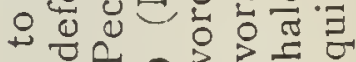
E एँ 3 की

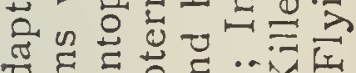

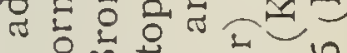

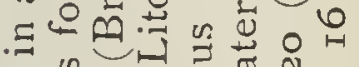

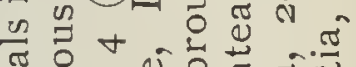
Eั0

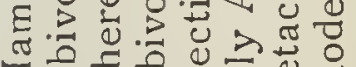

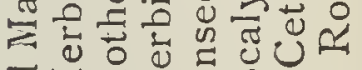
正和记.

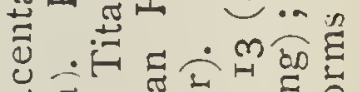
跣... Q 如

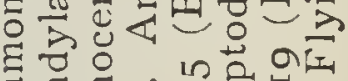

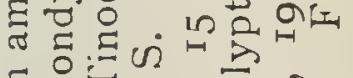

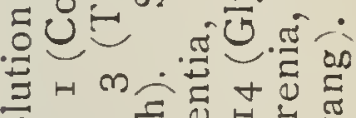

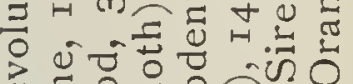
य 50 응

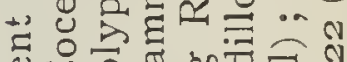
이에

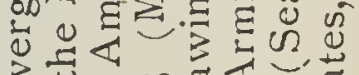
的政

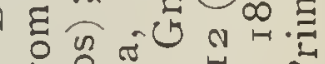
$\dot{0}=0$

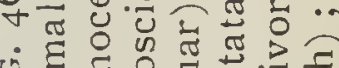
0

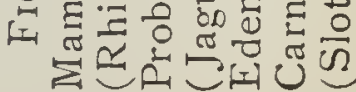




\section{Geological Record of Success and Failure r63}

of a not very flourishing division (Fig. 48), and many allied families have failed altogether. Thus we see that the existing families of Ungulates are but the scattered remnants of a far larger number of groups which flourished more or less successfully in the past (Fig. 47). And the same may be said of the history of all organisms? whether vertebrates or invertebrates, whether animals or plants. Many are the forms developed, few are those which survire. Those who believe in a guiding force directing the course of evolution must admit that it has been singularly blind and inefficient, leading more often to destruction than to success.

Still, it is sometimes argued, organisms seem to get inte a groove of specialization, to pursue a road along which they can no longer stop, to become over-specialized by virtue of some sort of momentum driving them over the limits of usefulness to inevitable destruction. Thus over and over again we see, in the record left by fossils, animals acquiring a larger and larger size, and then suddenly dying out. The large Amphibia of the Carboniferous, the monster Dinosaurs of the Jurassic and Cretaceous, the gigantic Moas (flightless birds of New Zealand), and among the mammals the huge Amblypods and Titanotheres, the giant sloths, and others, are all extinct. Again, some animals develop certain organs to an excessive extent, as, for instance, the canine teeth in the extinct sabre-toothed tiger (Machairodus), or the monstrous antlers of the extinct Irish elk. Now it is quite probable that these animals died out owing to overspecialization, a narrow adaptation to a particular environment accompanied by a corresponding loss of power of accommodation to changed circumstances; but it is a mistake to assume without clear proof that the course of 


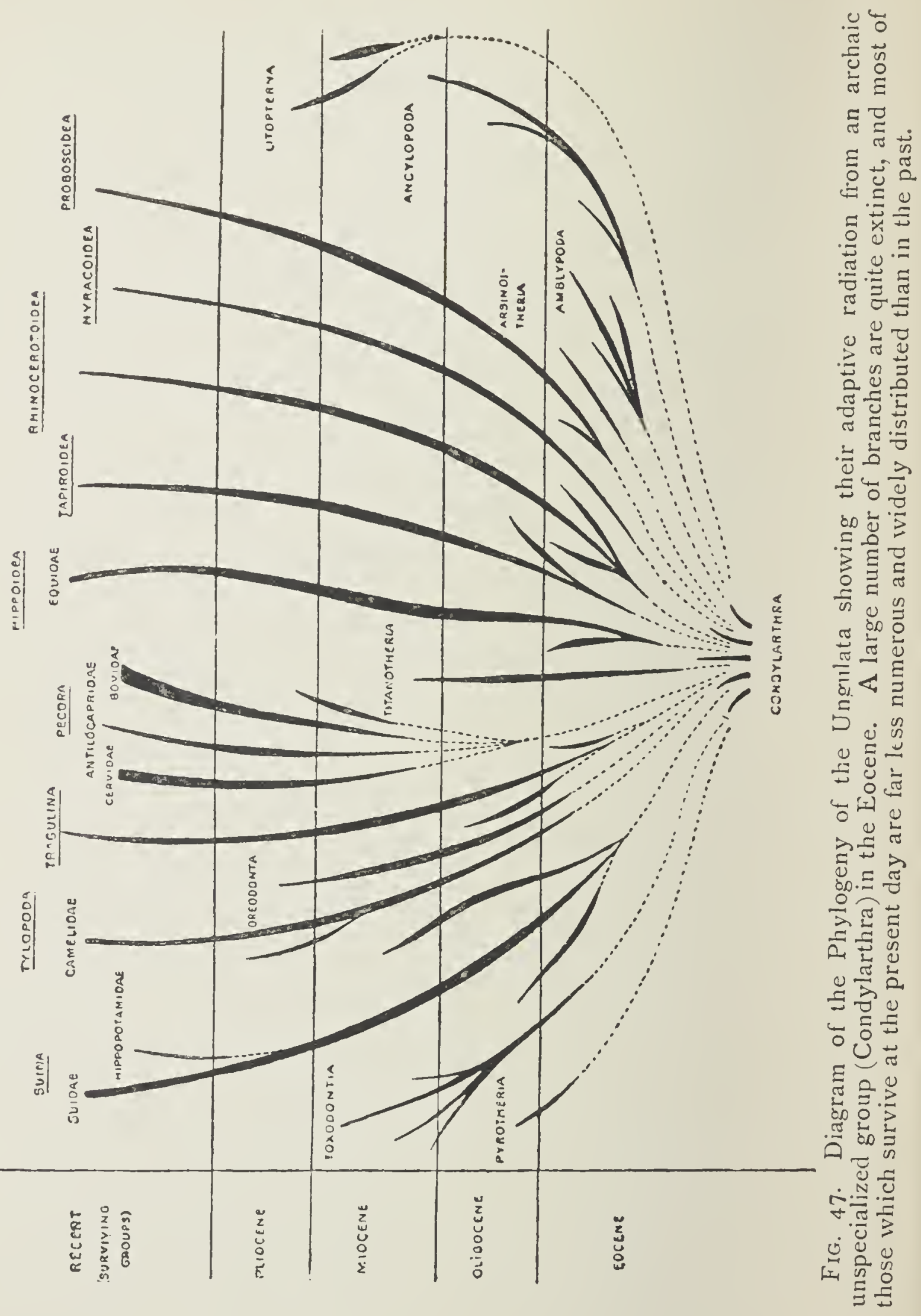


their evolution can have been useless. Variation (p. I 22) may be useless or harmful, and doubtless these unsuccessful forms may have got into grooves of variation; but variation is not evolution. And seeing that natural selection looks not to a distant future but to the immediate advantage, there is nothing in the history of these animals which cannot be explained as due to the ordinary action of selective elimination. We have every reason to suppose that every step in increase of size gave some advantage to the giant forms over their competitors. To assume the contrary would be as wise as to argue that the huge modern Dreadnoughts are useless ships of war because they may possibly in the future be driven off the seas by relatively small submarines and flying machines, or to deny that the progressive stages in the development of these men-of-war must each have surpassed in usefulness those which went before.

This brings us to another interesting subject on which palaeontology can throw some light-namely, the rate of evolutionary change. Some organisms have changed very little through long geological periods. The molluscan genus Nucula, and the genus Patella, which includes our common limpet, date back to the Silurian epoch; the Silurian scorpion (Palaephomus) differs little from modern forms; the Brachiopod Lingula has changed very little since the Ordovician; and many Protozoan skeletons are found in Cambrian rocks which differ but little from those of the present day. There can be no doubt, then, that the rate at which the various branches of the phylogenetic tree have grown varies very much. Presumably the persistent types have been sufficiently well adapted to keep their own place against competitors, though perhaps only where the struggle has not been 


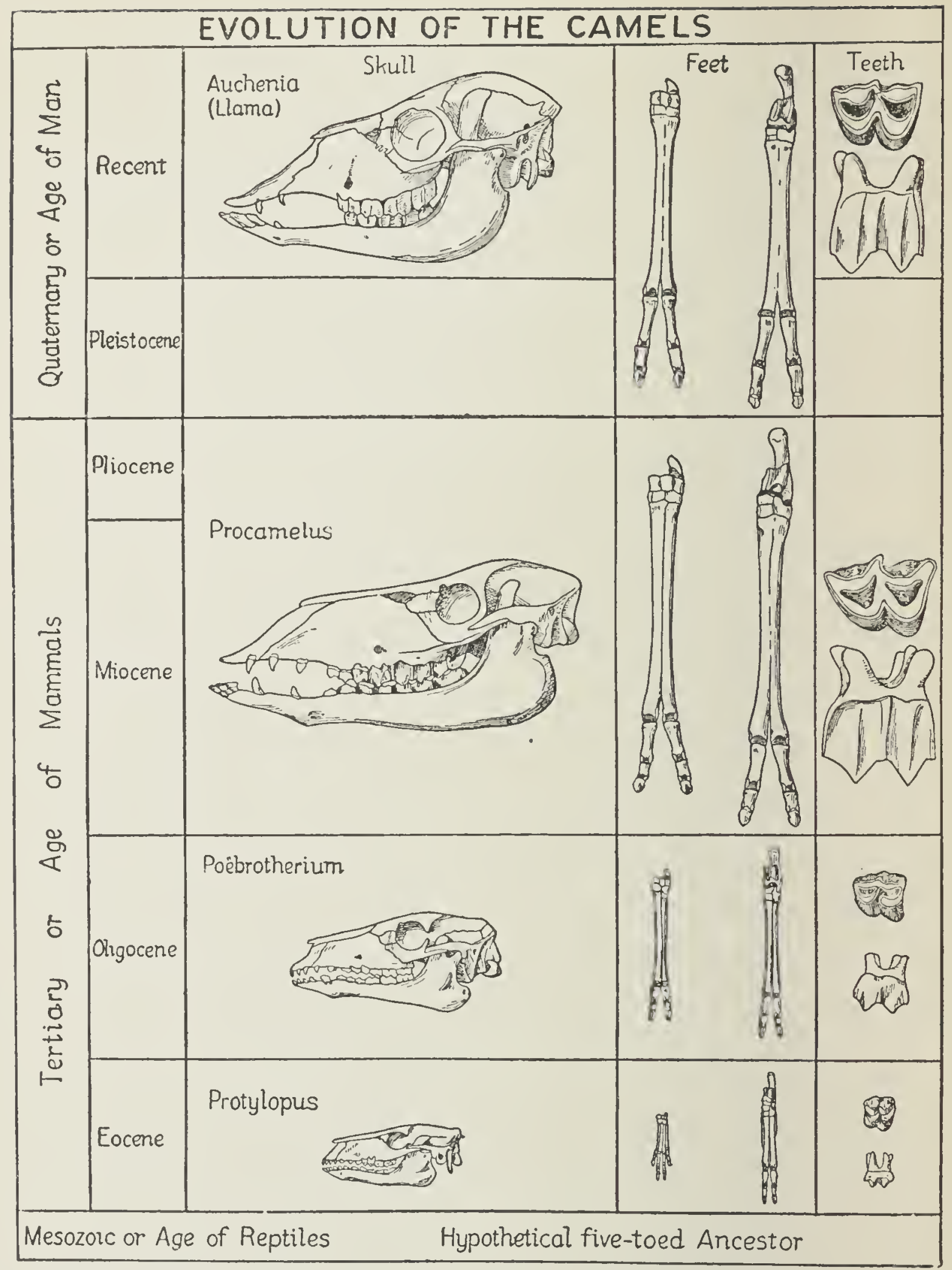

FIg. 48. Diagram illustrating the gradual evolution of the Camels. (Modified from Scott, from R. S. Lull, Organic Evolution.) 
very severe. The fact that they have changed little does not in the least prove that they have not varied, but merely that the divergent variations have not been selected. If variations are eliminated as fast as they occur, an organism may continue unchanged for an indefinitely long time. Change is no exact measure of variation.

It is sometimes objected that phylogenies are insecure speculations, that they are made up of series put together according to preconceived theory, that the conclusions have often proved erroneous. As the gaps become more completely filled up, certain forms are found to have been placed in the wrong order or to belong to diverging branches rather than to the same stem. But there can scarcely be any doubt that in the main these phylogenies represent the real course of evolution, and such mistakes in details do not shake our faith in the correctness of the conclusions as a whole.

Lery important also is the evidence of palaeontology, concerning the gradual character of the transition from one form to the other. We need not describe in detail the case of the horse, which is familiar to all, but shall only mention that it can be traced from an unspecialized comparatively small Eocene ancestral mammal, with five digits on each foot, a normal short skull, and the full complement of short-crowned teeth. The increased length of the crown, and the complex pattern on the grinding surface of the teeth, can be seen to evolve by almost insensible steps from the original six-cusped form, just as the lateral digits gradually become reduced on the feet (Fig. 49). Exactly how gradual these transitions have been we cannot often yet say, but the more complete the eviclence the smaller appear to have been the steps. 
Recent.

EQuUs.

A $B$ C D

E

$\mathrm{F}$

Pliocene.

Pliohippus.
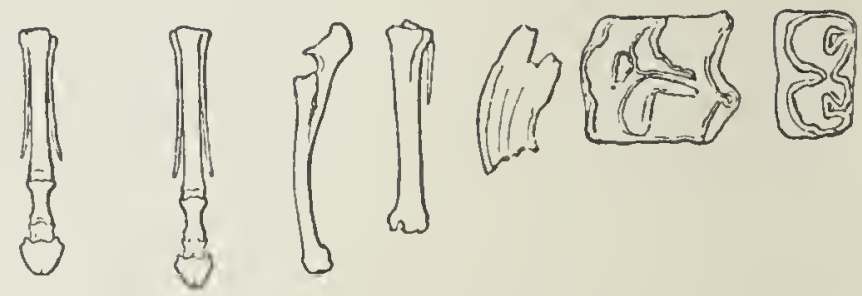

Mio-Pliocene.

Protohippus. (Hipparion.)
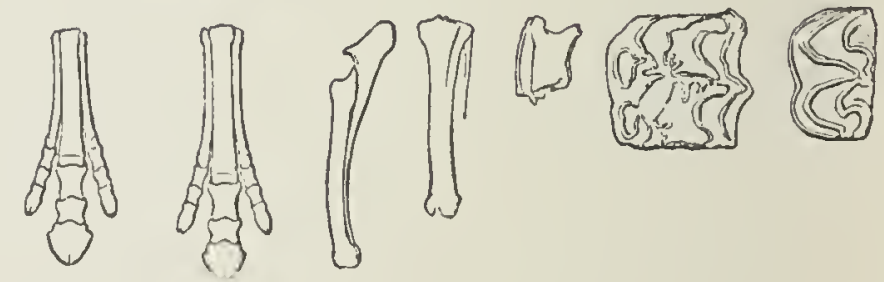

Miocene.

Miohippus. (Anchitherium.)
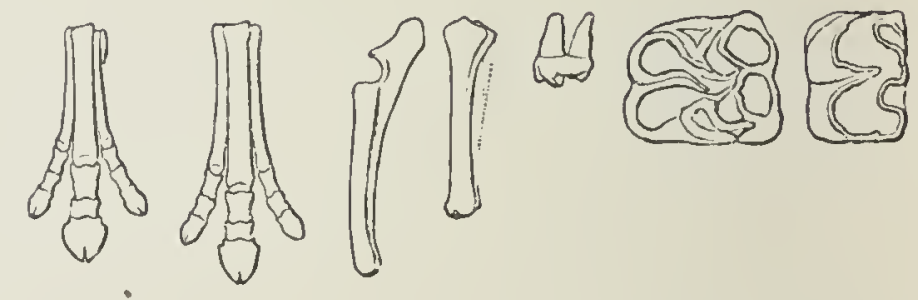

Mesohiprus.
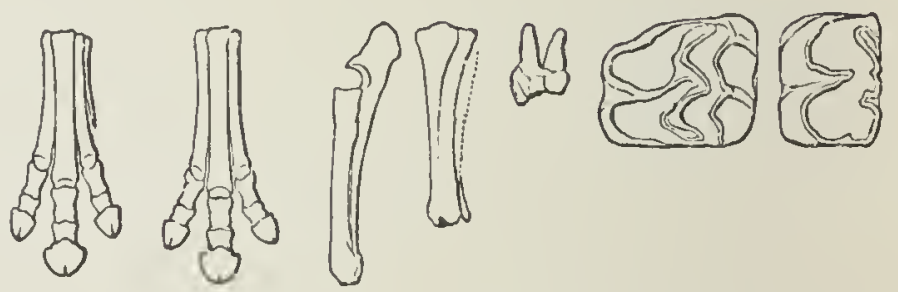

Eocene.
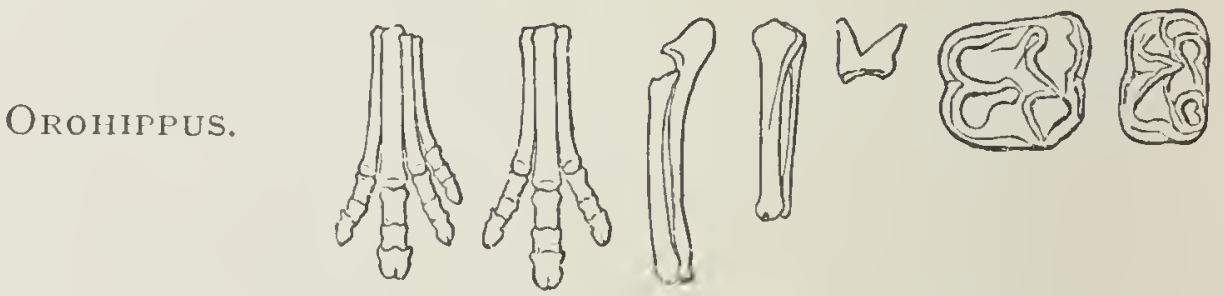

-F1G. 49. Diagram illustrating the erolution of the Limbs and Molars in the Equine Ungulata. A, fore-foot; $\mathrm{B}$, hind foot ; $\mathrm{C}$, fore arm; D, shin; E, worn upper molar, side and crown views; F, worn lower molar, crown view. (After Marsh, from A. Smith Woodward, Vertebrate Palaeontology.) 
Wonderfully gradual are the transitions described by Beecher in Trilobites and Brachiopods, by Hyatt and others in Ammonites, and in numberless other cases. Neumayer has traced the gradual evolution of Paludina nemmayeri, found in the lowest Pliocene deposits of Slavonia, into $P$. Hoernesi of the uppermost layers. Hoernes has shown that the Pliocene Cancellaria cancellata is intermediate between the Miocene and the recent forms of the same species, while Hilgendorf has followed the transformation of Planorbis through the successive geological strata of Steinheim.

In this record of the past we read the work of natural selection, the drastic action of elimination, and see on a large scale what is happening to-day not only among the competing groups of organisms, but among the struggling individuals. From the record we also learn that evolution does not proceed along an even course such as we might expect to see pursued owing to the pressure of some internal or external directive force. On the contrary, it is the rule that groups quickly expand, radiating in various directions of adaptation. This specialization leads to a certain rigidity, a loss of adaptability in other directions, and sooner or later to a failure to meet new conditions, while some obscure side branch committed as yet to no special line of adaptation acquires some advantageous combination of characters, enabling it to compete successfully with the dominant race. Evalution does not move along a straight line from one dominant specialized form to another, but by the constant uprising of new forms which supplant the old ones. The evidence of Palaeontology is all against the theory of orthogenesis (the transformation of one group into another along a straight line in ladder-like fashion). 
Adaptive radiation, a perpetual tendency to branch off in various directions founded on individual variations of indeterminate character, is seen in the history of all groups of organisms. The number of possible lines of development is indefinitely great; the external environment decides which, if any, shall succeed (see Figs. 43 and 47 ).

So it is not from the specialized Amphibia that the NB reptiles have been developed, but from some early undifferentiated form; neither is it from specialized Reptilia that the Mammalia have been derived. And among the manmals themselves, the Carnivora, Ungulata, Cheiroptera (bats), the Cetacea (whales), have not descended the one from the other; but have all divergerl from some primitive adaptable ancestor. They diverge more and more from each other as they become adapted to different modes of life. Man himself preserves many archaic anatomical characters, and the order Primates, of which he is the highest member, although its history is still imperfectly known, can be traced back to primitive Eocene forms. Extreme specialization may secure temporary triumph, and in very uniform conditions even lasting success, but adaptability is the most precious possession, and it is the creatures most ready to meet new and changeable conditions which have the future-before them. 


\section{IX}

\section{Psychology and the Evolution of Intelligence.}

WE have just seen that adaptability is one of the most $f(B)$ useful attributes an organism can possess. In plants it may be highly developed, but along comparatively simple lines of direct response. Here adaptability is shown in the power to respond in different ways to a variety of stimuli. The case of alpine and lowland forms has already been mentioned (p. 58), and many others are familiar to botanists. For instance, the plant Ranunculus acquires a very different shape and internal structure according as it grows on dry land or in water,-and the terrestrial or aquatic form can be developed in the same individual, by parts above and below the surface of the water (Fig. 50). To mention a simpler instance: a plant which lengthens rapidly in the shade may quickly reach the sunlight above the heads of its rivals. Also plants which in a normal climate develop ordinary stems and leaves may in dry or desert regions assume a very different form; the stems become succulent for storing water, and the leaves become reduced, spines being often developed in their stead, thus diminishing the surface whereby water is lost in transpiration (Fig. 5I). Now these and similar changes are often useful responses enabling the plant to accommodate itself to varying conditions. This manifold adaptability possessed by an individual is not due, as is so often assumed, to some mysterious power of automatically responding favourably to stimulus, but doubtless to the survival of 
those organisms which respond in the right way. To some extent this power of adaptation or accommodation is possessed by all organisms, and by variation and

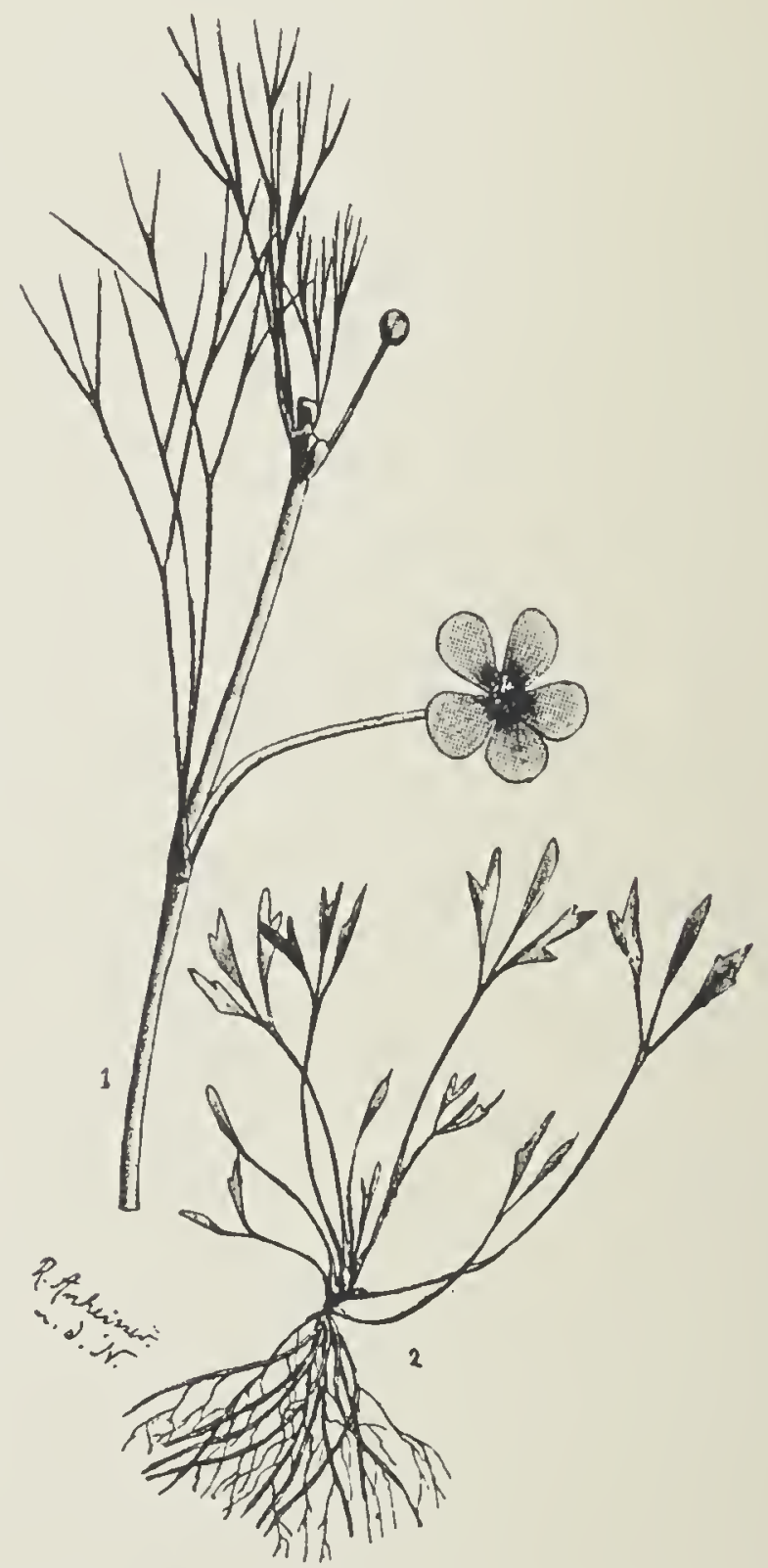

FIG. 50. Ranunculas fluilans. I, aquatic form;2, terrestrial furm. Two-thirds natural size. (From A. F. W. Schimper, Plant Geography.)

selection may lead to the establishment of definite series of responses in several possible useful directions. Potentially dimorphic and polymorphic species are thus produced both in the animal and in the vegetable ling- 


\section{Evolution of Intelligence}

dom, but while the accommodation of plants is of this simple and direct character that of animals is usually far more complex.

On the dangers attending specialization we have already dwelt (p. I69). Advantageous as it may be to acquire a special structure adapted to fulfilling a certain end with

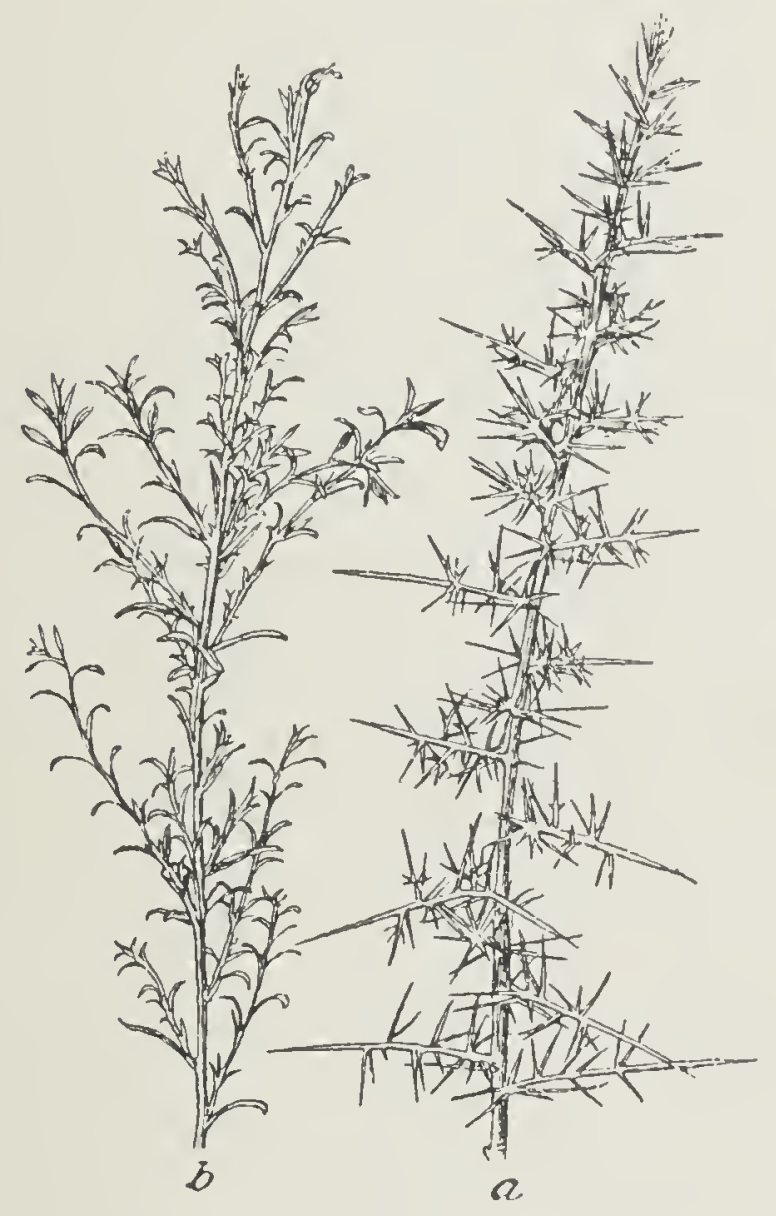

FIG. 5I. Ulex europaeus $a$, form of growth in ordinary air; $b$, in damp saturated air. (From A. F. W. Schimper, Plant Geography.)

rapidity, sureness, and precision, yet animals bave, so to speak, found it more profitable still to avoid overspecialization in one or even two or three directions, and to develop a readiness to respond to many sorts of stimuli, and a power of storing up the impression of past responses so as to benefit by 'experience'. In animals has been 
built up a system of 'behaviour' of such a kind that the character of the final response to the initial stimulus depends on the number and quality of the responses previously called forth. This power has been improved with the development of elaborate discriminating sense organs, and a complex conducting and co-ordinating nervous system.

Now this consideration brings us to the threshold of the rast domain of Physiological Psychology, which we cannot fully explore in this little volume. Yet something must be said about Instinct and Intelligence from the point of view of a scientific explanation of Evolution, while taking care not to trespass into the region of Philosophy. ${ }^{1}$

It was maintained above (p. 22) that the physicochemical processes of life form an unbroken series of changes; to these correspond the chain of mental processes. And we believe that to every mental process, whether of the 'highest' kind in the mind of man or of the 'lowest' in that of the most primitive organism, there corresponds some physico-chemical change. How intimately connected are the two sets of processes is matter of common knowledge. The slightest disturbance or interruption in the metabolism of the brain, due to an injury, an anaesthetic, a poison, will have its echo in a disturbance of the mental activities. Such complex mental processes as the sexual instincts are directly correlated with certain conditions of the body and of the genital organs in particular. The gradual elaboration of the sense organs and nerrous system found in the evolutionary series from the lowest forms up to man we

I The Mechanistic explanation here adopted should not be confused with Materialism, a discredited system of Philosophy which denies the existence of anything but the material or physical. 


\section{Evolution of Intelligence}

judge to be accompanied by a corresponding development of mental powers. So far as we know, neither the mental nor the metabolic processes can take place without the other. Yet, indissolubly bound together as they are, the one is certainly not the product of the other, nor can it interfere with the continuity of the other (p. is). The mind is not a product of metabolism as materialism would imply, still less is it an epiphenomenon or meaningless by-product as some have held. The mental and the physical series cannot break into each other's continuity because they are not independent of each other; what exactly is the nature of the connexion between them Philosophy may attempt to define, but Science is not called upon to describe. We may point out, however, that they appear to be two aspects of one and the same series of events; one seen from within and the other from without; one felt, the other observed. We call body and mind these two abstractions from a fundamental reality; and it is their artificial separation, unjustified by science, which has led to endless controversies about the possible action of one on the other. So in attempting to give a scientific explanation of evolution we can neither speak of mental processes as produced by or guided by physico-chemical processes, nor of metabolism as directed along its course by mind. Several theories of evolution seem to fall into this error. And the question, which is the more important in evolution - the mental or the physical series-really has no meaning since one cannot happen without the other. The two have evolved together pari passu. We know of no mind apart from body, and have no right to assume that metabolic processes can occur without corresponding mental processes, however simple they may be. The 
student of biology, howerer, is not concerned with the building up of systems of philosophy, though he should realize that the mental series of events lies outside the scope of Natural Science.

Now, if we only knew the whole series of physicochemical changes which correspond to the mental processes, the whole story of evolution could be told from beginning to end from the point of view of a scientific abstraction as an unbroken chain of metabolic changes. But unfortunately we are still very far from having obtained this complete knowledge, except perhaps in the case of plants; and so, in describing the behaviour of animals, we constantly pass over from the physicochemical to the psychological side, and describe behaviour in terms of mental processes (such as feeling, will, emotion) we know only in ourselves, but infer from external evidence to take place in animals also. The gaps in the physico chemical description are thus filled in from the other series. The physiologist is, however, daily extending our knowledge of the metabolic processes, and as fast as he advances he discards the psychical 'explanation'. But in doing so he often ignores the passage from one abstraction to the other, and erroneously concludes that mental processes are insignificant, superfluous, or nonexistent. He imagines that he has reduced them to mere physics and chemistry, an error into which we must be careful not to fall. If the whole chain of physico-chemical metabolic processes going on even in the human body and brain be some day discovered, the mental processes will still remain untouched and incapable of being described in the same terms. ${ }^{1}$

1 So we find that in a description of a simple reflcx action the physico. chemical chain of events (reception of external stimulus by sense organ, 


\section{Evolution of Intelligence}

The current method of dealing with mental processes, even morals and emotions, in a scientific description of evolution is then a makeshift, a provisional but convenient method; so the words feeling, memory, choice, and will, constantly creep into our descriptions of animal behaviour - no harm is done so long as their foreign origin is recognized. Since the two sets of processes correspond, are indeed indissolubly bound together, we need not be astonished at finding that the 'laws' of variation, inher- NB tance, and natural selection hold good in mental as in material evolution.

Having thus cleared the ground it may at once be pointed out that instinctive behaviour corresponds to adaptations fixed in definite directions; they are formed of a series of interlocking responses which must succeed each other when a particular stimulus is applied and reach a predetermined end, as surely as the piece of chocolate is yielded up by the penny-in-the-slot machine when the right coin is dropped in. From the simplest response we may pass to a 'reflex' action, such as the contraction of a muscle on the application of a stimulus to the skin, and thence, along a series of such direct chains of reactions of gradually increasing complexity, to the most elaborate instinct found in bees and other social insects (Fig. 52).

The scientific analysis of the behaviour of animals has only begun, and as a rule we can trace but very incom-

conveyance of impulse by nerve, contraction of muscle, \&c.) may appear to be so completely known that the corresponding mental events are usually not mentioned at all, and their very existence may be denied. On the contrary, when describing complex behaviour where impulses from cxternal or internal stimuli modify cach other before the final result is translated into action, it is the intervening physico-chemical processes which are unknown and perhaps ignored, and the action is then said to be voluntary, prompted by emotion or the will. 
pletely the actual physico-chemical processes which underlie it. But important advances have lately been made in this direction, chiefly by J. Loeb, who has suggested a physico-chemical explanation of the tropisms. Tropism is the name given to those simple reactions forming the material out of which the behaviour of plants and

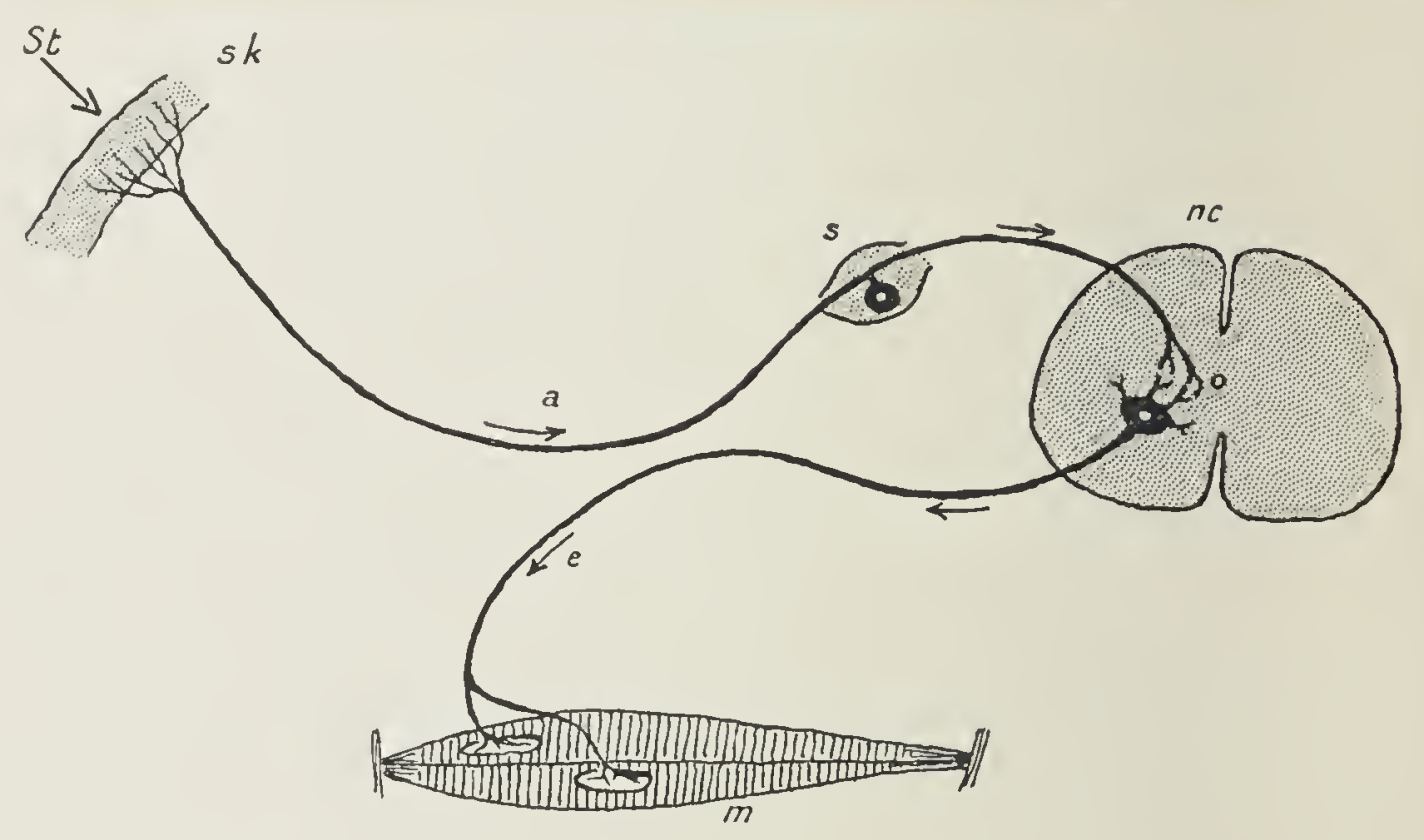

FIG. 52. Diagram illustrating the mechanism of 'reflex' action or response to stimulus; $a$, afferent nerve-fibre carrying sensory nerve impulse to central nervous system ; $c$, efferent nerve-fibre carrying motor nerve impulse to muscle, $m$, which contracts; $n c$, spinal cord in transverse section; $s$, spinal ganglion; sk, skin with sensory nerveendings; st, stimulus that excites nerve impulse.

lower animals is to a great extent composed, and which appear as direct responses to external stimuli. Thus, when a moth flies towards a flame, or a fly to a lighted window, it is said to be positively heliotropic (or phototropic); when a worm moves away from the light it is said to be negatively heliotropic. Similarly Chemotropism leads animals to move either away from or towards certain substances of particular chemical composition, as for instance food and water; and 
Geotropism leads them to move either with or against the force of gravity. Stereotropism is the name given to the peculiar instinct shown by certain animals to place as large a part as possible of the surface of their body in contact with foreign objects, and so induces them to creep into narrow chinks and crannies. Now although these tropisms may be built up and specialized by selection into elaborate instincts, adaptations for special purposes, they are really not primarily dependent on specialized sense organs and nervous systems, but are fundamental properties of protoplasm common to all animals and plants. They depend on the universal irritability of protoplasm, based on the instability of the complex compounds of which it is composed, and their capacity for being broken down, modified, or raised up by the action of external stimuli; or, in physiological language, they depend on changes in the metabolism (p. 12). A protoplasmic connexion between the various parts of the mechanism, irritability and conductivity (which is only a special form of irritability passing from one region to another) are the only essentials in the process.

Tropisms have long been known to occur in plants. Thus shoots, being negatively geotropic, grow upwards, while the positively geotropic tap-roots grow vertically downwards. A negatively heliotropic plant grows away from the light, and a positively heliotropic plant towards it, and so on. These results are brought about by differences in the metabolism due to the unequal action of the stimulus on the two sides of the plant structure. In the case of heliotropism, for instance, the side away from the source of light grows quicker than that towards it; thus curvature is caused, which ceases when the 
growing apex points directly to the source of light, and both sides are equally affected (Figs. 53 and 54).

Exactly the same thing happens with fixed animals like zoophytes (Fig. 55). Now Loeb, with great ingenuity, has applied the same explanation to the behaviour of freemoving animals, which turn their head towards or away

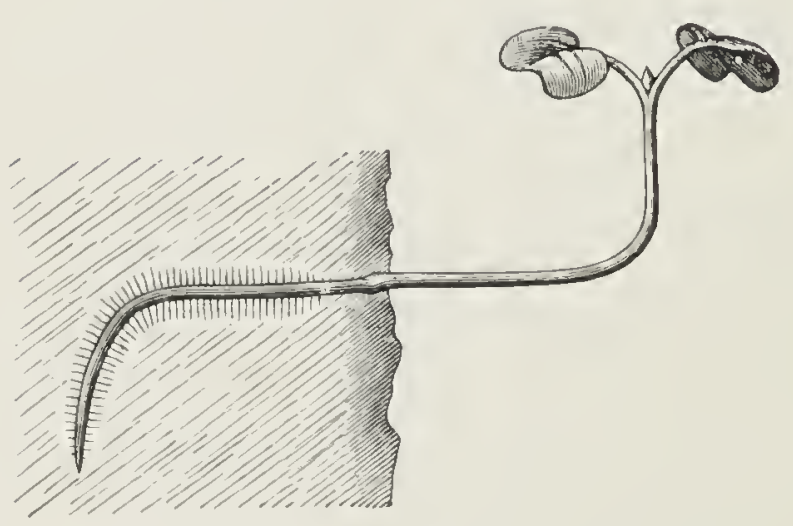

Fig. 53. Scedling of Brassica misra in which root and stem have curved into a vertical position, after being laid horizontally, as a result of geotropism or response to gravity.

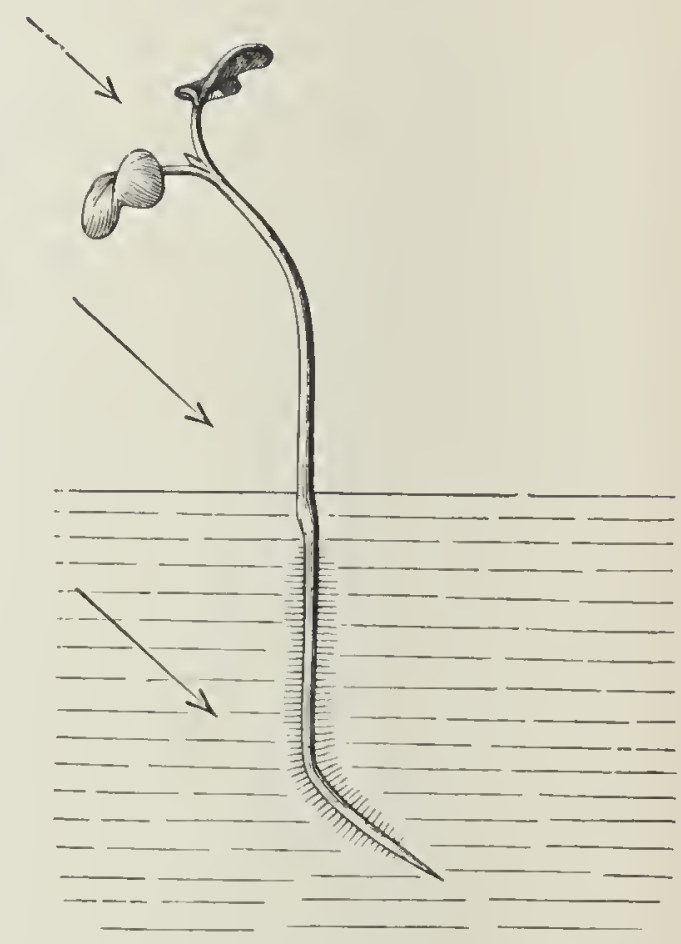

FIG. 54. Seedling of Sinapis alba growing in water. Arrows show direction of incident rays of light. The shoot shows a positive and the root a negative heliotropic curvature.

(From Pfeffer's Physiology of Plants.)

from the source of a stimulus. For instance, in bilaterally symmetrieat heliotropicanimals the symmetrical points on the right and left side are equally sensitive to light; and when light falls more on one side than on the other there will be greater chemical activity on one side than on the other, and the muscles on one side will be more stimulated so as to move the head round towards or away from the 
source of light. This inequality of muscular action will last until the animal is so situated as to point directly to or from the source of the stimulus. Thus, when a moth
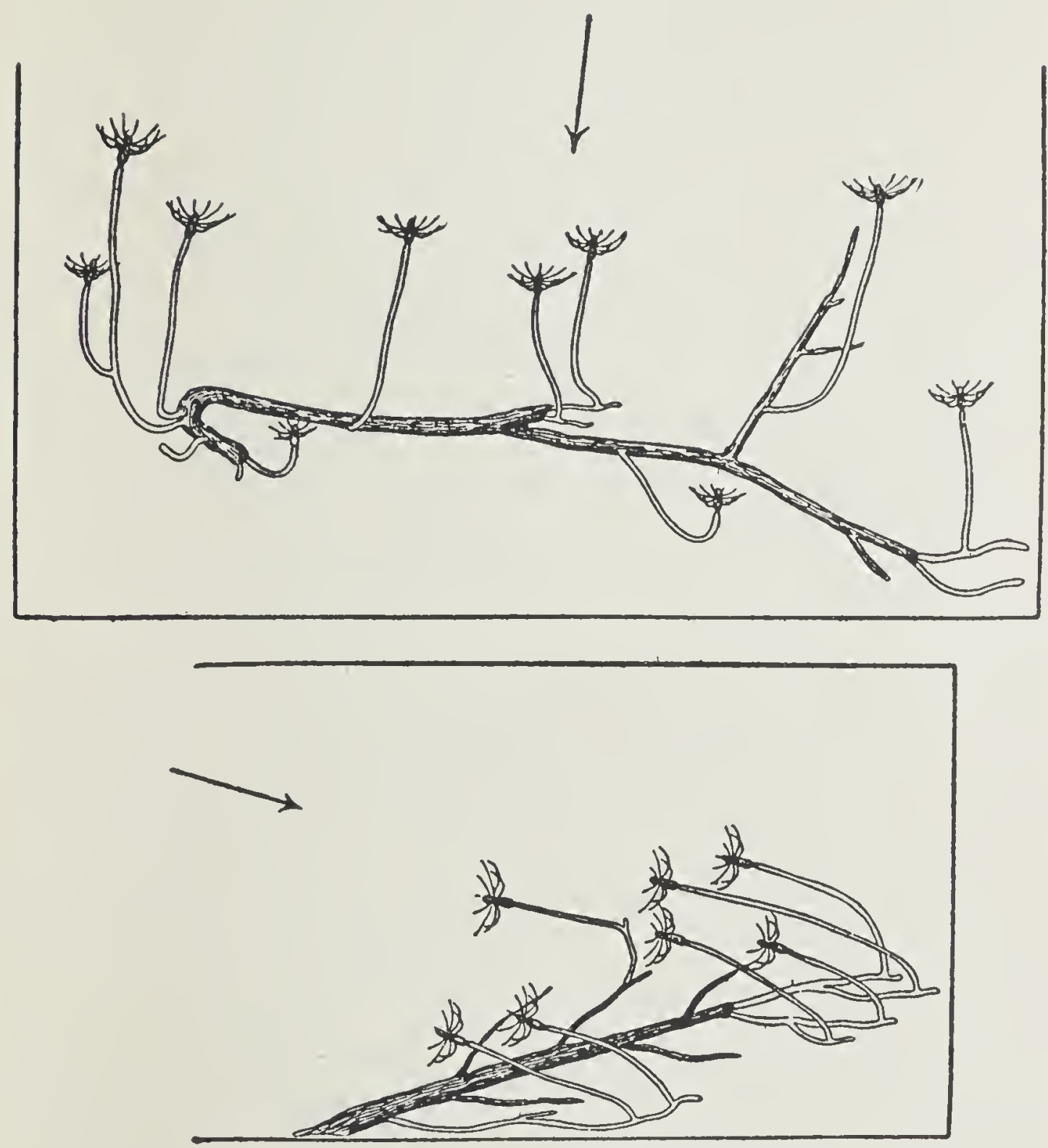

Fig. 55. Polyps of the zoophy te Eudendrium all growing towards the source of light. The arrow indicates the direction of the rays of light, which in one case come from above, and in the other from the left side. (From J. Loeb, Forced Movements.)

tends to fly straight into the flame of a candle it is driven by its mechanism, not by an interfering emotion or will. If one eye of a moth is darkened the insect will be 
unable to fly straight, but will continue to move in a circle. Animals are more or less heliotropic according as they possess more or less chemical substance capable of being decomposed by light, and their susceptibility will vary greatly according to temperature and

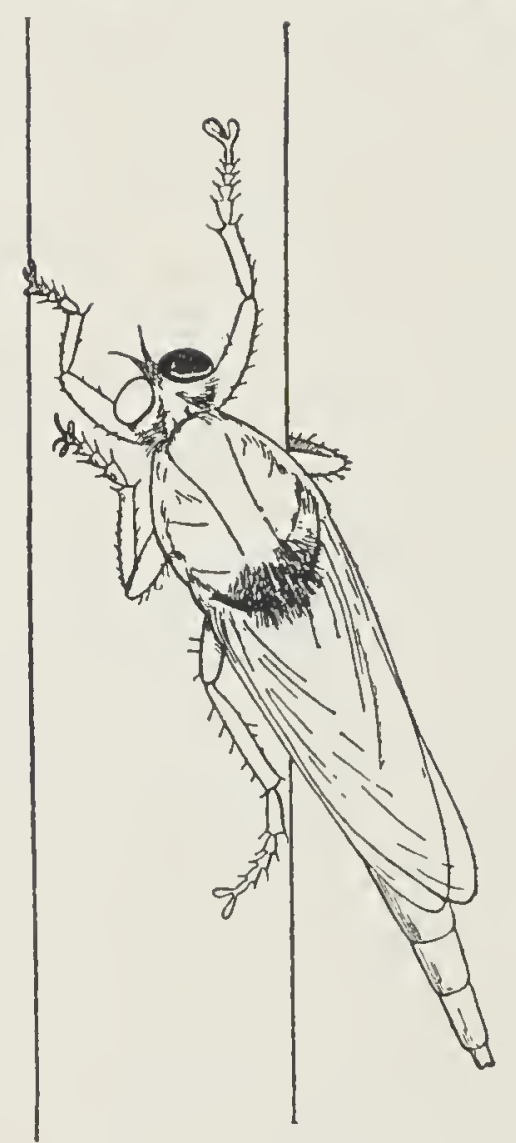

other conditions which hasten or retard the action. A weak acid added to the water containing small Crustacea, like Cyclops, can increase their heliotropism, or even change the heliotropism from negative to positive.

Another important element in the behaviour of organisms is known as 'differential sensibility', or the reaction to sudden and marked changes in the strength of the stimulus. Many leaves move and flowers open in strong light or heat. A shadow passing across a worm will cause it to contract; F1G. 56. Fly with one other instances easily suggest them(right) eye blackened can selves.

creep only in a spiral on a vertical stick, while normally it creeps in a straight line. (After Garey, analysed into manifestations of tropfrom J. Loeb, Forced isms and differential sensibility.
Morements.)

In the lower animals, as in plants, behaviour can be almost completely Their general movements when seeking food; their habit of gathering together in dark warm, or damp places; their sexual instincts; their instincts connected with reproduction (the laying of the eggs on appropriate substances for the young to feed on, and so forth), can all be interpreted as corresponding 
to metabolic changes, though all the steps in the physicochemical processes are not yet known to us. Interesting is the 'instinct' shown by the plant Limariacymbalara. At first positively heliotropic, its flowers become negatively heliotropic after pollination, and so it pushes its fruits into dark crevices, lodging them in places favourable for the subsequent germination of the seeds.

Instincts, or mental adaptations, are 'hereditary' (see p. 6o); that is to say, will reappear in succeeding generations under normal conditions, since they correspond to metabolic processes which depend on the interaction of certain constant factors of inheritance with certain conditions present in the environment. They vary, and in all probability are built up and preserved by natural selection according to their usefulness in the struggle for existence. But simple reflexes and tropisms need not be useful; on the contrary, as in the case of variation generally (p. I22), they may be useless or even injurious. Moreover, a tropism which is useful in the normal environment may be fatal under other circumstances-e.g. the moth and the candle. In so far as they have been built up by selection, instincts will be found to be advantageous. Apparent exceptions may be due to their being relics of past adaptations fallen into disuse, or to some change in the environment. What we have said in previous chapters about the development of the structural characters of organisms applies equally to the evolution and specialization of the metabolic processes to which the mental characters correspond. It must also be remembered that man by artificial selection has altered and improved the mental characters as well as the bodily characters of domestic races.

Sequences of interlocking and co-ordinated reflexes, 
each one of which sets off the next, give rise to the most complicated behaviour, as we see in the actions of our own internal digestive organs; but in the more elaborately differentiated instinctive behaviour of animals yet another element can be found, known as 'associative memory'. Eor example, the homing instinct of insects, enabling them to find their way back to the nest from a distance, has been shown to be due to the retention of effects produced by previous responses to visual stimuli. This lasting and cumulative effect of responses to stimulus, though not absent in the lowest organisms, enters very largely into the behaviour of the higher animals and of man,_but we know very little indeed of the corresponding physico-chemical processes in such cases.

This cumulation of the effects of previous responses, this formation of internal stimuli reacting on the behaviour is, of course, no new factor in the development of organisms (p. 93). It is the process of epigenesis, the means of differentiation in the ontogeny of the individual. Thus an organism will respond differently according as it is starved or well-fed. The storage of nutriment in the tissues of a plant provides an internal stimulus affecting its response; so a hungry animal will behave differently from one that is satiated. In fact, the whole behaviour of an organism is determined by the condition of the mechanism at the time the stimulus is received, and this again depends on the responses previously called forth. It should never be forgotten that an organism reacts as a whole, each response being closely or remotely related to every other and to the entire organization of the organism.

Intelligent behaviour, from the physiological point of view, is prompted by indirect responses. Influences are 
brought to bear on the course of metabolic changes diverting them in this or that direction, and so lead to this or that action in a manner which cannot be foreseen by an outside observer who is not acquainted with the entire past history of the animal. The final response may then appear to be spontaneous, and even unrelated to the initia! stimulus. The influences above mentioned are, besides the external stimuli or conditions of the environment, either due to the transmitted factors of the inheritance or the internal stimuli derived from the lasting effects of previous responses. ${ }^{1}$ Instinctive and intelligent behaviour are usually, perhaps always, combined; the rudiments of both are found in the lowest

1 Simple response to stimulus is the basis of all behaviour, whether instinctive or intelligent. It is generally held that instinctive behaviour depends on an inherited mechanism (variously called innate disposition, congenital prearrangement, and the like), while intelligent behaviour depends on experience acquired during the lifetime of the individual. Instinctive behaviour is said to be the working of a preformed mechanism set going by an appropriate releasing stimulus, and therefore to be definite, relatively invariable, and inherited. Intelligent behaviour is contrasted as indefinite, variable, not inherited but acquired. But all behaviour is made up of responses, and these, like structural responses or characters, are all the result of the combined action of the transmitted factors of inheritance and the moulding conditions of the environment (see p. 58). Instinctive response is neither more nor less acquired than intelligent response; neither can be transmitted as such. The so-called innate mechanism is the result of reaction to internal and external conditions of the past 'experience' of the individual. As with structural characters (p. 55) so with behaviour the distinction of kind is not in the results but in the causes which produce them. In so far as it depends on a mechanism consisting of a closely interlocked series of reactions specialized and adapted to respond in one direction to a particular evocative stimulus, behaviour may be said to be instinctive. In so far as it depends on a mechanism delicately balanced so as to respond in a variety of ways to environmental stimuli differing perhaps only slightly in nature and intensity, behaviour may be said to be intelligent. The first corresponds to constantly inherited bodily characters, the second to structural modifiability or individual adaptability. 
organisms; there is no convincing evidence that the one is more primitive or lower than the other.

Lastly, we are still in the dark as regards the evolution of consciousness, the highest stage in the development of the mental processes, for our knowledge of the anatomical structure and physico-chemical processes which accompany it is still too incomplete to enable us to determine when it first made its appearance in the animal series. We can tell approximately at what stage in the ontogeny of individuals of our own species consciousness begins to manifest itself as the tissues become differentiated, but as to its phylogenetic origin, we can only say that it probably appeared, as we know it in ourselves, when the cerebral hemispheres reached the high state of development seen in man, though the lower animals may possess it in some simpler stage of development.

Here again we must invole the principle of emergence or creative synthesis already mentioned on p. 25. As behaviour becomes more complex and intricate, as the parts of the mechanism become mare perfectly integrated, new qualities emerge and on the mental side culminate in consciousness. It is useless to ask which is the more important in evolution, the mental or the physico-chemical series, since one cannot happen without the other, and they evolve pari passu.

'Too often the Darwinian doctrines are represented as teaching that success in the struggle for existence is obtained only by tooth and nail, by blood and iron. This is a very mistaken view. Brutality, fraud, greed may secure temporary success; but the triumph of the human race over the lower organisms, and again of the higher civilizations over the lower, has been brought about, on the contrary, through mutual help, co-operation, 
self-sacrifice. These are the very bonds which hold societies together. Religion, art, and science all play an important part in evolution; and morality appears not as an external force working against a ruthless and unmoral Cosmic Process, but as a product of that very process, and an all-important factor in its development. We may be sure that in the long run it is those civilizations which are founded on justice and liberty, on law and order, which will succeed best and last longest.

We may here very briefly sketch the actual ancestry

\begin{tabular}{|c|c|c|c|}
\hline & \multicolumn{2}{|c|}{$\begin{array}{l}\text { AGES NAMED AFTER NATURE OF } \\
\text { IMPLEMENTS. }\end{array}$} & SPECIES OF MAN. \\
\hline $\begin{array}{l}\stackrel{0}{0} \\
\stackrel{0}{0} \\
\stackrel{0}{0} \\
\end{array}$ & \multicolumn{2}{|c|}{$\begin{array}{l}\text { Historic. } \\
\text { Iron Age. } \\
\text { Bronze Age. } \\
\text { Neolithic (New Stone Age). }\end{array}$} & \multirow[t]{2}{*}{ Modern Man. } \\
\hline \multirow{4}{*}{ 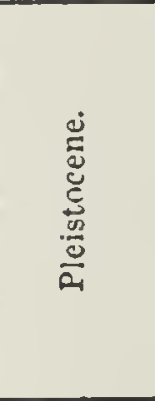 } & \multirow{5}{*}{\multicolumn{2}{|c|}{$\begin{array}{l}\text { Magdalenian. } \\
\text { Solutrean. } \\
\text { Aurignacian. } \\
\text { Mousterian. }\end{array}$}} & \\
\hline & & & Neanderthal Man. \\
\hline & & & $?$ \\
\hline & & & $\begin{array}{l}\text { Heidelberg Man. } \\
\text { Piltdown Mlan. }\end{array}$ \\
\hline Pliocene. & & & $?$ \\
\hline
\end{tabular}

FIG. 57. Table of Geological Ages during which Man has lived in Western Europe. (From A. Smith Woodward, Brit. Mus. Guide.)

of Man as revealed by recent researches. The Order Primates includes the Lemuroidea and the Anthropoidea (American Monkeys, Old-World Monkeys, Anthropoid Apes, and Man). It has been mentioned above (p. I 7o) that the earliest known fossil Primates in the Old and the New World are small primitive arboreal forms related to both the Lemurs and the Monkeys. Fragments of Parapithecus from the Oligocene of Egypt indicate the 
next step, a small primate with already the number of teeth characteristic of Man. Propliopithecus, from the same deposit, is larger and more advanced; while in the Miocene are found remains of larger apes, such as Dryopithecus, more generalized than, but closely allied to, the living Anthropoid Apes. Pithecanthropus erectus, from the Pliocene of Java, seems to represent a stage almost exactly half-way to Man (Fig. 6o). The discovery of artificial flint implements in Pleistocene and even in Pliocene deposits proves the existence at that early time of creatures which if not human were at all events sufficiently intelligent and skilful to make and use such rude tools. Associated with remains of Pliocene mammals and primitive flint implements has recently been found in Sussex the Piltdown skull, named Eoanthropus Darusoni by Dr. A. Smith Woodward (Figs. $5^{8}$ and 59). It is remarkable for its very ape-like lower jaw, large prominent canine teeth, and very low development of the brain as indicated by the shape of the cranial cavity. The genus Homo is first represented in the Pleistocene of Germany by a massive lower jaw with more human teeth (Fig. 58), and belonging to an early race called Homo heidelbergensis. The discovery of numerous more or less complete skeletons in Western Europe has revealed the existence in rather later Pleistocene times of a widespread primitive palacolithic race named Homo ncanderthalcusis from the first skull found in the Neanderthal cavern near Düsseldorf in 1857 . Although distinctly human, this species still retains many primitive features in the general build of the skeleton, the dentition, and the skull with its massive brow-ridges and very low brain-cavity. The lower jaw has not yet acquired the long chin-prominence characteristic of modern man (Figs. 

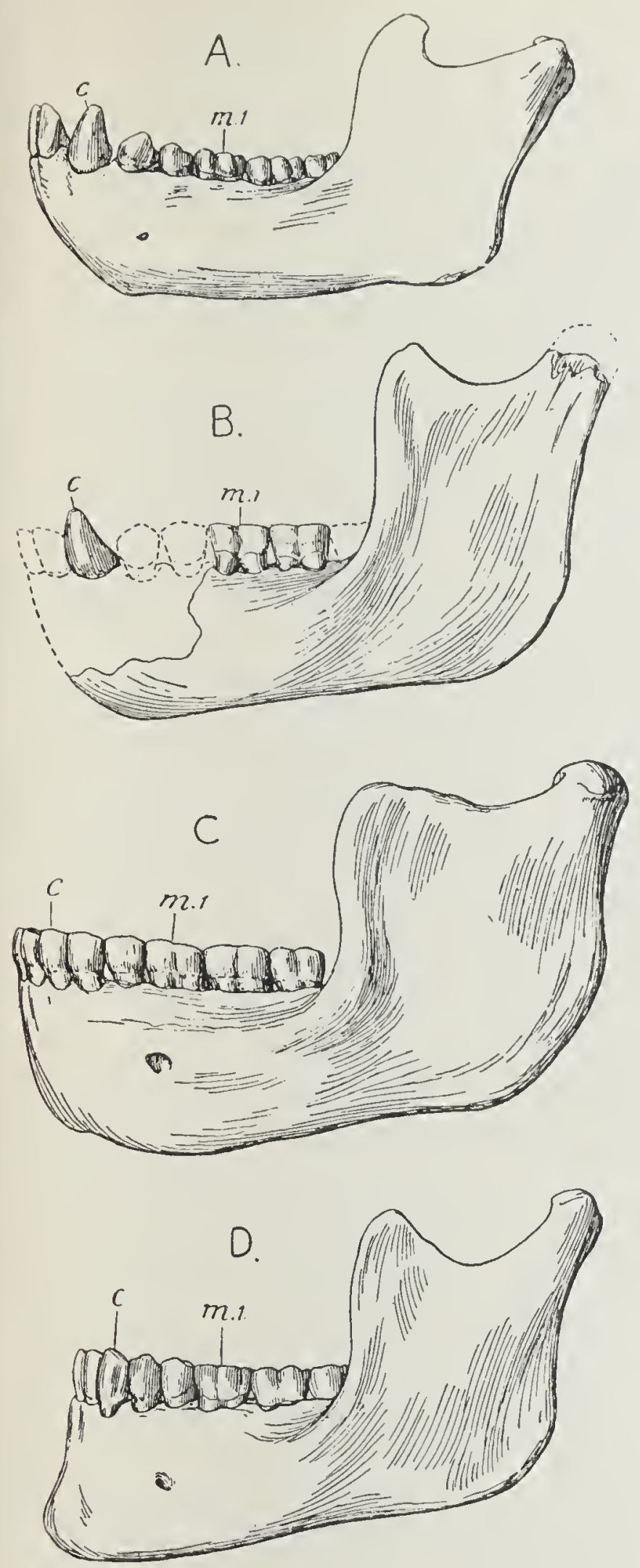

Fig. 58. Left outer side view of lower jaw of Chimpanzec, A ; Piltdown man, s ; Heidelbers man, C; modern man, D; about one-third natural size. $c$, canine tooth ; $m I$, first molar tooth. (From A. Smith Woodward, Brit. Mus. Guide.)
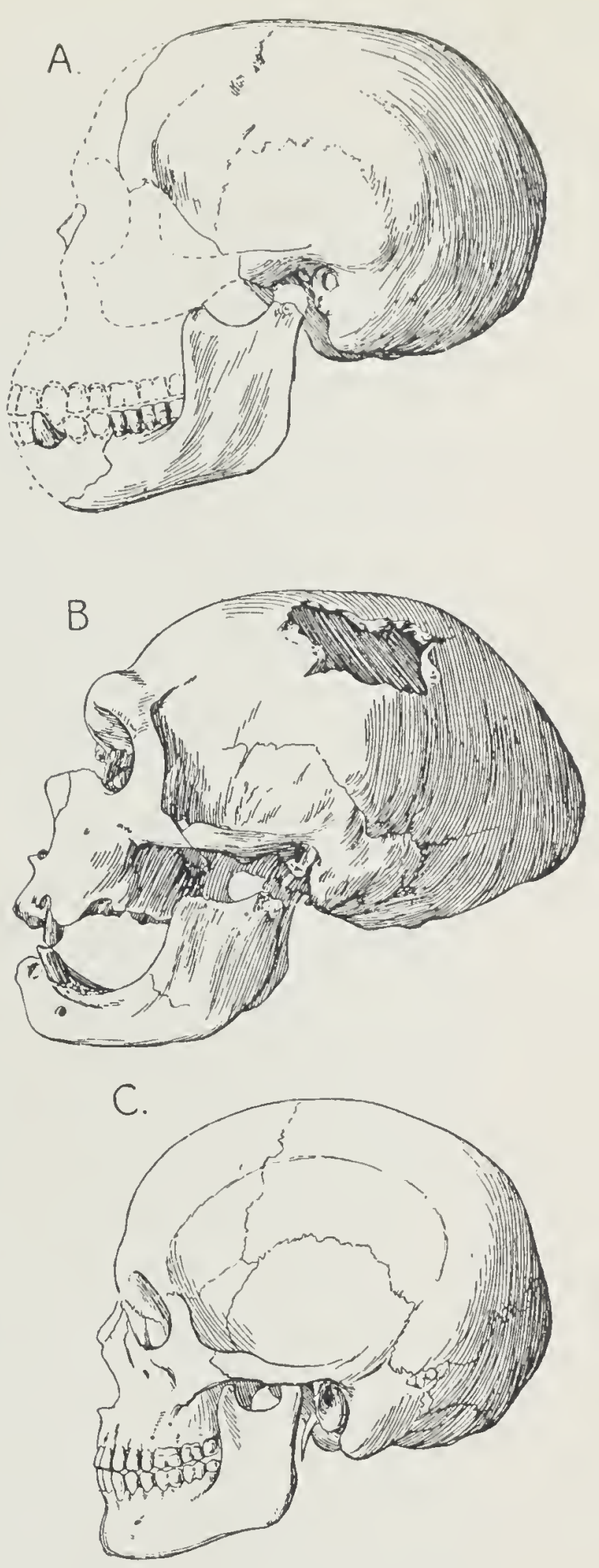

Fig. 59. Left side view of the skull of Piltdown man, A; Ncanderthal man (La Chapclle-aux-Saints, after Boule), в ; modern man, $\mathrm{C}$; about one-fifth natural size. (From $\Lambda$. Smith Woodward, Brit. MIus. Gruide.) 


\section{0 \\ Psychology and Evolution of Intelligence}

$5^{8}$ and 59). Certain remains recently found in Northern Rhodesia, but of uncertain geological age, belong to a race combining some primitive characters, such as enormous brow-ridges, and a low brain-case, with quite modern features. Remains of modern man (Homo sapiens) belonging to the Palaeolithic age appear in the later Pleistocene deposits. But, though much has been made out as to the development of human culture since these early times, little is yet known as to the relation of recent races to each other or their origin from the more primitive species.

Man has conquered in the struggle for existence not so much because his body is more powerful, his movements quicker, or his senses sharper than those of other animals, but because of his great capacity for retaining the impressions of past responses, and for bringing them to bear on the response to new stimulations. To this he owes his marvellous powers of adaptation to new and varying conditions. And this great development of associative memory has been accompanied by a corresponding enlargement of the brain, especially of the cerebral hemispheres. There can be little doubt that the giant mammals of past ages failed, in spite of their formidable offensive and defensive weapons, partly because their nervous system was not sufficiently developed. Their brain was absurdly small as compared with that of ordinary mammals of to-day; indeed, it was often scarcely larger than the brain of the gigantic reptiles which preceded them. The acquisition of stereoscopic vision, in which both eyes are brought to focus on an object near at hand, and the power of using and fashioning implements were important steps in the development of man's ancestors. But most of the peculiarities in the 


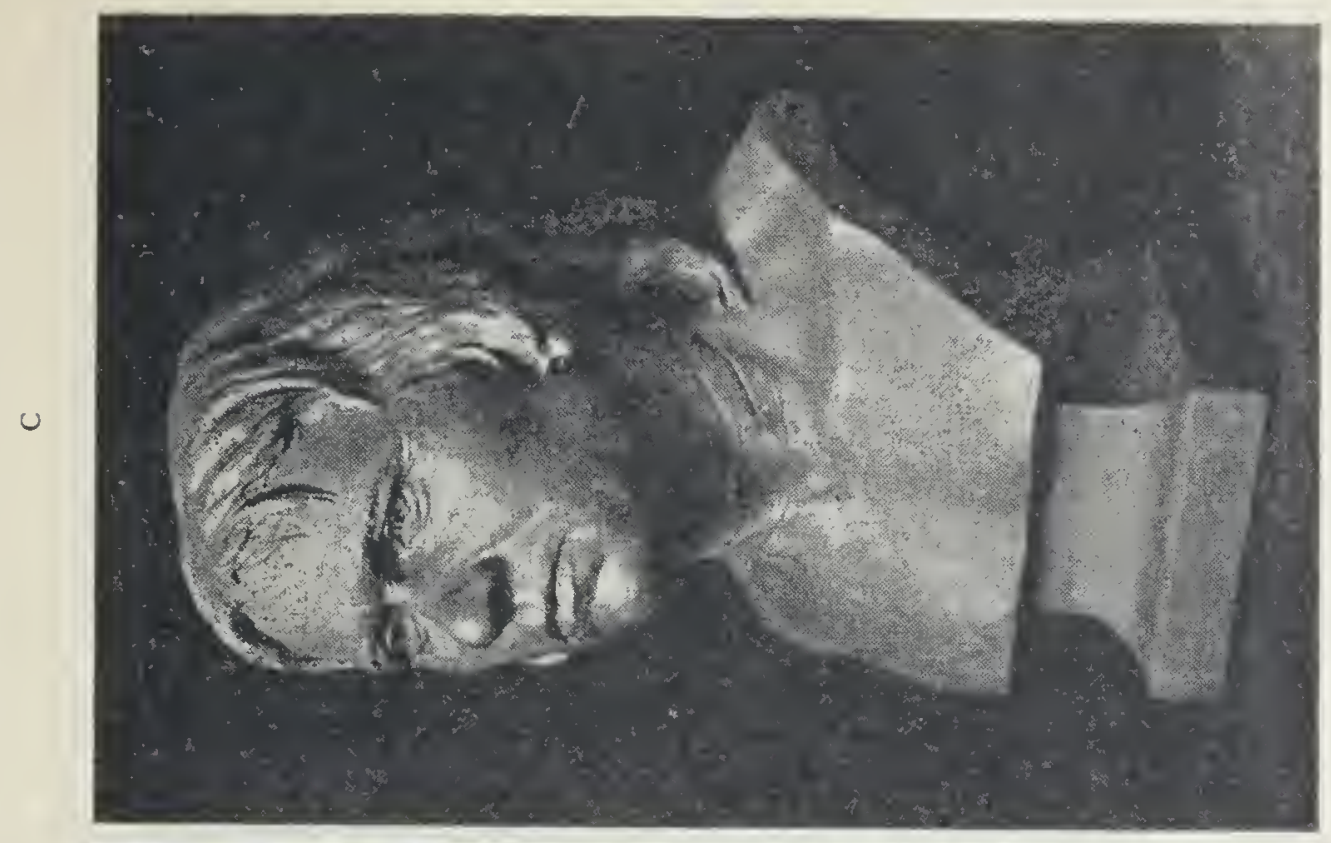

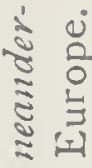

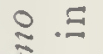

ปั บิ

๓

$\ldots$ 의

क

ป.

ป త్ర

?

ธิ

$=5$

¿

$\approx 0$

¿

in

$\because \frac{\bar{c}}{\circ}$

7

巳્ฮ

$\infty$

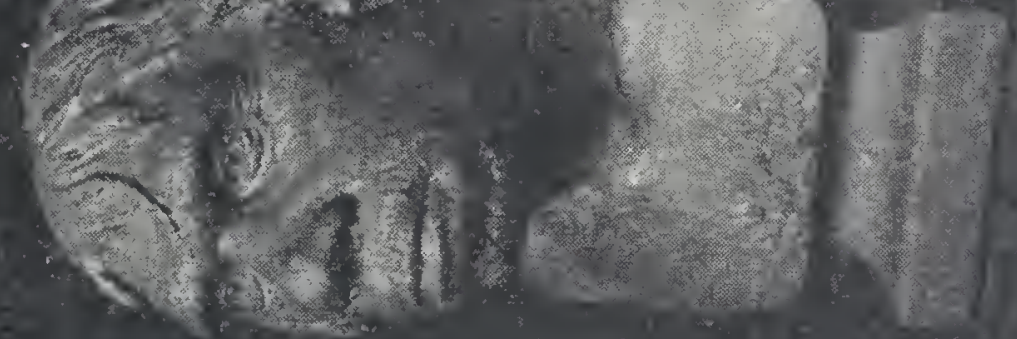

$\Xi$

$-20$

4 co 0

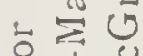

o 10

U

0 I

로우

జ

$\dot{0} \stackrel{0}{\circ}$

$\rightarrow 2$

อे की

⿰纟. วิ

유 है

त क

을 을

$\overrightarrow{v_{i}} ㅇ$

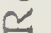

ن

응

نे है

至茫 
structure of the human body are closely related to the immense development of the brain. The size and shape of the brain-case has greatly influenced the development of the skull; and even the ereet-attitude and consequent modifications of the hind limbs, vertebral column, and other parts are probably an adaptation for supporting the heavy weight of the brain. In other respects the structure of man is not very specialized, and differs but little from that of his nearest allies, the anthropoid apes. It need hardly be pointed out that man owes his mastery of the world to brain-power, not brute force.

We may conclude by saying that evolution from the point of view of the Natural Sciences, as it appears to an outside observer, may be represented as a vast and continuous series of changes in a continuous stream of living matter. Each stage in the process is determined by that which precedes it, and determines that which follows. The scientific generalizations based on the observation of non-living matter, the 'laws' of physics and chemistry, hold good when applied to the changes in living matter. There is no special living element, no mysterious life-force: but life, scientifically described, is a physico-chemical process taking place in the complex compounds of the ordinary elements which make up the protoplasm of living organisms. Metabolism, as this process is called, is due to the instability of these conpounds, to the fact that external conditions or stimuli applied to them may alter their structure and composition. All the manifestations of life thus correspond to metabolic processes. From the very first origin of living protoplasm there has been an unbroken continuity of living processes and substance. The living organisms of the present day are the descendants of those of the 
past, and all the various forms of life are but the divergent streams from the original source of metabolism.

Variation is due to change in the metabolism; all organisms are the products of the interaction of transmitted factors of metabolism (the factors of the inheritance) and conditions or stimuli of the environment. The ever-changing and continuous stream of living matter is diverted into this or that channel of differentiation and specialization by the environment through natural selection. The environment moulds the organism, and the organism reacts on its environment, until in the case of man he seems to have become master of it and to shape his own destiny.

But as civilized man endeavours deliberately to direct the course of his own evolution the importance of heredity and other factors which influence the process becomes daily more apparent. Some knowledge of the chief results of the scientific study of organic evolution should therefore be acquired by all, and is indeed essential for the guidance of those who wish to promote the welfare of the human race on rational principles.

THE END 



\section{B I B L I O G R A P H Y}

The reader may be recommended to consult the following books for further information, but he should remember that a sound knowledge and understanding of the evidence on which the theory of Evolution is founded cannot be obtained without observation and experiment in the field and in the laboratory.

General Treatises: The standard works of $\mathrm{Ch}$. Darwin, including 'The Origin of Species', 'The Descent of Man', and 'Animals and Plants under Domestication'; A. R. Wallace, 'Darwinism', I889, and 'Natural Selection', I89I, 'Island Life', 3rd ed. I902; A. Weismann, 'The Evolution Theory', 2 vols. I904; de Vries, 'The Mutation Theory', 2 vols. I9 1o; A. Dendy, 'Outlines of Evolutionary Theory', 3rd ed. 1923; R. S. Lull, 'Organic Evolution', I917; C. Ray Lankester, 'The Advancement of Science', I89o, and 'The Kingdom of Man', I906 ; E. B. Poulton, 'Essays on Evolution', I908.

Physiology: W. M. Bayliss, 'Introduction to General Physiology', I919; M. Verworn, 'General Physiology', 1899 ; J. Loeb, 'The Organism as a Whole'; T. H. Morgan, 'Experimental Zoology', 1907, and 'Regeneration', ı9or ; J.W. Jenkinson, 'Experimental Embryology', I 909 .

Variation, Heredity, and Mendelism: W. Bateson, 'Materials for the Study of Variation', I894; H. M. Vernon, 'Variation in Animals and Plants', I903; F. Galton, 'Natural Inheritance', I889; K. Pearson, 'The Grammar of Science', I900 ; W. Bateson, 'Mendel's Principles of Heredity', I909; R. C. Punnett, 'Mendelism', 6th ed. I922; L. Doncaster, 'Heredity', Igıo; E. G. Conklin, 'Heredity and Environment', I922; Babcock and Clausen, 'Genetics in relation to Agriculture', IgI8; J. A. Thompson, 'Heredity', 3rd ed. I9I9; A. Reid, 'Principles of Heredity', I906.

Heredity and Cytology: E. B. Wilson, 'The Cell', 1900 ; T. H. Morgan, 'The Physical Basis of Heredity', Igrg; Morgan, Sturtevant, Muller, and Bridges, 'The Mechanism of Mendelian Heredity', I9r5; L. Doncaster, 'An Introduction to the Study of Cytology', 1920. 
Heredity and Sex: T. H. Morgan, 'Heredity and Sex', I913; R. Goldschmidt, 'The mechanism and physiology of Sex Determination', 1923.

Tropisms and Psychology: J. Loeb, 'Comparative Physiology of the Brain', 1905, and 'Forced Movements', I918; C. Lloyd Morgan, 'Animal Beliaviour', Igoo.

Evolution of Man: M. Boule, 'Les Hommes Fossiles', I921 ; W. J. Sollas, 'Ancient Hunters', 3rd ed. I924; G. Elliot Smith, 'The Evolution of Man', 1924. 


\section{N D E X}

Achatinella I29

Acquired characters 50, 6r

Adaptability I69, I 7 I

Adaptation 106, I69

Adaptive radiation $\mathrm{I} 54, \mathrm{I} 69$

Agama r 43 fig. 37

Albinism 77, I I3

Allelomorphic characters 77

Amphibia I 54

Amphidasys betularia I I 2

Amphisbaena I43 fig. 37, I 44

Anabolism I4, I6

Ancestral inheritance I I 7

Ancestry of Man 187

Andalusian fowl 72

Antirrhinum 69 fig. $x 6,70$

Aphidae 36

Archaeopteryx I4I, 142 fig. 36, I $5^{8}$

Artificial synthesis of organic compounds 23

Assimilation 32

Baby 22

Bacteria I6, 23, 28, 34

Baer, K. von 145

Bates 125

Bateson, W. 69, 77

Bayliss 20

Behaviour I 74

Bergson 145

Biogenetic Law I 45

Biology Io

Biometrics 48

Biophore 68

Blood precipitin test 147

Body and mind 175

Bonellia viridis ro 1

Bonnier 58

Botany ro

Brassica nigra I 80 fig. 53

Bridges, C. B. 98, 102

Bumpus I I 2

Bütschli 39
Canis occidentalis I 59 fig. 44, I6o fig. 45

Carbohydrate I I

Cariokyllesis $3 \mathrm{I}$

Castle I2I, I30

Catabolism I 4, I6

Cell 26

Cell-division 30

Cell theory 26

Centrosomes 31

Cesnola, di I 25

Chaetopoda 34

Chara crinita 36

Character 5 I

$$
\begin{aligned}
& , \quad \text { acquired 5o } \\
& , \quad \text { not inherited } 52,60 \\
& \text {, } \quad \text { constancy of } 57,60
\end{aligned}
$$

Characteristics of living organisms 9

Chlorophyll i 6

Chromatin 28, 3 I

Chromosomes $3^{2}$

Chromosomes and heredity 86

Cirripedes 137

Classification 147

Clausilia laminata 113

Coelentera 33

Colloid 25

Coloration 125

Columba livia 82

Conjugation 37,39

Consciousness 186

Conservation of Energy 13

," , Matter I3

Continuity of cells, etc. 30 ", , germ-plasm 39

", , protoplasm 30

Continuous variation I I9

Convergence 143

Copromonas subtilis 38 fig. 6

Correlation I I 7

Correns 69, 98

Crepidula Ior

Cytoplasm 28 
Darvin 9, 43, 44, 45, 50, 5I, 66, 68, го3, Іо8, І по, І п 7, г 22, І 23, I 33

Darwin, Erasmus 50

Death I6, 40

, origin of 40

Death-rate 106

Degeneration 137

Differential sensibility 182

Differentiation 94

Difflugia I 2 I

Diploid 87

Discontinuous variation I 9

Disease I 13

Domestic races $8 \mathrm{I}, 84$, I I 7

Dominance 74

Doncaster, L. 69, 98

Draba verila 149

Drosophila 79 fig. 22, 8o, 82, 102 , I 2 I, I 30

Dryopithecus I 88

\section{Ehrlich 147}

Elodea canadensis 105

Emergence 186

." principle of 25

Enriques 40 (foot-note)

Environment 32

$$
, \quad \text { effect of } 50
$$

Enzymes or ferments i 7

Eoanthropus Dawsoni i 88 , I89 fig. $5^{8}$

Epigenesis 90, 184

Eudendrium i 8 I fig. 55

Euphorbia arborea I 44 fig. 38

Excretion I3

Experience 185

Factors of inheritance 5I, 76, 86, 89, 94

Fat I I

Ferments or enzymes I 7

Fertilization 34

Fundulus 56 fig. I I

Galton 46, 5I. I I 7

Gamete or germ-cell 34

Gene 67

Genotype 62

Geological record I53

Germ-cells 34

$,, \quad, \quad$ and heredity 49
Germ-plasm 39

Giard Io I

Glaucoma 40 (foot-note)

Glossina morsitans I I I

Goldschmidt, R. Io2

Gomphognathus r6o fig. 45

Gould IO I

Gradation 167

Haeckel, E. I 45

Haemoglobin I2

Haploid 87

Hardy, G. H. 127

Heredity 45,48

, defined 52

Hermaphroditism 34

Hertwig, O. 62

Heterozygote 73

Hieracium 150

Homo heidelbergensis 188,189 fig. 58

Homo neanderthalensis I88, I 89 fig. 59, I9 I fig. 60

Homo sapiens I9o, I9 I fig. 60

Homozygote 73

Hormone 20

Hydra 29

Immunity I I 4

Inachus I I

Inbreeding I 30

Inheritance, factors of 49,5 I , 69, 89

Instinct 183

Instinctive behaviour 177

Integration by nervous system 19

" , secretions I9

Intelligent behaviour $\mathrm{I} 84$

Irritability I6, I 8, 20, 5 I

Isolation, geographical I 28

,$\quad$ parasitic 130

,, physiological I 30

, psychological I 30

Johannsen, W. 62,63

Jennings I2I

Lamarck 50, Io8

Lamarckism 50, 6I

I_ankester, Sir Ray 6I, 24

Laws of Mendelian heredity 69, 8 I

Length of life 43

Leptinotarsa 96, I I 3 
Life I 7

Living matter, composition of 10

Leob, J. '80 manufacture of 22

Lymantria dispar 102, 105

Mammalia ${ }^{1} 58$

Man, his ancestry 187

Mantis religiosa 125

Marptusa familiaris I 35

Maupas 39

McClung 98

Mendel 69, 74, 76 law of 82

Metabolism I 2

Metaphyta 28 its limitations 16

Metazoa 28

Mind and body 175

Modifiability 63

Modification 55

Monocystis 37

Moore 22

Morgan I2I

Morgan, T. H. 69, 8o, 98

Mucor 29

Miiller, F. I25

Musca carnaria Io3

Mutation 55 $\begin{array}{ll}, & \text { kinds of } 84 \\ , & \text { origin of } 95 \\ , & \text { artificial } 96\end{array}$

Nasturtium officinale I05

Natural selection 44, I ro

Nervous integration 19 not prophetic I 23

Nilsson-Ehle I 2 I

Nucleus 26, 28

Nutrition I3

Nuttall I 48

Oenothera 96

Origin of living matter 23

, of $\operatorname{sex} 37$

Orthogenesis 169

Ovum 34

Pangene 67

Paramecium 37, 4r fig. 7, 65 fig. I 4

Parapithecus 187
Pargenesis 66

Parthenogenesis 35

Passer domesticus I 12

Pasteur 23

Pearson 46, I I 7

Peckham I 35

Phaseolus vulgaris 63

Phenotype 62

Phylogeny I 36

Pilocercus sublunatus it 4 fig. 38

Pisum sativum 74

Pithecanthropus erectus I88, I9I fig. 60

Polyzoa 34

Porifera 33

Poulton 125

Preadaptation 109

Presence and Absence 77

Primates I 70, I87

Primula sinensis 60

Pritchard 5 I

Propliopithecus i 88

Protein I I

Protenor 99, and 99 fig. 28

Protophyta 28

Protoplasm I 4, 26

Protozoa 28 synthesis of 15

Psychology I 74

Punnett, R. C. 69

Pure lines $\sigma_{4}$

Purity of gametes 7 I

Quetelet 46

Ranunculus fluitans I7I, 172 fig. 50

Rate of evolution 165

Recapitulation 145

Recession 74

Reduction division 86

Reflex action 176

Regeneration 29

Regression 48, II 8

Reid, A. 6I

Reproduction, asexual 33

Reptilia I $54_{5}$ sexual 34

Respiration $\mathbf{I}_{3}$

Response $5^{8}, \mathrm{I} 84$

Response to stimulus I 8

Reversion 82 
Sacculina Io I

Salamandra 143 fig. 37

Schleiden 26

Schwann 26

Sedgwick, A. 6 I

Segregation of factors $7 \mathrm{I}$

Selection, effect of I I 5

Sex 34

value 122,124

Sex chromosome 99

, determination of 97

, origin of 37

Sexual characters, secondary 97. I3 I

Sexual reproduction 33,49

Sexual selection 133

Sinapis alba 180 fig. 54

Siphonops I 43 fig. 37 , I 44

Smith, G. W. 97, I I

Soma 40

Specialization 163

Specialization of cells 29

Species I 49 elementary I 49

Specificity of proteins I36

Spencer, H. 67

Spermatozooid 34

Spermatozoon 34

Sphenodon 157

Stapedia gigantea I 44 fig. $3^{8}$

Starling 20

Sterility I30, I 49

$$
\text { specific I } 49
$$

Stimuli or conditions 18 , of environ ment 5 r

Stimulus, external and internal ig

$" \quad$ internal i 84

Stockard 56

alld response 18

Struggle for existence 44, Io3

Survival of the fittest 24
Synthesis of protoplasm 15 , in green plants 16 , in Fungi 16 , in Bacteria 16

Taraxacum I5O

Taraxacum vulgare $5^{8}$

Tower I 13

Trifolium pratense I I I

Trirachodon I 59 fig. 44

Tropism 178

Trypanosoma Brucei I I I

Tschermak 69

Tunicata 34

Tunicates 137 and fig. 33

Typhlops I 44

Ulex europaeus 173

Ungulata I $_{\text {I }}$

Unit character 83

Variation $45,53,55$ (foot-note), 63 ", measurement of 46

", curves of 46

," causes of 53

Vaucheria 29 not adaptive 123

Vestigial organs I40

Vital element I 7

, force 17,2 I

Vries, de 69, 83, I 49

Wallace 44, I o3, I Io, I I 5, I 25, 135

Weismann $39,42,67,68$

Wildon 46, I 13

Wilson, E. B. 97,98

Woodruff 4 I (foot-note)

$\mathrm{X}$ chromosome 99

Y chromosome Ioo

Zoology io

Zygote 34 

poes scienes repfent Erovition. Dr Hoofer.

- 16 - 400

moxient hetery 

